Navigation Systems Research Program

Seismic Structural Considerations for the Stem and Base of Retaining Walls Subjected to Earthquake Ground Motions

Ralph W. Strom and Robert M. Ebeling

May 2005

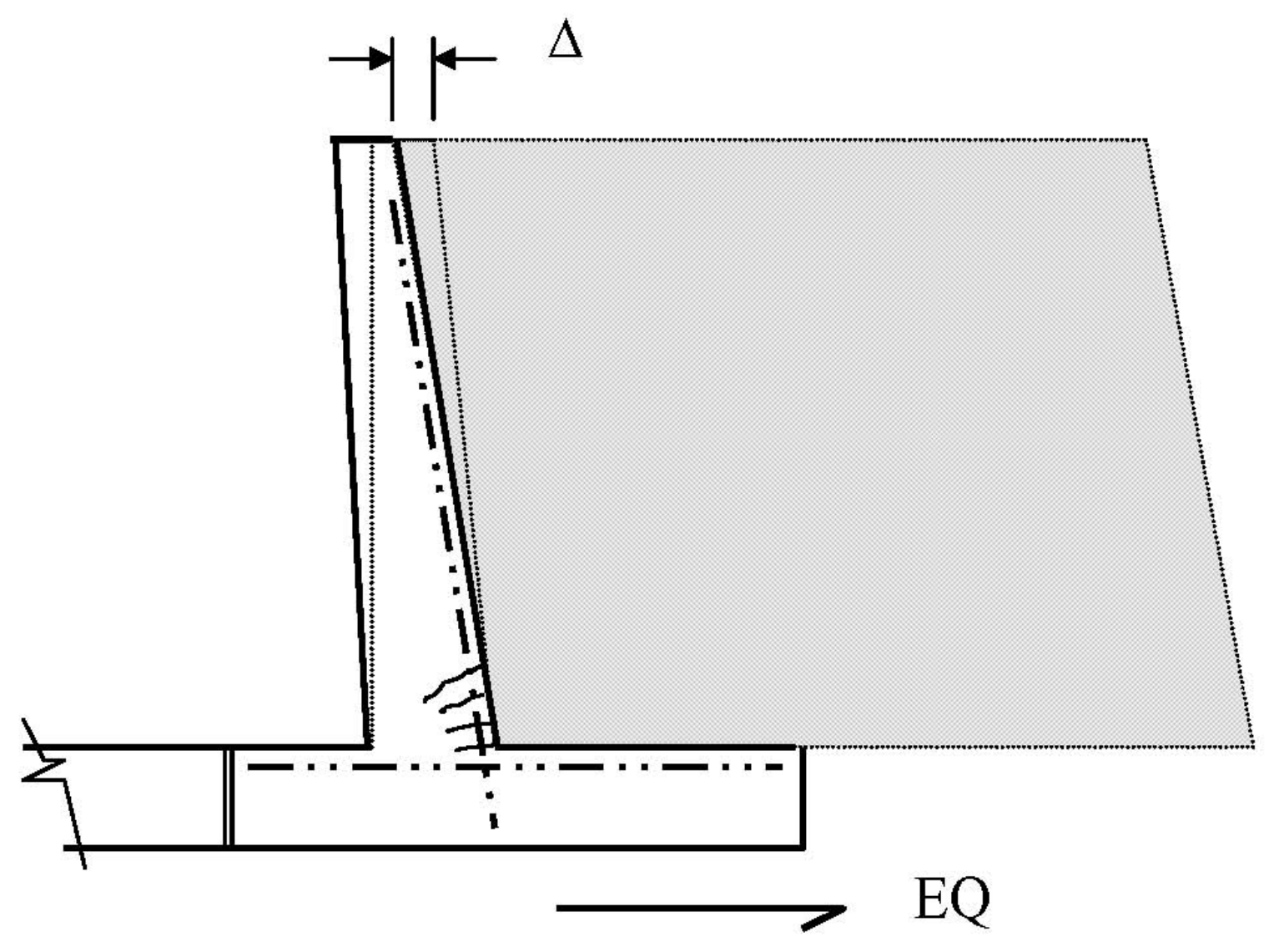




\section{Seismic Structural Considerations for the Stem and Base of Retaining Walls Subjected to Earthquake Ground Motions}

Ralph W. Strom

9474 SE Carnaby Way

Portland, OR 97266

Robert M. Ebeling

Information Technology Laboratory

U.S. Army Engineer Research and Development Center

3909 Halls Ferry Road

Vicksburg, MS 39180-6199

Final report

Approved for public release; distribution is unlimited 


\begin{abstract}
:
Cantilever retaining walls can respond externally to earthquake ground motions by sliding or by rotating, or internally by stem wall yielding. The type of response that will have the greatest impact on post-earthquake performance will likely depend on restraint conditions at the base of the wall. Walls founded on soil without an invert slab are most likely to dissipate the inertial energy imposed by earthquake ground motions by sliding. This may also be true for walls founded on fissured or fractured rock. Walls founded on soil or on fissured or fractured rock and prevented by an invert slab from moving laterally are more likely to tip (i.e., rotate) than to slide during a major earthquake event. Walls founded on competent rock without significant joints, faults, or bedding planes and prevented by a strong bond at the rock-footing interface from either translating or rotating are likely to dissipate energy through plastic yielding in the stem wall. All three responses can leave the retaining wall in a permanently displaced condition.

The purpose of this report is to provide methodologies for conducting a performance-based earthquake evaluation related to plastic yielding in the stem wall. The methodologies include evaluation of brittle or force-controlled actions and the evaluation of ductile or deformation-controlled actions. The later evaluation provides estimates of permanent (residual) displacement for walls dominated by a stem wall yielding response.

Performance-based evaluation methodologies are demonstrated with respect to a wall designed to current Corps ultimate strength design criteria and with respect to an older retaining wall designed to working stress design criteria. Lap splice deficiencies related to older walls are discussed and performance-based evaluation techniques proposed.

At present the Corps computer program CWRotate is able to estimate permanent displacements associated with a sliding response and a rotational response. An enhancement is proposed to provide estimates of permanent (residual) displacement for walls dominated by stem wall yielding.
\end{abstract}

DISCLAIMER: The contents of this report are not to be used for advertising, publication, or promotional purposes. Citation of trade names does not constitute an official endorsement or approval of the use of such commercial products. All product names and trademarks cited are the property of their respective owners. The findings of this report are not to be construed as an official Department of the Army position unless so designated by other authorized documents.

DESTROY THIS REPORT WHEN IT IS NO LONGER NEEDED. DO NOT RETURN TO THE ORIGINATOR. 


\section{Contents}

Conversion Factors, Non-SI to SI Units of Measurement................................. vii

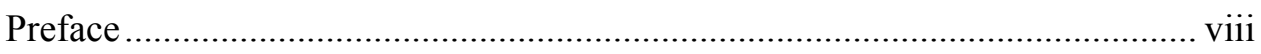

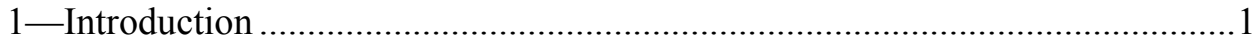

1.1 Behavior of Retaining Wall Systems Subjected to Earthquake

Ground Motions 1

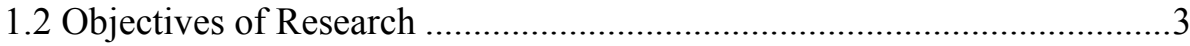

1.3 Response of Structures and Structural Systems to Earthquake

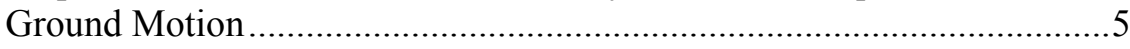

1.4 Pseudostatic Methods and Their Limitations............................................

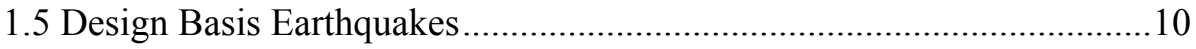

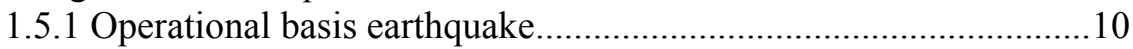

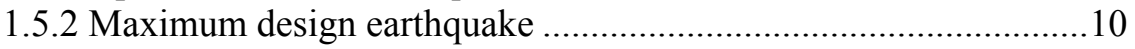

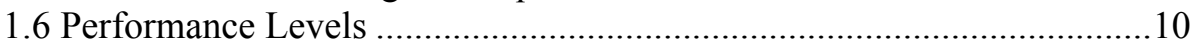

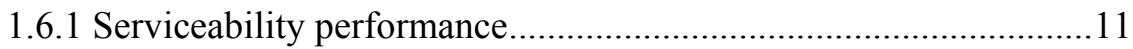

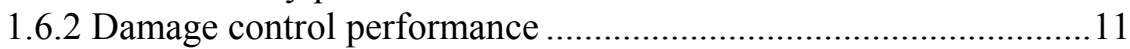

1.6.3 Collapse prevention performance.................................................11

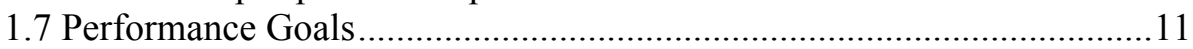

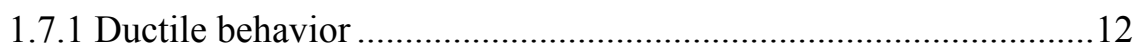

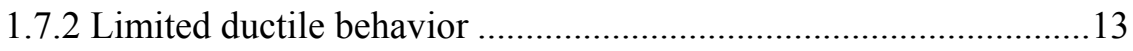

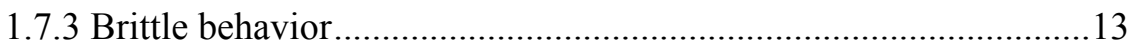

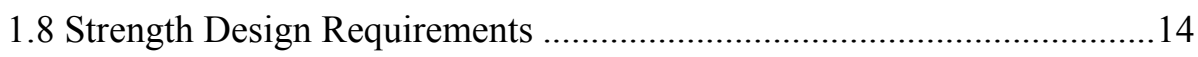

2-Estimating Earthquake Ground Motion Demands.........................................16

2.1 Specification of Earthquake Ground Motions .......................................16

2.1.1 Using response spectra for earthquake design and analysis ...........16

2.1.2 Standard response spectra .........................................................17

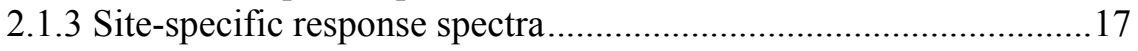

2.2 Earthquake Demands on Inelastic Systems .......................................18

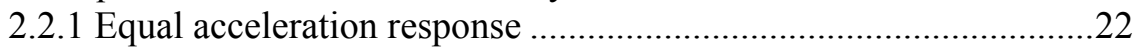

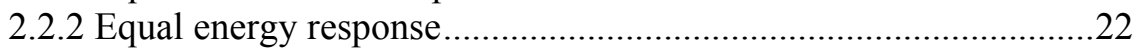

2.2.3 Equal displacement response ...................................................24

2.2.4 General relationship between required yield strength and

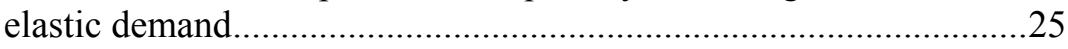

3-Methods of Seismic Analysis and Structural Modeling ...............................27

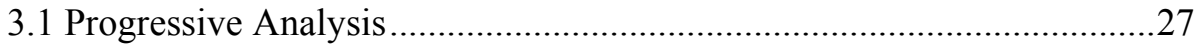

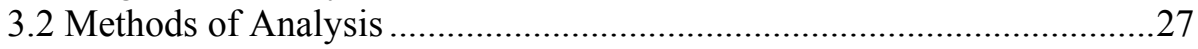


3.2.1 Pseudostatic (i.e., seismic coefficient) method.............................27

3.2.2 Equivalent lateral force method ...................................................28

3.2.3 Response spectrum-modal analysis procedure ............................29

3.2.4 Time-history-modal analysis procedure …....................................30

3.2.5 Time-history-direct integration procedure …................................30

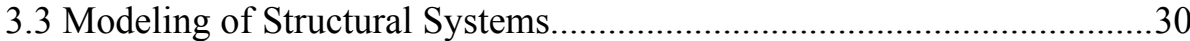

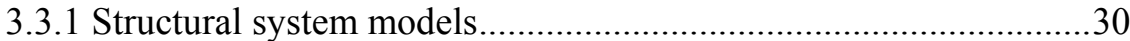

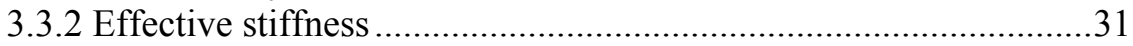

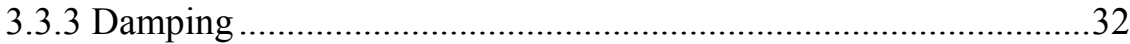

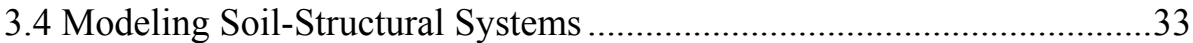

3.4.1 Veletsos and Younan analytical model ........................................33

3.4.2 Performance of retaining wall systems acting as rigid

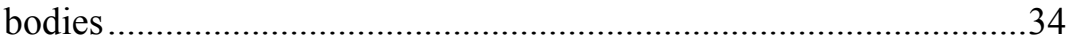

3.4.3 Performance of retaining wall systems acting as flexible

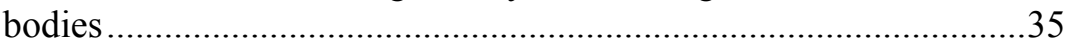

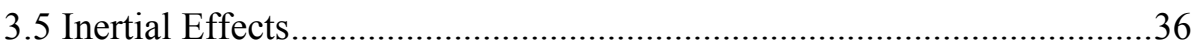

3.5.1 Dynamic soil pressures (yielding backfill conditions) ...................36

3.5.2 Dynamic soil pressures (nonyielding backfill conditions) ..............37

3.5.3 Permanent sliding displacement of retaining walls ........................37

3.5.4 Upper bound estimate of permanent sliding displacement..............37

3.5.5 Permanent sliding displacement by response history

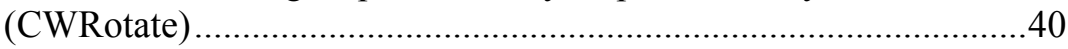

3.5.6 Permanent rotational displacement by response history

(CWRotate)

3.5.7 Permanent (residual) displacement due to stem wall yielding

4-Force and Displacement Capacity of Reinforced Concrete (R/C)

Structures

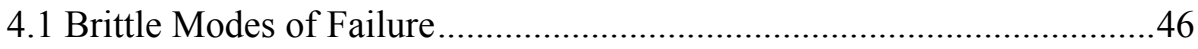

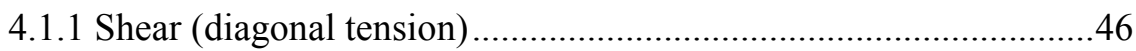

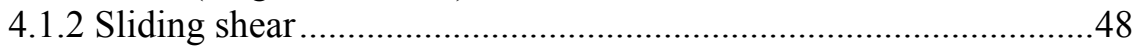

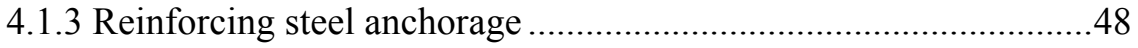

4.1.4 Reinforcing steel splices and hooked bars....................................49

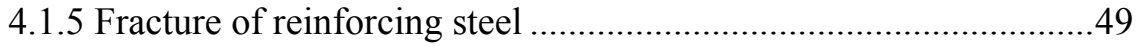

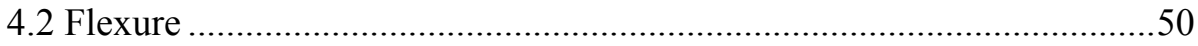

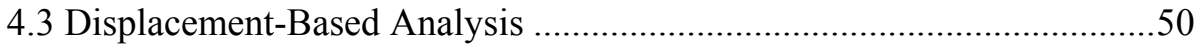

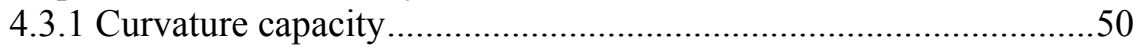

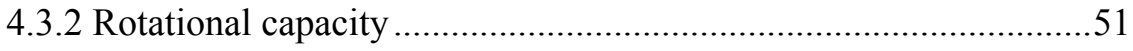

4.4 Displacement Capacity of Cantilever Structures ....................................52

4.5 Evaluating the Seismic Performance of Reinforced Concrete

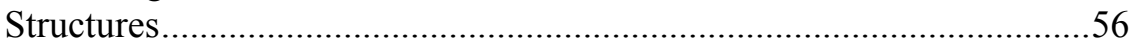

4.5.1 Proposed displacement-based approach for cantilever

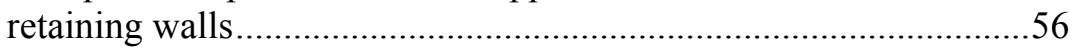

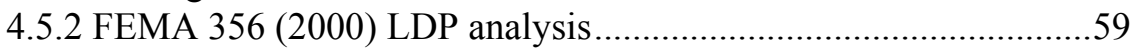

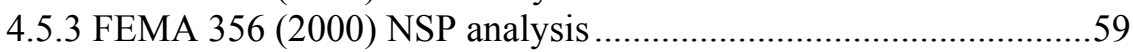

4.5.4 ATC-40 (1996) CSM analysis.......................................................61

4.6 Evaluating Performance of Retaining Wall Systems .............................62

4.6.1 Capacity to demand evaluation for force-controlled actions...........63

4.6.2 Displacement-based evaluations ................................................63 
5-Summary, Conclusions, and Recommendations .......................................64

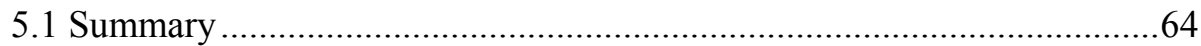

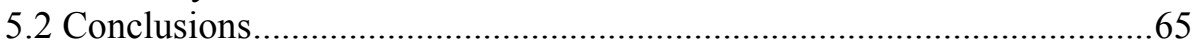

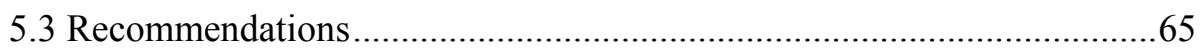

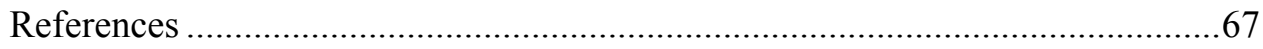

Appendix A: Historical Perspective - Corps Reinforced Concrete Design

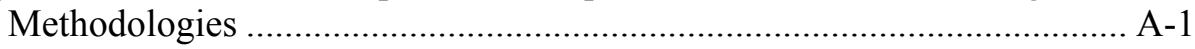

Appendix B: Evaluating Older Retaining Walls ..............................................

Appendix C: Developing Standard Response Spectra for USACE

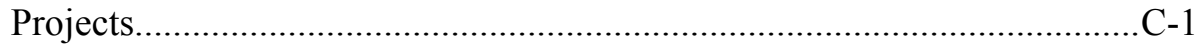

Appendix D: Corps Working Stress Design (WSD) Example by Working

Stress Design Methods Using EM 1110-2-2502 and

EM 1110-1-2101

Appendix E: Corps Ultimate Strength Design (USD) Example by

Ultimate Strength Design Methods Using EM 1110-2-2104,

EM 1110-2-2502, and EC 1110-2-6058 …………................................. E-1

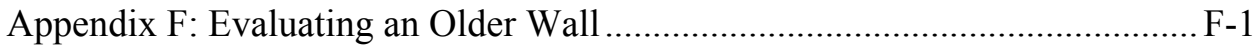

Appendix G: Criteria Review for Corps by Dr. Priestley and Dr. Moehle ....... G-1

Appendix H: Notation .................................................................................... H-1

SF 298

\section{List of Figures}

Figure 1.1. Permanent earthquake-induced sliding displacement $\Delta_{\mathrm{s}} \ldots \ldots \ldots \ldots \ldots . .2$

Figure 1.2 Permanent earthquake-induced rocking rotation $\theta_{\mathrm{r}} \ldots \ldots \ldots \ldots \ldots \ldots . . . . . .3$

Figure 1.3 Earthquake-induced flexural yielding of stem wall and permanent displacement ........................................................... 4

Figure $1.4 \quad$ Single-degree-of-freedom system ......................................... 6

Figure 1.5 Development of response spectra ...........................................

Figure 1.6 Driving and resisting wedges per Mononobe-Okabe ...................8

Figure 1.7 Idealized ductile behavior curve...............................................12

Figure $1.8 \quad$ Idealized limited-ductile behavior curve ..................................14

Figure $1.9 \quad$ Idealized brittle behavior curve .............................................. 15

Figure 2.1 Idealized example of earthquake demands on inelastic structures 
Figure 2.2 Standard acceleration response spectrum illustrating limits of equal acceleration, equal energy, and equal displacement response

Figure 2.3 Standard acceleration response spectrum indicating acceleration-, velocity-, and displacement-sensitive

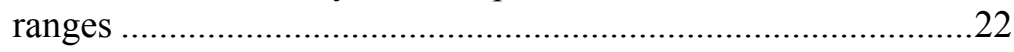

Figure 2.4 Equal acceleration response ……........................................23

Figure 2.5 Equal energy response.......................................................24

Figure 2.6 Equal displacement response ................................................25

Figure 3.1 Gravity dam sliding on foundation.........................................28

Figure 3.2 Distribution of wall pressures with height for various

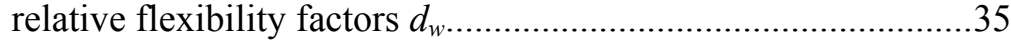

Figure 3.3 Permanent sliding displacement ................................................38

Figure 3.4 Permanent displacement as a function of $k_{y}$ and $A \ldots \ldots \ldots \ldots \ldots \ldots . . . .39$

Figure 3.5 Possible stem wall hysteretic behavior when earthquake

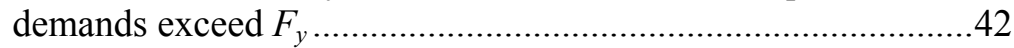

Figure 3.6 Permanent displacement at top of wall due to stem wall yielding ............................................................................. 43

Figure 4.1 Degradation of shear strength with ductility ............................47

Figure 4.2 Ultimate curve capacity where $\varepsilon_{c u}, \varepsilon_{s u}$ is the ultimate strain capacity of the concrete in compression and of the steel in tension, respectively .51

Figure 4.3 Idealized flexural curvature in a bridge pier ...........................53

Figure 4.4 Idealized flexural curvature in an intake tower .........................54

Figure 4.5 Idealized flexural curvature in a retaining wall .........................54

Figure 4.6 Displacement demand to capacity evaluation ...........................57

Figure 4.7 FEMA 356 NSP analysis load-displacement curve....................60

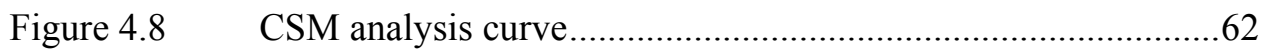




\section{Conversion Factors, Non-SI to SI Units of Measurement}

Non-SI units of measurement used in this report can be converted to SI units as follows:

\begin{tabular}{|l|l|l||}
\hline Multiply & By & To Obtain \\
\hline \hline feet & 0.3048 & meters \\
\hline inches & 25.4 & millimeters \\
\hline kips & $4,448.222$ & newtons \\
\hline kips per square foot & 47.88026 & kilopascals \\
\hline kips per square inch & 6.894757 & megapascals \\
\hline inch-kips & 112.9848 & meter-newtons \\
\hline inch-pounds & 16.269816 & joules \\
\hline kips per cubic feet & 157.087458 & kilonewtons per cubic meters \\
\hline kips per square foot & 47.8803 & kilopascals \\
\hline pounds (force) per square foot & 47.88026 & pascals \\
\hline pounds (force) per square inch & 0.006894757 & megapascals \\
\hline pounds (mass) & 0.4535924 & kilograms \\
\hline square inches & 645.16 & square millimeters \\
\hline \hline
\end{tabular}




\section{Preface}

The work described herein was sponsored by Headquarters, U.S. Army Corps of Engineers (HQUSACE), as part of the Navigation Systems Research Program. The Focus Area Leader for Inland Navigation was Ms. Yazmin SedaSanabria, Structural Engineering Branch, Geosciences and Structures Division, Geotechnical and Structures Laboratory (GSL), Vicksburg, MS, U.S. Army Engineer Research and Development Center (ERDC). The research was performed under Work Unit 4402JC, entitled "Soil-Structure Interaction for Seismic Evaluation of Earth-Retaining Lock and Cantilever Walls" for which Dr. Robert M. Ebeling, Engineering and Informatic Systems Division (EISD), Information Technology Laboratory (ITL), Vicksburg, MS, ERDC, was the Principal Investigator. The HQUSACE Technical Monitor is Ms. Anjana Chudgar, CECW-EW.

Dr. Sandra Knight, Coastal and Hydraulics Laboratory (CHL), Vicksburg, MS, ERDC, was the Technical Director for Navigation. The Navigation Business Line Leader was Mr. Barry Holliday, HQUSACE. Mr. James E. Clausner, Coastal Engineering Branch, CHL, was Navigation Systems Program Manager.

The research was performed and this report written by Dr. Ebeling and Mr. Ralph W. Strom, Portland, OR, under the general supervision of Dr. Charles R. Welch, Chief, EISD; Mr. David R. Richards, Technical Director for Computational Sciences and Engineering, ITL; Dr. Jeffery P. Holland, Director, ITL; Dr. Mary Ellen Hynes, Technical Director for Civil Works Infrastructure and Geosciences, GSL; and Dr. David W. Pittman, Acting Director, GSL.

Commander and Executive Director of ERDC was COL James R. Rowan, EN. Director was Dr. James R. Houston. 


\section{Introduction}

\subsection{Behavior of Retaining Wall Systems Subjected to Earthquake Ground Motions}

Cantilever retaining walls can respond externally to earthquake ground motions by sliding as indicated in Figure 1.1 or by rotating as indicated in Figure 1.2. They can also respond internally by stem yielding as indicated in Figure 1.3.

The type of response that will have the greatest impact on post-earthquake performance will likely depend on restraint conditions at the base of the wall. Walls founded on soil without an invert slab are most likely to dissipate the inertial energy imposed by earthquake ground motions by sliding. This may also be true for walls founded on fissured or fractured rock. Walls founded on soil or on fissured or fractured rock and prevented by an invert slab from moving laterally are more likely to tip (i.e., rotate) than to slide during a major earthquake event. Walls founded on competent rock without significant joints, faults, or bedding planes and prevented by a strong bond at the rock-footing interface from either translating or rotating are likely to dissipate energy through plastic yielding in the stem wall. All three responses can leave the retaining wall in a permanently displaced condition. The computer program CWRotate (Ebeling and White, in preparation) can be used to provide estimates of this permanent (residual) displacement for walls dominated by a sliding or rotational response. An enhancement to CWRotate could be made to provide estimates of the permanent displacement associated with a stem wall yielding response. This enhancement is described in Appendix F.

It should be recognized that the dynamic response of cantilever retaining walls is far from being well understood (Veletsos and Younan 1997). Often pseudostatic methods, such as those described in Ebeling and Morrison (1992), are used to investigate the response of retaining walls to earthquake ground motions. In other cases sophisticated stress-deformation methods are used. The sophisticated stress-deformation methods allow the user to consider various constitutive models for the soil-wall system and permit user-specified acceleration time-histories, e.g., Green and Ebeling (2002) and Veletsos and Younan (1997) to cite a few. 


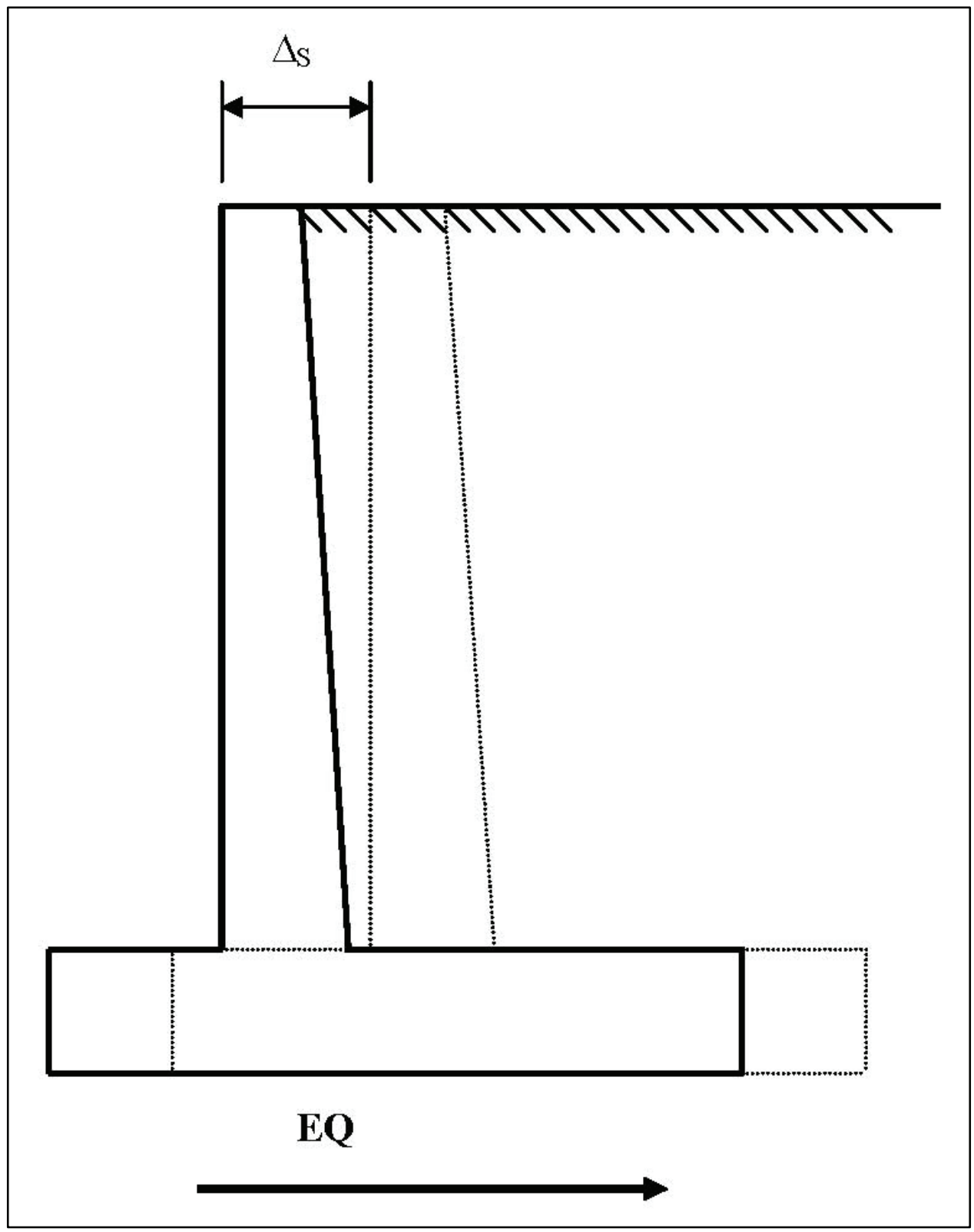

Figure 1.1 Permanent earthquake-induced sliding displacement $\Delta_{\mathrm{S}}$

Pseudostatic methods assume rigid body motion and therefore an equal acceleration response (i.e., retaining wall and ground move in unison). As such, pseudostatic methods cannot directly capture the ground motion amplification effects that may occur with flexible structures or structural systems. Using an "effective" value for acceleration, however, can approximate amplification effects. 


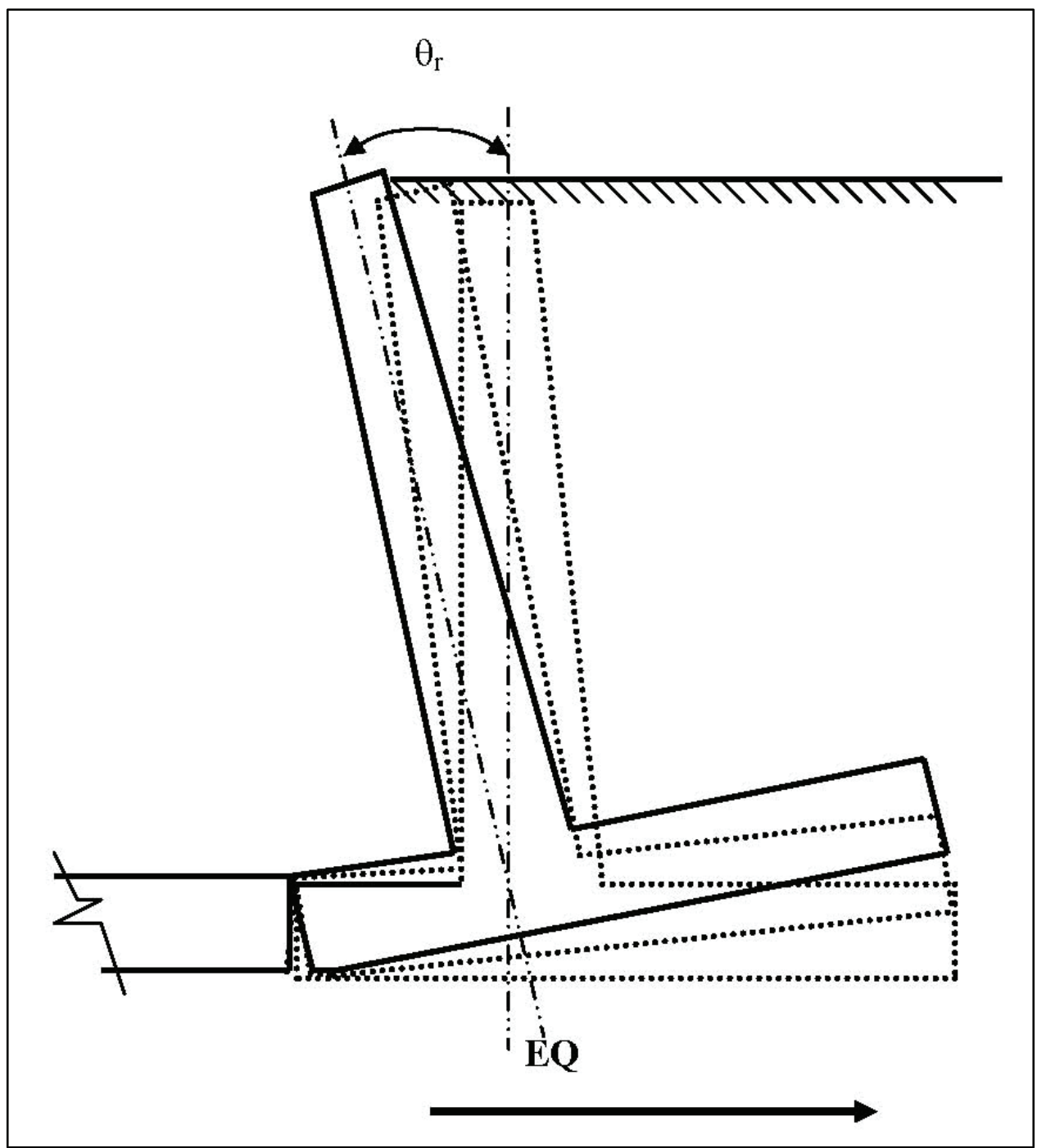

Figure 1.2 Permanent earthquake-induced rocking rotation $\theta_{\mathrm{r}}$

\subsection{Objectives of Research}

This research effort investigates the various potential responses that cantilever retaining wall structures can exhibit when subjected to earthquake ground motions, with special emphasis on a response that is dominated by flexural yielding in the stem wall. Flexural yielding in the stem is applicable to those cantilever retaining walls founded on rock without significant joints, faults, or bedding planes, and restrained against translation and rotation. Because of the reserve capacity associated with the design for static earth pressures, earthquake ground motions may or may not cause plastic yielding within the stem.

The report first describes the seismic behavior of all structures and structural systems to earthquake ground motions and discusses the various simple procedures often used for the seismic evaluation of building, bridges, and other structures not subject to soil-structure interaction. 


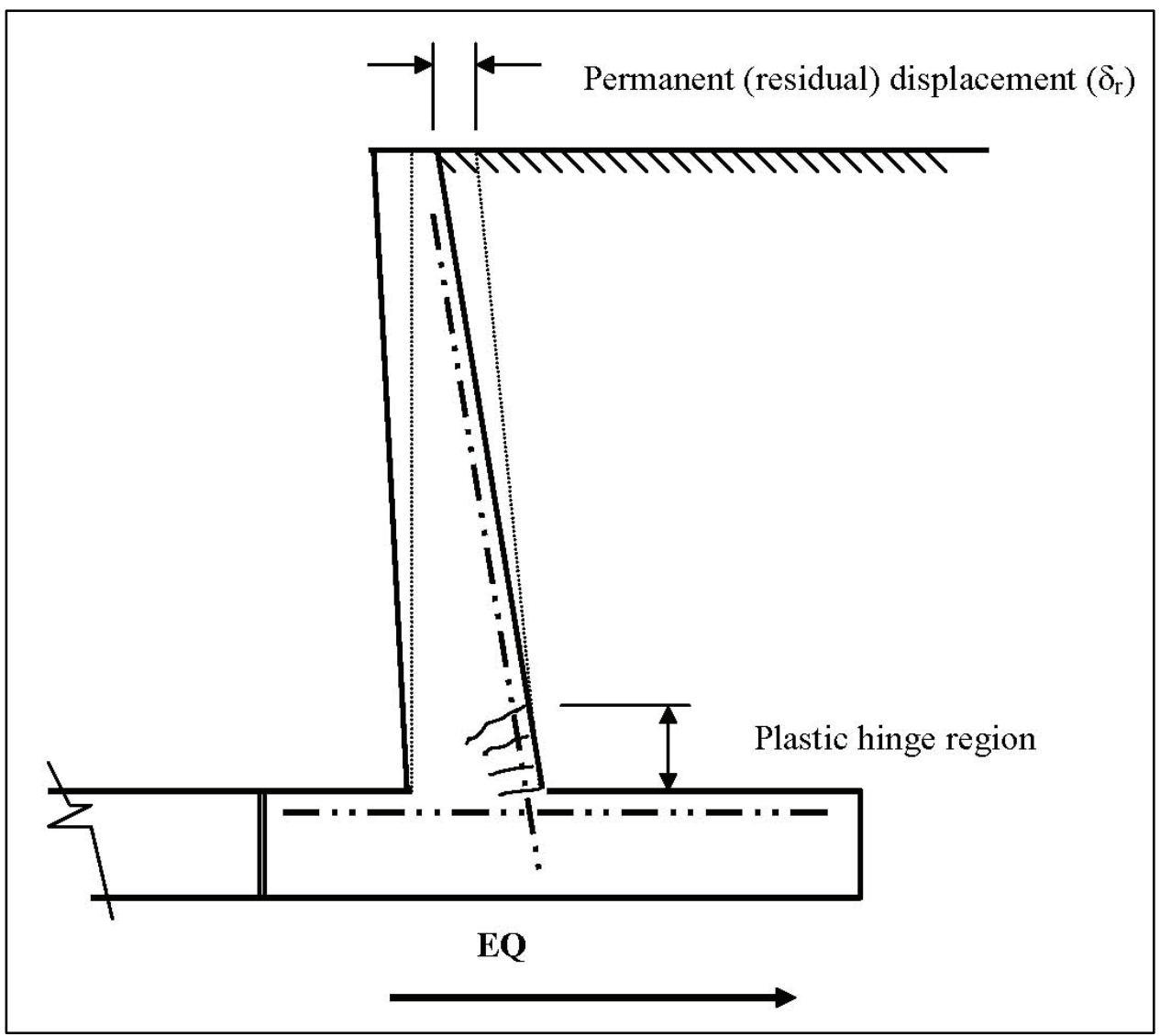

Figure 1.3 Earthquake-induced flexural yielding of stem wall and permanent displacement

The seismic evaluation of earth retaining wall structures is more complex due to soil-structure interaction effects. Pseudostatic methods and stress-deformation methods are often used for the seismic evaluation of cantilever retaining walls. Two methods described in this report are of special interest. One is the simple pseudostatic procedure described in Ebeling and Morrison (1992) and Seed and Whitman (1970). The other is the flexible cantilever wall procedure described in Veletsos and Younan (1997). Both procedures are described in this report and illustrated in the examples in the appendices. The flexible cantilever wall procedure, since it provides estimates for displacement demand, could facilitate a displacement-based evaluation. Displacement-based evaluations are needed for those walls where flexural demands exceed flexural capacities. The proposed displacement-based procedure is described and illustrated in Appendix F. A possible enhancement to CWRotate is also described in Appendix F. For retaining walls dominated by stem wall yielding, this enhancement could provide estimates of the permanent (residual) post-earthquake displacement by taking into account the contribution of each post-yield excursion that occurs during a given timehistory event.

As indicated earlier in this chapter, the capacity of a retaining wall to resist earthquake ground motion effects depends on the reserve capacity available in the design for static earth pressures. This aspect is investigated for older retaining wall systems by examining the margin of safety inherent in the old working 
stress design (WSD) approach. A similar approach is used for new walls by examining the margin of safety inherent in the current Corps ultimate strength design (USD) approach.

An example illustrating the Corps' old WSD approach, an approach used for the design of many older retaining walls, is presented in Appendix D. A retaining wall designed to current Corps USD practice is presented in Appendix E. The capacity of each design to resist earthquake ground motion effects is discussed. In addition, an older retaining wall designed to Corps past practices using outdated "low-bond" deformation type reinforcement is evaluated for each potential response mechanism and various seismic safety concerns (earthquake and postearthquake) addressed (see Appendix F). All potential modes of failure, both ductile and nonductile, are considered. Potential failure modes for reinforced concrete intake towers are described in Appendix B of Engineer Circular (EC) $1110-2-285^{1}$. Relevant provisions of the EC 1110-2-285 guidance will be updated in this report to accommodate the cantilever retaining wall seismic evaluation process.

\subsection{Response of Structures and Structural Systems to Earthquake Ground Motion}

In earthquake design and analysis, response spectra via spectral acceleration values are used to represent the peak acceleration response of single-degree-offreedom (SDOF) systems to a time-history of recorded ground motions. This topic is discussed in detail in Chapter 2, but is presented here to illustrate the response of systems that are considered to be infinitely stiff (rigid), as compared to systems that are flexible. Response spectrum methods are often applied to the seismic evaluation of flexible structures. Typical structures utilizing the response spectra method of design and analysis include concrete dams, intake towers, buildings, and bridges. Although not often evaluated by response spectrum methods, the behavior of cantilever retaining walls (a soil-wall system) can be illustrated with respect to the force demands on a system that is considered to be rigid versus a soil-wall system that is flexible. The term system will be used throughout the report to describe structural systems where soil-structure interaction effects can be important to the overall response. Although a response spectrum represents the maximum response of SDOF systems, the response of multidegree-of-freedom systems (MDOF) can also be evaluated by response spectrum analysis method. A type of SDOF system is illustrated in Figure 1.4.

Each SDOF system is represented by a single lumped mass atop a beam/column element with the beam/column element having a given stiffness and damping. The peak response of this particular system in terms of displacement, velocity, or acceleration can be recorded in response to a given timehistory record of earthquake ground motion. Figure 1.4 illustrates the peak acceleration response to earthquake ground motion.

\footnotetext{
${ }^{1}$ Appendix B of EC 1110-2-285, "Seismic Design and Evaluation of Free-Standing Intake Towers," by Strom, Ebeling, and French, 30 September 1995, has been superseded and is no longer in publication.
} 


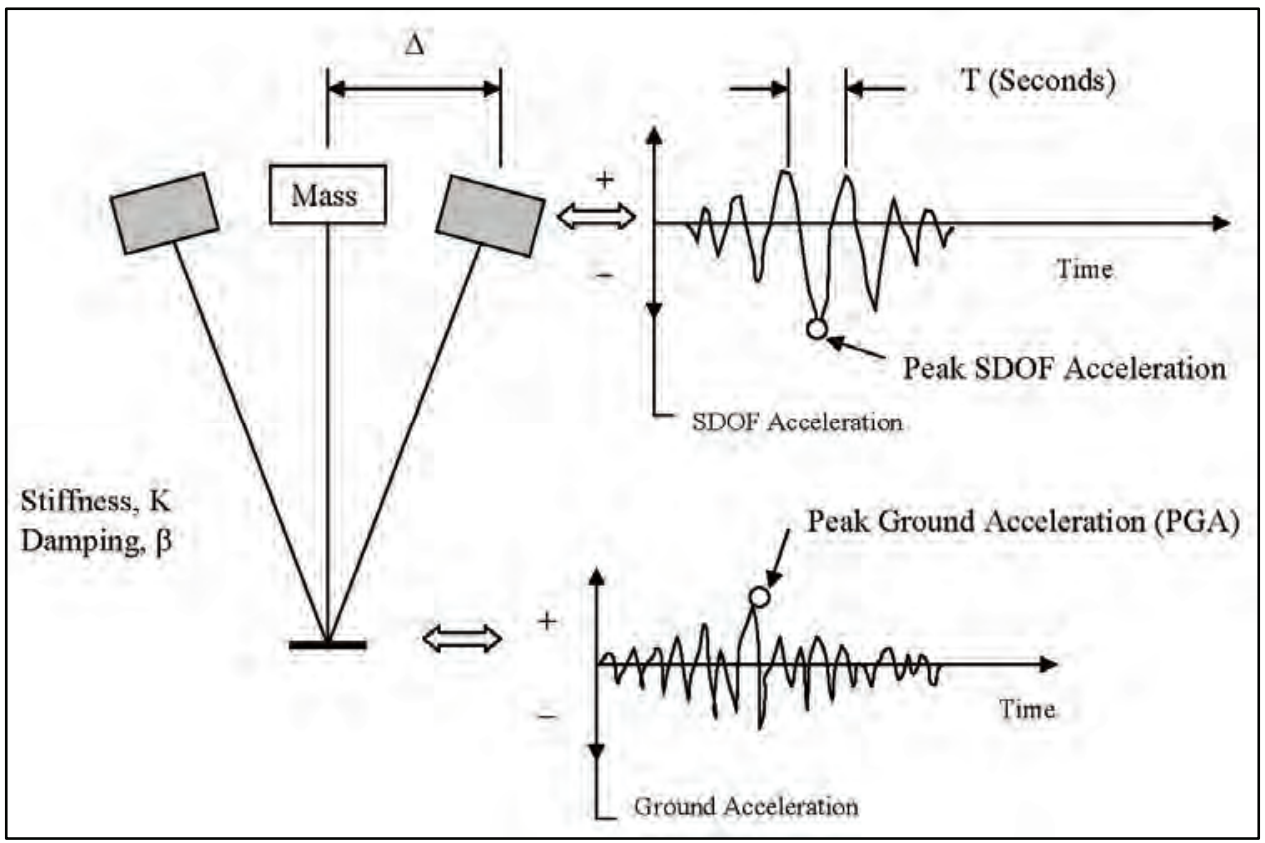

Figure 1.4 Single degree of freedom (SDOF) system

If a series of SDOF systems with similar mass, but with different stiffness (each SDOF will have a different period of vibration), is subjected to a given time-history record of earthquake ground motion, then with the peak response from each SDOF system analyzed, a response spectrum can be obtained. A plot of peak acceleration response against period of vibration is termed an acceleration response spectrum. Refer to Ebeling (1992) for a complete example of the steps involved in this type of analysis. Its characteristics are dependent on the site characteristics, i.e., firm or soft site, the earthquake intensity, distance from earthquake source to site, and source to site transmission path characteristics. Shown in Figure 1.5 is an acceleration response spectrum that has been smoothed to eliminate irregularities for purposes of this discussion.

A smooth response spectrum is generally used for earthquake design and evaluation of MDOF systems, and is often preferred over a natural response spectrum that has numerous peaks and valleys unique only to the particular timehistory record used in its development. The period of vibration (natural and undamped) of an SDOF system is equal to

$$
2 \pi \sqrt{\frac{\text { mass }}{\text { stiffness }}}
$$

SDOF systems with periods of vibration approaching zero are rigid systems that move with the ground, thus having peak acceleration equal to the peak ground acceleration. Very flexible, i.e., long-period, systems tend to have a low acceleration response since the mass tends to remain pretty much stationary with the ground moving relative to the stationary mass. For long-period systems the ground motion response can be suppressed in the structural system. For SDOF 
systems that approach resonance with the characteristic period of vibration of the ground motion, amplification of the ground motion response can occur within the structural system.

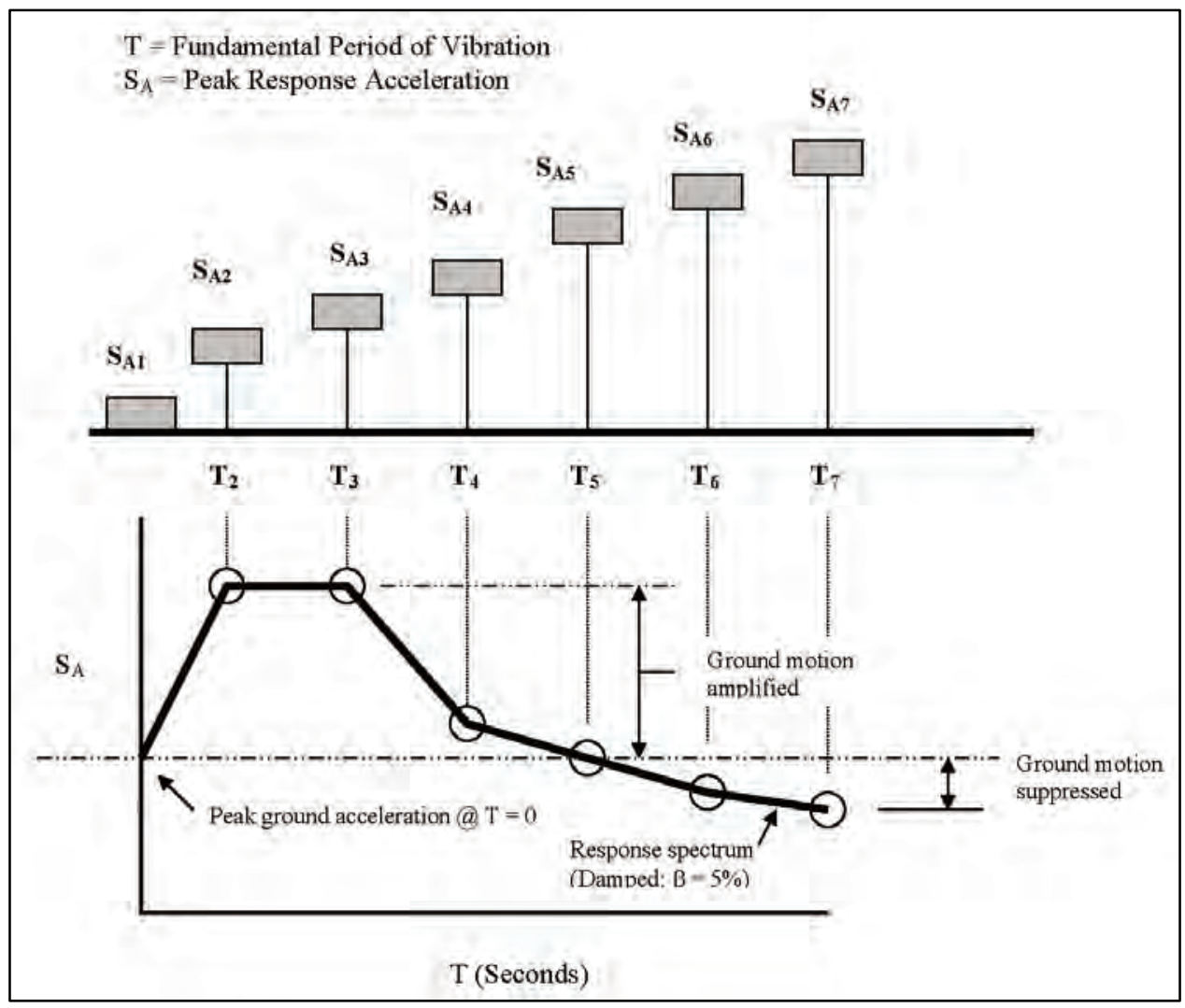

Figure 1.5 Development of response spectra

\subsection{Pseudostatic Methods and Their Limitations}

Cantilever retaining walls can be evaluated for earthquake ground motions and dynamic earth pressure effects by one of the following:

- Pseudostatic methods with a preselected seismic coefficient.

- Stress-deformation methods.

Both of these methodologies are described in Ebeling and White (in preparation). Veletsos and Younan (1997) using stress-deformation methods confirmed that dynamic earth pressure intensity and distribution are highly dependent on the flexibility of the stem wall and its base. For usual wall flexibilities when dynamic amplification effects in the retained soil are neglected, the magnitude of the total wall force (i.e., static plus incremental dynamic resultant earth pressure force) is in reasonable agreement with that determined by the Mononobe-Okabe (MO) relationship. The MO approach is a pseudostatic method that assumes limit-state (active) soil pressure conditions in the retained soil. This approach is one of the simple dynamic analysis procedures described in Ebeling and Morrison (1992). 
The MO approach can be applied to retaining walls in which the relative motion of the retaining structure and backfill is sufficient to fully mobilize the shear strength in the soil. The MO approach utilizes a soil wedge solution in which a wedge of soil bounded by the structural wedge and by an assumed failure plane within the retained soil are considered to move as a rigid body and with the same horizontal acceleration (Figure 1.6).

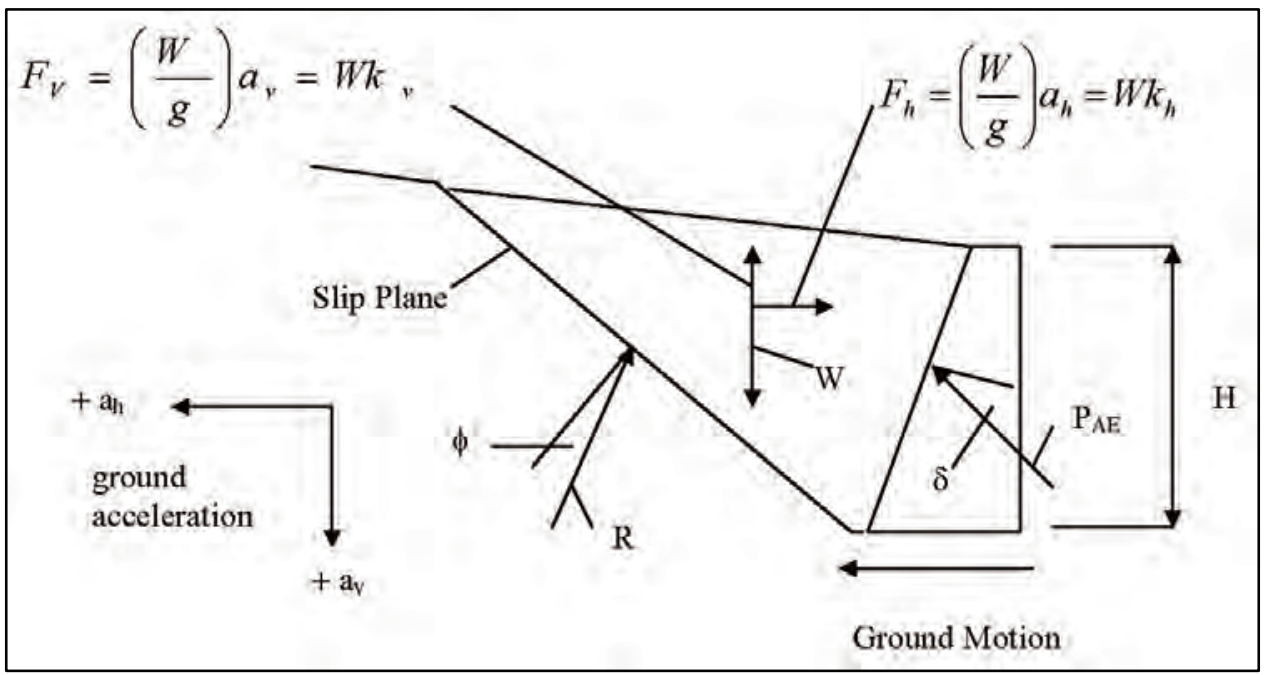

Figure 1.6 Driving and resisting wedges per Mononobe-Okabe

Symbols ${ }^{1}$ used in Figure 1.6 are defined as follows:

$g=$ acceleration of gravity

$W=$ weight of rigid body (i.e., wall or soil wedge)

$a_{h}=$ maximum horizontal ground acceleration equal to $k_{h} g$

$a_{v}=$ maximum vertical ground acceleration equal to $k_{v} g$

$k_{h}=$ fraction of horizontal acceleration

$k_{v}=$ fraction of vertical acceleration

$H=$ height of wall

$F_{h}=$ dynamic earth pressure force in horizontal direction

$F_{v}=$ dynamic earth pressure force in vertical direction

$R=$ resultant force on soil wedge

$P_{A E}=$ total active earth pressure force (dynamic + static)

$\phi=$ angle of $R$ with respect to the soil wedge slip plane

$\delta=$ angle of $P_{A E}$ with respect to landside wall face

The dynamic earth forces will then be proportional to the weight in the failure wedge times the horizontal seismic coefficient. The total backfill thrust (dynamic + static) against the wall using the MO pseudostatic approach is equal to

\footnotetext{
${ }^{1}$ For convenience, symbols and unusual abbreviations are listed and defined in the Notation (Appendix H).
} 


$$
P_{A E}=0.5 \gamma\left(1-k_{v}\right) H^{2}\left(K_{A E}\right)
$$

where

$\gamma=$ moist unit weight of the backfill

$K_{A E}=$ active stress coefficient, which is a function of (a) the friction angle of the retained soil, (b) the interface friction angle between the backfill and the wall, and (c) the horizontal and vertical acceleration coefficients $k_{h}$, and $k_{v}$, respectively, as per Equation 33 in Ebeling and Morrison (1992). $K_{A E}$ is given in Equation 34 in Ebeling and Morrison (1992).

A moist soil backfill above the groundwater table is assumed for Equation 1.1. ${ }^{1}$ Seed and Whitman (1970) as cited in Whitman (1990) and Ebeling and Morrison (1992) have provided a simple linear approximation for $K_{A E}$ that is applicable for cases where the vertical acceleration is zero:

$$
K_{A E}=K_{A}+(3 / 4) k_{h}
$$

where $K_{A}$ is the static coefficient of earth pressure.

Procedures for determining the failure wedge and dynamic soil pressure effects for active conditions are described in Ebeling and Morrison (1992). Included in the Ebeling and Morrison (1992) report is a simplified procedure for computing the dynamic active earth pressure on a vertical wall retaining dry backfill. This procedure is illustrated in the retaining wall examples in Appendices $\mathrm{D}$ and $\mathrm{E}$ of this report.

Since the MO approach assumes the soil-wall system moves as a rigid body, it can also be assumed that the natural period of the system is the same as that of a rigid body, i.e., equal to zero. This means that the dominant periods of vibration of the ground motion are extremely large compared with that of the soil-wall system. For a rigorous interpretation of a rigid soil-wall system analytical model, it may be inferred that the mass of the soil-wall system and the substrate will move together with no relative displacement. Acceleration is conserved whether the system performs linearly or nonlinearly. Most importantly when the simplified MO approach is used, no inertial force reduction may be realized through system ductility, i.e., through plastic hinging at the base of the stem wall.

Stress-deformation methods similar to those described in Ebeling and White (in preparation), Green and Ebeling (2002), and Veletsos and Younan (1997) must be used to assess the influence soil-wall system flexibility has on performance. As indicated in Veletsos and Younan (1997), dynamic amplification is possible with stem wall demands approaching twice those determined by applying the MO approach.

\footnotetext{
${ }^{1}$ Ebeling and Morrison (1992) provide relationships for $P_{A E}$ and pore-water pressures in the case of partially or fully submerged retained soils.
} 


\subsection{Design Basis Earthquakes}

The design basis earthquakes to be used by the Corps in the design and evaluation of cantilever retaining walls are the Operational Basis Earthquake (OBE) and the Maximum Design Earthquake (MDE). These design earthquake events are described in the following paragraphs and in Engineer Regulation (ER) 1110-2-1806 (Headquarters, U.S. Army Corps of Engineers (HQUSACE) 1995). Earthquake-generated inertial forces associated with the OBE are considered to be unusual loads. Those associated with the MDE are considered extreme loads. Earthquake loads are to be combined with other loads that are expected during routine operations.

\subsubsection{Operational basis earthquake}

The OBE is an earthquake that can reasonably be expected to occur within the service life of the project, that is, with a 50 percent probability of exceedance during the service life. (This corresponds to a return period of 144 years for a project with a service life of 100 years.) This design event, though important to the evaluation of other Corps structures, will typically not govern with respect to new cantilever retaining walls designed to current reinforced concrete design requirements. This is because the reserve capacity inherent in the load factors used for static earth pressure conditions will keep performance within the linear elastic range for the OBE event. Nevertheless per ER 1110-2-1806 requirements this load case needs to be considered for all Corps retaining structures, especially in regions with a high seismic hazard potential (e.g. many west-coast Corps sites).

\subsubsection{Maximum design earthquake}

The MDE is the maximum level of ground motion for which a structure is designed or evaluated. Generally, for other than critical structures, the probabilistically determined MDE is an earthquake that has a 10 percent chance of being exceeded in a 100-year period (or a 950-year return period). For critical structures the MDE is the same as the maximum credible earthquake (MCE). Critical structures, by ER 1110-2-1806 definition, are structures that are part of a highhazard project and whose failure will result in loss of life. The MCE is defined as the greatest earthquake that can reasonably be expected to be generated on a specific source, on the basis of seismological and geological evidence. It is anticipated because of the reserve capacity associated with static earth pressure design that earthquake load cases will govern only for retaining walls located in high seismic areas. Designers, however, will need to verify this for their particular project.

\subsection{Performance Levels}

Various performance levels are considered when evaluating the response of structures to earthquake ground motions. The performance levels commonly used 
are serviceability performance, damage control performance, and collapse prevention performance.

\subsubsection{Serviceability performance}

The structure is expected to be serviceable and operable immediately following earthquakes that can reasonably be expected to occur within the service life of the project. This performance objective, however, may not need to be evaluated for retaining walls because of the reserve capacity issue cited previously.

\subsubsection{Damage control performance}

Elements of the structure can perform beyond their elastic limits (nonlinear behavior) provided displacement demands and permanent post-earthquake displacements are within acceptable limits and provided the post-earthquake load capacity of the structure has not been significantly compromised. Damage may be significant, but it is generally repairable and concentrated in discrete locations where yielding occurs. The designer should identify all potential damage regions, and be satisfied that if necessary, it will be feasible to repair the earthquake damage before further damage by floods or earthquakes can occur. Except for extreme MCE events, it is desirable to control or limit damage to the stem of spillway retaining walls and to keep permanent post-earthquake displacements within acceptable limits.

\subsubsection{Collapse prevention performance}

Collapse prevention performance requires only that collapse of the structure be prevented in order to prevent possible loss of life. Damage may be unrepairable and permanent post-earthquake deformations unacceptable. The collapse prevention level of performance should be permitted only for extreme MCE events, and only where it is feasible to replace the damaged structure without a risk to life from near-term potential flood and earthquake hazard events.

\subsection{Performance Goals}

Both strength and serviceability should be considered in the design and evaluation of any structure. For retaining wall structures subject to earthquake loading, the capacity to prevent collapse and the impact permanent postearthquake displacements have on performance need to be investigated. For retaining wall structures, the consequences of inadequate strength can be failure by shear, sliding shear, flexure, and bond due to inadequate splice or development lengths. Critical and normal structures are defined in Appendix H of EC 1110-2-6058 (HQUSACE 2003a). For critical structures, failure to provide adequate strength can result in loss of life and severe economic loss. For normal (i.e., noncritical) structures, failure may result in severe economic loss. Permanent post-earthquake displacements if large enough can impair flood protection and 
the serviceability and operability of structures and equipment founded on the soil supported by the retaining wall structure.

The general performance goals for concrete hydraulic structures are demonstrated through the use of idealized force displacement curves (Figures 1.7 through 1.9). These curves represent ductile, limited-ductile, and brittle behavior. It must be remembered that information on both force and displacement demands is needed to properly assess the performance of structures that are ductile. Changes in stiffness that occur with the onset of yielding will influence both force and displacement demands. Pseudostatic methods are unable to account for this and therefore have their limitations with respect to the performance evaluation of ductile systems.

\subsubsection{Ductile behavior}

Ductile behavior is illustrated by Figure 1.7.

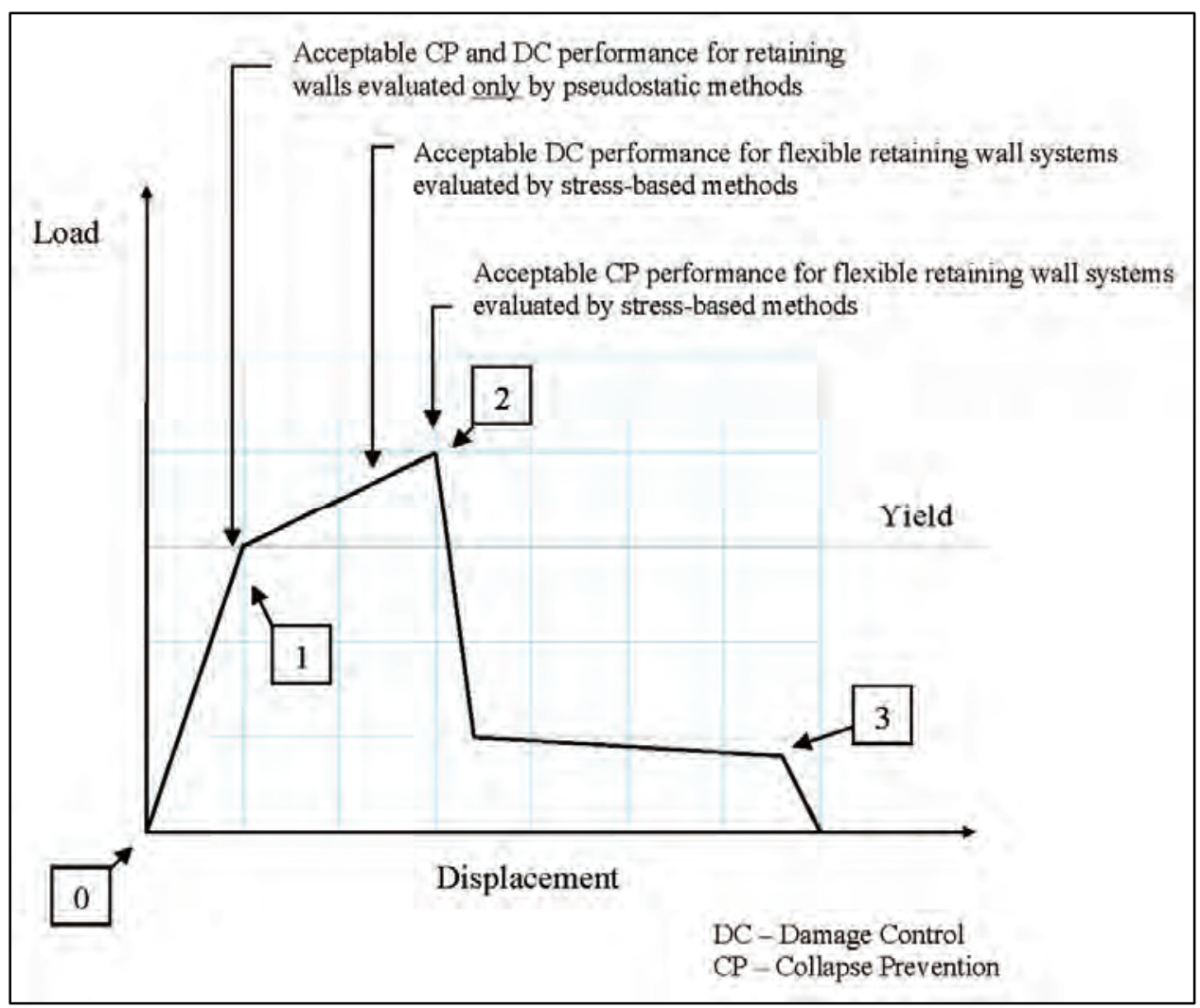

Figure 1.7 Idealized ductile behavior curve (after Federal Emergency Management Agency (FEMA) 356 (2000))

It is characterized by an elastic range (point 0 to point 1 on the curve), followed by a plastic range (points 1 to 3 ) that may include strain hardening or softening (points 1 to 2), and a strength-degraded range (points 2 to 3 ) in which some residual strength is still available before collapse occurs. Because shear and bond generally exhibit brittle behavior, these failure modes must be suppressed if 
ductile behavior as illustrated by Figure 1.7 is to be achieved. Retaining walls may exhibit ductile behavior in flexure; however, stress-based methods of analysis rather than pseudostatic methods may be required to determine if displacement demands are within acceptable limits. Retaining walls that are evaluated by only simplified pseudostatic methods should have collapse prevention (CP) performance and damage control (DC) performance in the linear elastic range as illustrated in Figure 1.7. Retaining wall structures when analyzed by stress-based methods may perform in the nonlinear range. Those classified as "critical" when subjected to MDE ground motion demands should have sufficient strength to assure $\mathrm{CP}$ performance will be within the inelastic region where strength increases with an increase in strain (strain hardening region). Those classified as "normal" when subjected to MDE ground motion demands should have sufficient strength to assure DC performance will be, say, within the middle one-third inelastic region where strength increases with an increase in strain and some reserve capacity is maintained for the design ground motion. The line between points 1 and 2 represents this inelastic region. Designers of new reinforced concrete structures should establish a hierarchy in the formation of failure mechanisms by allowing flexural yielding to occur while at the same time suppressing shear and other brittle or semi-ductile failure mechanisms. Such a design produces ductile behavior. Reinforced concrete retaining walls designed by older codes may not provide adequate rebar splice and development lengths or the proper details to assure ductile behavior. For older (existing) retaining wall structures it is necessary to evaluate all failure mechanisms to determine what type of overall structural behavior can be achieved. This process is similar to that for intake towers as described in EC 1110-2-285. An historical perspective on Corps reinforced concrete design practices is provided in Appendix A. Guidance with respect to the seismic evaluation of older retaining wall structures is proposed in Appendix B.

\subsubsection{Limited-ductile behavior}

Limited-ductile behavior (Figure 1.8) is characterized by an elastic range and plastic range that may include strain hardening or softening, followed by a complete loss of strength.

Older reinforced concrete retaining walls may exhibit this type of behavior although the plastic range may be limited. Limited ductile structures when subjected to MDE ground motion demands should have sufficient strength to assure performance will be within the middle one-third of the inelastic region where strength increases with an increase in strain (strain hardening region). As stated previously, when only simplified pseudostatic methods of analysis are used, performance should remain in the elastic range.

\subsubsection{Brittle behavior}

Brittle (nonductile behavior) is characterized by an elastic range followed by a rapid and complete loss of strength (see Figure 1.9).

Certain failures such as reinforcing steel splice failures and anchorage failures exhibit this type of behavior under earthquake loading conditions. Sudden 
failure can occur because the concrete is not adequately confined to prevent spalling, which in turn leads to a rapid loss of bond strength and to splice and anchorage failures during earthquake-induced load reversals. Performance should be within the elastic range for brittle failure mechanisms.

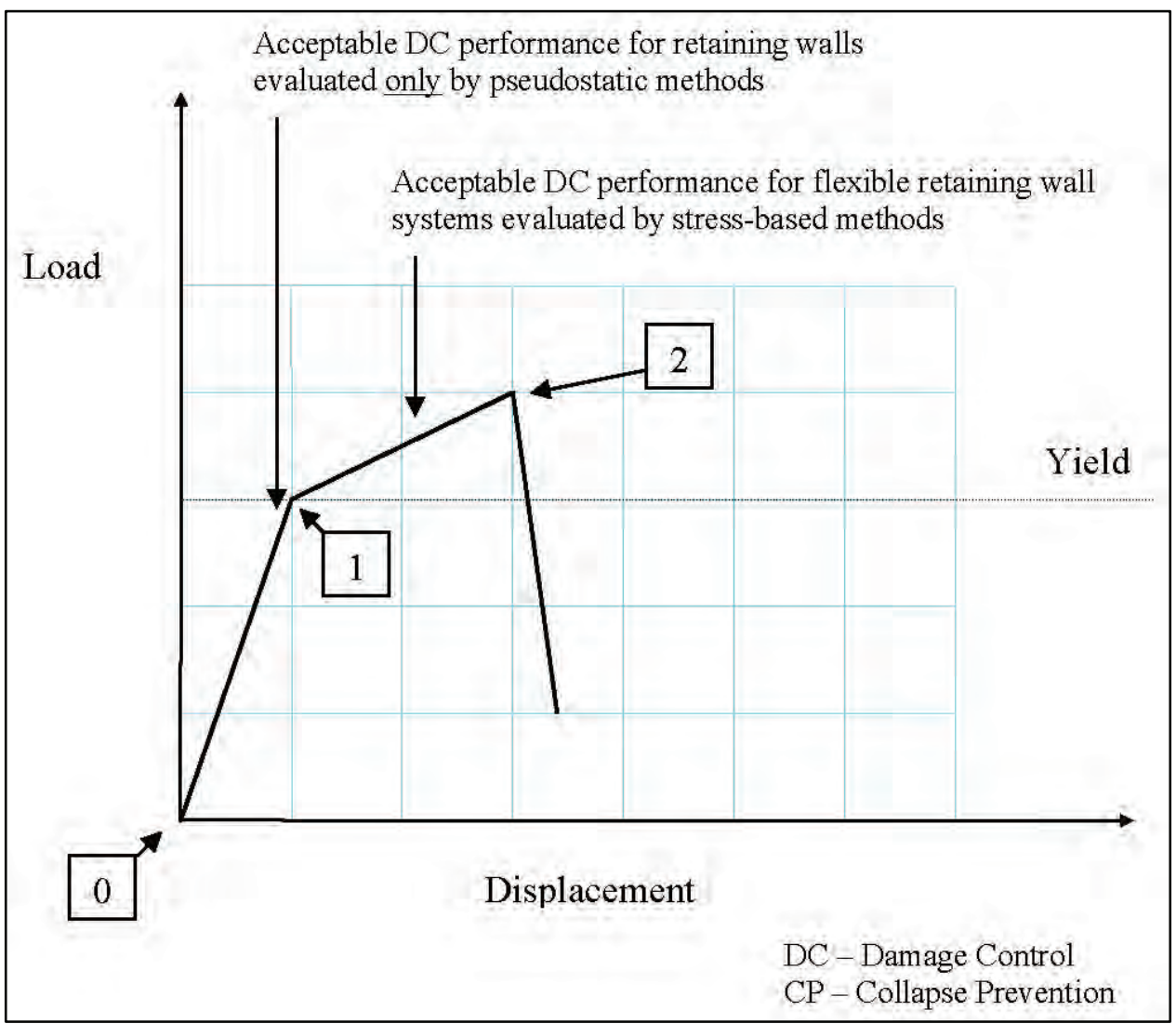

Figure 1.8 Idealized limited-ductile behavior curve (after FEMA 356 (2000))

\subsection{Strength Design Requirements}

Strength design for retaining walls subjected to earthquake ground motions is achieved by reducing the probability of collapse to an acceptable level. This is accomplished by selecting an appropriate design basis earthquake event to be used in combination with specific design and evaluation procedures that assure the structure will perform as intended. To meet this objective the design should, as a minimum, provide strength equal to or greater than that due to static earth pressure demands in combination with peak dynamic earth pressure demands. The design basis earthquake event used for strength evaluation is the MDE.

The following loading combination establishes the ultimate strength requirement for reinforced concrete retaining wall structures. The loading combination represents the total demand (dead load + live load + earthquake) for which the retaining wall must be designed or evaluated.

$$
Q_{D C}=Q_{D}+Q_{L} \pm Q_{M D E}
$$




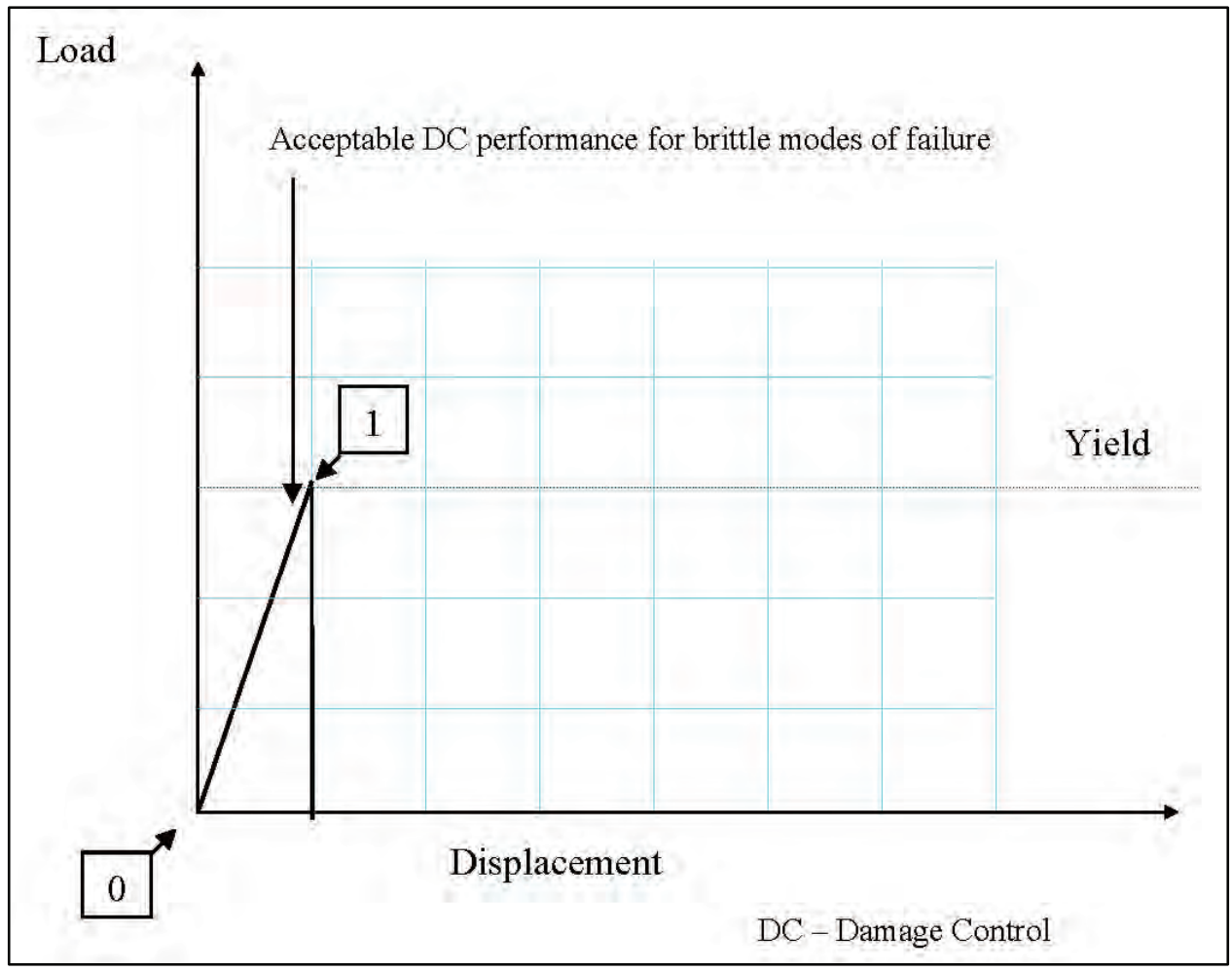

Figure 1.9 Idealized brittle behavior curve (after FEMA 356 (2000))

where

$Q_{D C}=$ combined action due to MDE loads, dead load, and live load for use in evaluating performance

$Q_{D}=$ dead load effect

$Q_{L}=$ live load effect

$Q_{M D E}=$ earthquake load effect from MDE earthquake ground motions.

Equation 1.3 has a load factor of one for dead load, live load, and earthquake load effects to facilitate a performance-based approach that directly compares earthquake demand with structure capacity. This is in accordance with the FEMA 356 (2000) performance-based approach. 


\section{Estimating Earthquake Ground Motion Demands}

\subsection{Specification of Earthquake Ground Motions}

The earthquake ground motions for design and evaluation of structures are generally characterized in terms of response spectra and acceleration timehistories. Information on response spectra can be found in EM 1110-2-6050 (HQUSACE 1999). Information on time-histories and time-history analysis can be found in EM 1110-2-6051 (HQUSACE 2003d). ER 1110-2-1806 (HQUSACE $1995)$ provides regulatory guidance and direction for the seismic design and evaluation of all civil works projects. As indicated in ER 1110-2-1806, seismic analysis should be performed in phases in order of increasing complexity. A progressive seismic approach is discussed in Chapter 3.

The pseudostatic method of analysis used in the seismic design and evaluation of retaining walls requires only that an estimate be made of the peak ground acceleration (PGA) associated with the $\mathrm{MDE}^{1}$. However, the flexible cantilever wall procedure described in Veletsos and Younan (1997) requires that an estimate be made of potential amplification of ground motion effects with respect to both force and displacement. Whether analyses are performed by pseudostatic or stress-based methods, it is always best to construct a standard response spectrum representing the MDE for the project site, especially in high seismic areas. This will provide a better understanding, once the system period is determined, of the potential for amplification of the force and displacement response.

\subsubsection{Using response spectra for earthquake design and analysis}

In earthquake design and analysis the spectral acceleration values defined by response spectra represent the peak acceleration response of each of a series of SDOF systems to a time-history of recorded ground motions. Information on response spectra can be found in Ebeling (1992). Earthquake response spectra can be site specific or standard (nonsite specific). Standard response spectra are developed using spectral shapes based on an accumulation of data at sites of similar subsurface characteristics subjected to numerous and different earthquake

\footnotetext{
${ }^{1}$ ER 1110-2-1806 also requires a second analysis for the OBE. Performance of the retaining structure during an $\mathrm{OBE}$ event requires no damage or easily repairable damage.
} 
events. These standard spectral shapes are often defined in amplitude using effective peak ground accelerations or spectral accelerations taken from seismic zoning maps developed by ground motion experts and others. Although a response spectrum represents the maximum response of SDOF systems, the response of MDOF systems can also be evaluated by the response spectrum analysis method. This is because the earthquake response of any linear MDOF system can be obtained by combining responses of several SDOF systems, each of which represents a mode of vibration of the MDOF system. The dynamics of MDOF systems is described in French, Ebeling, and Strom (1994) and in EM 1110-2-6050 (HQUSACE 1999).

\subsubsection{Standard response spectra}

Guidance is provided in FEMA 356 (2000) for constructing standard acceleration response spectra. FEMA 356 (2000) uses the latest national earthquake hazard maps developed by the United States Geological Survey (USGS). The USGS hazard maps are developed for ground motions with the following:

- 10 percent chance of exceedance in 50 years (475-year return period).

- 5 percent chance of exceedance in 50 years (950-year return period).

- 2 percent chance of exceedance in 50 years $(2,475$-year return period).

FEMA 356 (2000) also provides methods for estimating earthquake hazards for return periods other than those covered by the USGS maps.

The FEMA 356 (2000) guidance therefore provides one type of methodology that may be used for developing standard acceleration response spectra and effective peak ground accelerations for use in the seismic design and evaluation of the various structural features of USACE projects in accordance with ER 1110-2-1806 (HQUSACE 1995). The standard response spectra development process is illustrated in Appendix C. Standard response spectra can be used as a starting point for performing seismic designs and evaluations, and, if needed, for determining dynamic analysis requirements for more refined analysis.

\subsubsection{Site-specific response spectra}

Earthquake ground motions are dependent on tectonic source conditions, source-to-site transmission path properties, and site conditions. The source conditions include stress conditions, source depth, size of rupture area, amount of rupture displacement, rise time, style of faulting, and rupture directivity. The transmission path properties include the crustal structure and shear-wave velocity and damping characteristics of the crustal rock. The site conditions include the rock properties beneath the site to depths up to $2 \mathrm{~km}$, the local soil conditions at the site up to $100 \mathrm{~m}$ or more in depth, and the topography of the site. All these factors are considered in detail in a site-specific ground motion study, rather than in a general fashion as occurs in the standard response spectra methodology. Also, due to regional differences in some of the factors affecting earthquake ground motions, different attenuation relationships exist. There are two basic 
approaches to developing site-specific response spectra: the deterministic approach and the probabilistic approach. In the deterministic approach, typically one or more earthquakes are specified by magnitude and location with respect to a site. Usually, the earthquake is taken as the MCE, and assumed to occur on the portion of the source closest to the site. The site ground motions are then estimated deterministically, given the magnitude and source-to-site distance. In the probabilistic approach, site ground motions are estimated for selected values of probability of ground motion exceedance in a design time period or for selected values of the annual frequency or return period of ground motion exceedance. A probabilistic ground motion assessment incorporates the frequency of occurrence of earthquakes of different magnitudes on the various seismic sources, the uncertainty of the earthquake locations on the various sources, and the ground motion attenuation including its uncertainty. Guidance for developing sitespecific response spectra and for using both the deterministic approach and the probabilistic approach can be found in EM 1110-2-6050 (HQUSACE 1999).

\subsection{Earthquake Demands on Inelastic Systems}

The inelastic response of a structure subjected to earthquake ground motion is often different from the elastic response. The difference occurs because the vibrational characteristics of the structure change as the structure yields and because damping increases with inelastic action. The predominant change is a shift in the fundamental period of vibration. In most cases, a reduction in earthquake demand occurs as the period of the structure lengthens. However, amplification of earthquake demands may take place in short-period structures such as retaining walls.

In Figure 2.1, a capacity spectrum is used to illustrate the changes that occur when a system performs nonlinearly.

The earthquake demand is represented by USGS standard spectra. The structure capacity is represented by an ideal elasto-plastic response curve. The idealized elasto-plastic capacity curve assumes that after first yield the load capacity of the structural system remains the same (i.e., no strain hardening). The Figure 2.1 capacity curve also assumes a single plastic hinge, as would be expected with cantilever structures such as bridge piers and retaining walls. Although used to illustrate inelastic response, in practice the load-displacement capacity curve must be converted to spectral acceleration and displacements for direct comparison with the demand curve represented by the design response spectrum. Additional information on the capacity spectrum method (CSM) is provided in Chapter 4. In Figure 2.1, earthquake demands for the standard response spectrum curve are reconciled with the ideal elasto-plastic load/displacement capacity curve with the intersection of the two curves representing the point where capacity and demand are equal. The elasto-plastic capacity curve represents a ductile structure. The CSM information is condensed into a single diagram with spectral acceleration on the ordinate, spectral displacement on the abscissa, and lines of constant period radiating from the origin. 


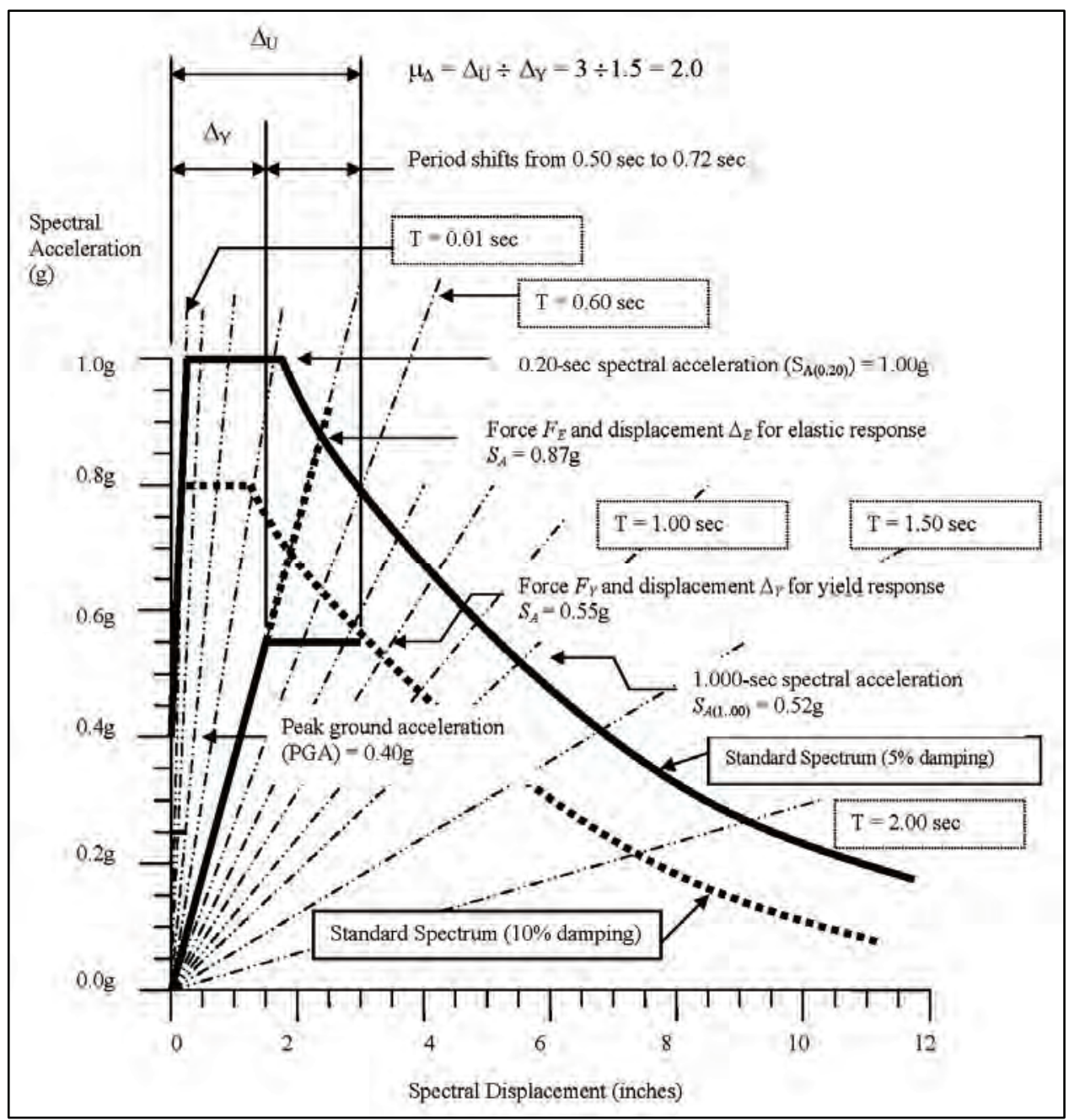

Figure 2.1 Idealized example of earthquake demands on inelastic structures

It can be seen that the earthquake force demands on the elasto-plastic system with an initial period of $0.5 \mathrm{sec}$ and a displacement ductility capacity $\mu_{\Delta}$ equal to 2.0 can be substantially less than that which the system would experience if it remained elastic. The spectral acceleration for the elastic system is $0.87 g$, while that for the elasto-plastic system is $0.55 \mathrm{~g}$. The associated force reduction factor $R$ would be equal to $F_{E} \div F_{Y}$, or $0.87 g \div 0.55 g=1.58$, where $F_{E}$ and $F_{Y}$ are the forces for elastic and yield responses, respectively.

For the elasto-plastic system shown, assuming damping with nonlinear response increases from 5 to 10 percent, collapse prevention would be prevented if the system has a displacement ductility capacity of two or more (displacement capacity equal to or greater than displacement demand). A shorter period system with the same yield capacity and ductility would likely fail. A longer period system with less displacement ductility capacity would likely meet performance objectives.

Earthquake-induced structural displacements are the primary cause of damage to structural systems. Veletsos and Newmark (1960) were early pioneers in 
the effort to use earthquake-induced displacements as a direct means for assessing structural performance. This approach will be described later with respect to the performance evaluation of retaining wall systems. Often structural deformations and their contribution to damage are represented indirectly through displacement ductility demand to displacement ductility capacity evaluations, as outlined by Moehle (1992). In other instances simple techniques are used for estimating the earthquake force demands on ductile inelastic systems. As described in Paulay and Priestley (1992) a potential force reduction $R$ associated with a given level of displacement ductility capacity $\mu$ can be determined. The force reduction technique is described in the following paragraphs and applicable to longer period structural systems (flexible systems). The force reduction technique is based on the following system responses:

- Equal acceleration response.

- Equal energy response.

- Equal displacement response.

Structures exhibiting an equal acceleration response or structures with a period of vibration between zero and $0.75 T_{o}$, where $T_{o}$ is characteristic ground motion period (period corresponding to the peak acceleration response), gain little in the way of force reduction benefits from system ductility ${ }^{1}$. In fact the period shift (period lengthening) that occurs with a stiffness reduction attributed to nonlinear response will often increase force demands. Since many of the retaining wall systems will exhibit an equal acceleration type response, they will be evaluated using earthquake-induced displacements as a direct measure of structural performance.

Structures with periods of vibration greater than $0.75 T_{o}$, however, will benefit from force reductions attributable to structure displacement ductility. The inelastic response of structures with fundamental periods of vibrations between $0.75 T_{o}$ and $1.5 T_{o}$ can be estimated using equal energy response principles. The inelastic response of structures with fundamental periods of vibration greater than $1.5 T_{o}$ can be estimated using equal displacement response principles.

The transition points delineating the three different responses were proposed by Paulay and Priestley (1992). The transition points are illustrated in Figure 2.2 with respect to an arithmetic plot of a typical USGS standard spectrum. Points are illustrated in Figure 2.3 with respect to a tripartite plot indicating ranges that are acceleration, displacement, and velocity sensitive. In a tripartite plot, acceleration, velocity, and displacement information can be shown on a single logarithmic graph. The Figure 2.3 tripartite plot is in terms of period. In other instances the tripartite plot will be in terms of frequency. The points on the arithmetic and tripartite plots are indications of the following:

1 Indicates the PGA at a period of zero seconds, and is the beginning of the acceleration-sensitive range.

2 Indicates the beginning of the constant acceleration range.

\footnotetext{
${ }^{1}$ An assessment of $T_{o}$ is part of the design ground motions assessment for Corps projects.
} 
3 Indicates the beginning of the velocity-sensitive range and the characteristic ground motion period $T_{o}$.

4 Indicates the beginning of the displacement-sensitive range.

The equal acceleration response, equal energy response, and equal displacement response are considered to occur within these indicated ranges as shown in Figure 2.2.

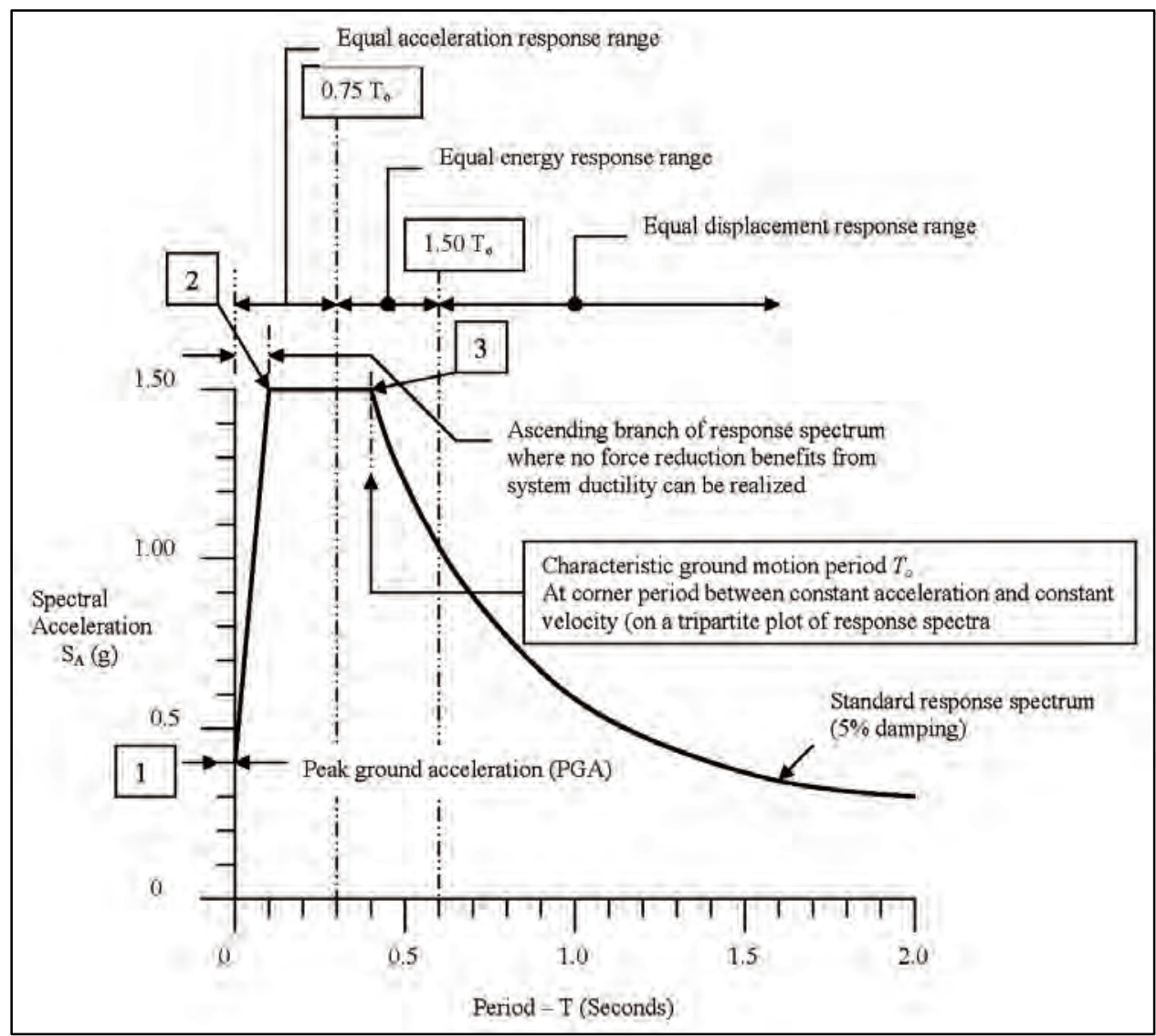

Figure 2.2 Standard acceleration response spectrum (arithmetic plot) illustrating limits of equal acceleration, equal energy, and equal displacement response

A complete discussion on the following equations describing the relationship between displacement ductility and force reduction can be found in Verma and Priestley (1994). 


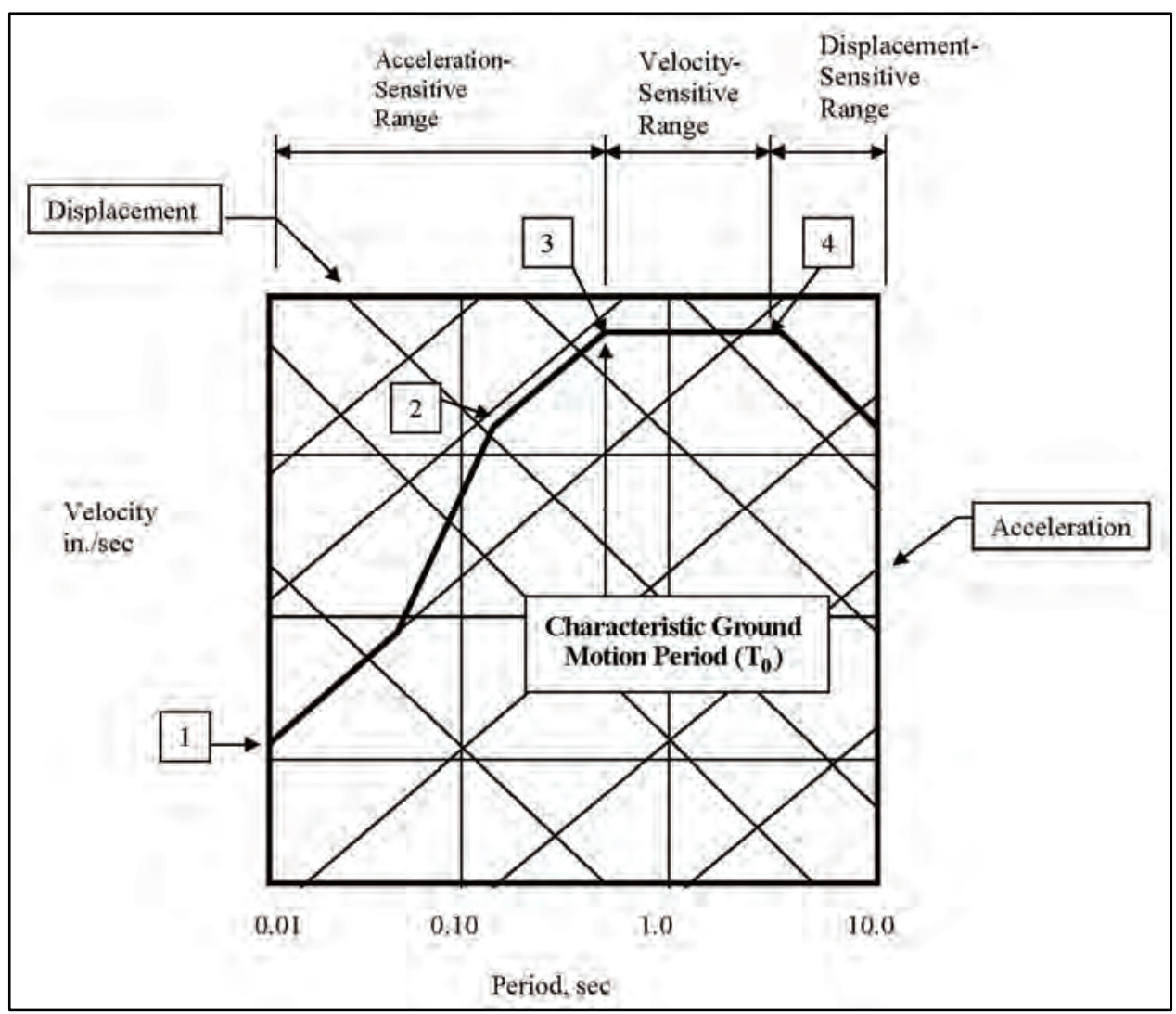

Figure 2.3 Standard acceleration response spectrum (tripartite plot) indicating acceleration-, velocity-, and displacement-sensitive ranges

\subsubsection{Equal acceleration response}

Rigid structures, with a period of vibration $T$ equal to zero, will exhibit an equal acceleration response. In this case acceleration is conserved regardless of any ductile properties attributed to the structure. The ascending ramp of demand (i.e., spectral acceleration $S_{A}$ versus period $T$ ), illustrated in Figure 2.2, represents the region where an equal energy response takes place. Figure 2.4 suggests that a system that yields will fail under an equal acceleration response. This happens because the period shift (period lengthening) that occurs with inelastic action (and its associated stiffness reduction) will significantly increase force demands.

As previously indicated, many retaining wall systems will exhibit an equal acceleration type response. For this reason they will be evaluated instead using earthquake-induced displacements as a direct measure of structural performance.

\subsubsection{Equal energy response}

Structural systems with fundamental periods of vibration between $0.75 T_{o}$ and $1.5 T_{o}$ will exhibit an equal energy response. Characteristic ground motion periods $T_{o}$ generally vary between 0.2 and $0.7 \mathrm{sec}$ depending on site conditions, with firm sites having shorter characteristic periods than soft sites. If inelastic 
behavior takes place, the system must have sufficient displacement ductility to provide the reserve inelastic energy needed to resist earthquake ground motion demands. The equal energy response concept is presented in Figure 2.5.

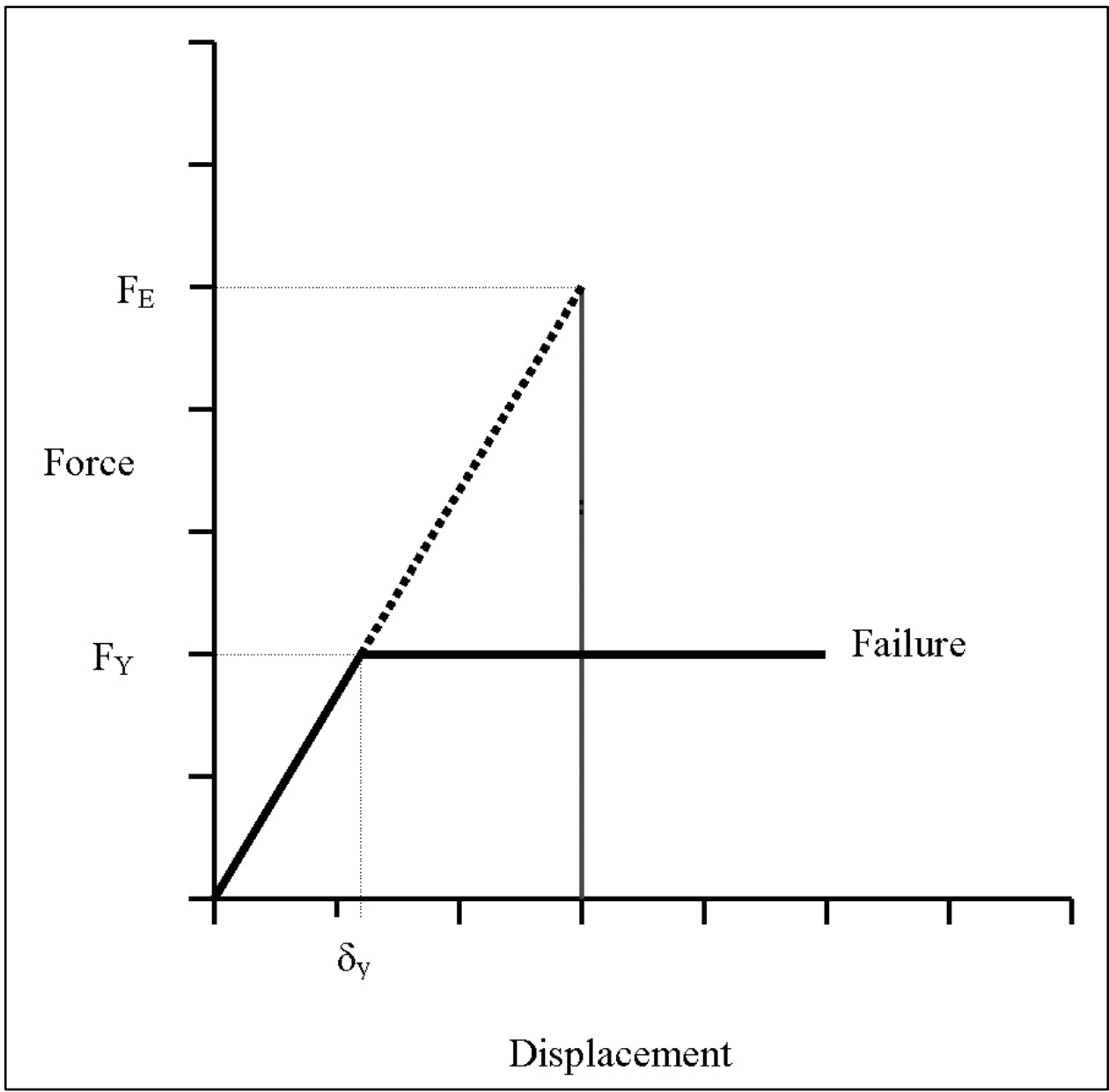

Figure 2.4 Equal acceleration response

For a given displacement ductility $\mu_{\Delta}$ the inelastic (yield) capacity $F_{Y}$ must be sufficient to produce an equal energy response. By equating the energy for a linear elastic response to that for an inelastic response (hatched area under the nonlinear portion of the load displacement curve equal to the hatched area under the linear elastic curve), it can be seen that the yield capacity of the system $F_{y}$ must be equal to or greater than the capacity required of the system if it were to remain elastic $F_{E}$ divided by $\sqrt{2 \mu_{\Delta}-1}$, or

$$
F_{Y}=\frac{F_{E}}{\sqrt{2 \mu_{\Delta}-1}}
$$

The denominator of Equation 2.1 can be obtained by equating the two crosshatched areas in Figure 2.5. 


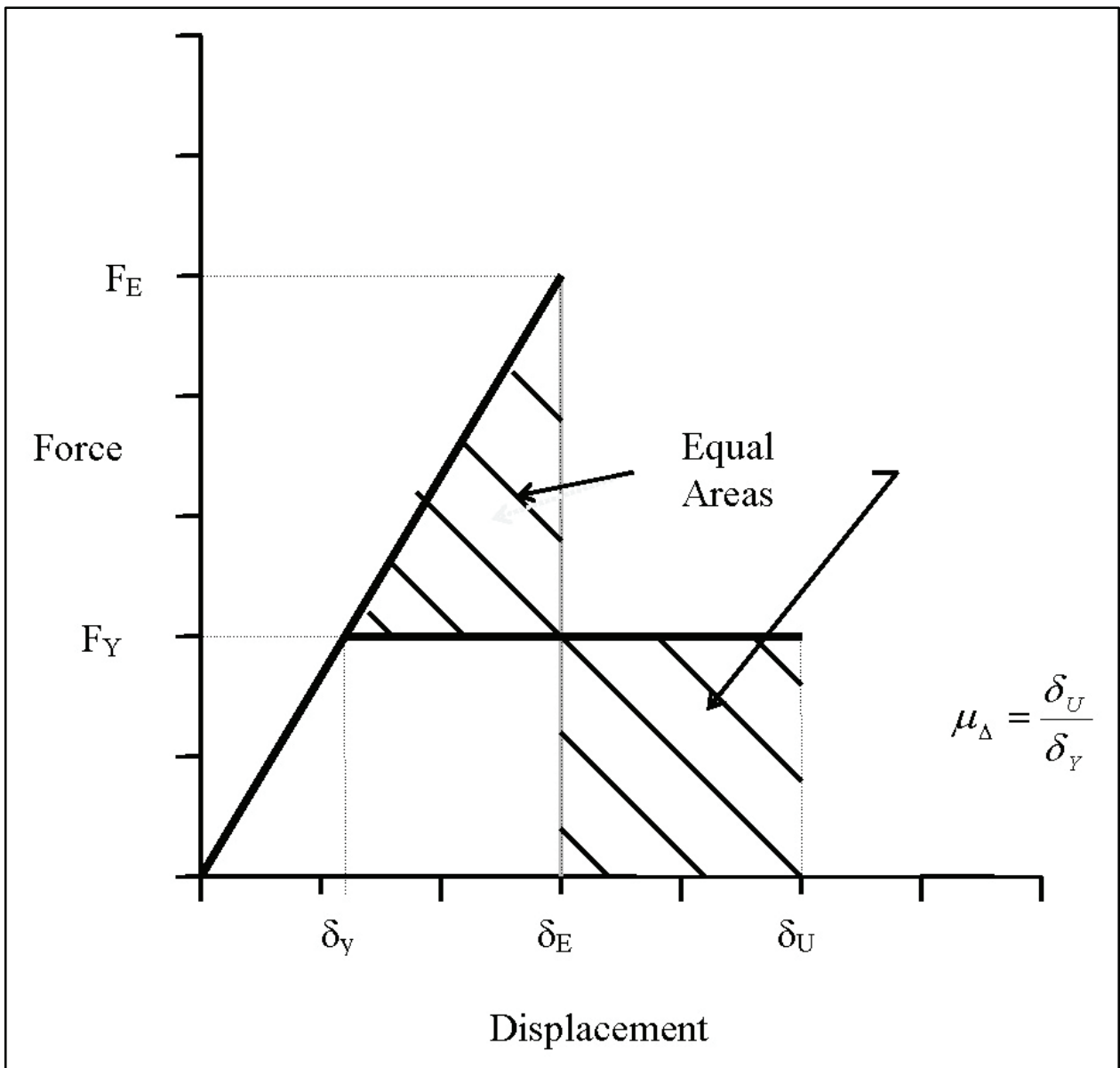

Figure 2.5 Equal energy response

\subsubsection{Equal displacement response}

Systems with fundamental periods of vibration greater than $1.5 T_{o}$ will exhibit an equal displacement response. An equal displacement response means that to perform as intended, the displacement ductility capacity must be sufficient to provide a system displacement capacity equal to, or greater than, the peak displacement the system will experience during the design earthquake. The equal displacement response concept is presented in Figure 2.6.

From Figure 2.6 it can be determined that the yield capacity of the system $F_{Y}$ must be equal to or greater than the capacity required of the system if it were to remain elastic $F_{E}$ divided by $\mu_{\Delta}$, or

$$
F_{Y}=\frac{F_{E}}{\mu_{\Delta}}
$$




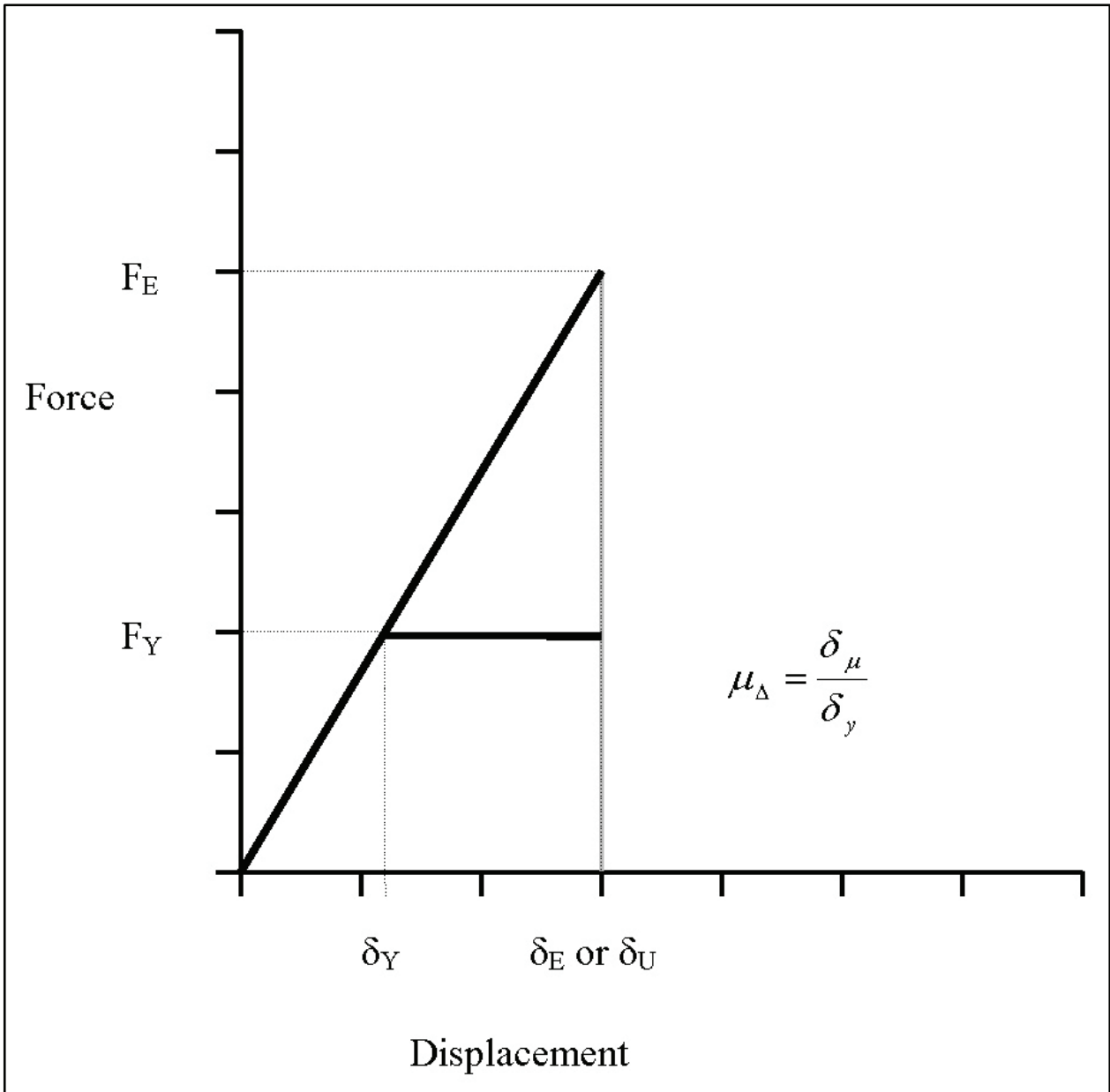

Figure 2.6 Equal displacement response

\subsubsection{General relationship between required yield strength $F_{Y}$ and elastic demand $F_{E}$}

A general relationship has been developed (Paulay and Priestley 1992;

Verma and Priestley 1994) for relating required yield strength to elastic demand. This relationship is dependent on the characteristic ground motion period $T_{o}$ and provides a smooth transition from an equal acceleration response $\left(F_{E} / F_{Y}=1\right.$ regardless of $\left.\mu_{\Delta}\right)$ at $T=0$, through the equal energy approximation ( $F_{E} / F_{Y}=\sqrt{2 \mu_{\Delta}-1}$ ) at about $T=0.75 T_{o}$, to the equal displacement approximation $\left(F_{E} / F_{Y}=\mu_{\Delta}\right)$ for $T \geq 1.5 T_{o}$. Letting $R$ represent the $F_{E} / F_{Y}$ ratio gives the relationship for the smooth transition:

$$
R=1+\frac{\left(\mu_{\Delta}-1\right) T}{1.5 T_{0}} \geq \mu_{\Delta}
$$


Using Equation 2.3, for a known level of displacement ductility $\mu_{\Delta}$ and a given elastic earthquake demand $F_{E}$, the required yield capacity of a system $F_{Y}$ can be determined. Equation 2.3 can be rewritten in terms of displacement ductility $\mu_{\Delta}$, and solved for the displacement ductility required to produce a given force reduction $R$.

$$
\mu_{\Delta}=\frac{1.5 T_{o}(R)}{T}-\frac{1.5 T_{o}}{T}+1
$$

The required displacement ductility capacity of a system required to achieve a force reduction ratio of two (yield capacity 50 percent of force an elastic structure would experience) has been calculated using Equation 2.4 and presented in Table 2.1. The calculations used to develop Table 2.1 assume a characteristic ground motion period $T_{o}$ of $0.467 \mathrm{sec}\left(1.5 T_{o}=0.70 \mathrm{sec}\right)$. As indicated earlier, characteristic ground motion periods vary between 0.2 and $0.7 \mathrm{sec}$ depending on site conditions, with firm sites having shorter characteristic periods than soft sites. Changes in site conditions (i.e., characteristic ground motion period) will change the values in Table 2.1.

\section{Table 2.1 \\ Displacement Ductility Required for a Force Reduction Factor of Two}

\begin{tabular}{||l|c|c|c|c|c|c|c||}
\hline \hline \multicolumn{7}{|c||}{ Structure Period $T$, sec } \\
\hline \hline 0.10 & 0.20 & 0.30 & 0.40 & 0.50 & 0.60 & 0.70 & 0.80 \\
\hline 8.0 & 4.5 & 3.3 & 2.8 & 2.4 & 2.2 & 2.0 & 2.0 \\
\hline \hline
\end{tabular}

Retaining walls encountered in practice will generally possess low to moderate displacement ductility capacity (in the range of $\mu_{\Delta}=2$ to 4 ). With $\mu_{\Delta}$ equal to 3 it can be seen from Table 2.1 that a force reduction factor of 2 can be achieved only for soil-wall systems with periods of vibration of $0.40 \mathrm{sec}$ or greater. Preliminary research by Veletsos and Younan (1997) indicates the period of vibration for soil-cantilever wall systems that are encountered in practice may be within the range 0.04 and $0.80 \mathrm{sec}$. Therefore based on Table 2.1 results, many retaining wall systems will not see significant force reduction benefits from system ductility. This suggests that retaining wall systems should be evaluated using earthquake-induced displacements (rather than displacement ductility) as an indicator of structural performance. Performance would then be assessed by comparing earthquake-induced displacements (displacement demands) to retaining wall displacement capacity. 


\section{Methods of Seismic Analysis and Structural Modeling}

\subsection{Progressive Analysis}

The evaluation of structures and structural systems for earthquake ground motions should be performed in phases in order of increasing complexity progressing from simple pseudostatic and equivalent lateral force methods, to linear elastic response spectrum and time-history analysis, and to nonlinear methods if necessary. The following paragraphs describe the various analytical methods used to assess earthquake ground motion effects beginning with the simplest method and progressing to the more complex methods. In each analysis procedure idealized models of structural systems are used to estimate the dynamic response of these systems to earthquake ground motions.

\subsection{Methods of Analysis}

\subsubsection{Pseudostatic (i.e., seismic coefficient) method}

Pseudostatic or traditional seismic coefficient methods of analysis are often used to evaluate seismic stability. In the pseudostatic method the inertial force acting on the structure is computed as the product of the total mass (structure mass plus any added mass used to represent hydrodynamic effects and dynamic soil pressure effects) times a seismic coefficient. For retaining wall systems the structural mass also includes the soil mass contained in a wedge bounded on one side by the stem wall and on the other side by a vertical plane extending from the heel of the base slab to the ground surface. The magnitude of the seismic coefficient is often assumed to be equal to, or some fraction of, the peak ground acceleration expressed as a decimal fraction of the acceleration of gravity. For flexible systems the seismic coefficient method fails to account for the true dynamic characteristics of the structural system. The method, however, can give reasonable results when the system acts primarily as a rigid body. An example would be for the sliding response of a gravity dam as illustrated in Figure 3.1. The pseudostatic method is commonly used to assess the sliding response of gravity dams (EC 1110-2-6058 (HQUSACE 2003a); Zhang and Chopra 1991). The 
pseudostatic method is also used to assess the sliding response of retaining wall systems (Ebeling and White, in preparation).

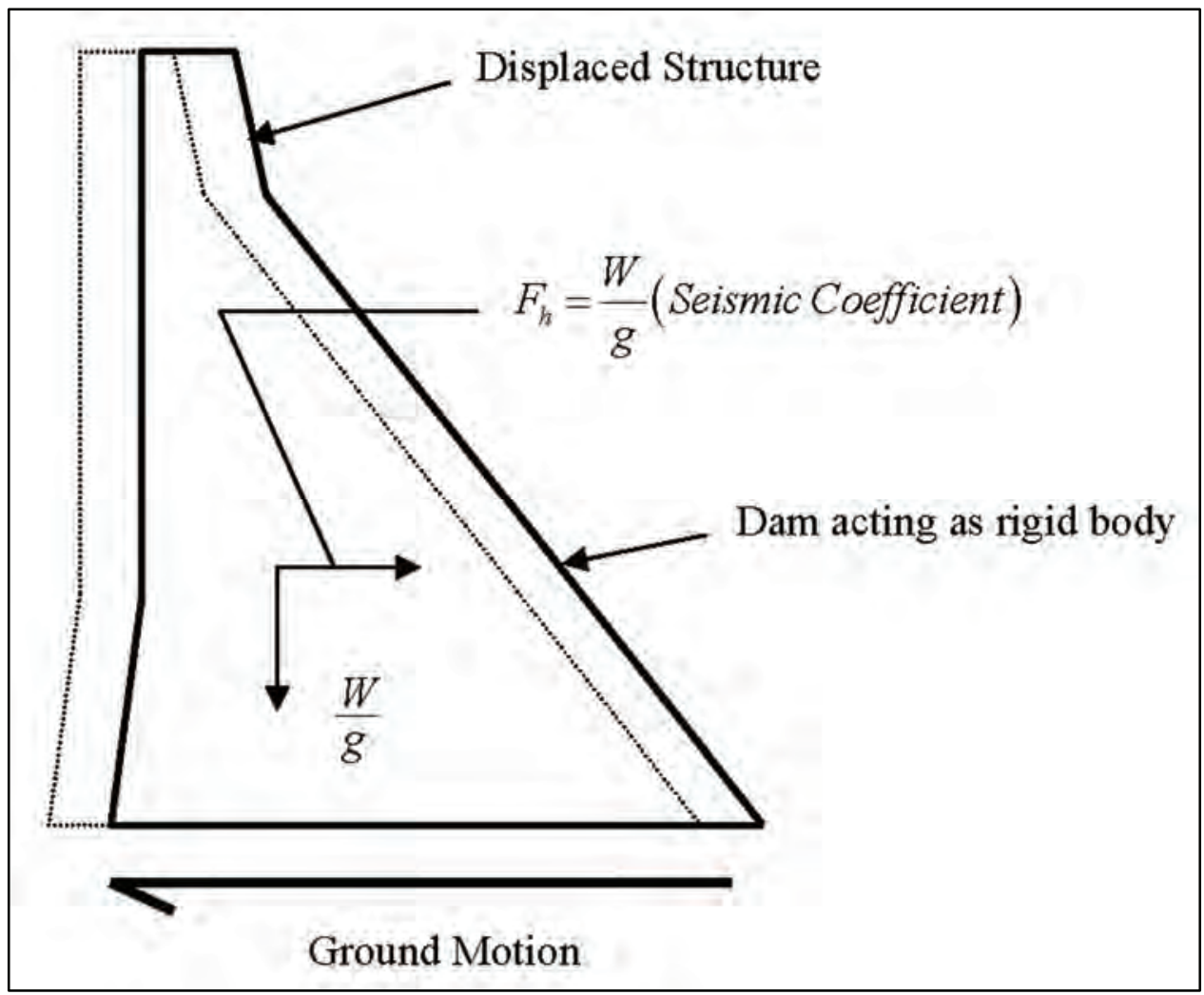

Figure 3.1 Gravity dam sliding on foundation

Approximate pseudostatic methods have been developed for evaluating the sliding response of gravity dams that are considered to be flexible (Zhang and Chopra 1991). In this approximate procedure the gravity dam is treated as rigid. Its sliding response is analyzed with respect to a base acceleration representing the average peak acceleration a flexible dam would experience under conditions where no base sliding takes place. This average acceleration response method has also been applied to the sliding response evaluation of retaining walls (Ebeling and White, in preparation).

\subsubsection{Equivalent lateral force method}

The equivalent lateral force (ELF) method is commonly used for the seismic design of flexible systems such as buildings. Procedures have also been developed for use in the preliminary seismic analysis of gravity dams (Fenves and Chopra 1986) and for intake towers (EM 1110-2-2400 (HQUSACE 2003c)). In most cases, the fundamental mode of vibration (first mode) will contribute 80 percent or more of the total seismic response. Therefore, if the period of vibration of the first mode and the general deflected shape for the first mode are known, a set of inertial forces (equivalent lateral loads) can be developed for use in a seismic design or evaluation. In general the steps of an ELF analysis are as follows: 
- Estimate the period of vibration of the first mode. This can be done using a general formula developed for the particular structure under consideration based on what is known about the stiffness of the structure-foundation system $K$ and the total system mass (structure mass + hydrodynamic mass + some "effective" soil mass). The formula will be of the general form:

$$
T=2 \pi \sqrt{\frac{M}{K}}
$$

where $M$ is the system mass and $K$ is the system stiffness.

- Determine the spectral acceleration $S_{A}$ for an equivalent SDOF system. This can be done using the period of vibration determined previously in combination with a standard or site-specific acceleration response spectrum. In some cases, as for buildings, the spectral acceleration will be represented by a standard spectrum in equation form as part of a base shear formula.

- Determine the total inertial force and force distribution on the structural system. This is accomplished using standard modal analysis techniques.

Once all the inertial forces have been determined, the analysis will proceed in the same fashion as any static analysis. Because the dynamic characteristics of flexible structural systems are considered when determining earthquake demands and when distributing inertial forces to the structural system, the ELF method is an excellent static force method. The ELF method is part of the Linear Static Procedure (LSP) described in FEMA 356 (2000).

\subsubsection{Response spectrum-modal analysis procedure}

In the response spectrum-modal analysis procedure the peak responses of linear elastic structural systems to earthquake ground motions as represented by response spectra are determined. Several modes of vibration are considered. The number of modes included in the analysis is that sufficient to capture the total response of the system to earthquake ground motions. This typically occurs when the total mass participation of the modes used in the analysis is approximately 90 percent or more of the total response. Modal analysis is always performed using computer software capable of determining the periods of vibration and mode shapes for all contributing modes. Most structural analysis programs have this capability, and for many reasons this type of analysis is preferred over the ELF method of analysis. Detailed information on the response spectrum-modal analysis procedure can be found in EM 1110-2-6050 (HQUSACE 1999). The response spectrum-modal analysis is part of the Linear Dynamic Procedure (LDP) described in FEMA 356 (2000). 


\subsubsection{Time-history-modal analysis procedure}

This procedure is similar to that described for the response spectrum-modal analysis procedure, except earthquake demands are in the form of acceleration time-histories rather than response spectra and the results are in terms of a stress (or force) history or a displacement history. Peak responses must be extracted from the time-history results. Time-history-modal analysis procedures generally provide valuable information that is not provided by the response spectrummodal analysis procedure. Especially important is the number of excursions beyond acceptable displacement. As with the response spectrum-modal analysis procedure, the analysis is limited to a linear elastic response. Detailed information on the time-history-modal analysis procedure can be found in EM 1110-26051 (HQUSACE 2003d). The time-history-modal analysis is part of the LDP.

\subsubsection{Time-history - direct integration procedure}

This type of time-history analysis involves the direct integration of the equations of motion, and therefore is the most sophisticated method available for evaluating the response of structures to earthquake ground motions. It is a stepby-step procedure that determines stresses (or forces) and displacements by summing the response of the structure during very short time increments. Six numerical step-by-step procedures used in computational structural dynamics are described in Ebeling, Green, and French (1997). Its advantage is that it can be used in nonlinear analyses, since structure properties (including nonlinear behavior) can be modified during each step of the analysis to capture damage propagation. The time-history-direct integration procedure is part of the Nonlinear Dynamic Procedure (NDP) described in FEMA 356 (2000).

\subsection{Modeling of Structural Systems}

\subsubsection{Structural system models}

Structural system models are developed much in the same manner as for static analyses. The purpose, however, of a seismic analysis is to capture the system response near or beyond first yield. This means the effective stiffness of the system will be less than that used for static analysis, and the damping will often be greater than that used for an elastic structure. In addition the structural system model should capture the influence of the foundation with respect to period lengthening effects and foundation material and radiation damping effects. Various types of structural system models are used. The model may be a rigid block, a frame model composed of beam elements, or a two-dimensional or threedimensional model employing finite elements. Beam or frame elements are commonly used to model free-standing intake towers. Plane and threedimensional finite elements are employed for navigation locks and concrete dams. Beam element models have a distinct advantage in the dynamic modeling of reinforced concrete structures since the earthquake demands are expressed in moments, shears, and axial loads. These are the quantities needed to design reinforced concrete members in new structures or to evaluate reinforced concrete 
members in existing structures. Two- and three-dimensional finite element models are generally used for the seismic evaluation of gravity lock walls and gravity dams and other plain (unreinforced) concrete structures. Two- and threedimensional finite element models are also used for reinforced concrete structures whose behavior cannot be captured by beam or frame elements. Often structure-foundation interaction and structure-water interaction effects can be accommodated in the special finite element models developed for gravity and arch dam evaluation. Since foundation properties, structural properties, and boundary conditions can vary, it is advisable to systematically vary parameters that have a significant effect on structure response until the final results envelop the probable responses the structure could experience during the design earthquake.

\subsubsection{Effective stiffness}

The effective stiffness of structural systems under yield conditions can be significantly less than that represented by gross section properties. For reinforced concrete systems the effective stiffness should be calculated and used in response spectrum and time-history analyses to assure that the response of the structure to earthquake ground motions is reasonable. For retaining wall (soil-wall) systems the effective stiffness under yield conditions is unknown.

To obtain a best estimate of force and displacement demands on reinforced concrete members, the cracked section (i.e., effective) stiffness rather than the gross stiffness is often used. The effective stiffness used is one that is an average value for the entire member and considers the distribution of cracking along the member length. The effective stiffness of reinforced concrete structures can be estimated based on the relationship between the cracking moment (i.e., the moment required to initiate cracking while ignoring the reinforcing steel) and the nominal moment capacity of the reinforced concrete section. The nominal moments and cracking moments used to estimate effective stiffness are those at regions where positive or negative moments are at their maximums, in other words, at the base of cantilever members and at the midspan for simple and continuous spans. Once the cracking moment $M_{C R}$ and the nominal moment capacity $M_{N}$ have been determined, the ratio of the effective stiffness $I_{E}$ to the gross stiffness $I_{G}$ can be estimated as follows:

$$
\frac{I_{E}}{I_{G}}=0.8-0.9\left[\frac{M_{N}}{M_{C R}}-1\right]
$$

The ratio of $I_{E} / I_{G}$ should not be greater than 0.8 , nor less than 0.25 , according to Priestley (1997). ${ }^{1}$

Equation 3.1 is a simplified version of American Concrete Institute (ACI) (2002) 318-02 equations commonly used for the deflection evaluation of

\footnotetext{
${ }^{1}$ M.J.N. Priestley, 1997, “Criteria Review for Corps-Seismic Design and Evaluation of Powerhouse Superstructures," presented in Appendix G of this report.
} 
reinforced concrete structures. The basis for the simplified version is contained in Priestly (1997) and also discussed in Moehle (1997) ${ }^{1}$ with respect to lightly reinforced concrete structures.

The nominal moment strength can be determined in accordance with standard ACI 318-02 procedures. The cracking moment $M_{C R}$ can be determined by equating the maximum tensile stress in a member (gross section) subjected to an axial load and bending moment to the modulus of rupture as defined by ACI 318-02. This process results in the following expression:

$$
M_{C R}=\left(f_{r}+\frac{P}{A}\right) S_{b}
$$

where

$$
\begin{aligned}
f_{r} & =\text { modulus of rupture }=7.5 \sqrt{f_{c}^{\prime}} \text { (psi units) } \\
P & =\text { axial load } \\
A & =\text { area } \\
S_{b} & =\text { section modulus }
\end{aligned}
$$

\subsubsection{Damping}

Effective damping at 5 percent of critical will typically provide a reasonable estimate of concrete structure response at or near yield. It should be realized that damping is much lower than 5 percent for unyielding structures (about 2 percent) and much higher than 5 percent after significant damage has occurred. Structurefoundation interaction will increase the effective damping due to energy radiation and material damping that occurs in the foundation. Effective damping can also increase due to structure-water interaction and reservoir bottom absorption. Unless interaction effects are involved, a viscous damping value of 5 percent will reasonably represent the damping of concrete structures at displacement levels that typically occur in response to earthquake ground motions. Higher equivalent damping values should be used where interaction effects play an important role. Acceleration response spectra at viscous damping values other than 5 percent can be obtained by multiplying the 5 percent earthquake spectra values by the damping adjustment factors shown in Table 3.1. The factors in this table are based upon empirical relations given by Newmark and Hall (1982) for median spectral shapes. The Table 3.1 factors represent a rounded-off average of the Newmark damping values for the constant acceleration range and constant velocity range of the spectral shape (TM 5-809-10 (U.S. Army 1986)). More accurate damping adjustment factors, if needed, can be developed using the information provided in Newmark and Hall.

\footnotetext{
${ }^{1}$ J.P. Moehle, 1997, “Criteria Review for Corps - Seismic Evaluation of Intake Towers," presented in Appendix G of this report.
} 


\begin{tabular}{|c|c|}
\hline \multicolumn{2}{|c|}{$\begin{array}{l}\text { Table } 3.1 \\
\text { Damping Adjustment Factors (after TM 5-809-10.1 (U.S. Army } \\
\text { 1986)) }\end{array}$} \\
\hline Damping $\beta$, percent & Damping Adjustment Factor \\
\hline 2 & 1.25 \\
\hline 5 & 1.00 \\
\hline 7 & 0.90 \\
\hline 10 & 0.80 \\
\hline 15 & 0.70 \\
\hline 20 & 0.60 \\
\hline
\end{tabular}

\subsection{Modeling Soil-Structure Systems}

Three analytical methods and their analytical models that can be used to evaluate the response of cantilever retaining walls to earthquake ground motion are described in Ebeling and White (in preparation):

- Pseudostatic methods with a preselected seismic coefficient.

- Sliding block methods.

- Stress-deformation methods.

This section will focus on a particular stress-deformation method used by Veletsos and Younan (1997) in their research efforts to assess the seismic performance of flexible cantilever retaining walls. This flexible wall approach in addition to the benefits described by Veletsos and Younan (1997) provides seismic evaluators with the following potential methodologies:

- Estimating the fundamental period of vibration of the soil-wall system.

- Estimating potential amplification effects due to system flexibility.

- Conducting a displacement-based performance evaluation.

\subsubsection{Veletsos and Younan analytical model}

The analytical model used by Veletsos and Younan (1997) utilizes a simplified flexible cantilever retaining wall model that is elastically constrained against rotation at the base. Soil or rock foundation response and half-space simulation are not considered in the Veletsos and Younan analysis. The retained soil is modeled as a uniform, linear, viscoelastic stratum of constant thickness and semiinfinite extent in the horizontal direction. Parameters varied in the study include the flexibility of the wall, the flexibility of the wall base, the properties of the retained medium, and earthquake ground motions. Since the focus of this report is primarily on the earthquake demands at the base of the stem wall under conditions of base slab fixity, only those aspects from the Veletsos and Younan report are discussed herein. 
The primary parameter governing the response of the Veletsos and Younan (1997) analytic model is the relative flexibility of the wall $d_{W}$ characterized as

$$
d_{W}=\frac{G H^{3}}{D_{W}}(\text { dimensionless })
$$

where

$$
G=\text { shear modulus of elasticity for the retained soil }
$$

$H=$ height of soil retained by wall

$D_{W}=$ flexural rigidity of the wall per unit length of wall (see below)

$$
D_{W}=\frac{E_{W} t_{W}^{3}}{12\left(1-v_{W}^{2}\right)}
$$

where

$E_{W}=$ Young's modulus of elasticity for the wall

$t_{W}=$ wall thickness

$v_{W}=$ Poisson's ratio for the wall

Illustrating for the Corps cantilever retaining wall example of Appendix D, a wall that has been designed using American Concrete Institute-Ultimate Strength Design (ACI-USD) procedures in accordance with Corps requirements:

$$
\begin{aligned}
E_{W} & =475,000 \mathrm{ksf}(3,000 \mathrm{psi} \text { normal weight concrete })^{1} \\
t_{W} & =1.5 \mathrm{ft} \\
v_{W} & =0.20 \text { (normal weight concrete) } \\
G & =\gamma\left(v_{s}\right)^{2} \div \mathrm{g}=0.125(500)^{2} \div 32.2=971 \mathrm{ksf}
\end{aligned}
$$

where

$$
\begin{aligned}
\gamma & =\text { density of soil }=0.125 \mathrm{kcf} \\
v_{S} & =\text { shear wave velocity of soil }=500 \mathrm{fps} \\
g & =\text { acceleration of gravity }=32.2 \mathrm{ft} / \mathrm{sec}^{2} \\
D_{W} & =475000(1.5)^{3} \div 12\left[1-(0.20)^{2}\right]=139,220 \mathrm{kip}-\mathrm{ft} \\
d_{W} & =971(18.5)^{3} \div 139,220=\mathbf{4 4 . 2}
\end{aligned}
$$

\subsubsection{Performance of retaining wall systems acting as rigid bodies}

Veletsos and Younan (1997) first described the performance of flexible retaining wall systems acting as rigid bodies (i.e., wall system period is

\footnotetext{
${ }^{1}$ A table of factors for converting non-SI units of measure to SI units is found on page vii.
} 
extremely small compared to the characteristic ground motion period). Figures in their report illustrate the relationship between wall flexibility and the following:

- Total earth pressure (i.e., dynamic + static).

- Wall shear due to total soil pressure effects.

- Wall bending moments due to total soil pressure effects.

The effect of wall flexibility on total earth pressure as determined by Veletsos and Younan (1997) is generally illustrated in Figure 3.2.

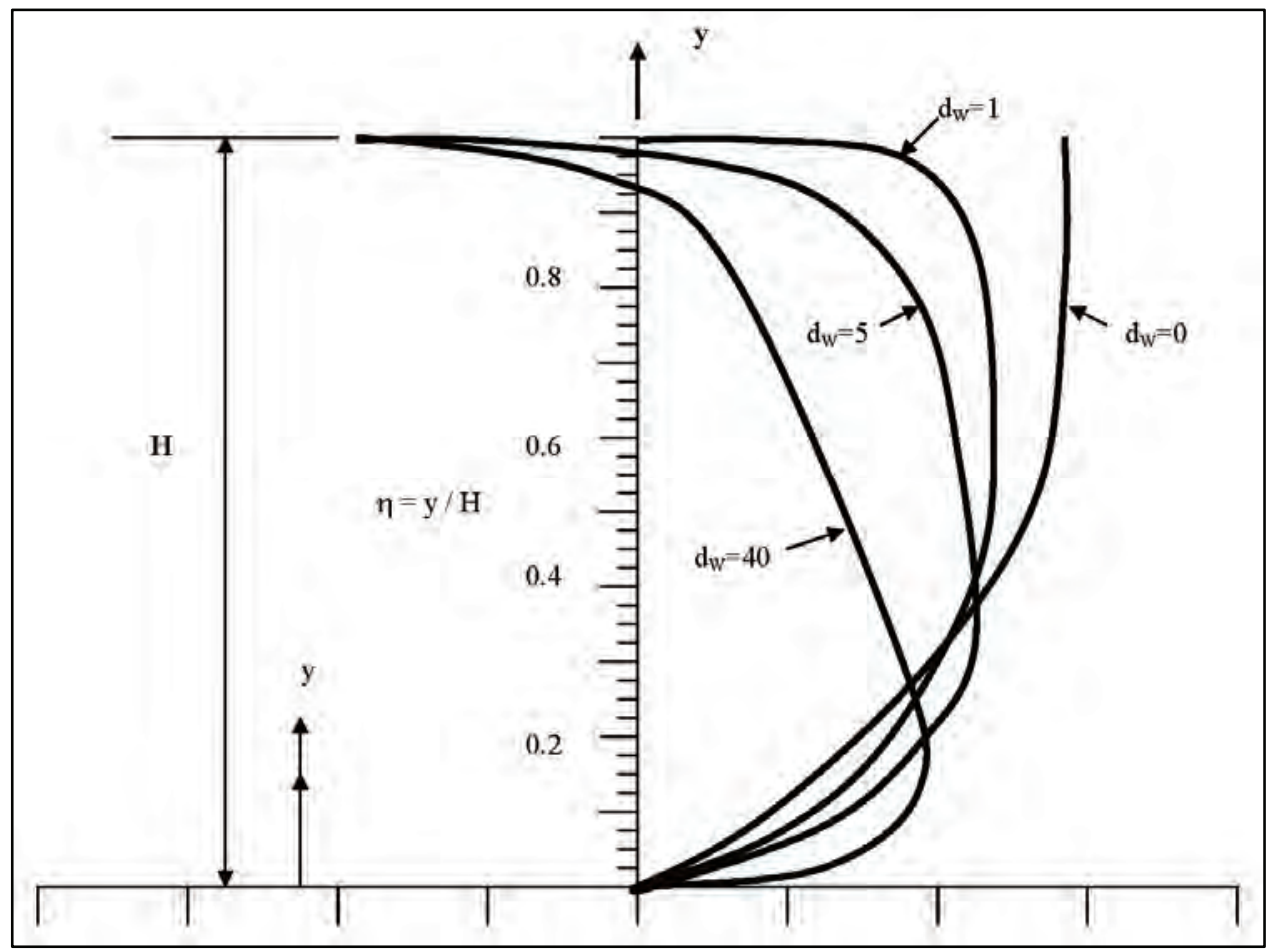

Figure 3.2 Distribution of wall pressures with height for various relative flexibility factors $d_{W}$ (after Veletsos and Younan 1997). Note: $y$ is the distance above the base of the cantilever retaining wall and $\eta$ is the ratio of the distance above the base to total wall height

A key observation of the Veletsos and Younan (1997) results as depicted by Figure 3.2 is that wall pressures reduce significantly with small increases in wall flexibility.

\subsubsection{Performance of retaining wall systems acting as flexible bodies}

Veletsos and Younan (1997) demonstrated that flexible wall systems could amplify the response determined for those flexible wall systems assumed to act as rigid bodies. Considering effective damping at 5 percent of critical and subjecting flexible wall systems to the north-south component of the 1940 El Centro earthquake led to the following determinations:

- Base shear amplification ranged from 1.32 to 1.93 . 
- Retaining wall top displacement amplification ranged from 1.39 to 2.38.

The peak ground acceleration for the 1940 El Centro earthquake was $0.312 g$. The fundamental periods of vibration $T_{1}$ for the soil stratum for the various heights considered ranged between 0.04 and $0.80 \mathrm{sec}$. The fundamental period of the retained soil was assumed equal to

$$
T_{1}=\frac{4 H}{V_{S}}
$$

Illustrating for the Corps ACI-USD cantilever retaining wall example of Appendix D, the fundamental period of vibration for the soil-wall system would be

$$
\mathrm{T}_{1}=4(18.5) \div 500=0.15 \mathrm{sec}
$$

Note that the soil-wall system of the simplified/idealized Veletsos and Younan (1997) analytical model includes the wall and soil retained by the wall but excludes any consideration of potential interaction effects with the foundation substrate.

Referring to Figure C.8, the design response spectrum developed in Appendix $\mathrm{C}$ for the MDE event, it can be seen that with a period of vibration equal to $0.15 \mathrm{sec}$ the dynamic amplification with respect to base shear would be equal to 2.5 (amplification of 2.5 for 5 percent damping). Base shear amplification is at a maximum.

\subsection{Inertial Effects}

During an earthquake, time-varying displacements that originate in the foundation bedrock cause distortions in the structure as well as in the soils that may underlie or surround the structure. Water surrounding the structure is also affected by ground and structure distortions. The displacement response of the system (structure-soil-water) generates inertial forces. These inertial forces, often referred to as earthquake loads, can be attributed to the inertial mass of the system, including structure mass, the mass of the soil contained within the structural wedge, dynamic earth pressure forces acting on the structural wedge, and hydrodynamic pressures. The magnitude of these inertial forces is a function of the earthquake ground motion and the total system mass (structure + "effective" soil + water), as well as system stiffness and system energy-absorbing characteristics (i.e., material damping and radiation damping).

\subsubsection{Dynamic soil pressures (yielding backfill conditions)}

The term yielding backfill conditions means that wall movements due to earthquake ground motions are sufficient to fully mobilize shear resistance along 
the retained soil "wedge" creating a limit state condition. The dynamic earth forces will then be proportional to the mass in the failure wedge times the acceleration. When designing retaining walls with yielding backfill conditions (i.e., full mobilization of the shear resistance within the retained soil) for earthquake ground motions, the MO pseudostatic approach is often used.

\subsubsection{Dynamic soil pressures (nonyielding backfill conditions)}

For massive structures with soil backfill, it is unlikely that movements sufficient to develop backfill yielding will occur during an earthquake. Wood (1973) analyzed the response of a wall under nonyielding backfill to dynamic excitation assuming the soil backfill to be an elastic material. He found that a steady-state dynamic thrust equal to $\gamma H^{2} a / g$ occurred at a height of $0.63 \mathrm{H}$ above the base of the wall where $a$ is the acceleration at the base of the structure. The Wood procedure for nonyielding dry backfill conditions can be found in Chapter 5 of Ebeling and Morrison (1992) along with methods applicable to submerged and partially submerged walls.

\subsubsection{Permanent sliding displacement of retaining walls}

Retaining walls that are stable under static load conditions may slide when earthquake ground motions generate inertial forces, which, when combined with static forces, exceed the sliding resistance at the wall-foundation interface. The acceleration that generates sufficient force to initiate sliding is termed the maximum transmissible acceleration $N^{*} g$, sometimes referred to as the yield acceleration (Chapter 6 in Ebeling and Morrison 1992). Every time the ground acceleration $a_{g}$ exceeds the maximum transmissible acceleration $N^{*} g$, the structure will slide.

\subsubsection{Upper bound estimate of permanent sliding displacement}

In upper bound solutions for permanent sliding displacement the ratio of the yield acceleration to the acceleration of gravity $N^{*} g / g$ is usually identified as the yield coefficient $k_{y}$, and the ratio of the PGA to the acceleration of gravity termed the seismic coefficient $A$. As shown in Figure 3.3, each time the ground acceleration exceeds the yield acceleration, some displacement at the structure-

foundation interface will occur. These will add up throughout the duration of the earthquake and result in a final permanent displacement.

The total permanent displacement will be a function of the earthquake characteristics such as duration and intensity, with the major factor being the number of times the yield acceleration is exceeded.

The expected permanent displacement of a soil slope, retaining wall, or dam can be estimated using the Newmark (1965) sliding block analogy. Also, as a part of extensive parametric studies, Richards and Elms (1977) have suggested the following equation for estimating the permanent sliding displacement: 


$$
\Delta=0.087 \frac{v_{g}^{2}}{A g}\left[\frac{k_{y}}{A}\right]^{-4}
$$

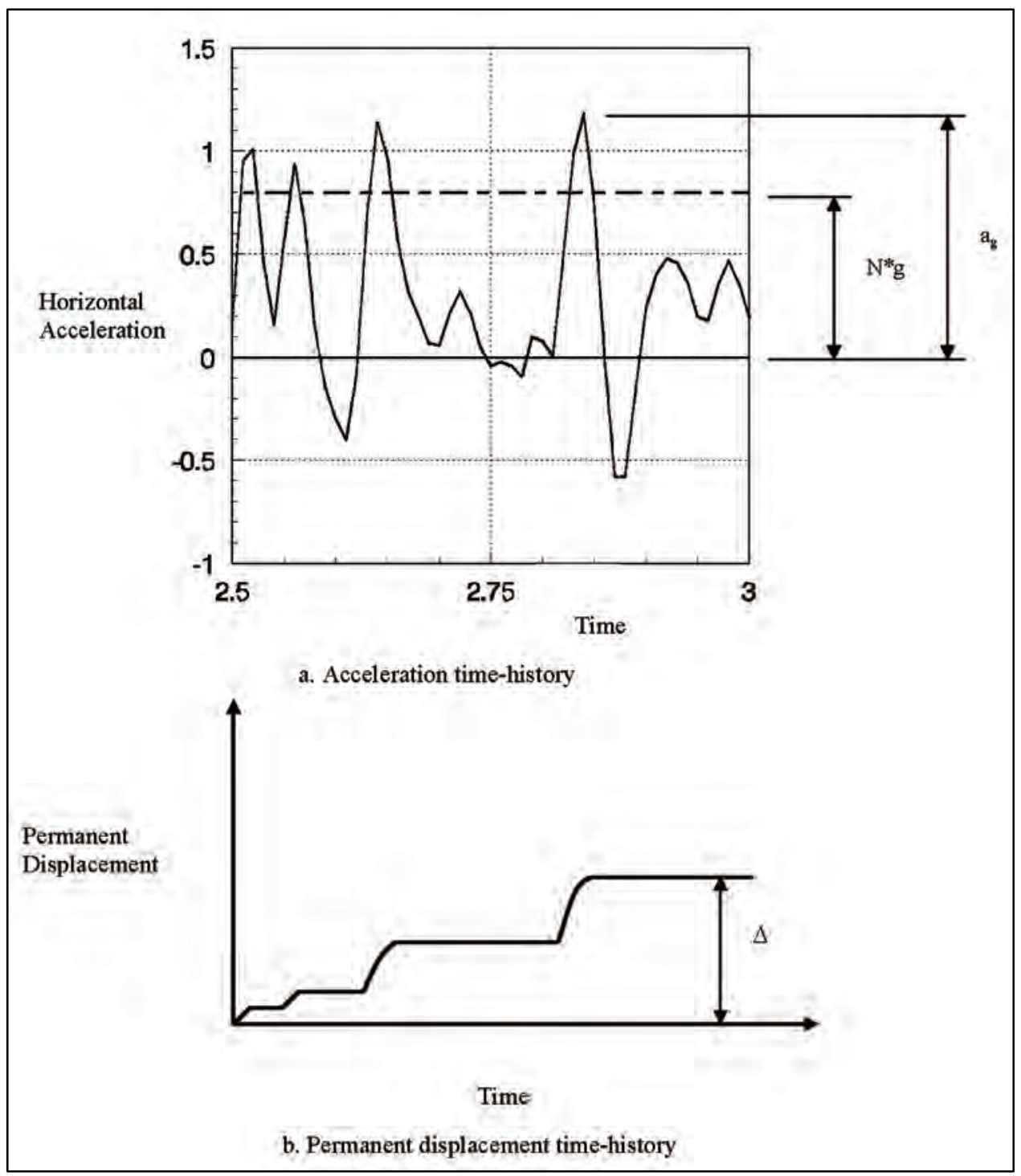

Figure 3.3 Permanent sliding displacement

where

$\Delta=$ permanent sliding displacement, in.

$v_{g}=$ peak ground velocity of the earthquake, in./sec

$A=$ seismic coefficient representing the PGA expressed as a fraction of the acceleration of gravity

$g=$ acceleration of gravity $\left(386 \mathrm{in} . / \mathrm{sec}^{2}\right)$ 
$k_{y}=$ yield coefficient expressed as a fraction of the acceleration of gravity, representing the yield acceleration that initiates sliding (sliding factor of safety equal to 1.0)

For preliminary design purposes the PGA can be assumed to be equal to

$$
v_{g}=0.75 \mathrm{~A}, \mathrm{in} . / \mathrm{sec}
$$

This relationship then can be simplified to:

$$
\Delta=0.2 \frac{A^{5}}{k_{y}^{4}}, \text { in }
$$

A plot of this relationship is shown in Figure 3.4.

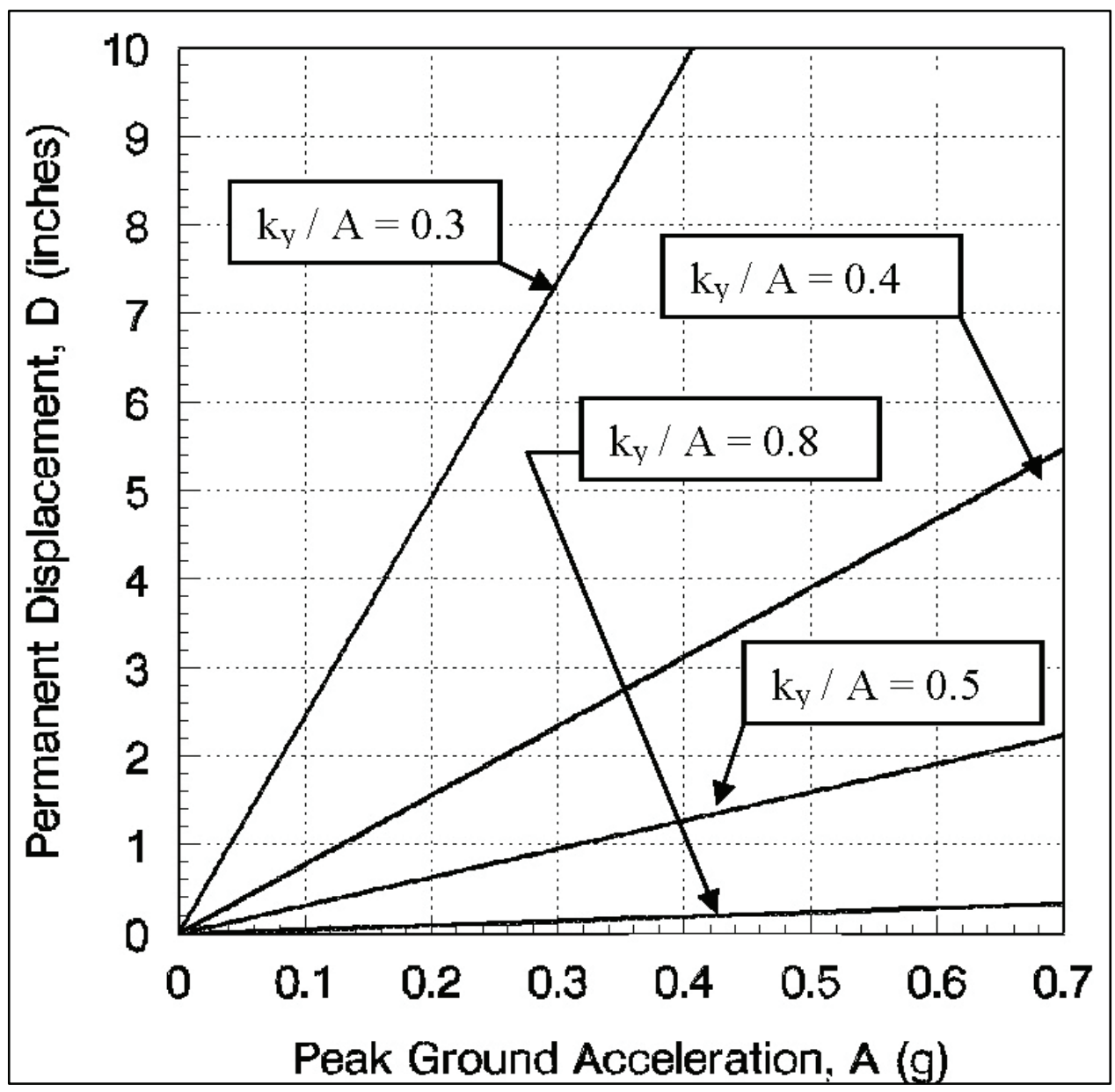

Figure 3.4 Permanent displacement as a function of $k_{y}$ and $A$

This plot can be used as a preliminary evaluation tool for estimating permanent displacement in retaining walls and dams. An alternative relationship by Whitman and Liao (1985) is given in Section 6.3.2 of Ebeling and Morrison 
(1992). Additional information relative to the sliding displacement of concrete dams can be found in Zhang and Chopra (1991).

\subsubsection{Permanent sliding displacement by response history (CWRotate)}

CWRotate has the ability to perform a sliding analysis and determine the permanent (residual) displacement that might take place during a response that is dominated by sliding. This sliding analysis is accomplished in CWRotate by describing the overall wall geometry, backfill geometry, and material properties and by providing baseline-corrected horizontal and vertical acceleration timehistories to represent the earthquake ground motions. Also, in CWRotate the user, by specifying a limit-state resisting force $P_{\text {resist }}$, can approximate the restraining effect an invert spillway slab may have on the toe of the cantilever wall. The magnitude of the $P_{\text {resist }}$ may be estimated using the simplified procedure developed by Strom and Ebeling (2004). Details regarding the sliding block method of analysis formulated are given in Ebeling and White (in preparation).

\subsubsection{Permanent rotational displacement by response history (CWRotate)}

CWRotate can also evaluate the rotational-dominated response of a toerestrained cantilever retaining wall subjected to earthquake ground motions. Rock-founded cantilever walls that are buttressed at the toe by an invert spillway slab are likely to be dominated by a rotational response. As with the sliding response, the buttressing effect of the invert spillway slab is represented by a user-specified force $P_{\text {resist }}$ acting on a vertical section extending upward from the toe of the wall. As described in Zeng and Steedman (2000), rotation of a rigid block model of the structural retaining wall system is assumed to occur about the toe of the structure (i.e., the rigid block is "pinned" to the rigid base at its toe). The CWRotate procedure differs from the Steedman and Zeng formulation by (a) formal consideration of a toe restraint in the analysis; (b) the ability of the user to assign a vertical acceleration time-history in addition to a horizontal acceleration time-history; and (c) the implementation of this formulation within CWRotate using a graphical user interface for input of geometry, input of material properties, input/verification of earthquake time-history files, and visualization of results. In addition, a sweep-search wedge formulation within the retained soil is used to determine the value of $P_{A E}$ rather than relying on the $\mathrm{MO}$ relationship (cited in the Steedman and Zeng (1998) formulation). The advantage of the sweep-search method as formulated in CWRotate is that it allows for the analysis of bilinear ground surfaces and the analysis of "cohesive" soils. Details regarding the rotating block method of analysis are provided in Ebeling and White (in preparation).

\subsubsection{Permanent (residual) displacement due to stem wall yielding}

The residual displacement response of bridge piers and building columns to strong earthquake ground shaking is described in Kawashima et al. (1998). 
Because of a constant lateral force (static earth pressure force) it is even more likely that a residual displacement will occur in retaining wall systems. The residual displacement will increase for each cycle where the earthquake-induced moment demand exceeds the moment capacity (i.e., nominal moment capacity) of the stem wall. The magnitude of this residual displacement will depend on the hysteretic behavior of the stem wall, the number of excursions beyond the yield (nominal) capacity of the stem wall, and the magnitude of each excursion. This residual displacement process is illustrated in Figures 3.5 and 3.6. A residual displacement analytical approach is described in Appendix F. Although some

aspects of this formulation are speculative, the authors of this report believe that the approach described contains the essential fundamental features to characterize the response. Enhancements can be made to CWRotate (Ebeling and White, in preparation) to permit engineers to use the aforementioned approach as a means for estimating the residual displacement that might occur during a retaining wall response that is dominated by stem wall yielding. 


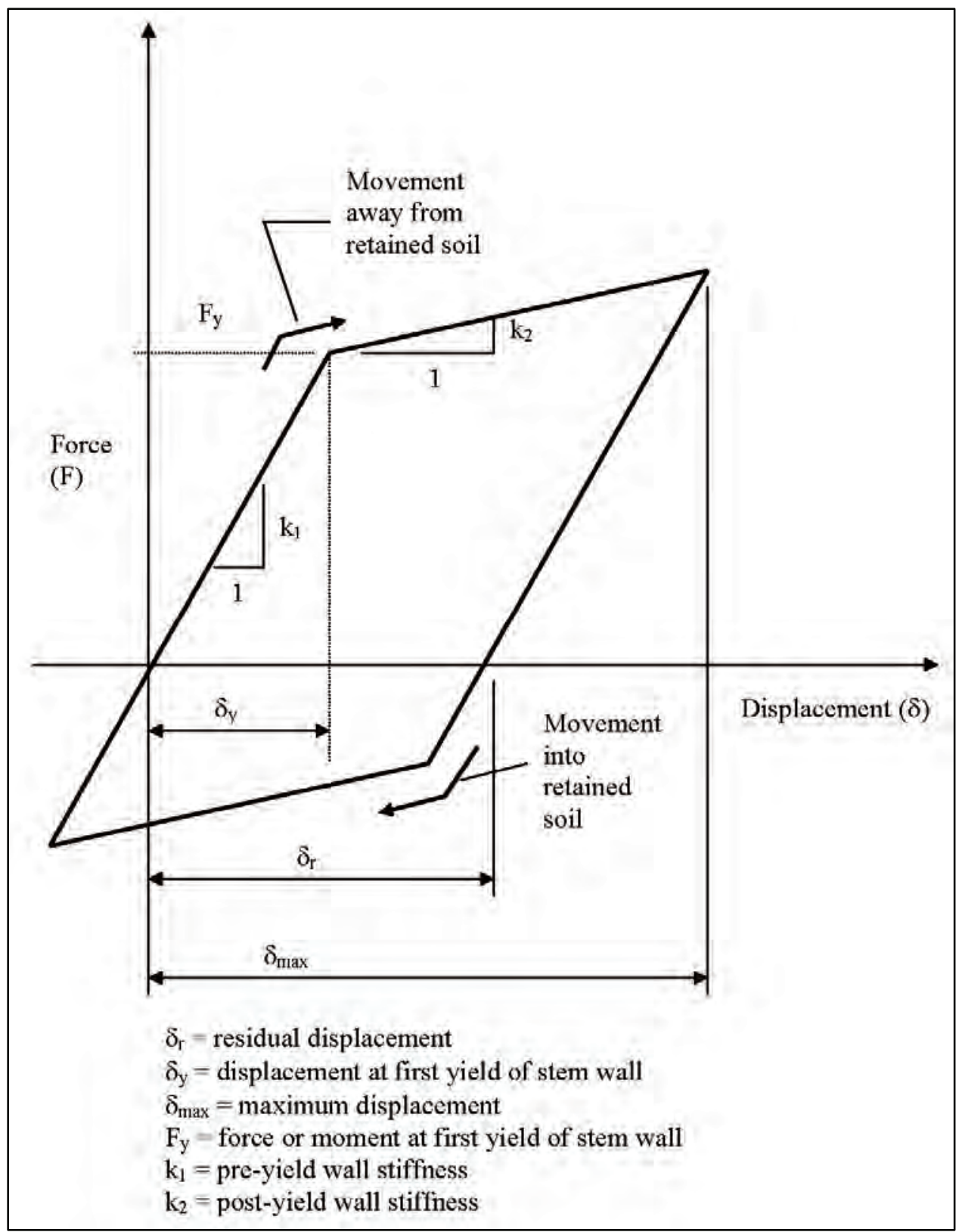

Figure 3.5 Possible stem wall hysteretic behavior when earthquake demands exceed $F_{y}$ 


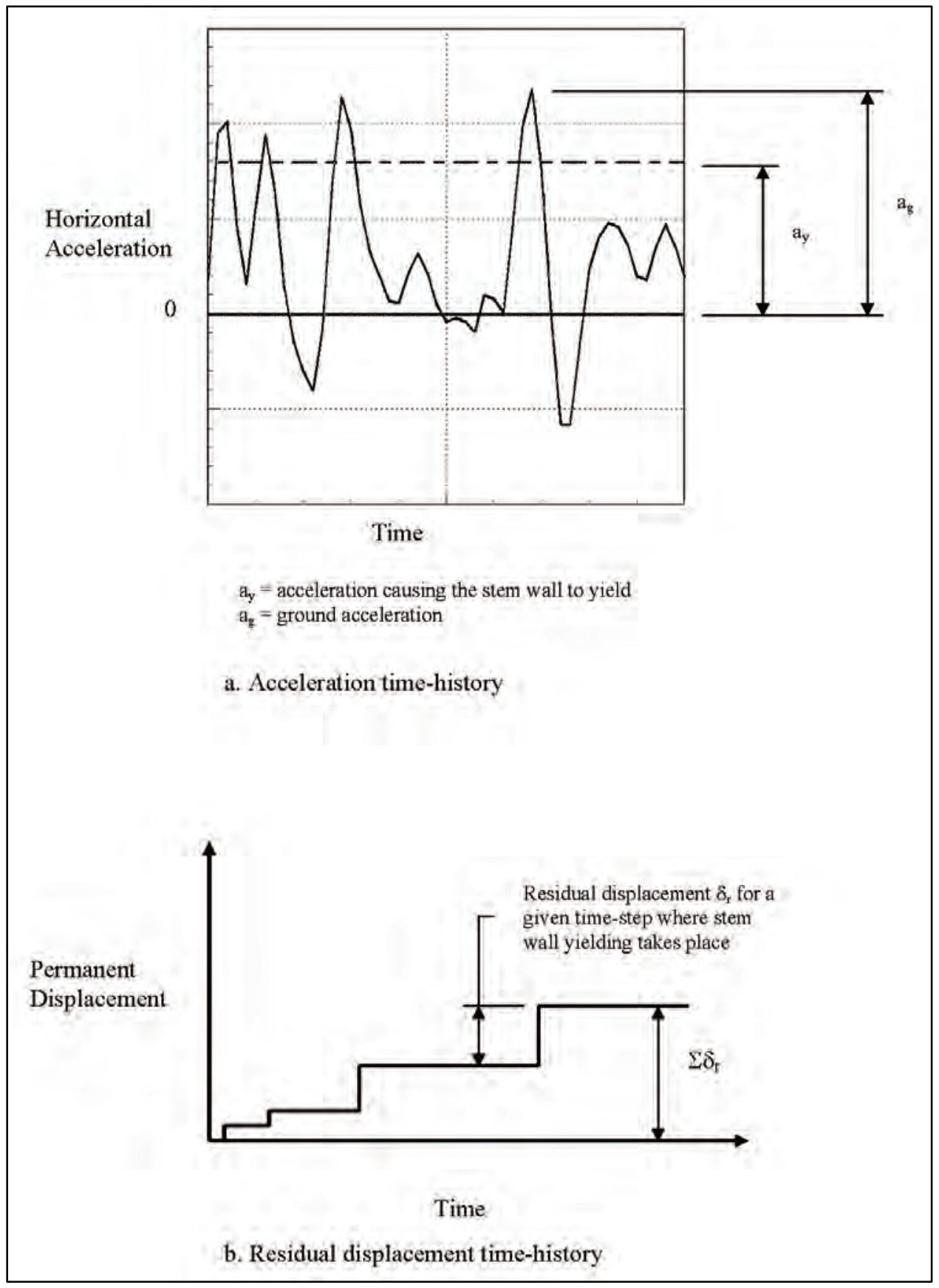

Figure 3.6 Permanent displacement at top of wall due to stem wall yielding 


\section{Force and Displacement Capacity of Reinforced Concrete (R/C) Structures}

Earthquake-related catastrophic failures have occurred in major civil works structures, reinforced concrete building structures, and bridge structures. As a result, structural codes have been revised dramatically in the past 25 years. Due to the age of most civil works projects, many of the earthquake-related deficiencies found in buildings and bridges designed by older codes also exist in Corps structures. These deficiencies, however, should be examined with respect to the unique characteristics of the particular civil works structure or structural system being investigated. The major differences between major civil works structures and buildings/bridge type structures are as follows:

- Many major civil works structures are lightly reinforced with reinforcement percentages generally less than 0.5 percent.

- Major civil works structures have low axial load ratios.

- Major civil works structures have large shear capacities because of large cross-sectional dimensions.

- In major civil works structures the concrete protection (cover) and reinforcing bar spacing exceed those found in bridge and building type structures.

- Major civil works structures are generally of massive wall-slab construction rather than beam-column construction.

All potential modes of failure, both brittle and ductile, must be investigated during a performance-based seismic evaluation. In FEMA 356 (2000) brittle modes of failure are designated as force-controlled actions and ductile modes of failure as deformation-controlled actions. The brittle modes to be investigated include the following:

- Splice and anchorage failure of flexural reinforcement.

- Shear (diagonal tension) failure. 
- Sliding shear failure.

- Compressive spalling failure.

- Fracture of reinforcement.

The latter failure mechanism is associated with lightly reinforced concrete structures and is therefore not a potential failure mechanism with respect to most cantilever retaining walls.

Flexure is the ductile failure mechanism usually considered in a seismic evaluation. In many instances a flexural plastic hinge will form at the base of the stem of a retaining wall before any of these brittle failure mechanisms can develop. This hierarchy in strength (where development of a flexural hinge precedes all potential brittle modes of failure) is an important aspect of good seismic design. Unfortunately for many older retaining wall structures it is possible that the reinforcing steel lap splices at the base of the stem wall will fail before a flexural plastic hinge develops. This lap splice deficiency is due either to inadequate lap splice length or to using reinforcing steel with "low bond" deformation patterns.

In most instances the compressive strains in the concrete are low and earthquake demands are usually not sufficient to cause a shear failure. Bond deterioration under cyclic loading occurs only if the maximum compressive strain at the location of reinforcing bar splices reaches levels where longitudinal microcracking develops. When compressive strains are below 0.2 percent $(0.002)$, the chance for microcracking and bond deterioration that could lead to reinforcing steel splice failure is low. ${ }^{1}$ When compressive strains are below 0.4 percent, the chance for concrete spalling is low. ${ }^{1}$ This means that in most Corps civil works structures, spalling will not occur, and the disastrous consequences of spalling, such as the loss of concrete cover, the loss of confinement reinforcement, and the buckling of reinforcing steel (during earthquake-induced cyclic load reversals), will also not occur. In order to meet performance requirements, all brittle modes of failure (all failure modes other than flexure) must be suppressed. Brittle modes of failure include shear (diagonal tension), sliding shear (shear-friction), and fracture of flexural reinforcing steel. Inelastic flexural response will limit shear demands. Therefore, it is necessary only to provide shear strength equal to or greater than the shear demand corresponding to that associated with the maximum feasible flexural strength. Fracturing of reinforcing steel is unique to lightly reinforced concrete members and will occur when strains in the reinforcing steel exceed 5 percent. ${ }^{1,2}$ This mode of failure can be prevented by limiting the displacement ductility capacity of members to that producing reinforcing steel strains less than 5 percent. Reinforcing steel used to resist flexural demands must also have splice and anchorage length sufficient to develop the maximum bar strength including strain hardening effects. The capacity of reinforced concrete members can be determined using the procedures described in Sections 4.2 and

\footnotetext{
${ }^{1}$ M.J.N. Priestley, 1995, "Criteria Review for Corps - Seismic Evaluation of Intake Towers," presented in Appendix G of this report.

2 J.P. Moehle, 1997, "Criteria Review for Corps - Seismic Evaluation of Intake

Towers," presented in Appendix G of this report.
} 
4.3. The capacity of members available to resist brittle modes of failure is discussed first. Brittle modes of failure are considered to be force-controlled actions (FEMA 356, 2000). For force-controlled actions, the capacity (nominal or ultimate strength) of the member at the deformation level associated with maximum flexural ductility demand must be greater than the force demands caused by earthquake, dead, and live loads. The flexural mode of failure is considered to be a displacement-controlled action. In a displacement-controlled action, moment demands can exceed moment capacities; however, the displacement capacity of members must be greater than the inelastic displacement demands placed on the structure due to earthquake, dead, and live loads. The flexural displacement capacity will usually be limited either by the compressive strain in the concrete (a maximum of 0.02 percent if bond deterioration is to be prevented), or by the tensile strain in the reinforcing steel (a maximum of 5 percent if fracture of the reinforcing steel is to be prevented $\left.{ }^{1}\right)$.

\subsection{Brittle Modes of Failure}

\subsubsection{Shear (diagonal tension)}

Since shear failure is a brittle failure, it is necessary to inhibit shear failure by ensuring that shear strength exceeds the shear demand corresponding to that associated with the maximum feasible flexural strength. Shear strength in plastic hinge regions is a function of the flexural displacement demand. As plastic-hinge rotations increase, shear cracks widen, and the capacity of the concrete to transfer shear by aggregate interlock decreases. The concrete component of shear strength can be expressed as

$$
V_{c}=k \sqrt{f_{c}^{\prime}} A_{e}
$$

where

$k=$ factor dependent on member flexural displacement ductility demand. As shown in Figure 4.1, $k$ can range from a maximum of 3.5 at low ductility demand levels to 1.2 at high ductility demand levels

$f_{c}^{\prime}=$ actual concrete compressive strength (per Priestley, ${ }^{1}$ the actual concrete compressive strength, which may be as high as or higher than 1.5 times the design compressive strength, should be used when calculating the shear capacity)

$$
\begin{aligned}
& A_{e}=0.8 A_{g} \\
& A_{g}=\text { gross concrete area }
\end{aligned}
$$

FEMA 356 (2000) indicates that within yielding regions of components with low ductility demands (i.e., ductility demand less than two) the calculation of concrete shear strength can be in accordance with the procedures of Chapter 11, ACI 318-02 (ACI 2002). With the ACI 318-02/FEMA 356 (2000) provisions,

\footnotetext{
${ }^{1}$ M.J.N. Priestley, 1995, “Criteria Review for Corps — Seismic Evaluation of Intake Towers," presented in Appendix G of this report.
} 
members with low ductility demand and subjected to shear and flexure would have a $k$ factor equal to only two. A ductility model for concrete shear strength (Priestley et al. 1994) is illustrated in Figure 4.1.

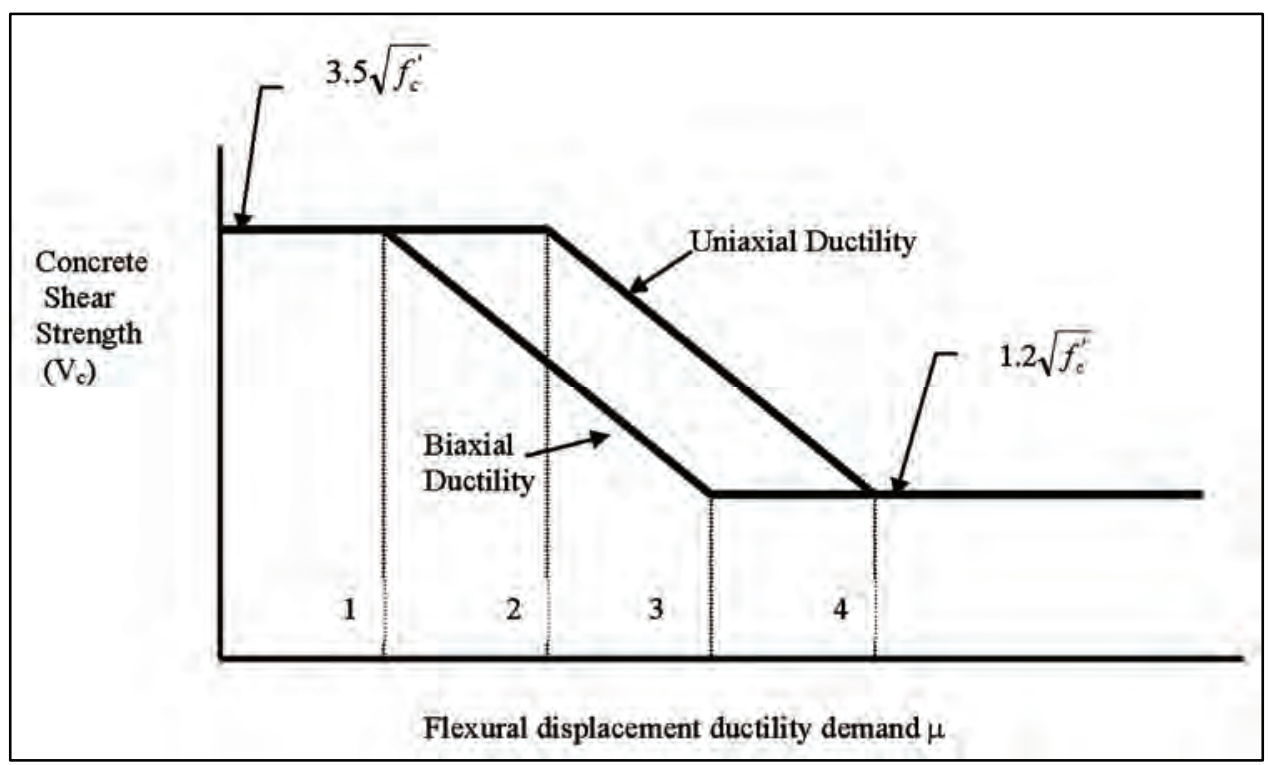

Figure 4.1 Degradation of shear strength with ductility (psi units)

In order to meet damage control performance requirements for MDE loadings, the capacity of the reinforced concrete structures in shear shall be equal to or greater than the lesser of

- The full elastic demand placed on the member by the design earthquake.

- The shear corresponding to 1.5 times the shear associated with the nominal flexural strength.

The capacity of the concrete in shear due to aggregate interlock, and to a lesser extent the shear resistance available from the transverse reinforcing (traditional truss mechanism), and the shear strength enhancement as the result of axial load may be considered. The total ultimate shear strength $V_{U}$ can be taken as

$$
V_{U}=\phi\left(V_{C}+V_{S}\right)=0.85\left(V_{C}+V_{S}\right)
$$

For rectangular sections the contribution of shear steel to the total shear capacity per ACI 318-02 (ACI 2002) is

$$
V_{S}=\frac{A_{v} f_{y} d}{s}
$$

where

$$
V_{S}=\text { contribution to shear capacity provided by the shear reinforcement }
$$




$$
\begin{aligned}
A_{V}= & \text { area of shear reinforcement within a distance } s \\
f_{y}= & \text { yield capacity of reinforcement } \\
d= & \text { depth from compression face to centroid of longitudinal tension } \\
& \text { reinforcement } \\
s= & \text { spacing of shear reinforcement }
\end{aligned}
$$

\subsubsection{Sliding shear}

Sliding shear (shear friction) along the base of a structure or structural member should also be investigated. Per Priestley, ${ }^{1}$ the shear friction shear capacity $V_{S F}$ can be determined by the following expression:

$$
V_{S F}=\mu_{S F}\left(P+0.25 A_{s} f_{y}\right)
$$

where

$$
\begin{aligned}
\mu_{S F}= & \text { sliding shear coefficient of friction, per ACI 318-02 (ACI 2002) } \\
P= & \text { axial load on section } \\
A_{s}= & \text { area of the longitudinal reinforcing steel across the potential failure } \\
& \text { plane } \\
f_{y}= & \text { yield strength of the reinforcing steel }
\end{aligned}
$$

\subsubsection{Reinforcing steel anchorage}

The strength of deformed straight, discontinuous bars embedded in concrete, with a clear cover over the embedded bar not less than three bar diameters $\left(3 d_{b}\right)$ can be calculated according to FEMA 356 (2000), Equation 6-3, or

$$
f_{s}=\frac{2500}{d_{b}} l_{e} \leq f_{y}
$$

where

$f_{s}=$ maximum stress that can be developed in an embedded bar having an embedment length $l_{e}$, psi

$d_{b}=$ diameter of reinforcing steel, in.

$l_{e}=$ embedment length, in.

$f_{y}=$ yield strength of reinforcing steel, psi

\footnotetext{
${ }^{1}$ M.J.N. Priestley, 1995, "Criteria Review for Corps — Seismic Evaluation of Intake Towers," presented in Appendix G of this report.
} 


\subsubsection{Reinforcing steel splices and hooked bars}

Development of reinforcing steel splices and hooked bars should be calculated using methods described in Section 6.4.5 of FEMA 356 (2000). Development of straight bars and hooked bars are determined using ACI 318-02 procedures (ACI 2002) with the following modifications:

a. Within yielding regions of components with moderate or high ductility demand (see Table 6-6, FEMA 356 (2000)) deformed straight bars, hooked bars, and lap-spliced bars should meet the development requirements of Chapter 21 of ACI 318-02. Within yielding regions of components with low ductility demands and outside yielding regions for all ductility demands, bars should meet the development requirements of Chapter 12 of ACI 318-02, except requirements for lap splices can be the same as those for straight bars in tension without consideration of lap splice classification.

$b$. Where existing deformed straight bars, hooked bars, and lap-spliced bars do not meet these development requirements, the capacity of existing reinforcement shall be calculated using Equation 4.6 (FEMA 356 (2000) Equation 6-2)

$$
f_{s}=\frac{l_{b}}{l_{d}} f_{y}
$$

where

$$
\begin{aligned}
f_{s}= & \text { maximum stress that can be developed in the bar for the lap or splice } \\
& \text { length provided } l_{b} \\
l_{b}= & \text { lap or splice length provided } \\
l_{d}= & \text { lap or splice length required by ACI } 318-02
\end{aligned}
$$

For existing structures, the actual compressive strength rather than the design compressive strength should be used to evaluate splice lengths and anchorages. Deterioration of bond and splice strengths of reinforcing bars is one of the greatest problems in the design of earthquake-resistant reinforced concrete structures. Large concrete covers and transverse reinforcement provide the best protection against splice strength degradation. The ACI 318-02 development length equations allow these factors to be considered. Appendix F by example illustrates the aforementioned process for an older existing retaining wall structure.

\subsubsection{Fracture of reinforcing steel}

It is likely that fracture of reinforcing steel can be prevented if enough flexural reinforcing steel is provided to produce a nominal moment strength equal to, or greater than, the 1.2 times the cracking moment capacity of the section. To prevent a brittle fracture mechanism, a nominal moment strength equal to 120 percent of the cracking is considered to be the lowest minimum 
reinforcement limit. ${ }^{1}$ Nominal moment capacities equal to 200 percent of the cracking moment are preferred for earthquake-resistant structures. ${ }^{1}$ Existing structures that cannot meet this nominal moment capacity requirement can be considered to meet performance requirements if it can be demonstrated that displacement ductility demands are low enough to keep reinforcing steel strains below 5 percent. This requires a displacement-based evaluation.

\subsection{Flexure}

The nominal moment strength of reinforced concrete members can be determined in accordance with ACI 318-02 requirements (ACI 2002). The nominal strength is the capacity to be used in determining demand-to-capacity ratios (DCRs) for use in FEMA 356 (2000) LSP and LDP methods. Displacementbased procedures as part of displacement demand to displacement capacity analysis are the preferred method of evaluating displacement-controlled actions (flexure). The displacement-based approach is described in the following section.

\subsection{Displacement-Based Analyses}

Displacement-based analyses are required to determine if member flexural displacement capacities are greater than flexural displacement demands. Flexural displacement capacity is related to curvature capacity, plastic hinge length (length of zone where yielding occurs), and member length. Displacement demands described herein are those occurring at the top of the structure in relationship to the base of the structure.

\subsubsection{Curvature capacity}

The curvature capacity will depend on the maximum amount of strain that can be placed on the concrete and reinforcing steel. To prevent fracturing of the reinforcing steel, the steel strain should be limited to 5 percent. Static load testing produces ultimate strain capacities of 18 percent or more, but due to low cycle fatigue effects, the maximum permitted for earthquake load conditions is 5 percent. ${ }^{1,2}$ The maximum ultimate strain capacity of concrete under dynamic loadings is approximately 0.4 percent. However, when there is inadequate confinement steel to prevent splice failures, the maximum ultimate strain capacity should be limited to about 0.2 percent. ${ }^{1}$ Using this information, the ultimate curvature capacity of a reinforced concrete section can be determined (Figure 4.2).

\footnotetext{
${ }^{1}$ M.J.N. Priestley, 1995, "Criteria Review for Corps — Seismic Evaluation of Intake Towers," presented in Appendix G of this report.

2 J.P. Moehle, 1997, "Criteria Review for Corps - Seismic Evaluation of Intake

Towers," presented in Appendix G of this report.
} 


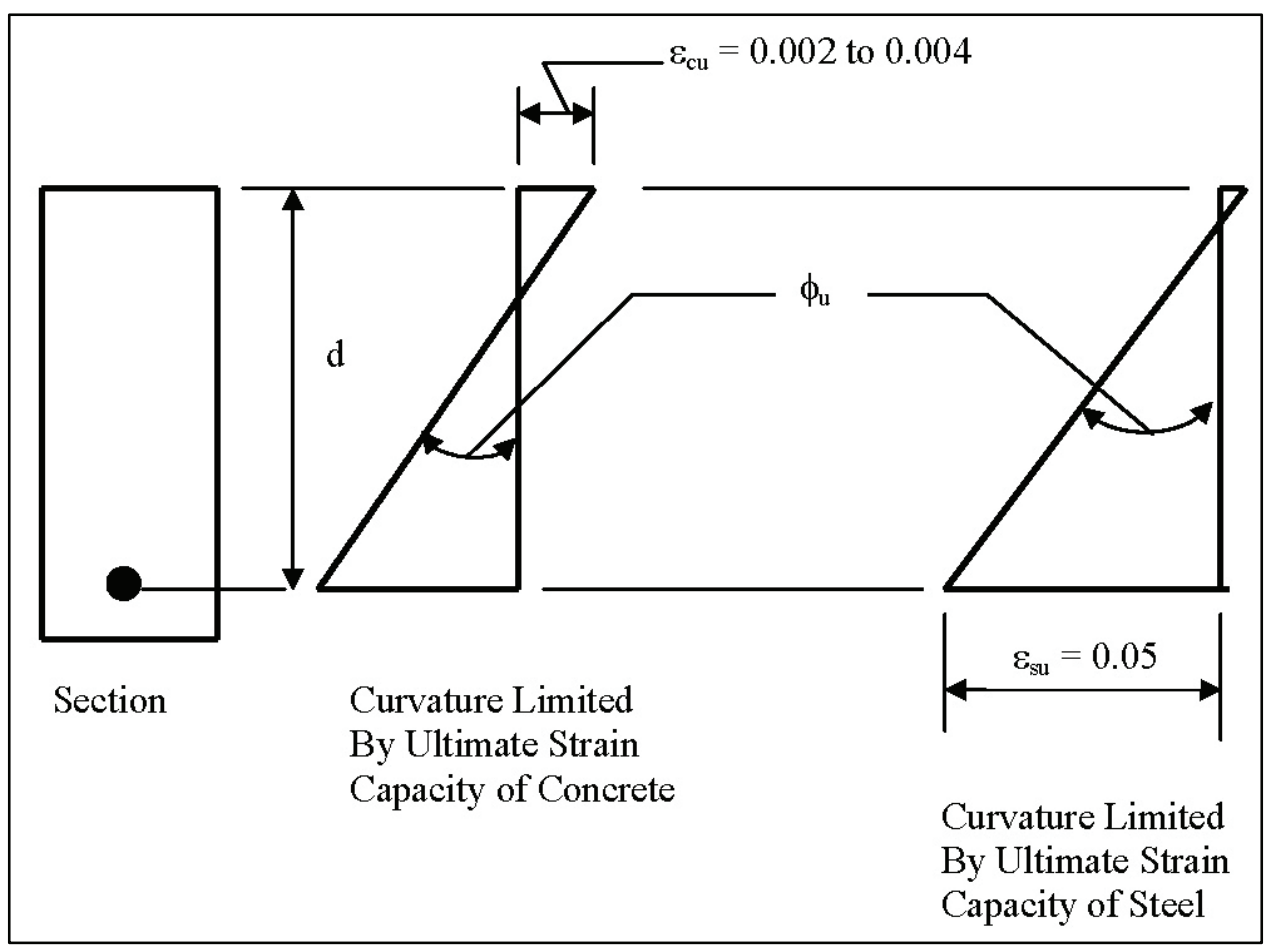

Figure 4.2 Ultimate curve capacity where $\varepsilon_{c u}, \varepsilon_{s u}$ is the ultimate strain capacity of the concrete in compression and of the steel in tension, respectively

\subsubsection{Rotational capacity}

Ultimate rotation capacity is equal to the ultimate curvature capacity times the plastic hinge length. In accordance with Priestley, ${ }^{1}$ when the nominal moment capacity $M_{N}$ is less than 1.2 times the cracking moment $M_{C R}$, the plastic hinge length to be used in calculating rotational capacity is

$$
l_{p}=0.30 f_{y} d_{b} \text { in. (ksi units) }
$$

Members with nominal moment capacities less than 120 percent of the cracking moment capacity are characterized by the formation of a single crack in the plastic hinge region. The nominal moment capacity for these lightly reinforced members is insufficient to spread cracking along the length of the member. According to Priestley and Park (1987), the width of the single crack is due to two reasons: slip of the reinforcement (bond-slip) relative to the concrete and the influence of shear on the crack pattern. The width of the single crack (i.e., plastic hinge length) is approximated by Equation 4.7. Plastic hinge length depends on the amount of strain penetration occurring on each side of the crack. This in turn depends on bond slip between the reinforcement and the concrete. Therefore, the length of embedment required to fully develop the bar should influence the plastic hinge length. Since embedment length is a function of bar

\footnotetext{
${ }^{1}$ M.J.N. Priestley, 1995, “Criteria Review for Corps - Seismic Evaluation of Intake Towers," presented in Appendix G of this report.
} 
diameter, it would be expected that plastic hinge length would also be a function of bar diameter as indicated by Equation 4.7.

In accordance with Priestley, ${ }^{1}$ when the nominal moment $M_{N}$ is greater than twice the cracking moment $M_{C R}$, the plastic hinge length to be used in calculating rotational capacity is

$$
l_{p}=0.08 L+0.15 f_{y}\left(d_{b}\right) \text { in. (ksi units) }
$$

where $L$ is the length of the member.

For nominal moment strengths between $1.2 M_{C R}$ and $2.0 M_{C R}$ the plastic hinge length can be determined by linear interpolation between the results obtained from the two plastic hinge length equations. ${ }^{1}$

In accordance with Priestley, ${ }^{1}$ the ultimate rotational capacity of the member can be estimated as follows:

$$
\theta_{u}=\phi_{u}\left(l_{p}\right)
$$

where

$$
\begin{aligned}
\theta_{\mathrm{u}} & =\text { ultimate rotational capacity } \\
\phi_{\mathrm{u}} & =\text { ultimate curvature capacity }
\end{aligned}
$$

For cantilevered structures such as intake towers and bridge piers it is advantageous to determine ultimate displacement ductility capacities and use those to compare with the displacement ductility demands obtained from a seismic analysis. This process is described in the next section. For more complex structures composed of wall and slab elements, the rotational capacities of plastic hinge regions can be determined by Equation 4.9 and compared to the rotation demands estimated from a linear elastic analysis or obtained directly from a nonlinear analysis. For cantilever retaining walls a process that compares the earthquake displacement demands on the soil-wall system to the displacement capacity of the retaining wall is recommended (Section 4.5.1).

\subsection{Displacement Capacity of Cantilever Structures}

The displacement capacity of intake towers, spillway piers, bridge piers and powerhouse superstructure walls and other members that behave as cantilever structures can be determined using the models shown in Figures 4.3-4.5. For structures where the mass can be assumed to occur at the top of the structure, such as a bridge pier, the concentrated mass model of Figure 4.3 applies. The

\footnotetext{
${ }^{1}$ M.J.N. Priestley, 1995, “Criteria Review for Corps — Seismic Evaluation of Intake Towers," presented in Appendix G of this report.
} 
Figure 4.4 distributed mass model applies for structures such as intake towers where the mass is distributed along the entire height. The retaining wall model presented in Figure 4.5 assumes the mass decreases linearly with height. The total displacement capacity is the sum of the preyield and postyield displacement capacities. The preyield displacement capacity can be determined using the elastic curve integration procedures common to static analysis. Postyield displacement is just the product of the rotational capacity (ultimate curvature capacity minus the yield curvature times the plastic hinge length) and the effective height. ${ }^{1}$ The ultimate displacement ductility capacity is just the ultimate displacement capacity divided by the yield displacement.

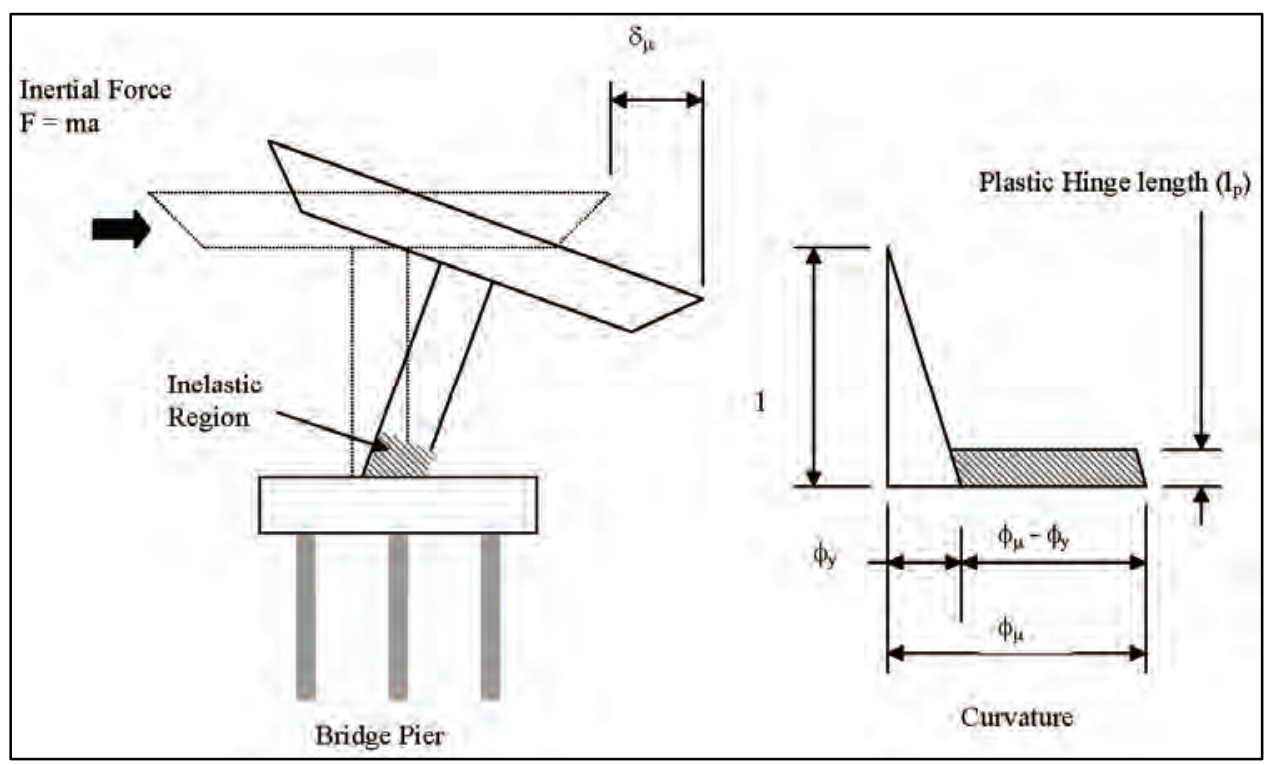

Figure 4.3 Idealized flexural curvature in a bridge pier

For the bridge pier concentrated mass model (Figure 4.3) the ultimate displacement capacity can be estimated as described in Moehle (1992) by

$$
\delta_{\mu}=\frac{\phi_{y} l^{2}}{3}+\left(\phi_{\mu}-\phi_{y}\right) l_{p}\left(l-\frac{l_{p}}{2}\right)
$$

Or the ultimate displacement ductility capacity can be estimated by

$$
\mu=1+3\left(\frac{\phi_{u}}{\phi_{y}}-1\right) \frac{l_{p}}{l}\left(1-0.5 \frac{l_{p}}{l}\right)
$$

where

$$
\begin{aligned}
\phi_{\mathrm{y}} & =\text { curvature at first yield of the reinforcing steel } \\
l & =\text { length of cantilever }
\end{aligned}
$$

\footnotetext{
${ }^{1}$ M.J.N. Priestley, 1995, "Criteria Review for Corps - Seismic Evaluation of Intake Towers," presented in Appendix G of this report.
} 


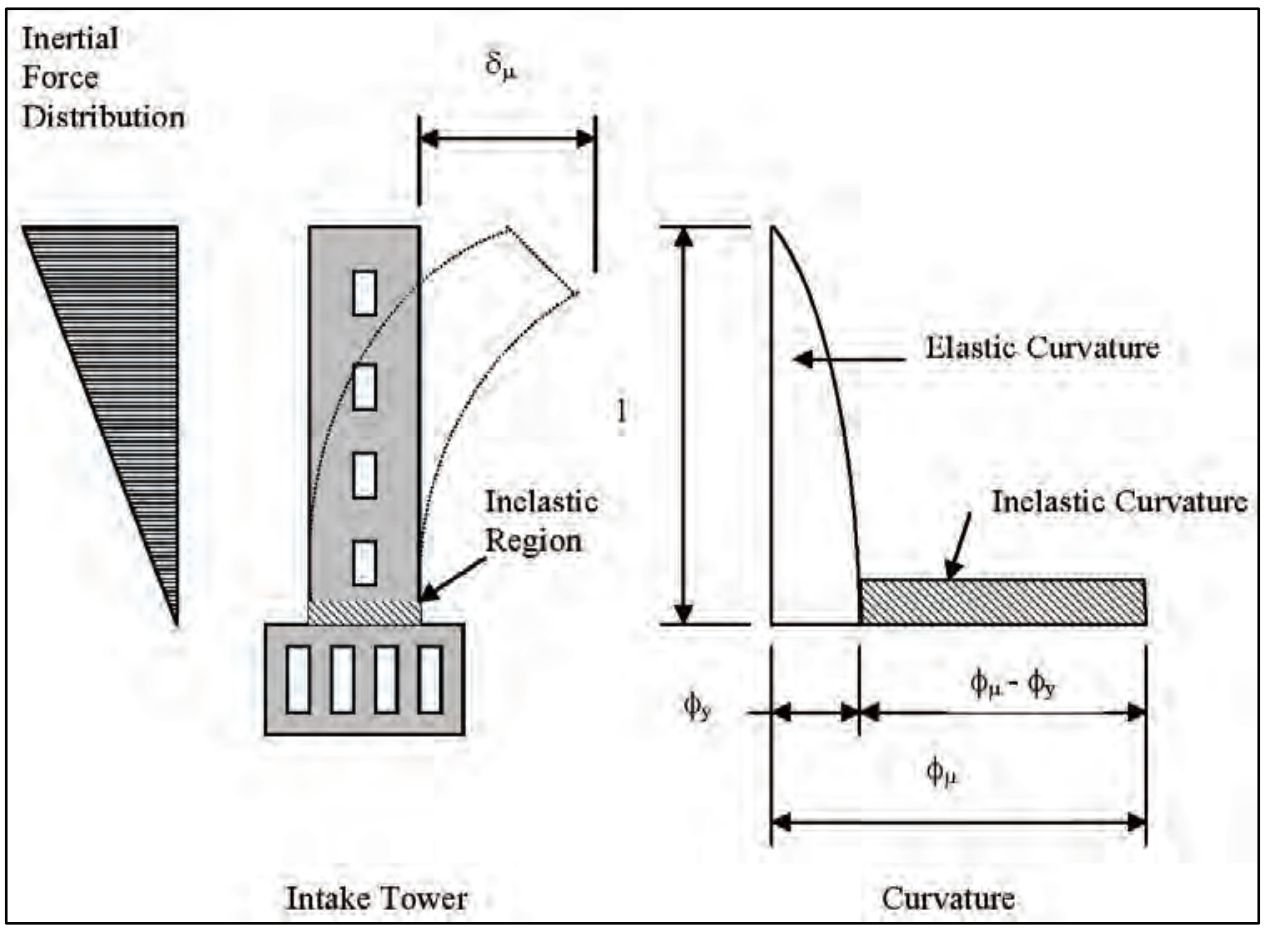

Figure 4.4 Idealized flexural curvature in an intake tower

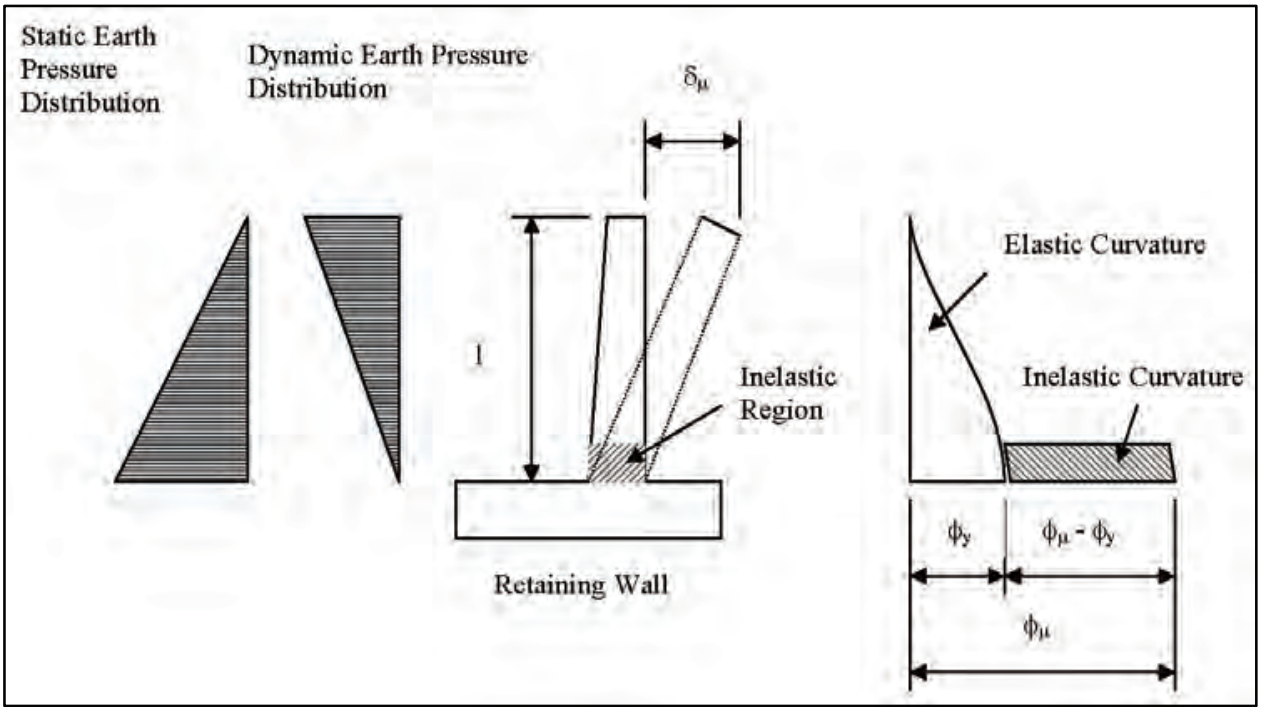

Figure 4.5 Idealized flexural curvature in a retaining wall

For the intake tower distributed mass model (Figure 4.4) the ultimate displacement capacity can be estimated as described in Ehsani (1993) ${ }^{1}$ by

\footnotetext{
${ }^{1}$ M.R. Ehsani, 1993, "Evaluation of seismic retrofit and ductility needs of reinforced concrete structures," draft report, U.S. Army Engineer Waterways Experiment Station, Vicksburg, MS.
} 


$$
\delta_{\mu}=\frac{11}{40} \phi_{y} l^{2}+\left(\phi_{\mu}-\phi_{y}\right) l_{p}\left(l-\frac{l_{p}}{2}\right)
$$

Or the ultimate displacement ductility capacity can be estimated by

$$
\mu=1+3.64\left(\frac{\phi_{u}}{\phi_{y}}-1\right) \frac{l_{p}}{l}\left(1-0.5 \frac{l_{p}}{l}\right)
$$

For the retaining wall model (Figure 4.5) the ultimate displacement capacity at the top of the stem wall relative to its base can be estimated by

$$
\delta_{\mu}=\frac{1}{5} \phi_{y} l^{2}+\left(\phi_{\mu}-\phi_{y}\right) l_{p}\left(l-\frac{l_{p}}{2}\right)
$$

Or the ultimate displacement ductility capacity can be estimated by

$$
\mu=1+5\left(\frac{\phi_{u}}{\phi_{y}}-1\right) \frac{l_{p}}{l}\left(1-0.5 \frac{l_{p}}{l}\right)
$$

Most structures will not conform strictly to these ideal concentrated and distributed mass models. The model best representing the actual inertial force condition, however, should provide a reasonable estimate of displacement capacity and displacement ductility capacity. As a refinement, the structure can be investigated using the concentrated mass model with the distance from the base to the center of mass equal to the effective height. ${ }^{1}$ The effective height $l_{\text {eff }}$ representing the center of seismic force is

$$
l_{\text {eff }}=\frac{\sum\left(m_{n} \phi_{n} l_{n}\right)}{\sum m_{n} \phi_{n}}
$$

where

$$
\begin{aligned}
m_{n} & =\text { mass at level } n \text { of a multiple lumped mass system } \\
\phi_{n} & =\text { modal value at mass level } n \\
l_{n} & =\text { height from base to mass at level } n
\end{aligned}
$$

\footnotetext{
${ }^{1}$ M.J.N. Priestley, 1995, "Criteria Review for Corps — Seismic Evaluation of Intake Towers," presented in Appendix G of this report.
} 


\subsection{Evaluating the Seismic Performance of Reinforced Concrete Structures}

Damage control through the control of displacements is the essence of performance-based earthquake engineering. Many simple methods have been devised to evaluate the seismic performance of structures. These methods have been developed primarily for use in evaluating building and bridge systems. Cantilever retaining wall systems differ from building and bridge systems in that static lateral loads (static soil pressure loads) act in combination with the dynamic loads (dynamic earth pressure loads). The most promising methodology for the seismic evaluation of cantilever retaining walls is a displacement-based approach where the displacement demands on the soil-wall system are compared to the displacement capacity of the reinforced concrete retaining wall. This proposed methodology is described in the following text along with methodologies used to evaluate building and bridge systems. The most prominent of the simple methods used to evaluate building and bridge systems include the following:

- FEMA 356 (2000) Linear Dynamic Procedure (LDP) type analyses.

- FEMA 356 (2000) Nonlinear Static Procedure (NSP) type analyses.

- ATC 40 (Applied Technology Council (ATC) 1996) Capacity Spectrum Method (CSM) type analyses.

\subsubsection{Proposed displacement-based approach for cantilever retaining walls}

In performance-based earthquake engineering it is possible to estimate earthquake demands on a particular structure for a given earthquake event and to compare them to the displacement capacity of the structure or member under investigation. For cantilever retaining walls the flexible wall procedure described in Veletsos and Younan (1997) could be a method for approximating the displacement demands on flexible retaining wall systems that respond elastically to earthquake ground motions. It also may be possible, as described in Appendix F, to use the Veletsos and Younan flexible wall approach in combination with CWRotate enhancements to approximate the permanent (residual) displacement demands on yielding wall systems. Note that Veletsos and Younan (1997) indicate that with high ground accelerations and with amplification effects considered, the displacement range of the soil-wall systems that respond elastically is less than 0.1-0.4 percent of the wall height. The aforementioned range is that generally associated with the development of active limit-state condition in the retained soil material, per Chapter 6 of Clough and Duncan (1991), and in Chapter 2 of Ebeling and Morrison (1992).

Displacement capacities for the reinforced concrete retaining wall would be determined by methods described in Section 4.4. The performance of displacement-controlled action (flexure) would be evaluated by a displacement demand to capacity evaluation, with displacement demands determined as illustrated in Figure 4.6. 


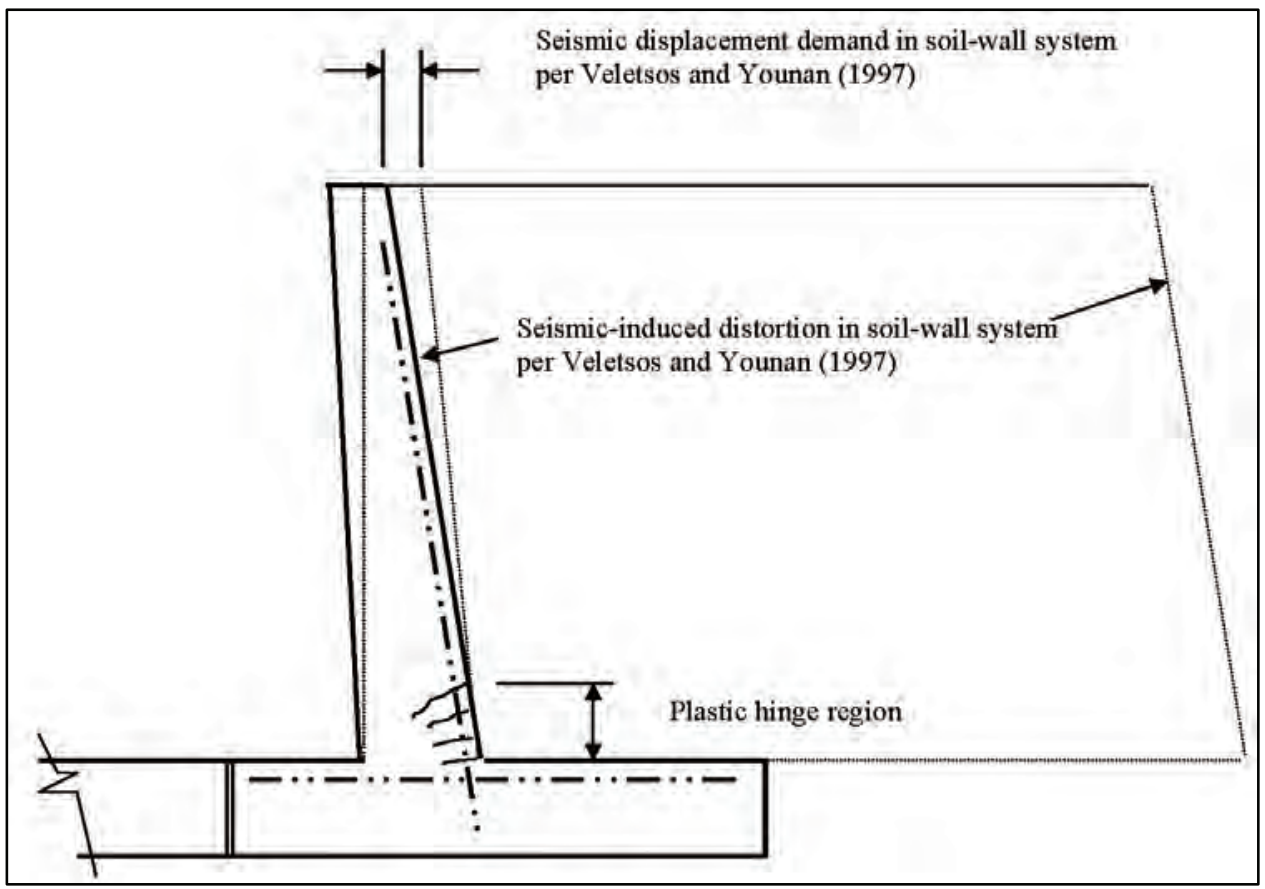

Figure 4.6 Displacement demand to capacity evaluation (performance determined by comparing the displacement demands on the wall with the displacement capacity of the wall

Force-controlled actions (brittle failure mechanisms) would be evaluated by a force-based demand to capacity evaluation, using peak demands from a CWRotate analysis and the capacities as determined in Section 4.1.

Assuming a linear elastic response and using the Veletsos and Younan (1997) upper bound shear-beam displacement response, the maximum displacement demand for the ACI-WSD wall of Appendix D is estimated to be

$$
\delta_{E}=0.50 \frac{\ddot{X}_{g} H^{2}}{v_{s}^{2}}=0.50 \frac{0.764(32.2)(18.5)^{2}}{(500)^{2}}=0.0168 \mathrm{ft}=0.20 \mathrm{in} .
$$

where

$$
\begin{aligned}
\ddot{X}_{g} & =\text { peak ground acceleration } \\
v_{s} & =\text { shear wave velocity of the soil } \\
H & =\text { wall height }
\end{aligned}
$$

Using an upper bound dynamic amplification factor of 2.2, as recommended by Veletsos and Younan (1997) the amplified displacement $\delta_{A E}$ is

$$
\delta_{A E}=2.2(0.20)=0.44 \text { in., or only about } 0.2 \% \text { of the wall height }
$$


The ultimate displacement capacity $\delta_{\mu}$ for the ACI-WSD wall of Appendix $\mathrm{D}$, neglecting the elastic contribution prior to first yield, is

$$
\delta_{\mu}=\left(\phi_{\mu}-\phi_{\mathrm{y}}\right) l_{p}\left(1-0.5 l_{p}\right)
$$

assuming yield and ultimate curvature capacities per Figure F.5, Appendix F, and conservatively assuming that the nominal moment capacity $M_{N}$ is less than 1.2 times the cracking moment $M_{C R}$ and single crack conditions as described in Section 4.3.2. The plastic hinge length $l_{p}$ is at a minimum and equal to

$$
l_{p}=0.30 f_{y} d_{b}=0.30(40)(1.00)=12.0 \text { in., and }
$$

$\delta_{\mu}=\left(\phi_{\mu}-\phi_{\mathrm{y}}\right) l_{p}\left(1-0.5 l_{p}\right)=(0.004032-0.000092) 12(222-6)=10.2 \mathrm{in}$.

With respect to the single crack issue, testing performed by the Corps related to lightly reinforced intake towers (Dove 1998, 2000) indicated that the width of the single crack for lightly reinforced members was independent of the bar diameter. Testing however was limited to \#3, \#4, and \#5 reinforcing bars. The ultimate crack width $C_{U}$ as determined by experimental testing per Dove (2000) was equal to

$$
C_{U}=0.175913+1.03506\left(\varepsilon_{\mathrm{U}}\right)(\text { in. })
$$

where $\varepsilon_{U}$ equals the ultimate rupture strain of the reinforcing steel, which is taken as 5 percent for structures subjected to earthquake loading. Therefore $C_{U}$, the width of the single crack as expressed by Equation 4.22, is equal to 0.23 in.

By Dove (2000), the ultimate displacement capacity $\delta_{\mu}$, neglecting the elastic contribution prior to first yield, is

$$
\delta_{\mu}=\left(C_{U} \div l_{w}\right) 1=(0.23 \div 18)(222)=2.84 \text { in. }
$$

where $l_{w}$ is the depth of the member, or $18 \mathrm{in}$. This is significantly less than that determined in accordance with Priestley, ${ }^{1}$ but still greater than the displacement demand predicted by the Veletsos and Younan shear-beam formulation.

These computations suggest that retaining walls with adequate splice and development lengths should have sufficient displacement capacity to resist earthquake displacement demands under conditions when residual displacements do not build up with each additional excursion into the postyield range. A proposed method for estimation of the postyield residual displacement build-up is described in Section 3.5.7 and Appendix F.

\footnotetext{
${ }^{1}$ M.J.N. Priestley, 1995, "Criteria Review for Corps - Seismic Evaluation of Intake Towers," presented in Appendix G of this report.
} 


\subsubsection{FEMA 356 (2000) LDP analysis}

In the FEMA 356 (2000) LDP analysis, a linear elastic response spectrum analysis or linear elastic time-history analysis is used to determine the force and displacement demands on the structural system under investigation. An equal displacement response is assumed, i.e. the displacement of the nonlinear structure is the same as that the structure would experience if it remained elastic during the design earthquake event.

Force-based demand to capacity evaluations are made for "brittle" failure modes (i.e., force-controlled actions). Performance is acceptable if force demand to force capacity ratio (DCR) is less than one. It should be recognized, however, that capacity often will decrease as greater displacement ductility demands are made on the structure.

Displacement-based demand to capacity evaluations are made for "ductile" failure modes (i.e., displacement-controlled actions). Flexure is the primary displacement-controlled action of interest. Performance is acceptable if the displacement demand to displacement capacity ratio (DCR) is less than one. Since an equal displacement response is assumed, a force-based (i.e., moment-based for a flexural response) DCR evaluation can be made with the resulting DCR indicating the displacement-ductility demand on the structural component under investigation. This DCR would be the ratio of the moment demand from a response spectrum, or time-history analysis, divided by the nominal (yield) moment capacity of the member. The DCR to meet performance objectives should be less than the displacement ductility capacity of the member as determined previously, or as indicated by the $\mathrm{m}$-factors prescribed for reinforced concrete structures in Chapter 6 of FEMA 356 (2000). The m-factor is a measure of the expected displacement ductility of a particular member under prescribed loading parameters. It would be difficult to adapt the FEMA LDP analysis to cantilever retaining wall systems, since displacement demands are a function of both dynamic and static earth pressures, and because the analytical model must include both a structural and soil system and their interaction.

\subsubsection{FEMA $356(2000)$ NSP analysis}

The FEMA 356 (2000) NSP analysis is a "pushover" type static analysis, in which an analytical model representing the structure is loaded incrementally until plastic hinging (yielding) occurs. The applied loading is distributed to provide displacements representing those associated with first mode response. As hinges develop in members, the associated system stiffness is modified to reflect the stiffness reduction that occurs with the onset of yielding. The displacement demands on the system are represented by a "target" displacement $\delta_{t}$ that is determined based on the first mode spectral acceleration response of the system, or

$$
\delta_{t}=C_{0} C_{1} C_{2} C_{3} S_{a}\left[\left(T_{e}\right)^{2} \div 4 \pi^{2}\right]
$$

where 
$T_{e}=$ Fundamental period of vibration based on the effective stiffness of the structural system

$S_{a}=$ Spectral acceleration of the design earthquake for period $T_{e}$

The term $S_{a}\left[\left(T_{e}\right)^{2} \div 4 \pi^{2}\right]$ converts spectral acceleration to spectral displacement and

$C_{0}=$ modification factor to relate spectral displacement to inelastic displacement at the top of the structure

$C_{1}=$ modification factor to relate "top of structure" inelastic displacement to displacement obtained for the elastic response obtained by pseudolateral load analysis, response spectrum analysis, or linear elastic time-history analysis

$C_{2}=$ modification factor to represent the effects of severe strength deterioration (i.e., pinched hysteresis curve)

$C_{3}=$ modification factor to account for any second-order displacement $(P$ - $\Delta$ ) effects

Performance is considered acceptable when it is possible to push the structure to the target displacement level without exceeding various plastic hinge rotational capacities as defined for reinforced concrete members in Chapter 6 of FEMA 356 (2000).

A FEMA 356 (2000) NSP displacement-based analysis is illustrated in Figure 4.7.

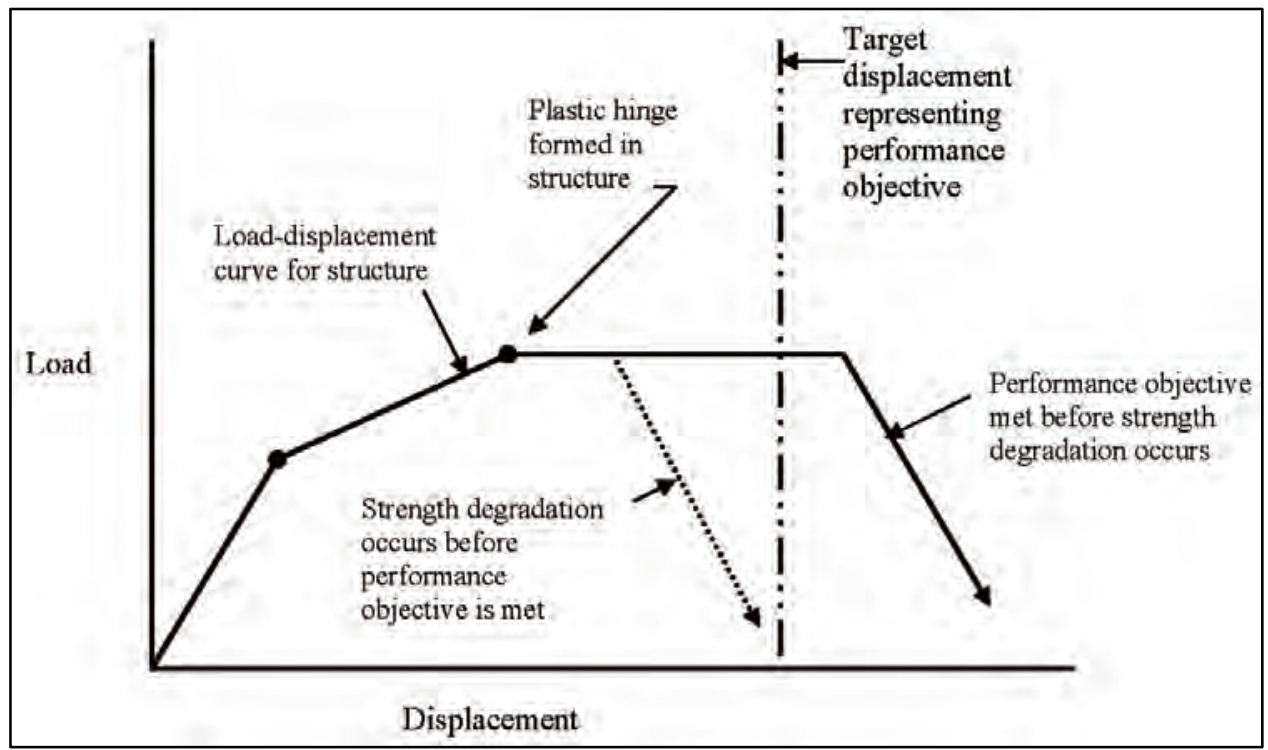

Figure 4.7 FEMA 356 (2000) NSP analysis load-displacement curve

The FEMA NSP analysis provides a visual description of the loaddeformation characteristics of the structure and the amount of displacement 
ductility required to meet earthquake displacement demands. Assuming the fundamental period of the retained soil-wall system $T_{1}$ can be estimated using the Veletsos and Younan (1997) shear beam model:

$$
T_{1}=\frac{4 H}{v_{s}}
$$

Then, using the FEMA NSP approach it would be possible to estimate the displacement demands on the retaining wall. This approach is illustrated in Appendix F.

In addition to FEMA 356 (2000), information on the NSP analysis can be found in Whittaker et al. (1998).

\subsubsection{ATC 40 (1996) CSM analysis}

The capacity spectrum analysis is another type of NSP pushover analysis. In this case the load-displacement response of the structural system is converted to spectral acceleration-spectral displacement response and compared directly to the demands of the design earthquake as represented by a design response spectrum. The more recent application of a CSM analysis is described in ATC 40 (1996). A description and evaluation of the CSM is also presented in Chopra and Goel (2000).

Unique to the ATC 40 (1996) methodology is that the viscous damping ratio used to obtain the spectral demands of the design earthquake is related to the displacement ductility demand on the system. The process therefore becomes an iterative one reconciling displacement demand, which is a function of effective damping, with displacement ductility performance or with the load-displacement performance of the structural system. Two iterative techniques are described in Chopra and Goel (2000). The report indicates that the ATC 40 (1996) CSM procedures are deficient relative to even the elastic design spectrum approach in estimating the peak deformation of an inelastic system where the effective period of the system is in either the velocity-sensitive or displacement-sensitive range of the spectrum. For this and other reasons already cited, the CSM procedure is not considered as one that would be useful in a performance-based seismic evaluation of retaining walls.

The CSM procedure is illustrated in Figure 4.8.

Performance objectives are assumed to have been satisfied if the system has sufficient displacement ductility capacity to reach the point indicated in Figure 4.8 where capacity is reconciled with demand. 


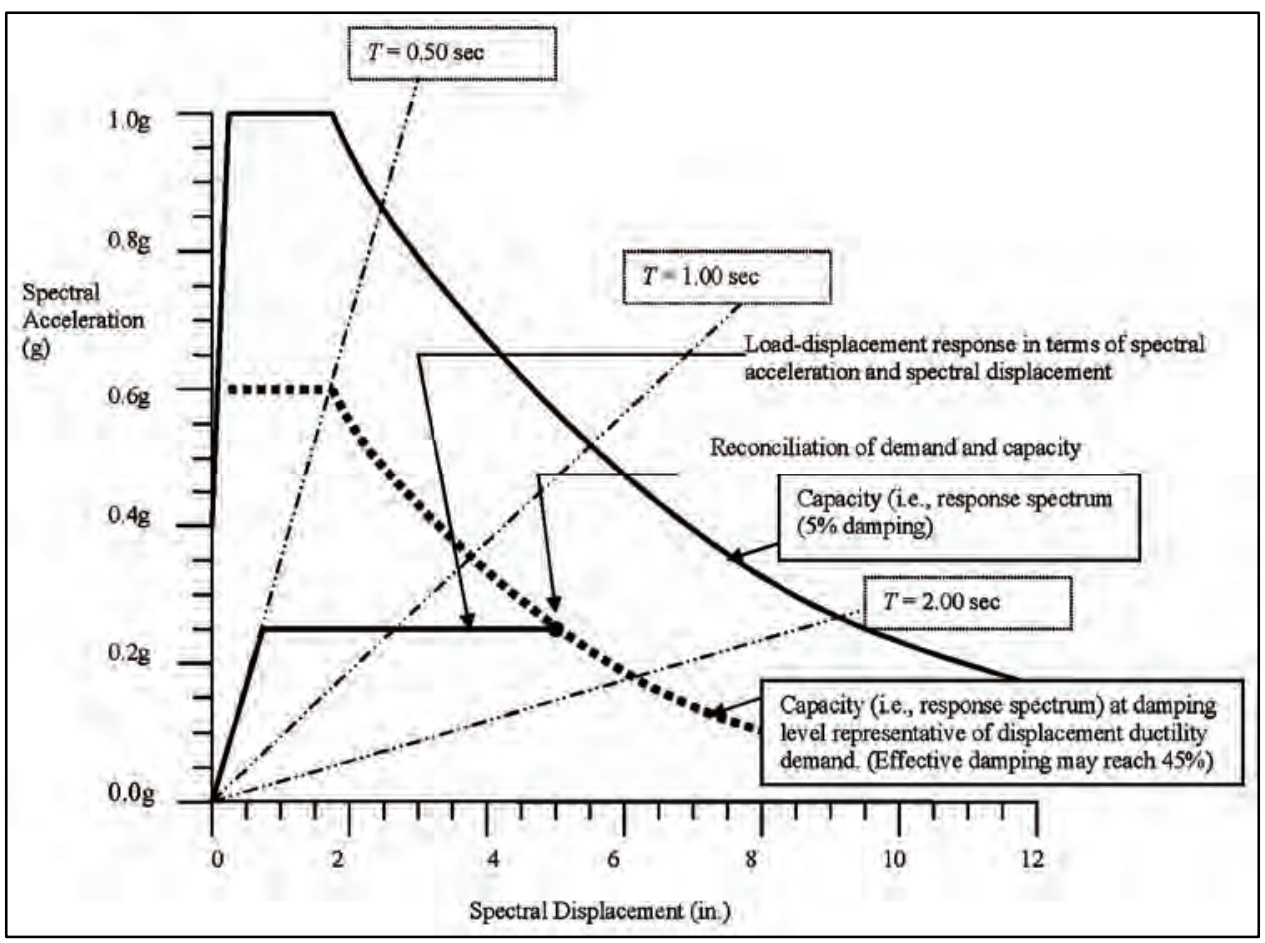

Figure 4.8 CSM analysis curve

\subsection{Evaluating Performance of Retaining Wall Systems}

The focuses of this report are the earth-retaining L-walls and T-walls that border spillway channels, outlet works channels, and other flood-control discharge channels. It is anticipated these structures will be founded on and backfilled with competent materials and that these materials will not be susceptible to liquefaction. As such it is assumed that if the wall displacements due to sliding, rotation, or stem wall yielding are kept within acceptable limits, settlements in the retained soil will also be within acceptable limits. What is considered to be an acceptable limit with respect to the horizontal displacement at the top of a spillway, outlet works, or flood-control channel retaining wall is a matter of judgment and highly dependent on project post-earthquake operational requirements. It is anticipated that on most Corps projects any earthquake damage to retaining walls will be repairable, and that repairs can be made in time to meet flood discharge and other flood routing operational requirements. For these projects it is necessary only to assure that potential earthquake-induced force and displacement demands will not lead to a collapse mechanism that could result in loss of life. In special circumstances on power projects or flood-control projects with a conservation pool, it may be necessary to expeditiously draft the pool following a major earthquake. For instance, the reason for this may be to protect against the postearthquake failure of an embankment dam damaged by the earthquake. In such a case earthquake-induced displacement demands on the retaining walls could create abrupt offsets in the outlet channel. These offsets could lead to cavitation damage, or otherwise limit the ability to draft the pool in a timely manner. 


\subsubsection{Capacity to demand evaluation for force-controlled actions}

All potential brittle failure mechanisms (i.e., force-controlled actions) should be examined to assure that their force capacity is equal to or greater than the force demands generated by the MDE. This process is demonstrated in Appendix F.

\subsubsection{Displacement-based evaluations}

Displacement demands on retaining wall systems resulting from an MDE event should be evaluated to assure that they will not create a collapse mechanism or otherwise impair the post-earthquake ability of the project to draft the pool or meet other flood routing requirements. Displacement demands due to possible sliding, rotation, and stem wall yielding should all be considered. Sliding and rotational demands can be estimated using CWRotate (Ebeling and White, in preparation). Enhancements to CWRotate are proposed herein to provide a means for estimating the upper bound residual (permanent) displacement that may develop as a result of stem wall yielding. A process that may be useful in estimating this upper bound permanent displacement is illustrated in Appendix F. 


\section{Summary, Conclusions, and Recommendations}

\subsection{Summary}

There is much yet to be learned regarding the external and internal response of earth retaining structures to earthquake ground motions. The two external responses are sliding and rotation. A time-history evaluation of these responses can be performed using CWRotate (Ebeling and White, in preparation). In addition to the two external responses, an internal response involving flexural yielding at the base of the stem wall is possible. Once any one of these three responses occurs, it is presumed that the other two responses will be suppressed. This report is directed toward the force-based and displacement-based evaluation of a response dominated by yielding at the base of the stem wall. This is the region where plastic hinging is most likely to develop during major earthquake events. The external sliding and rotational responses are the subject of Ebeling and White (in preparation).

This report first covered the general behavior of structures and structural systems to earthquake ground motions, and then described a few simple procedures often used for evaluating the performance of structures such as buildings and bridges, i.e., systems not subject to soil-structure interaction.

The seismic evaluation of earth retaining wall structures is much more complex due to soil-structure interaction effects. The Mononobe-Okabe equation is considered the standard for design and evaluation of retaining structures subject to earthquake ground motions and active limit-state conditions. This simple pseudostatic procedure is described in Ebeling and Morrison (1992) and Seed and Whitman (1970). A flexible cantilever wall procedure described in Veletsos and Younan (1997) is of special interest because it provides a methodology for assessing displacement demands on retaining wall systems dominated by a stem wall yielding response. Both the pseudostatic procedure and the flexible cantilever wall procedure are discussed in the report and illustrated in the examples contained in the appendices.

For retaining wall systems dominated by stem wall yielding it is necessary first to determine if there are any brittle failure mechanisms that can lead to collapse of the retaining wall during the design earthquake event. This process is described in the report and illustrated in the appendices. Brittle failure 
mechanisms are evaluated by comparing the force demands due to static earth and dynamic earth pressures on various retaining wall components (i.e., footing and stem wall) with the capacity of those components. Earth pressure demands can be based on active limit-state conditions and the Mononobe-Okabe equation approach as modified by Seed and Whitman (1970). It is anticipated earth pressure demands will be determined using CWRotate since it could provide these force-based demands whether the retaining wall is dominated by a sliding response, rotational response, or stem wall yielding response. Assuming brittle failure mechanisms and collapse of the retaining wall are prevented, it then becomes necessary to determine if residual displacements due to sliding, rotation, or stem wall yielding might jeopardize post-earthquake project operations.

CWRotate provides permanent displacement demands for responses dominated by either sliding or rotation. Enhancements to CWRotate are recommended so it will also provide estimates of permanent displacements for a response dominated by stem wall yielding. One possible approach is described in Appendix F.

\subsection{Conclusions}

Reinforced concrete retaining wall structures are first sized and designed for static earth pressure conditions. The margin of safety against a lateral load failure provides significant reserve capacity to resist earthquake loadings. The margin of safety is greater for Corps-designed retaining walls than for walls designed for typical use in building and highway construction. It is anticipated that because of their reserve lateral load capacity, almost all retaining walls in low or moderate earthquake hazard zones and most Corps retaining walls in even moderate to high earthquake hazard zones should perform reliably without experiencing a brittle failure. The possible exception is older walls that have deteriorated with time or older walls that have reinforcing steel with inadequate splice and development lengths. Methods applicable to the design of Corps retaining walls (past and present) are described and illustrated in the report and appendices. Force-based demands can be obtained from a CWRotate analysis. Permanent displacements required for a performance-based analysis can also be obtained from CWRotate for responses dominated by either sliding or rotation. Enhancements are needed to provide displacement demands for a response dominated by stem wall yielding.

\subsection{Recommendations}

Specific seismic evaluation methodologies are described and demonstrated in the report. Forces (i.e., moments and shears) to be obtained from CWRotate are recommended for use in evaluating brittle failure mechanisms associated with responses dominated by either sliding or rotation. The Mononobe-Okabe equation approach as given in Ebeling and Morrison (1992) to determine the value for $P_{A E}$ with its point of application determined using the approach proposed by Seed and Whitman (1970) is the force-based methodology recommended for use in the evaluation of brittle failure mechanisms associated with a response dominated by stem wall yielding. This too should be made a part of a CWRotate analysis. Displacement-based methodologies recommended for use in the performance 
evaluation of responses dominated by sliding or rotation are those described in Ebeling and White (in preparation) and contained in CWRotate. The displacement demands associated with a response dominated by stem wall yielding are in need of further research and development. A proposed residual displacement approach is described in the report and illustrated in Appendix F. This approach is based on the flexible wall model proposed by Veletsos and Younan (1997).

Some aspects of this approach need further development with the final methodology verified using other stress-deformation methods and experimental testing. Although some aspects of this formulation are speculative, the authors of this report believe that the approach described contains the essential fundamental features to characterize the response.

Earthquake damage can be tolerated if displacement demands are within the displacement capacity of the structural system and certain brittle (nonductile) modes of failure are prevented. This is the premise of the performance-based earthquake engineering approach presented in this report. The displacement capacities for walls with adequate reinforcing steel lap and development lengths appear to be sufficient to resist residual displacement demands associated with major earthquake events and a response dominated by stem wall yielding. However, older walls with insufficient lap and development lengths may be susceptible to failure during a major earthquake event. Walls with a "weak bond" condition due to the deficiencies cited are also in need of further research. This research should be directed toward developing a methodology for reliably estimating their displacement capacity. 


\section{References}

American Concrete Institute. (2002). "Building code requirements for reinforced concrete," ACI 318, Detroit, MI.

ACI Committee 224 Report. (1980). "Control of cracking in concrete structures,"Concrete International, 35-76.

ACI Committee 350 Report. (2003). "Environmental engineering concrete structures," American Concrete Institute, Detroit, MI.

American Concrete Institute. (1965). "Reinforced concrete design handbook Working stress method," ACI-SP3, Detroit, MI.

American Society of Civil Engineers. (1998). "Minimum design loads for buildings and other structures," ASCE 7-98, Reston, VA, 337 pp.

Applied Technology Council. (1996). "Seismic evaluation and retrofit of concrete buildings," ATC-40, Redwood City, CA.

Chopra, A. K., and Goel, R. G. (2000). "Evaluation of NSP to estimate seismic deformation: SDF Systems," ASCE Journal of Structural Engineering, April 2000, 483-490.

Clough, G. W., and Duncan, J. M. (1991). "Earth pressures.” Foundation Engineering Handbook. H. Y. Fang, ed., Van Nostrand Reinhold, New York.

Concrete Reinforcing Steel Institute. (2001). "Evaluation of reinforcing bars in old reinforced concrete structures," Engineering Data Report Number 48, Schaumberg, IL.

Cornell, A. C. (1969). "A probability-based structural code," ACI Journal, December, 1969, 974-985.

Dove, R. C. (1998). "Performance of lightly reinforced concrete intake towers under selected loadings," Technical Report SL-98-1, U.S. Army Engineer Waterways Experiment Station, Vicksburg, MS.

Dove, R. C. (2000). "Ultimate deflection response of lightly reinforced concrete intake towers," Report EDRC/SL TR-00-6, U.S. Army Engineer Research and Development Center, Vicksburg, MS. 
Ebeling, R. M. (1992). "Introduction to the computation of response spectrum for earthquake loading," Technical Report ITL-92-4, U.S. Army Engineer Waterways Experiment Station, Vicksburg, MS.

Ebeling, R. M., and Morrison, E. E. (1992). "The seismic design of waterfront structures," Technical Report ITL-92-11, U.S. Army Engineer Waterways Experiment Station, Vicksburg, MS.

Ebeling, R. M., and White, B. C. "The rotational or sliding response to earthquake ground motions of toe-restrained walls retaining moist backfills" (in preparation), U.S. Army Engineer Research and Development Center, Vicksburg, MS.

Ebeling, R. M., Green, R. A., and French, S. E. (1997). "Accuracy of response of single-degree-of-freedom systems to ground motions," Technical Report ITL-97-7, U.S. Army Engineer Waterways Experiment Station, Vicksburg, MS.

Federal Emergency Management Agency. (2000). "Prestandard and commentary for the seismic rehabilitation of buildings," FEMA 356, Washington, DC.

Fenves, G., and Chopra, A. K. (1986). "Simplified analysis for earthquake resistant design of concrete gravity dams," UCB/EERC-85-10, University of California, Earthquake Engineering Research Center, Berkeley, CA.

Ferguson, P. M. (1960). Reinforced concrete fundamentals. Second Printing, John Wiley and Sons, New York.

Ferguson, P. M. (1973). Reinforced concrete fundamentals. Third Edition, John Wiley and Sons, New York.

French, S. E., Ebeling, R. M., and Strom, R. (1994). "Dynamics of intake towers and other MDOF structures under earthquake loads," Report ITL-94-4, U.S. Army Engineer Waterways Experiment Station, Vicksburg, MS.

Green, R. A., and Ebeling, R. M. (2002). "Seismic analysis of cantilever retaining walls, Phase 1," EDRC/ITL TR-02-3, U.S. Army Engineer Research and Development Center, Vicksburg, MS.

Headquarters, U.S. Army Corps of Engineers. (1989). "Retaining and flood walls," EM 1110-2-2502, Washington, DC.

Headquarters, U.S. Army Corps of Engineers. (1995). "Earthquake design and evaluation for civil works projects," ER 1110-2-1806, Washington, DC.

Headquarters, U.S. Army Corps of Engineers. (1999). "Response spectra and seismic analysis for concrete hydraulic structures," EM 1110-2-6050, Washington, DC.

Headquarters, U.S. Army Corps of Engineers. (2003a(30 Nov)). "Stability analysis of concrete structures," EC 1110-2-6058, Washington, DC. 
Headquarters, U.S. Army Corps of Engineers. (2003b). "Strength design for reinforced-concrete hydraulic structures," EM 1110-2-2104, Washington, DC.

Headquarters, U.S. Army Corps of Engineers. (2003c). "Structural design and evaluation of outlet works," EM 1110-2-2400, Washington, DC.

Headquarters, U.S. Army Corps of Engineers. (2003d). "Time-history dynamic analysis of concrete hydraulic structures," EM 1110-2-6051, Washington, DC.

Idriss, I. M., and Sun, J. I. (1992). "User's manual for SHAKE 91, A computer program for conducting equivalent linear seismic response of horizontally layered soil deposits, as modified from the original SHAKE program by Schnabel et al., 1972," Department of Civil and Environmental Engineering, University of California, Davis, CA.

Kawashima, K., MacRae, G. A., Hoshikuma, J., and Nagaya, K. (1998). "Residual displacement response spectrum," ASCE Journal of Structural Engineering, 124, 523-530.

Klein, F., Hoffman, E. S., and Rice, P. F. (1981). "Application of strength design methods to sanitary structures," Concrete International, April 1981, 35-40.

Liu, T. C., and Gleason, S. (1981). "Strength design of reinforced concrete structures," Technical Report SL-80-04, U.S. Army Engineer Waterways Experiment Station, Vicksburg, MS.

Loov, R. E. (1991). "Reinforced concrete at the turn of the century," Concrete International, December 1991, 67-73.

Mathsoft Engineering and Education, Inc. (1998). "Mathcad 8," Cambridge, MA.

MacGregor, J. G. (1983). "Load and resistance factors for concrete design," ACI Journal, July-August, 1983, 279-287.

Moehle, J. P. (1992). "Displacement-based design of RC structures subjected to earthquakes," Earthquake Spectra 8(3), 403-428.

Monti, G., and Spacone, E. (2000). "Reinforced concrete fiber beam element with bond-slip," ASCE Journal of Structural Engineering 126, 654-661.

Newmark, N. M. (1965). "Effects of earthquakes on dams and embankments," Geotehnique 15(2), 139-160.

Newmark, N. M., and Hall, W. J. (1982). "Earthquake spectra and design," Engineering Monographs on Earthquake Criteria, Structural Design, and Strong Motion Records, Vol 3, Earthquake Engineering Research Institute, Berkeley, CA.

Paulay, T., and Priestley, M. J. N. (1992). Seismic design of reinforced concrete and masonry buildings. John Wiley, New York. 
Priestley, M. J. N., and Park, R. (1987). "Strength and ductility of concrete bridge columns under seismic loading," ACI Structural Journal, JanuaryFebruary 1987.

Priestley, M. J. N., Verma, R., and Xaio, Y. (1994). "Seismic shear strength of reinforced concrete columns," ASCE Journal of Structural Engineering 120(8).

Richards, R., and Elms, D. G. (1977). "Seismic behaviour of retaining walls and bridge abutments," Report 77-10, Department of Civil Engineering, University of Canterbury, Christchurch, New Zealand.

Schnabel, P. B., Lysmer, J., and Seed, H. B. (1972). "SHAKE: A computer program for earthquake response of horizontally layered sites," Report No. EERC/72-12, Earthquake Engineering Research Center, University of California, Berkeley, CA, 88 pp.

Seed, H. B., and Whitman, R. V. (1970). "Design of earth retaining structures for dynamic loads." Proceedings of Specialty Conference on Lateral Stresses in the Ground and the Design of Earth Retaining Structures. American Society of Civil Engineers, New York, 103-147.

Steedman, R. S., and Zeng, X. (1998) "Rotation of large gravity walls on rigid foundations under seismic loading," ASCE Geotechnical Publication No. 60, American Society of Civil Engineers, New York.

Strom, R. W., and Ebeling, R. M. (2004). "Simple methods used to estimate the limit-state axial load capacity of spillway invert slabs," ERDC/ITL TR-04-3, U.S. Army Engineer Research and Development Center, Vicksburg, MS.

U.S. Army. (1986 (27 February)). "Seismic design guidelines for essential buildings,"Army Technical Manual TM 5-809-10-1.

Veletsos, A. S., and Newmark, N. M. (1960). "Effect of inelastic behavior on the response of simple systems to earthquake motions." Proceedings, Second World Conference on Earthquake Engineering, Japan. 2, 895-912.

Veletsos, A. S., and Younan, A. H. (1997). "Dynamic response of cantilever retaining walls," ASCE Journal of Geotechnical and Geoenvironmental Engineering, February 1997.

Verma, R., and Priestley, M. J. N. (1994). "Optimal trends in seismic design of single column reinforced concrete bridge piers," Earthquake Spectra 10(3), 589-614.

Whitman, R. V. (1990). "Seismic design and behavior of gravity retaining walls." Design and performance of earth retaining structures, Proceedings, 1990 Specialty Conference on Design and Performance of Earth Retaining Structures, Ithaca, NY, June 18-21, 1990. Geotechnical Special Publication No. 25, Philip Lambe and Lawrence A. Hansen, ed., Geotechnical Engineering Division, American Society of Civil Engineers, Reston, VA. 
Whitman, R. V., and Liao, S. (1985). "Seismic design of retaining walls," Miscellaneous Paper GL-85-1, U.S. Army Engineer Waterways Experiment Station, Vicksburg, MS.

Whittaker, A., Constantinou, M., and Tsopelas, P. (1998). "Displacement estimates for performance-based seismic design," Journal of Structural Engineering, American Society of Civil Engineers, August 1998.

Wilson, E. L., and Habibullah, A. (1990). "SAP90-A series of computer programs for the finite element analysis of structures," Computers and Structures, Inc., Berkley, CA.

Wood, J. (1973). "Earthquake-induced soil pressures on structures," Report No. EERL 73-05, California Institute of Technology, Pasadena, CA, 311 pp.

Zeng, X., and Steedman, R. S. (2000). "Rotating block method for seismic displacement of gravity walls," Journal of Geotechnical and Geoenvironmental Engineering, August 2000, 709 -716.

Zhang, L., and Chopra, A. K. (1991). "Base sliding response of concrete dams to earthquakes," Report No. UCB/EERC-91/04, University of California at Berkley. 


\section{Appendix A}

Historical Perspective - Corps Reinforced Concrete Design Methodologies

\section{A.1 Reinforced Concrete Design}

Many Corps projects date back to the early 1900's. Therefore, it is important that engineers evaluating the seismic vulnerability of these older structures understand aspects related to the following:

- Concrete and reinforcing steel material properties used in their design.

- Codes and guidance governing their design.

\section{A.2 Material Properties}

The year in which a Corps project was constructed will have significant influence on how it will perform when subjected to earthquake ground motions. Historical information on material properties valuable in assessing seismic performance is provided in Chapter 6 of Federal Emergency Management Agency (FEMA) 356 (2000). ${ }^{1}$ Default strength and yield properties from FEMA 356 (2000) that are useful in the preliminary seismic assessment of older Corps structures are presented in the tables in this appendix. Additional information may be available on the contract drawings or in the contract specifications. In many instances, sampling and testing will be required to confirm that strengths are the same as those originally assumed for preliminary seismic evaluations.

\section{A.2.1 Reinforcing steel}

In the early 1900's the reinforcing steel could consist of plain round bars, twisted square bars, or round and square bars with "low bond" deformations.

\footnotetext{
${ }^{1}$ References cited in this appendix are included in the References section at the end of the main text.
} 
Many of these early bars were patented or part of patented reinforcing systems (Loov 1991). The term low bond is used to distinguish these bars from the "high bond" deformation type reinforcing steel that became common in 1947 and basically unchanged to the present day (Concrete Reinforcing Steel Institute 2001). Information useful to the evaluation of older reinforced concrete structures, in addition to FEMA 356 (2000), can be found in Concrete Reinforcing Steel Institute (2001). Use of this information with respect to evaluating the seismic performance of older structures is discussed in Appendix B. Table A.1 provides tensile and yield properties of reinforcing bars for various years. Table A.2 provides tensile and yield properties of reinforcing bars for various American Society for Testing and Materials (ASTM) designations.

\begin{tabular}{|c|c|c|c|c|c|c|c|}
\hline \multicolumn{8}{|c|}{$\begin{array}{l}\text { Table A.1 } \\
\text { Default Lower-Bound Tensile and Yield Properties of Reinforcing Bars for Various } \\
\text { Periods }{ }^{1} \text { (after Table 6-1, FEMA } 356(2000) \text { ) }\end{array}$} \\
\hline \multirow[b]{4}{*}{ Year } & \multirow[b]{2}{*}{ Grade } & Structural $^{2}$ & Intermediate $^{2}$ & Hard $^{2}$ & \multirow[b]{2}{*}{60} & \multirow[b]{2}{*}{70} & \multirow[b]{2}{*}{75} \\
\hline & & 33 & 40 & 50 & & & \\
\hline & Minimum Yield, psi & 33,000 & 40,000 & 50,000 & 60,000 & 70,000 & 75,000 \\
\hline & Maximum Yield, psi & 55,000 & 70,000 & 80,000 & 90,000 & 95,000 & 100,000 \\
\hline 1911-1959 & & $x$ & $\mathrm{x}$ & 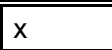 & & & \\
\hline 1959-1966 & & $x$ & $x$ & $x$ & $x$ & & $x$ \\
\hline 1966-1972 & & & $x$ & $x$ & $x$ & & \\
\hline 1974-1987 & & & $x$ & $x$ & $x$ & $x$ & \\
\hline 1987-Present & & & $x$ & $x$ & $x$ & $x$ & $x$ \\
\hline
\end{tabular}

\section{A.2.2 Concrete}

Concrete properties and strength are also dependent on the time frame in which construction occurred. Many older structures are not air entrained and therefore may have suffered freeze-thaw deterioration. A condition assessment is always an important part of any seismic evaluation. Table A.3 provides lowerbound compressive strengths for structural concrete for various time periods.

\section{A.2.3 Probable versus lower-bound strength}

The probable strength of materials used in construction is generally greater than the lower-bound strength values used for design. FEMA 356 (2000) provides information to relate expected strengths of concrete and reinforcing steel to their lower-bound design basis values. This information is provided in Table A.4. 


\begin{tabular}{|c|c|c|c|c|c|c|c|c|c|}
\hline \multicolumn{10}{|c|}{$\begin{array}{l}\text { Table A.2 } \\
\text { Default Lower-Bound Tensile and Yield Properties of Reinforcing Bars for ASTM } \\
\text { Specifications and Periods }{ }^{1} \text { (after Table 6-2, FEMA } 356(2000) \text { ) }\end{array}$} \\
\hline \multirow[b]{4}{*}{$\begin{array}{l}\text { ASTM } \\
\text { Desig. }^{3}\end{array}$} & \multirow[b]{4}{*}{ Steel Type } & \multirow[b]{4}{*}{ Year Range } & \multirow[b]{2}{*}{ ASTM Grade } & \begin{tabular}{|l} 
Structural $^{2}$ \\
\end{tabular} & Intermediate $^{2}$ & Hard $^{2}$ & \multirow[b]{2}{*}{60} & \multirow[b]{2}{*}{70} & \multirow[b]{2}{*}{75} \\
\hline & & & & 33 & 40 & 50 & & & \\
\hline & & & \multirow{2}{*}{\begin{tabular}{|l|} 
Minimum \\
Yield, psi \\
Maximum \\
Yield, psi
\end{tabular}} & \multirow{2}{*}{\begin{tabular}{|l}
33,000 \\
55,000
\end{tabular}} & \multirow{2}{*}{\begin{tabular}{|l}
40,000 \\
70,000
\end{tabular}} & 50,000 & \multirow[b]{2}{*}{90,000} & \multirow[b]{2}{*}{95,000} & \multirow[b]{2}{*}{100,000} \\
\hline & & & & & & 80,000 & & & \\
\hline A15 & Billet & \begin{tabular}{|l|}
$1911-1966$ \\
\end{tabular} & & $\bar{x}$ & $\bar{x}$ & ex & & & \\
\hline A16 & Rail $^{4}$ & \begin{tabular}{|l|}
$1913-1966$ \\
\end{tabular} & & & & $\bar{x}$ & & & \\
\hline A61 & Rail $^{4}$ & 1963-1966 & & & & & $x$ & & \\
\hline A160 & Axle & 1936-1964 & & $x$ & $x$ & $x$ & & & \\
\hline A160 & Axle & $1965-1966$ & & $x$ & $x$ & $x$ & $x$ & & \\
\hline A408 & Billet & 1957-1966 & & $x$ & $x$ & $x$ & & & \\
\hline A431 & Billet & 1959-1966 & & & & & & & $x$ \\
\hline A432 & Billet & \begin{tabular}{|l|}
$1959-1966$ \\
\end{tabular} & & & & & $x$ & & \\
\hline A615 & Billet & 1968-1972 & & & $x$ & & $x$ & & $x$ \\
\hline A615 & Billet & \begin{tabular}{|l|}
$1974-1986$ \\
\end{tabular} & & & $\bar{x}$ & & $\bar{x}$ & & \\
\hline A615 & Billet & 1987-1997 & & & $x$ & & $x$ & & $x$ \\
\hline A616 ${ }^{5}$ & Rail $^{4}$ & 1968-1997 & & & & $\mathrm{x}$ & $x$ & & \\
\hline A617 & Axle & 1968-1997 & & & $x$ & & $x$ & & \\
\hline A706 & Low-Alloy & 1974-1997 & & & & & & $\mathrm{x}$ & \\
\hline A955 & Stainless & 1996-1997 & & & $x$ & & $x$ & & $x$ \\
\hline $\begin{array}{l}\text { 1. } x=g r \\
\text { 2. The te } \\
\text { 3. ASTM } \\
\text { 4. Rail } B \\
\text { 5. Bars } r\end{array}$ & $\begin{array}{l}\text { was availab } \\
\text { structural, i } \\
\text { el is marked } \\
\text { are marked } \\
\text { ked "s" (AST }\end{array}$ & $\begin{array}{l}\text { in those yea } \\
\text { itermediate an } \\
\text { with the letter } \\
\text { vith the letter" } \\
\text { 1 616) have st }\end{array}$ & $\begin{array}{l}\text { S. } \\
\text { d hard became } \\
\text { "W." } \\
\text { R." } \\
\text { upplementary re }\end{array}$ & $\begin{array}{l}\text { solete in } 1968 \\
\text { irements for } b\end{array}$ & nd tests. & & & & \\
\hline
\end{tabular}

\section{Table A.3}

Default Lower-Bound Compressive Strength of Structural Concrete (psi) (after Table 6-3, FEMA 356 (2000))

\begin{tabular}{||l|l|l|l|l|l||}
\hline \hline Time Frame & Footings & Beams & Slabs & Columns & Walls \\
\hline \hline $1900-1919$ & $1000-2500$ & $2000-3000$ & $1500-3000$ & $1500-3000$ & $1000-2500$ \\
\hline $1920-1949$ & $1500-3000$ & $2000-3000$ & $2000-3000$ & $2000-3000$ & $2000-3000$ \\
\hline $1950-1969$ & $2500-3000$ & $3000-4000$ & $3000-4000$ & $3000-4000$ & $2500-4000$ \\
\hline $1970-$ Present & $3000-4000$ & $3000-5000$ & $3000-5000$ & $3000-10000$ & $3000-5000$ \\
\hline
\end{tabular}

\begin{tabular}{|l|l||}
\hline Table A.4 \\
Factors to Translate Lower-Bound Material Properties to Expected \\
Strength Material Properties (after Table 6-4, FEMA 356 (2000)) \\
\hline \hline Material Property & Factor \\
\hline \hline Concrete compressive strength & 1.50 \\
\hline Reinforcing steel tensile and yield strength & 1.25 \\
\hline Connector steel yield strength & 1.50 \\
\hline
\end{tabular}




\section{A.3 Reinforced Concrete Design Codes and Corps Guidance}

The safety provisions contained in the various American Concrete Institute (ACI) building design codes and Corps guidance are in part based on the following:

- Testing of the strength and other physical properties of concrete and reinforcing steel.

- Testing of structural members and systems.

- Past failures and lessons learned.

- Sound engineering judgment.

Although the probability of failure can be determined with respect to given members under well-defined loading parameters, it is not practical to assign a probability of failure to a given structure designed and constructed to code requirements because of the following factors (Cornell 1969):

- Difficulties in correlating lab strength with in-place strengths.

- Local, long-term, and nonlinear stress distributions.

- Assumed loads and load distributions versus actual loads and load distributions.

- Combined moment, shear, and torsion effects.

Establishing a probability of failure becomes even more difficult when soilstructure interaction occurs. However, with all the problems involved in establishing a probability of failure, or other stated performance objective, the use of probability theory and analysis has become the basis for establishing the load and resistance factors common to the modern-day ACI ultimate strength design (USD) code. Up-to-date code and guidance requirements are used to evaluate the performance of existing structures when subjected to earthquake ground motions. The probabilistic basis for this guidance is discussed in Section A.3.5. First, however, a brief history of design guidance, past to present, is provided to give evaluators a general understanding of the type of methodologies used for the design of older structures. A methodology used for the design of an older retaining wall structure is illustrated in Appendix D. The resulting design is compared to a design performed under current Corps guidance. Potential deficiencies in older designs are discussed in Appendix B.

\section{A.3.1 Design of Corps reinforced concrete hydraulic structures}

Over the years Corps practice in the design of reinforced concrete hydraulic structures, with some notable exceptions, followed the guidance contained in 
"Building Code Requirements for Reinforced Concrete" (ACI 2002). This is a code that is continually updated by the ACI 318 Committee. Therefore, Corps design requirements changed as required to keep pace with changes in the ACI Code. The most notable changes occurred with the shift from a working-stress design (WSD) based code to an ultimate strength-based design (USD) code. Other major changes occurred over the years with respect to many of the ACI code design provisions, including the following:

- Flexural capacity.

- Shear capacity.

- Anchorage, development, and lap splice lengths.

- Combined bending and axial load.

- Load and resistance factors for USD.

The Corps requirements for reinforced concrete hydraulic structures used the ACI code as the basis for design but imposed additional, more stringent requirements to assure serviceability under the severe environmental conditions associated with water containment, water pressure, and high-velocity water flow.

A.3.1.1 Working stress design for Corps hydraulic structures. Workingstress design was used within the Corps until the early 1970s. During the WSD years the Corps required the maximum allowable compressive stress in the concrete to be 35 percent of the specified compressive strength $\left(0.35 f_{c}^{\prime}\right)$. The ACI-WSD code recommended a value equal to 45 percent of the specified compressive strength $\left(0.45 f_{c}^{\prime}\right)$. Corps working stress design requirements were specified in EM 1110-1-2101, "Working Stresses for Structural Design." Listed as hydraulic structures in this EM were the following:

- Stilling basin slabs and walls.

- Concrete-lined channels.

- Exterior portions of powerhouses.

- Spillway piers.

- Spray walls and training walls.

- Flood walls.

- Intake and outlet structures below maximum high water and wave action.

- Lock walls and guide and guard walls.

- Retaining walls subject to contact with water.

Allowable stresses in the reinforcement were to be in accordance with the ACI Building Code except the allowable tension in deformed bars with a yield strength of 60,000 psi or more was not to exceed 20,000 psi. Illustrated in

\footnotetext{
${ }^{1}$ Working stress design guidance discussed in this section is taken from the 1963 version of EM 1110-1-2101, a Corps document that is no longer in publication.
} 
Appendix D is a working stress design for a retaining wall. Table A.5 contains typical allowable stress design information applicable to hydraulic structures.

\begin{tabular}{|l|l||}
\hline $\begin{array}{l}\text { Table A.5 } \\
\text { Typical Allowable Unit Stresses for Concrete (WSD) }\end{array}$ \\
\hline \hline Description & Allowable Unit Stress \\
\hline \hline Flexure - extreme fiber in compression $\left(\mathrm{f}_{\mathrm{c}}\right)$ & $0.35 f_{c}^{\prime}$ \\
\hline Shear as a measure of diagonal tension $\left(v_{\mathrm{c}}\right)$ & $0.03 f_{c}$ \\
\hline Bond $(\mu)$ & $0.10 f_{c}$ \\
\hline Bond - Top Bars $(\mu)$ & $0.07 f_{c}$ \\
\hline
\end{tabular}

Flexure is used to illustrate the WSD approach. A flexural analysis is performed herein for the retaining wall in Appendix D. The wall in Appendix D was designed using WSD methods. This is done to provide evaluators with the terminology and methodology used in the design of older Corps hydraulic structures. The following assumptions are used in a working stress design or analysis for flexure:

- Plane section before bending remains plane after bending (i.e., strains vary linearly across the depth of the section).

- Stresses are proportional to strain.

- Tensile strength of the concrete is neglected.

- Strain is transferred through bond in the cracked section (i.e., the stress in the equivalent transformed section is $f_{s} \div n$, where $n$ is the modular ratio of steel to concrete).

- $\quad$ Equilibrium must be satisfied (i.e., $\Sigma \mathrm{F}=0, \Sigma \mathrm{M}=0$ )

These assumptions are applied to the analysis of the Appendix D retaining wall stem where it intersects with the base slab (Figure A.1).

A.3.1.2 WSD analysis computations. Determine neutral axis location by taking moments of areas about the centroidal axis of the cracked section. ${ }^{1}$

$$
\begin{aligned}
& b(k d)\left(\frac{k d}{2}\right)=n A_{S}(d-k d) \\
& 6 k^{2}(15.5)^{2}=9.2(1.58)(15.5-15.5 k) \\
& 1441.5 k^{2}+225.3 k-225.3=0
\end{aligned}
$$

\footnotetext{
${ }^{1}$ Each of the appendixes in this report has its own system of notation. Many of the symbols used in this appendix are defined in the text of this appendix. Others are commonplace to reinforced concrete design and retaining wall design. Readers not understanding a particular symbol notation should consult the references cited in this appendix for the definition.
} 


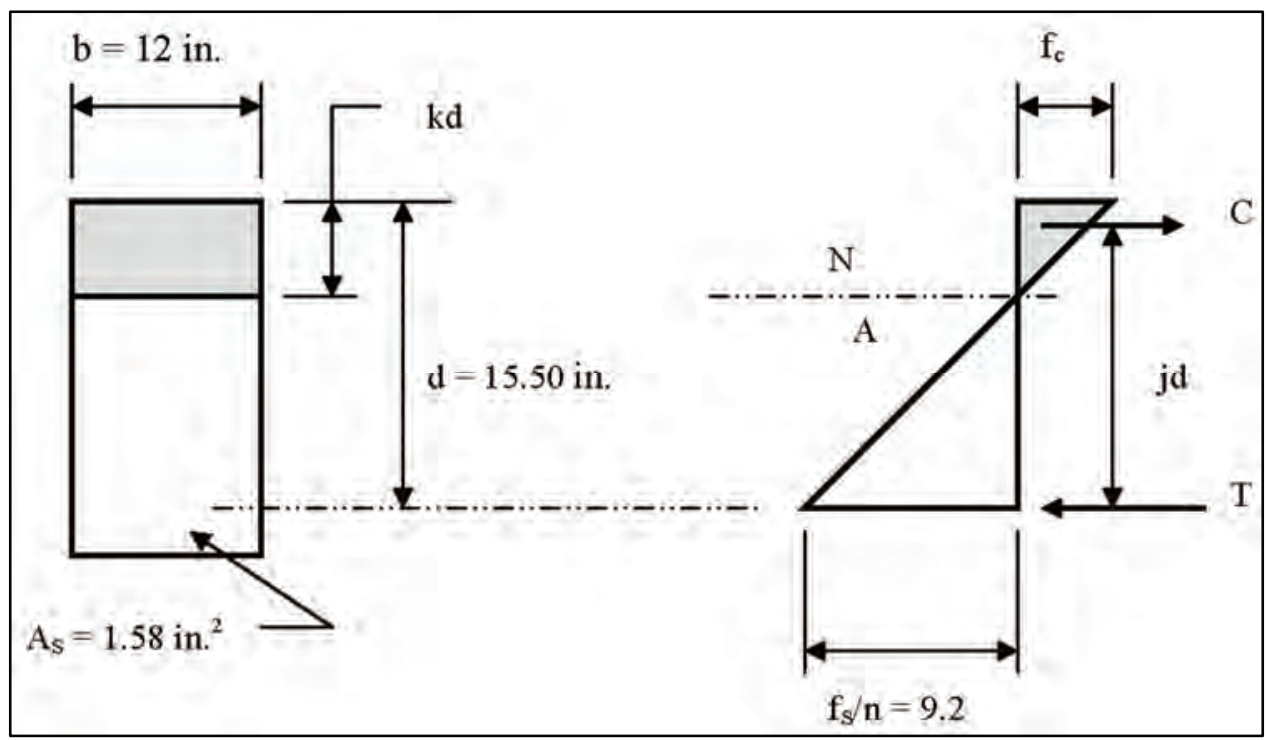

Figure A.1 WSD analysis of Appendix D stem wall

$$
\begin{aligned}
& k=\frac{-225.3 \pm \sqrt{(225.3)^{2}-4(1441.5)(225.3)}}{2(1441.5)}=0.31 \\
& j d=d-\frac{k d}{3}=15.5-\frac{0.31(15.5)}{3}=13.4 \text { in. } \quad \mathrm{j}=0.865
\end{aligned}
$$

Moment of tensile force about $\mathrm{C}$

$M_{T}=A_{S} f_{S} j d=1.58(20,000)(13.4)=423,440$ in. $-\mathrm{lb}=35.28 \mathrm{ft}-\mathrm{kips} \leftarrow$ Governs

Moment of compressive force about $\mathrm{T}$

$M_{C}=0.5 f_{c} k j b d^{2}=0.5(1350)(0.31)(0.865)(12)(15.5)^{2}=521,827$ in. $-1 \mathrm{~b}=$ $43.49 \mathrm{ft}-$ kips

The allowable stress requirement for the reinforcing steel controls the allowable service load moment, and therefore the allowable service load moment by WSD is equal to $35.28 \mathrm{ft}$-kips.

A.3.1.3 Ultimate strength design (USD) for Corps hydraulic structures. In the early 1970's the Corps switched from WSD to USD. The initial guidance followed the ACI Building Code (ACI 2002), except additional, more stringent requirements were imposed to assure the resulting USD, for reasons of serviceability, provided results matching those that would be obtained by the old WSD. 
This guidance was presented in EM 1110-2-2103. ${ }^{1}$ EM 1110-2-2103 included several provisions intended to produce designs similar to the old WSD method. Higher load factors were used. For instance the Corps usual loading condition for dead $D+$ live $L$ load had the following ultimate strength requirement $U$ :

$$
U=1.5 D+1.9 L
$$

where the ACI Building Code required that

$$
U=1.4 D+1.7 L
$$

In addition to higher load factors, EM 1110-2-2103 required that USD be based on yield strengths of 40,000 psi and 48,000 psi for ASTM Grade 40 and 60 steels, respectively. The ACI Building Code permitted a yield strength of 60,000 psi for ASTM Grade 60 steel. Design aids for the Corps USD methods were presented in Liu and Gleason (1981).

EM 1110-2-2104 (Headquarters, U.S. Army Corps of Engineers (HQUSACE) 2003b) was issued in 1992. It contains the current Corps USD guidance. The EM 1110-2-2104 guidance follows recommendations in the ACI Committee 350 Report, first titled "Sanitary Engineering Concrete Structures," but now titled "Environmental Engineering Concrete Structures" (ACI Committee 350 2003). In order to assure a durable watertight structure the ACI Committee 350 utilized an additional sanitary durability coefficient, which was to be applied to the ACI (2002) Building Code strength requirements $U$ to increase load factor requirements. The effect of this coefficient is to provide better crack control by reducing service load stresses in the reinforcing steel to levels consistent with allowable WSD. The resulting design is expected to limit crack widths to about 0.010 in. (Klein et al. 1981). Additional background on the ACI 350 Committee USD approach to durable concrete structures can also be found in Klein et al. (1981).

The Corps adopted the ACI Committee 350 (2003) USD approaches, but identified the sanitary durability coefficient as a hydraulic factor $H_{f}$. For hydraulic structures, excluding members in direct tension, the ACI Building Code strength requirements $U$ are to be multiplied by a hydraulic factor $H_{f}$ equal to 1.3 , or the hydraulic structure is to have a required strength $U_{f}$ equal to $1.3 U$. For members in direct tension the hydraulic factor increases from 1.3 to 1.65 per ACI 350 Committee recommendations. In EM 1110-2-2104, the required strength equations in the ACI Building Code are used to obtain $U$.

The hydraulic factor is an indirect way of providing stress levels in the reinforcement equivalent to those obtained by ACI-WSD methods. Low stress levels promote good crack control. In general, Corps structures are dominated by live load requirements (i.e., hydrostatic pressure, earth pressure, etc.). For flexure, the hydraulic factor results in a maximum load factor of $1.3(1.7)=2.21$. Since the factor of safety is equal to the load factor divided by the strength reduction factor

\footnotetext{
${ }^{1}$ EM 1110-2-2103, "Details of Reinforcement-Hydraulic Structures," is no longer in
} publication. 
$\phi$, the factor of safety, $\mathrm{FS}=\mathrm{LF} \div \phi=2.21 \div 0.90=2.5$. This means that when ASTM Grade 60 steel is used, the service load stresses in the steel will be approximately equal to $24,000 \mathrm{psi}$, the ACI-WSD allowable for Grade 60 reinforcing steel.

The hydraulic factor method does not mean in all cases that crack widths will satisfy performance objectives. ACI Committee 224 (1980) provides equations that can be used to predict crack width, and indicates the following with respect to crack control:

- Low steel stress is the important aspect.

- Bars located close to the face are better than bars located far from the face.

- Small bars at close spacings are better than large bars at wide spacings.

ACI Committee 224 (1980) also provides tolerable crack widths for various exposure conditions. These are indicated in Table A.6.

\begin{tabular}{|c|c|}
\hline \multicolumn{2}{|c|}{$\begin{array}{l}\text { Table A.6 } \\
\text { Tolerable Crack Widths for Reinforced Concrete (after ACI } \\
\text { Committee } 224 \text { 1980) }\end{array}$} \\
\hline Exposure Condition & Tolerable Crack Width, in \\
\hline Dry air or protective membrane & 0.016 \\
\hline Humidity, moist air, soil & 0.012 \\
\hline Deicing chemicals & 0.007 \\
\hline Seawater and saltwater spray; wetting and drying & 0.006 \\
\hline Water retaining structures & 0.004 \\
\hline
\end{tabular}

Formulas for estimating probable maximum crack widths are also provided in ACI Committee 224 (1980). Using Equation 4.1a from that report for the Figure A. 2 steel arrangement (i.e., \# 8 bars at 6 in. oc., $A_{S}=1.58 \mathrm{in.}^{2} / \mathrm{ft}$ ), the probable maximum crack width $w_{b}$ is

$$
\begin{aligned}
& w_{b}=0.091 \sqrt[3]{t_{b} A} \beta\left(f_{s}-5\right) \times 10^{-3}=0.091 \sqrt[3]{2.50(30)} 1.18(24-5) \times 10^{-3}=0.0086 \mathrm{in} . \\
& t_{b}= \text { bottom cover to center of bar }=2.5 \mathrm{in.} \\
& A= \text { area of concrete symmetric with reinforcing steel bar }=30.00 \mathrm{in.}^{2} \\
& \quad \text { Figure A.2) } \\
& \beta= \text { ratio of distance between neutral axis and tension face to distance } \\
& \text { between neutral axis and centroid of reinforcing steel }=18.00-2.07 \\
& \div 18.00-2.07-2.50=16.24 \div 13.74=1.18
\end{aligned}
$$




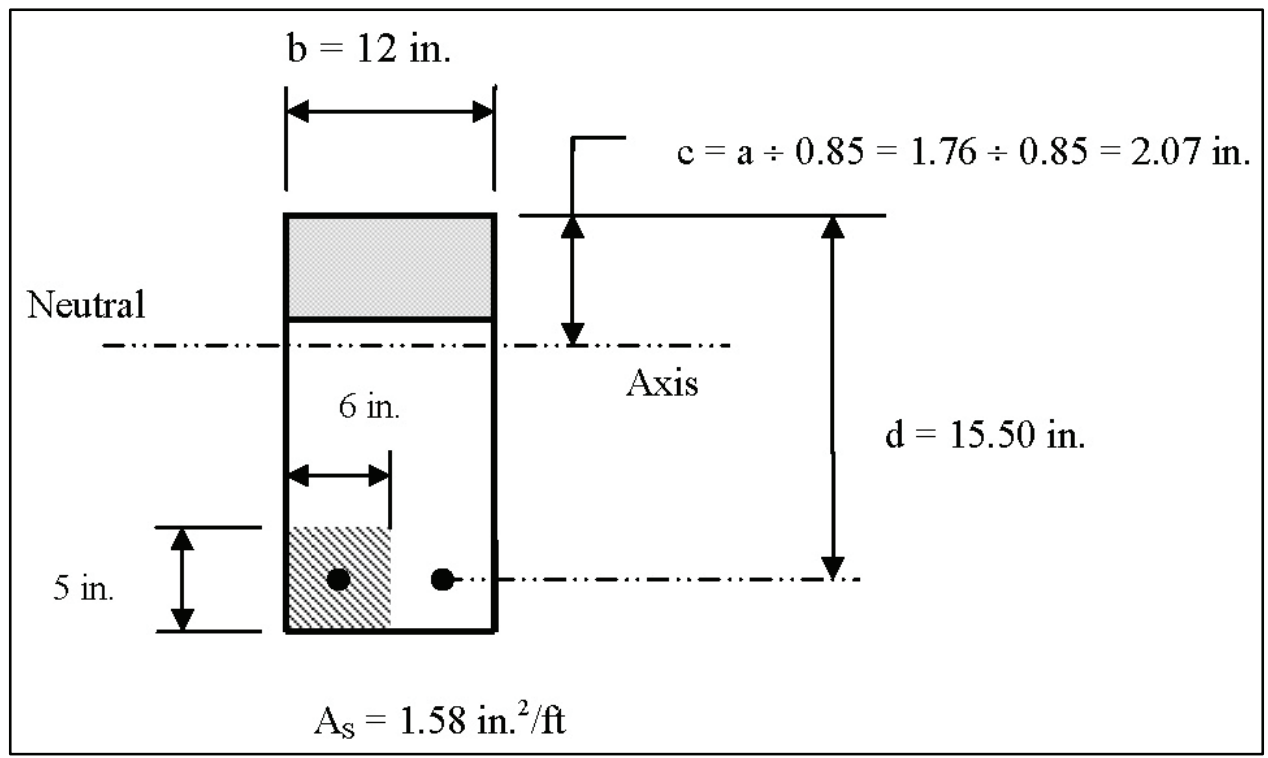

Figure A.2 Parameters used to estimate crack width

It should be noted that in addition to the ACI (2002) Building Code strength requirement equations, the Corps permits a single load factor method (i.e., $U=$ $1.7(D+L))$. The single load factor method facilitates the design of structures involving soil-structure interaction. The previous more stringent load factors and yield strength requirements in the old EM 1110-2-2103 no longer apply.

As with WSD, flexure is used to illustrate the USD approach. A USD flexural analysis will be made of the retaining wall in Appendix D designed by WSD. The following well-known assumptions are used in a USD analysis for flexure:

- Conditions of equilibrium and compatibility of strains are satisfied.

- Strain in the reinforcing steel and concrete shall be assumed directly proportional to the distance from the neutral axis.

- The maximum useable strain in the extreme concrete compression fiber shall be assumed equal to 0.003 .

- Stress in the reinforcement less than the specified yield strength $f_{y}$ for the grade of steel used shall be taken as the modulus of steel $E_{s}$ times the steel strain. For strains greater than that corresponding to the specified yield strength $f_{y}$, the stress in the reinforcement shall be considered independent of strain and equal to $f_{y}$.

- Tensile stress of the concrete shall be neglected.

- For concrete with specified compressive strengths $f_{c}^{\prime}$ less than 4,000 psi, a concrete stress of $0.85 f_{c}^{\prime}$ shall be assumed uniformly distributed over an equivalent compression zone bounded by the edges of the cross section and a straight line located parallel to the neutral axis at a distance $a$ equal to 0.85 times the neutral axis depth $c$, i.e., $a=0.85 c$. 
These assumptions are applied to the analysis of nominal moment capacity of the retaining wall stem at its intersection with the base slab (Figure A.3).

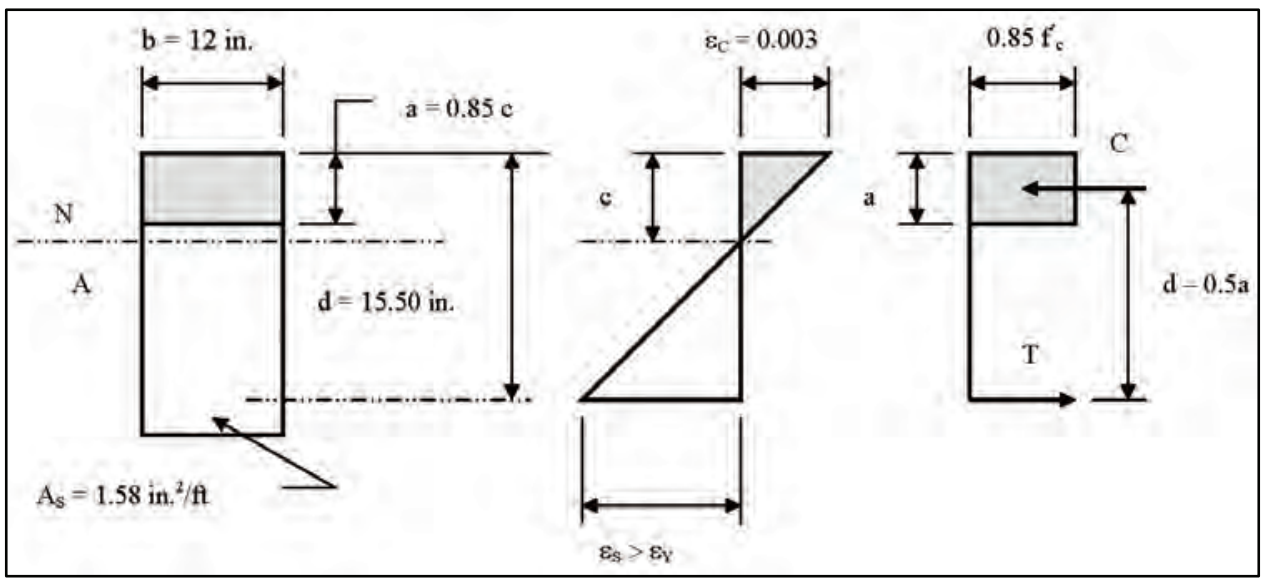

Figure A.3 USD analysis of Appendix D stem wall

A.3.1.4 USD analysis computations. Summing forces to get the compressive force $C$ and the depth of the stress block $a$ :

$$
\begin{aligned}
& C=T=A_{S} f_{Y}=1.58(40 \mathrm{ksi})=63.2 \mathrm{kips} \\
& a=C \div 0.85 b\left(f_{c}^{\prime}\right)=63.2 \div 12(3)=1.76 \mathrm{in} .
\end{aligned}
$$

Summing moments about the compressive force $C$ to get the nominal moment capacity $M_{N}$ :

$$
M_{N}=T(d-0.5 a)=63.2(15.5-0.88)=924 \text { in.-kips }=77.0 \mathrm{ft}-\mathrm{kips}
$$

This is a brief summary of the Corps approach in the design of reinforced concrete hydraulic structures past to present. Notice that the retaining wall designed by WSD methods provides a bending moment factor of safety equal to $77.0 \div 35.28=2.18$. The factors of safety of structures designed by WSD are variable, but generally in the range of 2.0 to 2.5 .

A.3.1.5 Ultimate strength design (USD) per ACI 318-02. It should be noted that the latest ACI (2002) Building Code (ACI 318-02) has revised their load factor combinations to be consistent with American Society of Civil Engineers (ASCE) 7-98 (ASCE 1998). The load factors and resistance factors of ACI 318-02 are established based on probabilistic methods considering the likelihood that the loads used for design might be exceeded during the life of the structure and the likelihood that material strength used for design may be less than assumed. The probabilistic approach to establishing load and resistance factors for USD is discussed in the following section. 


\section{A.3.2 Probabilistic basis for $\mathrm{ACl}$ 318-02 load and resistance factors}

The ACI-USD design safety provisions over the years have required that the design loads or design loading effects when multiplied by Code-specified load factors must be equal to or greater than nominal resistances multiplied by Codespecified resistance factors. Load factors reduced the likelihood that the nominal loads assumed for design would be exceeded during the lifetime of the structure (50 years). Resistance factors reduced the likelihood that the actual strength would be less than the nominal strength assumed for design.

Variability in load effects is due to the variability of the load, its distribution on the structure, inaccuracies in the structural system analytical model, and inaccuracies in the analysis techniques. Variability in resistance to loads results from variability in material strengths, member dimensions, and inaccuracies in assumed stress/strain relationships.

The probabilistic approach used to develop the ACI 318-02 load and resistance factors is described in MacGregor (1983). In MacGregor (1983), the term $Y$ is used to represent the margin of safety and

$$
Y=R-Q
$$

where

$$
\begin{aligned}
& R=\text { strength } \\
& Q=\text { load effects }
\end{aligned}
$$

For the mean margin of safety:

$$
\bar{Y}=\bar{R}-\bar{Q}
$$

And for the standard of deviation:

$$
\sigma_{Y}=\sqrt{\sigma_{R}^{2}+\sigma_{Q}^{2}}
$$

The safety index $\beta$ is

$$
\beta=\bar{Y} / \sigma_{Y}
$$

where $\beta$ is a measure of the reliability of a structural member and per MacGregor (1983) is illustrated in Figure A.4. 


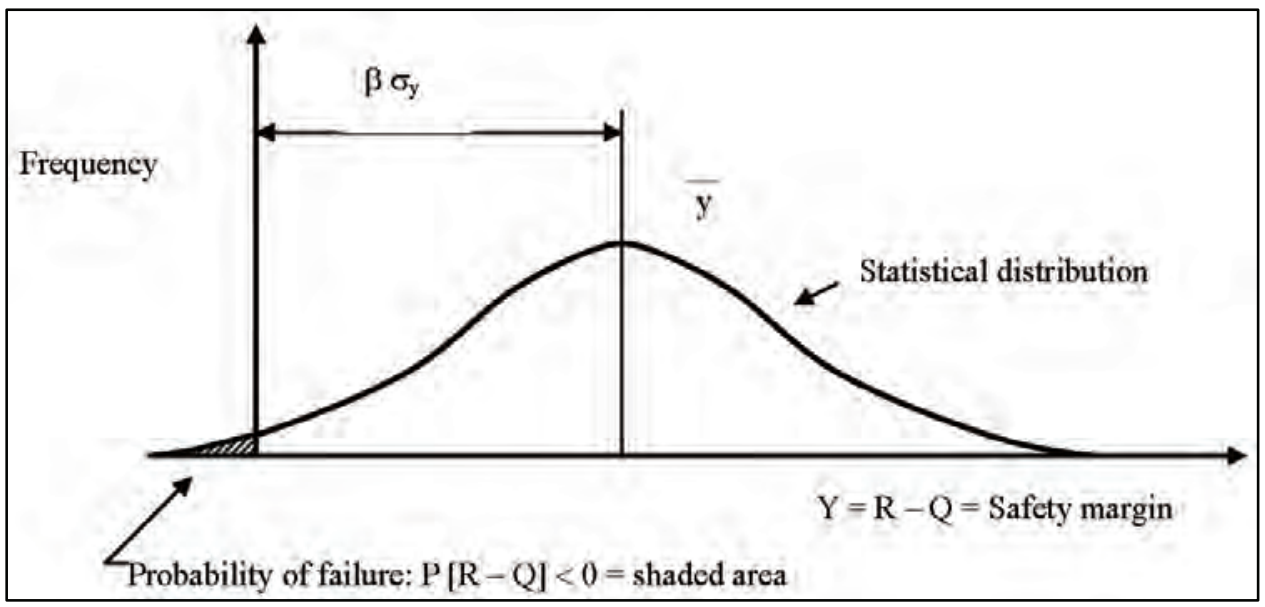

Figure A.4 Definition of failure (after MacGregor 1983)

The ACI 318-02 load and resistance factors were based on studies performed by Drs. Cornell, Ellingwood, Galambos, and MacGregor. From these studies target reliability values ( $\beta$-values) were established for load factors and resistance factors. Loading combination $\beta$-values ranged from 2.0 to 3.0 with a $\beta$-value equal to 3.0 for the dead + live load combination. Resistance factor $\beta$-values ranged from 3.0 to 3.5 with the higher $\beta$-value assigned to strength reduction factors ( $\phi$-factors) associated with brittle failure mechanisms. As a result of the studies performed by Drs. Cornell, Ellingwood, Galambos, and MacGregor, the ACI 318-02 load and resistance factor requirements have changed. The most notable change is a reduction from 1.7 to 1.6 in various live loads related load factors. No changes have been made in the Corps Required Strength provisions for USD. It should be recognized that the probability-based studies conducted by Drs. Cornell, Ellingwood, Galambos, and MacGregor were related to building systems and members. It is always difficult to apply these provisions to cantilever retaining wall structures where soil interaction effects are involved. This topic is discussed in Ferguson (1973). 


\section{Appendix B Evaluating Older Retaining Walls}

Older retaining walls will likely not have development and splice lengths that comply with current American Concrete Institute (ACI) (2002) ${ }^{1}$ ACI 318-02 Code requirements. In addition, retaining walls constructed before 1947 are unlikely to have the high-bond deformation patterns typical of modern-day reinforced concrete structures. Information on the yield and tensile strength properties of older reinforcing steel is provided in Appendix A. This appendix provides guidance on one approach that can be used to assess the strength of older retaining walls that do not have adequate splice and development lengths. This deficiency can be the result either of past Code design practice, or because the older reinforcement has a low-bond deformation pattern. The information contained herein is based on Federal Emergency Management Agency (FEMA) 356 (2000) and Concrete Reinforcing Steel Institute (CRSI) (2001).

\section{B.1 FEMA 356 (2000) Ductility Demand Classifications}

FEMA 356 (2000) defines three classifications of displacement ductility demand: low, moderate, and high.

The ranges of ductility demand for each classification, per FEMA 356 (2000), are listed in Table B.1.

\begin{tabular}{|l|l||}
\hline \hline \multicolumn{2}{|l||}{ Table B.1 } \\
Component Ductility Demand Classifications \\
\hline \hline Maximum Value of Displacement Ductility & Classification Description \\
\hline \hline$<2$ & Low ductility demand \\
\hline 2 to 4 & Moderate ductility demand \\
\hline$>4$ & High ductility demand \\
\hline
\end{tabular}

\footnotetext{
${ }^{1}$ References cited in this appendix are included in the References section at the end of the main text.
} 
FEMA 356 (2000) requires that deformed straight bars, hooked bars, and lapspliced bars in yielding regions of components with moderate or high displacement ductility demand meet the splice and development requirements of Chapter 21, "Special Provisions for Seismic Design," ACI 318-02 (ACI 2002). Deformed straight bars, hooked bars, and lap-spliced bars in yielding regions of components with low displacement ductility demand can meet the splice and development requirements of Chapter 11, "Shear and Torsion," ACI 318-02. In most cases, because of the reserve capacity of retaining walls designed to meet static earth pressure loadings, displacement ductility demands due to earthquake ground motions will be low. The tensile capacity of the reinforcement must be reduced for those older cantilever retaining wall structures that fail to meet these Code-specified splice and development length requirements. FEMA 356 (2000) guidance for this is provided in the following paragraph.

\section{B.2 FEMA 356 (2000) Requirements for Nonconforming Splice and Development Lengths}

Where existing deformed straight bars, hooked bars, and lap-spliced bars do not meet the development requirements in the Code provisions specified previously, the capacity of the existing reinforcement shall be calculated using the following equation: ${ }^{1}$

$$
f_{S}=\left(l_{b} \div l_{d}\right) f_{Y}
$$

where

$f_{S}=$ maximum stress that can be developed in the bar for the straight development, hook, or lap splice length $l_{b}$ provided

$l_{d}=$ length required by ACI 318-02, Chapter 12 or 21 as appropriate for straight development, hook development, or lap splice length, except required splice lengths may be taken as straight bar development lengths in tension

$f_{Y}=$ yield strength of the reinforcing steel

Where transverse reinforcement is distributed along the development length with spacing not exceeding one-third of the effective depth of the component, it shall be permitted to assume that the reinforcement retains the calculated maximum stress to high ductility demands. For larger spacings of transverse reinforcement, the development stress shall be assumed to degrade from $f_{S}$ to $0.2 f_{S}$ at a ductility demand equal to two.

\footnotetext{
${ }^{1}$ Each of the appendixes in this report has its own system of notation. Many of the symbols used in this appendix are defined in the text of this appendix. Others are commonplace to reinforced concrete design and retaining wall design. Readers not understanding a particular symbol notation should consult the references cited in this appendix for the definition.
} 
The strength of deformed straight, discontinuous bars embedded in concrete sections or beam-column joints, with clear cover over the embedded bar not less than three bar diameters $3 d_{b}$, shall be calculated as follows:

$$
f_{S}=\left(2500 \div d_{b}\right) l_{e} \leq f_{Y}
$$

where

$f_{S}=$ maximum stress, psi, that can be developed in an embedded bar having an embedment length $l_{e}$, in.

$d_{b}=$ diameter of embedded bar, in.

When $f_{S}$ is less than $f_{Y}$, and the calculated stress in the bar due to design loads equals or exceeds $f_{S}$, the maximum developed stress shall be assumed to degrade from $f_{S}$ to $0.2 f_{S}$ at a ductility demand equal to two.

\section{B.3 Splice and Development Length Requirements for Low-Bond Deformation Bars}

CRSI (2001) indicates that:

"For older structures, it is prudent to consider all varieties of reinforcing bars - plain round, old style deformed, twisted square, and so on - conservatively and simply as 50 percent effective in bond and anchorage as current bars. In other words, the tension development lengths, $l_{d}$, for the old bars would be twice (double) the $l_{d}$ required for modern reinforcing bars. Since most strength design reviews for flexure will be based on a yield strength, $f_{Y}=33,000 \mathrm{psi}$ instead of today's $60,000 \mathrm{psi}$, the tension development lengths for the old bars can be determined by adding 10 percent to any current table of tension development lengths, $l_{d}$, for modern reinforcing bars."

FEMA 356 (2000) is more tolerant with respect to older square reinforcement that is twisted, allowing the development strength to be as specified for deformed bars in ACI 318-02 (ACI 2002). In the ACI 318-02 computations an effective round bar diameter is determined based on the gross area of the square bar. Square straight bars, however, are to be treated as plain bars using the CRSI (2001) process described previously. FEMA 356 (2000) permits higher development strengths for bars classified as "plain" if they can be justified by approved tests or calculations that consider only the chemical bond between the bar and the concrete.

It is recommended for Corps cantilever retaining walls that those ACI 318-02 development equations that take advantage of the confining effects due to added concrete cover be used when determining the development length requirements. This process is demonstrated in the examples in Appendices D, E, and F. 


\section{Appendix C Developing Standard Response Spectra for USACE Projects}

\section{C.1 Recommended Procedure}

The following is one approach that can be used for developing standard spectra for use in the preliminary design and analysis of U.S. Army Corps of Engineers civil works structures. This approach is based on the Federal Emergency Management Agency (FEMA) $356(2000)^{1}$ methodology using the latest national earthquake maps developed by the United States Geological Survey (USGS). The hazard maps used in the construction of standard response spectra are in terms of spectral response accelerations at periods of 0.2 and $1.0 \mathrm{sec}$ (as a percent of the acceleration of gravity) for earthquake events with return periods of 475 and 2,475 years, respectively. The spectral response approach permits the construction of standard response spectra directly.

\section{C.2 Site Effects}

The shapes of response spectra are influenced by site characteristics. Flexible or long-period structures on soft soils respond more to ground motions than flexible structures on firm soils or rock, and rigid or short-period structures on firm soils or rock respond more to ground motions than rigid structures on soft soils. These site effects are accounted for in the development of standard spectra by the use of site coefficients. The two-factor approach of the FEMA 356 (2000) provisions has been incorporated into the standard spectra methodology. This methodology recognizes that for soil sites, short-period as well as long-period rock accelerations can be amplified with the magnitude of the amplification related to the level of shaking as well as to soil characteristics. Site coefficients for use with the USGS spectral acceleration response maps are provided in Tables C.1 and C.2. The spectral acceleration response maps are based on

\footnotetext{
${ }^{1}$ References cited in this appendix are included in the References section at the end of the main text.
} 
earthquake records from soil sites with Site Class B characteristics. Descriptions of the various site classes are as follows: ${ }^{1}$

a. Hard rock with measured shear wave velocity, $\bar{v}_{S}>5,000 \mathrm{ft} / \mathrm{sec}$ $(1,500 \mathrm{~m} / \mathrm{sec})$.

b. Rock with $2,500 \mathrm{ft} / \mathrm{sec}<\bar{v}_{S} \leq 5,000 \mathrm{ft} / \mathrm{sec}\left(760 \mathrm{~m} / \mathrm{sec}<\bar{v}_{S} \leq\right.$ $1,500 \mathrm{~m} / \mathrm{sec})$.

c. Very dense soil and soft rock with $1,200 \mathrm{ft} / \mathrm{sec}<\bar{v}_{S} \leq 2,500 \mathrm{ft} / \mathrm{sec}$ $\left(360 \mathrm{~m} / \mathrm{sec}<\bar{v}_{S} \leq 760 \mathrm{~m} / \mathrm{sec}\right)$ or with either $\bar{N}>50$ or $\overline{s_{u}} \geq 2,000 \mathrm{psf}$ $(100 \mathrm{kPa})$.

d. Stiff soil with $600 \mathrm{ft} / \mathrm{sec} \leq \bar{v}_{S} \leq 1,200 \mathrm{ft} / \mathrm{sec}\left(180 \mathrm{~m} / \mathrm{sec} \leq \bar{v}_{S} \leq\right.$ $360 \mathrm{~m} / \mathrm{sec})$ or with either $15 \leq \bar{N} \leq 50$ or $1,000 \mathrm{psf} \leq \overline{s_{u}} \leq 2,000 \mathrm{psf}(50$ $\left.\mathrm{kPa} \leq \overline{s_{u}} \leq 100 \mathrm{kPa}\right)$.

e. A soil profile with $\bar{v}_{S}<600 \mathrm{ft} / \mathrm{sec}(180 \mathrm{~m} / \mathrm{sec})$ or any profile with more than $10 \mathrm{ft}(3 \mathrm{~m})$ of soft clay defined as soil with PI $>20, w \geq 40$ percent, and $\bar{s}_{u}<500 \mathrm{psf}(25 \mathrm{kPa})$.

f. Soils requiring site-specific evaluations.

\begin{tabular}{|c|c|c|c|c|c|}
\hline \multicolumn{6}{|c|}{$\begin{array}{l}\text { Table C.1 } \\
\text { Values of Site Coefficient } F_{(0.2)} \text { as a Function of Site Class and Mapped 0.2-Sec } \\
\text { Earthquake Spectral Acceleration (Adapted from FEMA } 356 \text { (2000) Table 1-4) }\end{array}$} \\
\hline \multicolumn{6}{|c|}{ Mapped Maximum Spectral Response Acceleration at 0.20-Sec Period } \\
\hline Site Class & $S_{(0.2)} \leq 0.25$ & $S_{(0.2)}=0.50$ & $S_{(0.2)}=0.75$ & $S_{(0.2)}=1.00$ & $S_{(0.2)} \geq 1.25$ \\
\hline A & 0.8 & 0.8 & 0.8 & 0.8 & 0.8 \\
\hline B & 1.0 & 1.0 & 1.0 & 1.0 & 1.0 \\
\hline C & 1.2 & 1.2 & 1.1 & 1.0 & 1.0 \\
\hline $\mathbf{D}$ & 1.6 & 1.4 & 1.2 & 1.1 & 1.0 \\
\hline$E$ & 2.5 & 1.7 & 1.2 & 0.9 & 0.9 \\
\hline$F$ & 1 & 1 & 1 & 1 & 1 \\
\hline
\end{tabular}

\footnotetext{
${ }^{1}$ Each of the appendixes in this report has its own system of notation. Many of the symbols used in this appendix are defined in the text of this appendix. Others are commonplace to reinforced concrete design and retaining wall design. Readers not understanding a particular symbol notation should consult the references cited in this appendix for the definition.
} 


\begin{tabular}{|c|c|c|c|c|c|}
\hline \multicolumn{6}{|c|}{$\begin{array}{l}\text { Table C.2 } \\
\text { Values of Site Coefficient } F_{(1.0)} \text { as a Function of Site Class and Mapped 1.0-Sec } \\
\text { Earthquake Spectral Acceleration (Adapted from FEMA } 356(2000) \text { Table 1-5) }\end{array}$} \\
\hline \multicolumn{6}{|c|}{ Mapped Maximum Spectral Response Acceleration at 1.00-Sec Period } \\
\hline Site Class & $S_{(0.2)} \leq 0.1$ & $S_{(0.2)}=0.2$ & $S_{(0.2)}=0.3$ & $S_{(0.2)}=0.4$ & $S_{(0.2)} \geq 0.5$ \\
\hline A & 0.8 & 0.8 & 0.8 & 0.8 & 0.8 \\
\hline B & 1.0 & 1.0 & 1.0 & 1.0 & 1.0 \\
\hline C & 1.7 & 1.6 & 1.5 & 1.4 & 1.3 \\
\hline $\mathbf{D}$ & 2.4 & 2.0 & 1.8 & 1.6 & 1.5 \\
\hline$E$ & 3.5 & 3.2 & 2.8 & 2.4 & 2.4 \\
\hline$F$ & & 12 & & & 1 \\
\hline
\end{tabular}

\section{C.3 Standard Spectra Construction}

Standard spectra representing the design earthquakes for a particular project feature can be developed using the USGS Maps listed in Table C.3 or larger scale versions of the same maps developed for specific regions of the United States.

\begin{tabular}{||l|l||}
\hline \hline Table C.3 \\
USGS Maps Used in Standard Spectra Construction \\
\hline Map 25 & $\begin{array}{l}\text { Probabilistic Ground Motion for the United States. 0.2-sec Spectral Response Acceleration (5\% of Critical Damping). } \\
10 \% \text { probability of exceedance in } 50 \text { years (475-year return period) }\end{array}$ \\
\hline Map 26 & $\begin{array}{l}\text { Probabilistic Ground Motion for the United States. 1.0-sec Spectral Response Acceleration (5\% of Critical Damping). } \\
10 \% \text { probability of exceedance in 50 years (475-year return period) }\end{array}$ \\
\hline Map 27 27 & $\begin{array}{l}\text { Probabilistic Ground Motion for the United States. 0.2-sec Spectral Response Acceleration (5\% of Critical Damping). } 2 \% \\
\text { probability of exceedance in 50 years (2,475-year return period) }\end{array}$ \\
\hline Map 28 & $\begin{array}{l}\text { Probabilistic Ground Motion for the United States. 1.0-sec Spectral Response Acceleration (5\% of Critical Damping). } 2 \% \\
\text { probability of exceedance in 50 years (2,475-year return period) }\end{array}$ \\
\hline
\end{tabular}

The information needed to construct standard response spectrum is provided in Table C.4. Figure C.1 provides an arithmetical plot of the standard spectrum showing all the points and curves covered in Table C.4.

Maps used in the construction of standard spectra are based on a specific hazard or probability level. USGS maps with probability levels of 10 percent chance of exceedance in a 50-year period (475-year return period), and 2 percent chance of exceedance in a 50-year period (2,475-year return period) are used to construct standard spectra for Corps projects. 


\begin{tabular}{|c|c|c|}
\hline \multicolumn{3}{|c|}{$\begin{array}{l}\text { Table C.4 } \\
\text { Information for Constructing Standard Horizontal Acceleration } \\
\text { Response Spectra (Refer to Figure C.1) }\end{array}$} \\
\hline Point ${ }^{1}$ & Period, sec & Equation for $S_{A}$ \\
\hline A & 0.0 & \\
\hline A-B & & $S_{A}=0.6 \frac{S_{A(0.2)}\left(F_{(0.2)}\right)(T)}{T_{B}}+0.4\left(S_{A(0.2)}\right)\left(F_{(0.2)}\right)$ \\
\hline $\mathrm{B}$ & $T_{B}=\frac{0.2\left(S_{A(1.0)}\right)\left(F_{(1.0)}\right)}{\left(S_{A(0.2)}\right)\left(F_{(0.2)}\right)}$ & \\
\hline B-C & & $S_{A}=S_{A(0.2)} F_{(0.2)}$ \\
\hline $\bar{C}$ & $T_{C}=\frac{S_{A(1.0)}\left(F_{(1.0)}\right)}{S_{A(0.2)}\left(F_{(0.2)}\right)}$ & \\
\hline C-D & & $S_{A}=\frac{S_{A(1.0)}\left(F_{(1.0)}\right)}{T}$ \\
\hline \multicolumn{3}{|c|}{$\begin{array}{l}\text { Note: } \\
S_{A}=\text { Spectral response acceleration for use in constructing a standard acceleration response spectrum } \\
S_{A(0.2)}=\text { Spectral response acceleration at a period of } 0.2 \text { sec for the return period under consideration. } \\
S_{A(1.0)}=\text { Spectral response acceleration at a period of } 1.0 \text { sec for the return period under consideration. } \\
T_{B}=\text { Period used to locate spectral ordinate at point } \mathrm{B}, \text { sec. } \\
T_{C}=\text { Period used to locate spectral ordinate at point } \mathrm{C}, \mathrm{sec} . \\
T=\text { Period of vibration of single degree of freedom system, sec. } \\
F_{(0.2)}=\text { Site coefficient from Table C. } 1 . \\
F_{(1.0)}=\text { Site coefficient from Table C. } 2 . \\
{ }^{1} \text { See Figure C. } 1 \text { for points on the standard response spectrum. }\end{array}$} \\
\hline
\end{tabular}

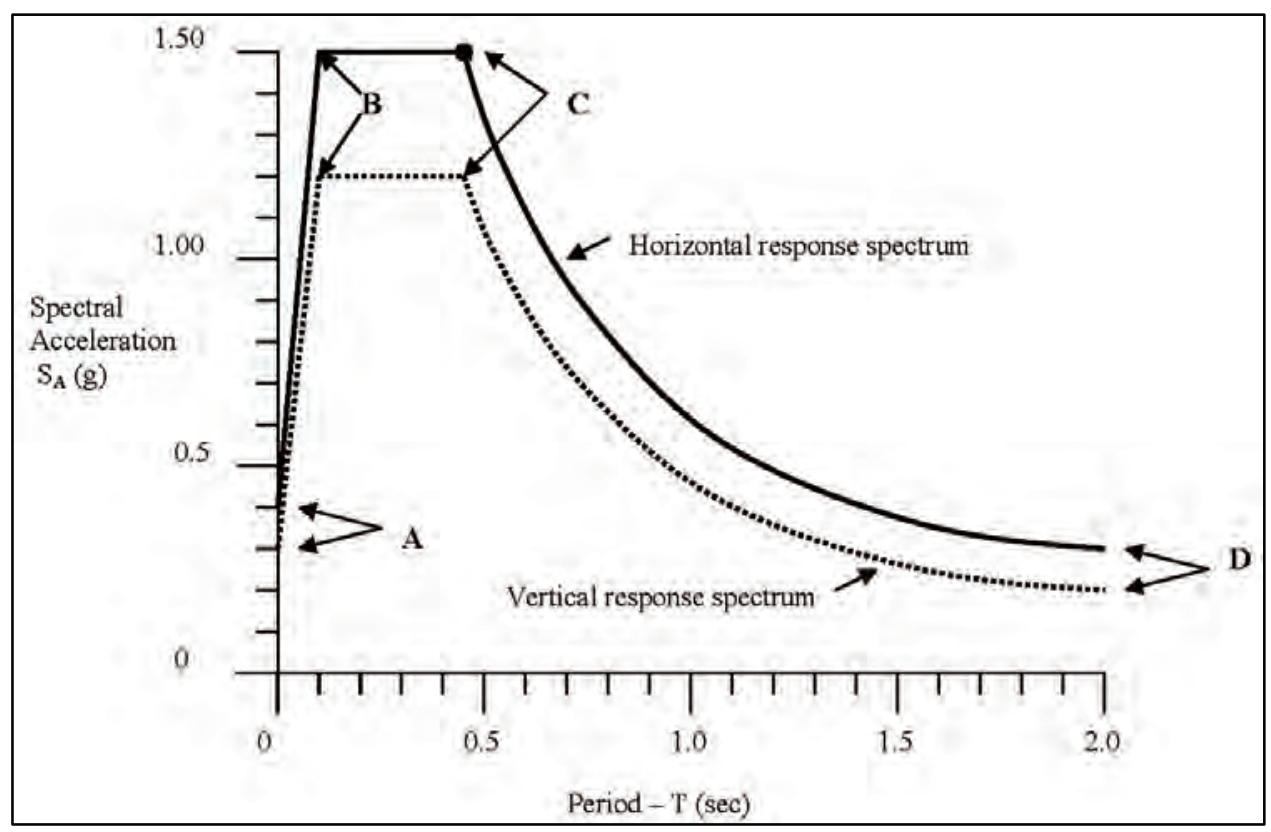

Figure C.1 Standard acceleration response spectrum construction points (arithmetical plot) 


\section{C.4 Relationship Between Probability and Recurrence Interval}

The design earthquake for a project may be designated as an earthquake that has either a specified percent chance $P e$ of being exceeded in $t$-years or a return period (recurrence interval) of $T_{r}$ years. The conversion from one type designation to the other is accomplished by the Poisson equation. The inverse of the return period $T_{r}$ is the annual frequency of exceedance $v$.

\section{C.5 Spectrum Construction for Different Probability Levels}

The USGS spectral acceleration maps include ground motions associated with a 10 percent chance of exceedance in 50 years (a return period of 475 years), and ground motions associated with a 2 percent chance of exceedance in 50 years (a return period of 2,475 years). These maps can be used to develop spectral accelerations for earthquake events with return periods other than 475 or 2,475 years. The procedures for doing this are described in FEMA 356 (2000) and illustrated in the example.

\section{C.6 Site-Specific Versus Standard Spectra}

Site-specific ground motion studies can more reasonably predict the effect magnitude, distance, transmission path characteristics, and site conditions have on ground motions. The standard spectra process can quantify these effects only in general terms. ER 1110-2-1806 (Headquarters, U.S. Army Corps of Engineers (HQUSACE) 1995) describes the conditions requiring a site-specific ground motion study. Methods for developing site-specific spectra are described in EM 1110-2-6050 (HQUSACE 1999).

\section{C.7 Damping}

The response spectra described herein are all based on 5 percent damping. The 5 percent damping level is generally appropriate for most concrete hydraulic structures. Response spectra at different damping levels can be easily constructed using the damping conversion factors in Table C.5. The conversion of a response spectrum to a damping level other than 5 percent is accomplished by multiplying the Point B through Point D values of the standard spectra by the damping factor conversion factor provided in Table C.5. 


\begin{tabular}{||l|l|}
\hline \multicolumn{2}{|l|}{$\begin{array}{l}\text { Table C.5 } \\
\text { Damping Conversion Factors (after TM 5-809-10.1 (U.S. Army 1986)) }\end{array}$} \\
\hline \hline Damping, percent & Damping Conversion Factor \\
\hline \hline 2 & 1.25 \\
\hline $\mathbf{5}$ & $\mathbf{1 . 0 0}$ \\
\hline 7 & 0.90 \\
\hline 10 & 0.80 \\
\hline 15 & 0.70 \\
\hline 20 & 0.60 \\
\hline
\end{tabular}

\section{C.8 Vertical Response Spectra}

The previous paragraphs described procedures for constructing horizontal acceleration response spectra for use in the design of civil works structures. In some instances it may be useful to have vertical acceleration response spectra available for design work. This can be accomplished through the use of a conversion factor $F_{V}$, which when multiplied times the horizontal response spectrum ordinates produces a vertical acceleration response spectrum suitable for preliminary design. The conversion factors used to convert horizontal acceleration response spectra to vertical acceleration response spectra are presented in Table C.6. These factors were based on information provided in Figure 3-17 of EM 1110-2-6050 (HQUSACE 1999). Table C.7 gives information needed to construct standard vertical response spectra.

\begin{tabular}{|c|c|}
\hline \multicolumn{2}{|c|}{$\begin{array}{l}\text { Table C. } 6 \\
\text { Horizontal to Vertical Spectrum Conversion Factor } F_{V} \text { for Periods of } \\
\text { Vibration between } 0.0 \text { and } T_{C} \text { sec }\end{array}$} \\
\hline Source to Site Distance $R, \mathrm{~km}$ & Conversion Factor $F_{V}$ \\
\hline$\leq 10$ & 1.00 \\
\hline 25 & 0.84 \\
\hline$\geq 40$ & 0.67 \\
\hline \multicolumn{2}{|c|}{$\begin{array}{l}\text { Note: } \\
\text { 1. For periods of vibration greater than } T_{C} \text { use } 67 \% \text { of the horizontal acceleration spectral value (for } \\
\text { values of } T_{c} \text { for vertical response spectra see Table C.7). } \\
\text { 2. A value of } F_{V} \text { for intermediate values of } R \text { can be obtained by linear interpolation. } \\
\text { 3. } F_{V}=\text { horizontal to vertical spectrum conversion factor. }\end{array}$} \\
\hline
\end{tabular}




\begin{tabular}{|c|c|c|}
\hline \multicolumn{3}{|c|}{$\begin{array}{l}\text { Table C.7 } \\
\text { Information for Constructing Standard Vertical Acceleration Response Spectra (refer to } \\
\text { Figure C.1) }\end{array}$} \\
\hline Point ${ }^{1}$ & Period, sec & Equation for $S_{A}$ \\
\hline A & 0.0 & \\
\hline A-B & & $S_{A}=0.6 \frac{S_{A(0.2)}\left(F_{(0.2)}\right)(T)}{T_{B}}+0.4 F_{V}\left(S_{A(0.2)}\right)\left(F_{(0.2)}\right)$ \\
\hline B & $T_{B}=\frac{0.2 F_{V}\left(S_{A(1.0)}\right)\left(F_{(1.0)}\right)}{\left(S_{A(0.2)}\right)\left(F_{(0.2)}\right)}$ & \\
\hline B-C & & $S_{A}=F_{V}\left(S_{A(0.2)} F_{(0.2)}\right)$ \\
\hline C & $T_{C}=\frac{0.67 S_{A(1.0)}\left(F_{(1.0)}\right)}{\left(F_{V}\right) S_{A(0.2)}\left(F_{(0.2)}\right)}$ & \\
\hline C-D & & $S_{A}=\frac{0.67 S_{A(1.0)}\left(F_{(1.0)}\right)}{T}$ \\
\hline \multicolumn{3}{|c|}{$\begin{array}{l}\text { Note: } \\
S_{A}=\text { Spectral response acceleration for use in constructing a standard acceleration response spectrum. } \\
S_{A(0.2)}=\text { Spectral response acceleration at a period of } 0.2 \text { sec for the return period under consideration. } \\
S_{A(1.0)}=\text { Spectral response acceleration at a period of } 1.0 \text { sec for the return period under consideration. } \\
T_{B}=\text { Period used to locate spectral ordinate at point } B \text {, sec. } \\
T_{C}=\text { Period used to locate spectral ordinate at point } C \text {, sec. } \\
T=\text { Period of vibration of single-degree-of-freedom system, sec. } \\
F_{(0.2)}=\text { Site coefficient from Table } C .1 \text {. } \\
F_{(1.0)}=\text { Site coefficient from Table } C .2 \text {. } \\
F_{v}=\text { Horizontal response spectrum conversion factor (see Table C.4). } \\
{ }^{v} \text { See Figure C. } 1 \text { for points on the standard response spectrum. }\end{array}$} \\
\hline
\end{tabular}

\section{C.9 Response Spectrum Example}

The following example illustrates the procedure described in Section C.1 and Table C. 4 for constructing a standard horizontal acceleration response spectrum for a design earthquake with a return period of 1,000 years (maximum design earthquake (MDE)).

\section{C.9.1 Problem description}

Project Name: Unnamed Spillway Chute Retaining Wall

Project Location: Los Angles Basin

Site Conditions: Soft Rock Foundation, Soil Profile B

Structure Classification: Normal (i.e., not critical)

MDE to have a return period of 1,000 years

\section{C.9.2 Development of standard horizontal acceleration response spectrum}

C.9.2.1 Obtain spectral acceleration for project from USGS maps. Using USGS Maps 29, 30, 31, and 32 determine the spectral response accelerations at 
periods of $0.20 \mathrm{sec}$ and $1.00 \mathrm{sec}$. Spectral accelerations on the USGS Maps are expressed as a percent of gravity $g$.

For a return period $P_{R}$ of 475 years:

From USGS Map 29, $S_{A(0.2)}=1.54 g$ (Figure C.2)

From USGS Map 30, $S_{A(1.0)}=0.50 g$ (Figure C.3)

For a return period $P_{R}$ of 2,475 years:

From USGS Map 31, $S_{A(0.2)}=2.70 \mathrm{~g}$ (Figure C.4)

From USGS Map 32, $S_{A(1.0)}=1.00 g$ (Figure C.5)

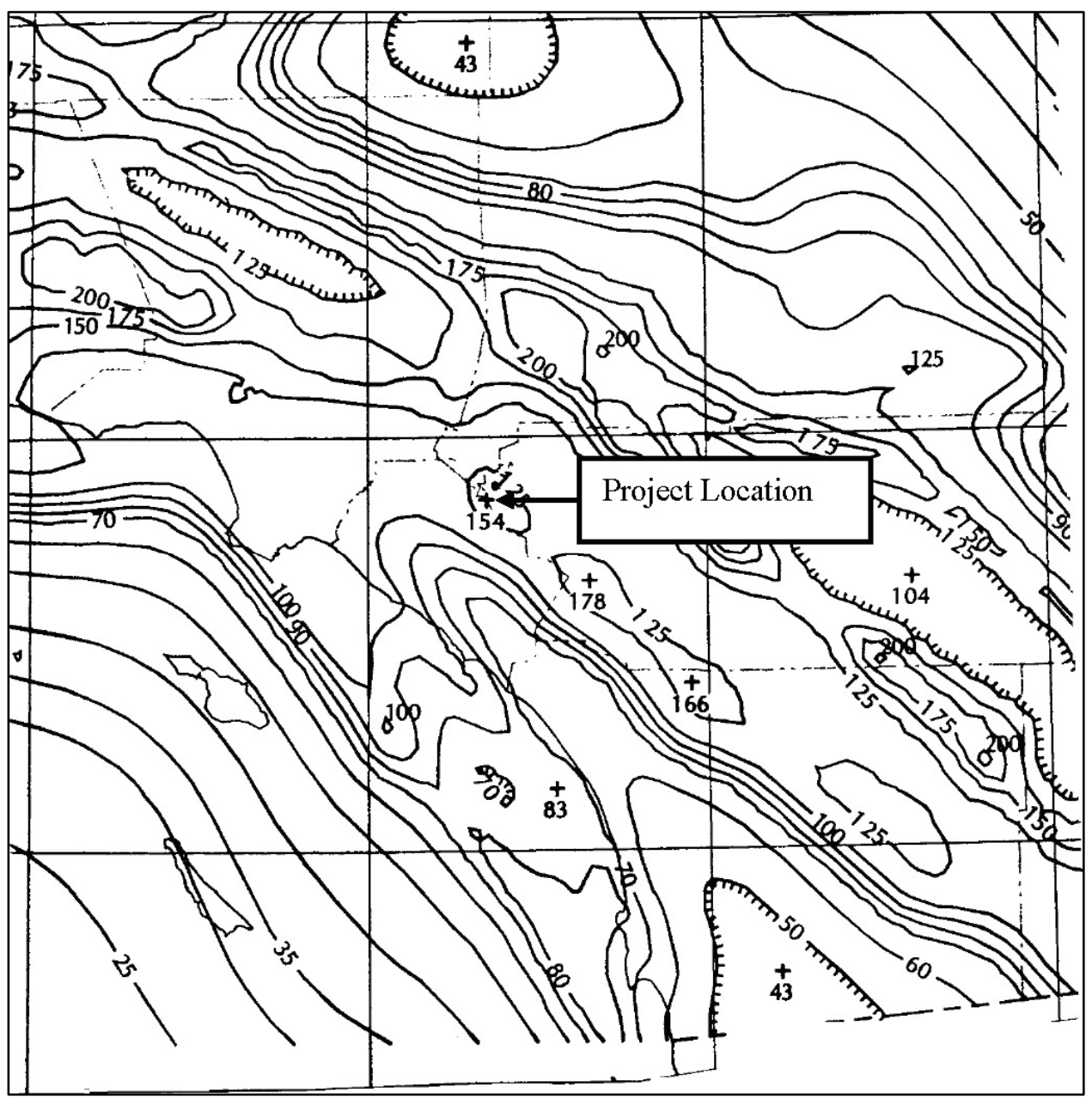

Figure C.2 USGS Map 29, probabilistic earthquake ground motion for California/Nevada, 0.20 -sec spectral response acceleration ( $5 \%$ of critical damping), $10 \%$ probability of exceedance in 50 years (return period of 475 years), LA Basin spillway chute retaining wall 


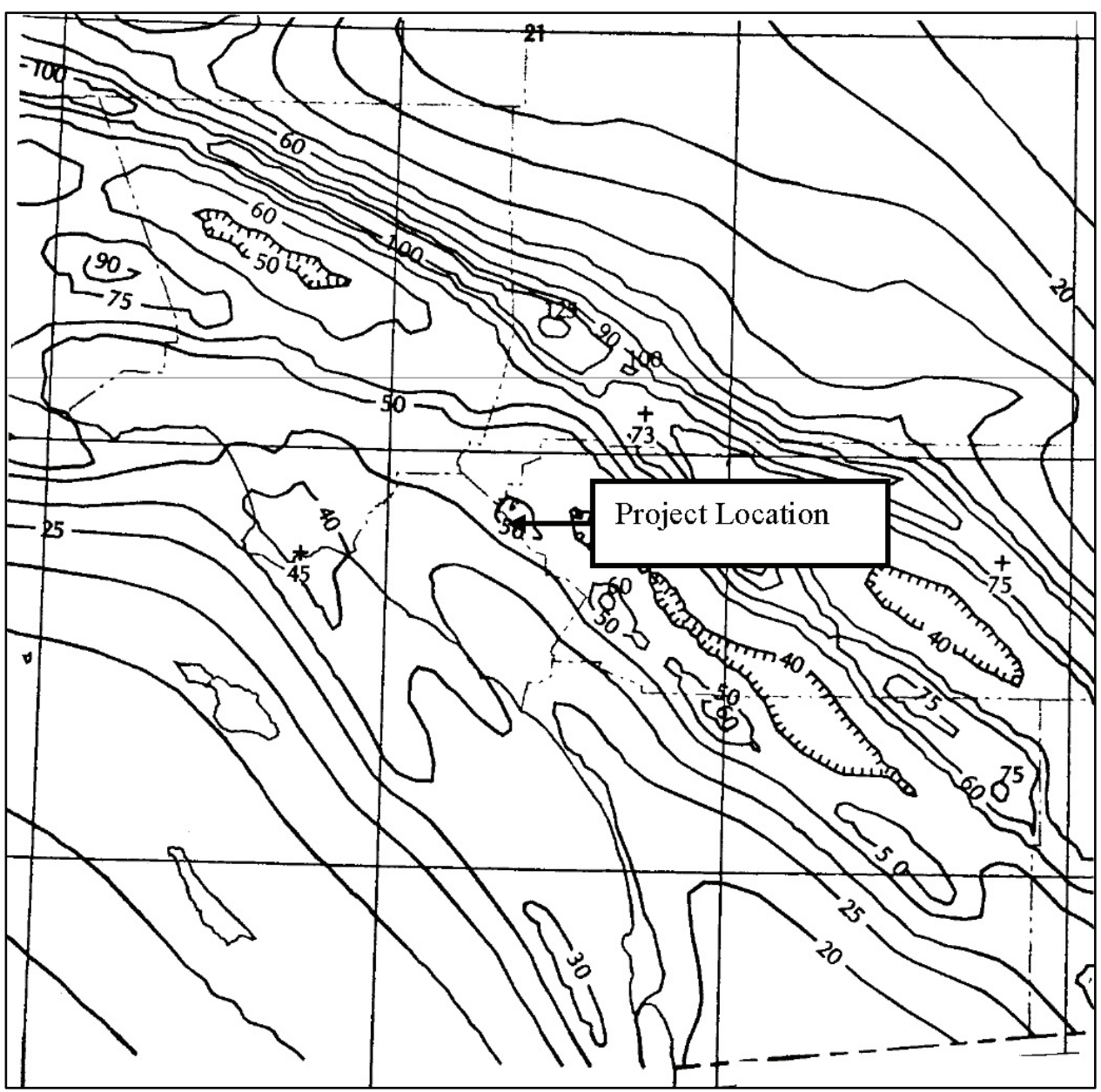

Figure C.3 USGS Map 30, probabilistic earthquake ground motion for California/Nevada, 1.00 -sec spectral response acceleration $(5 \%$ of critical damping), $10 \%$ probability of exceedance in 50 years (return period of 475 years), LA Basin spillway chute retaining wall 


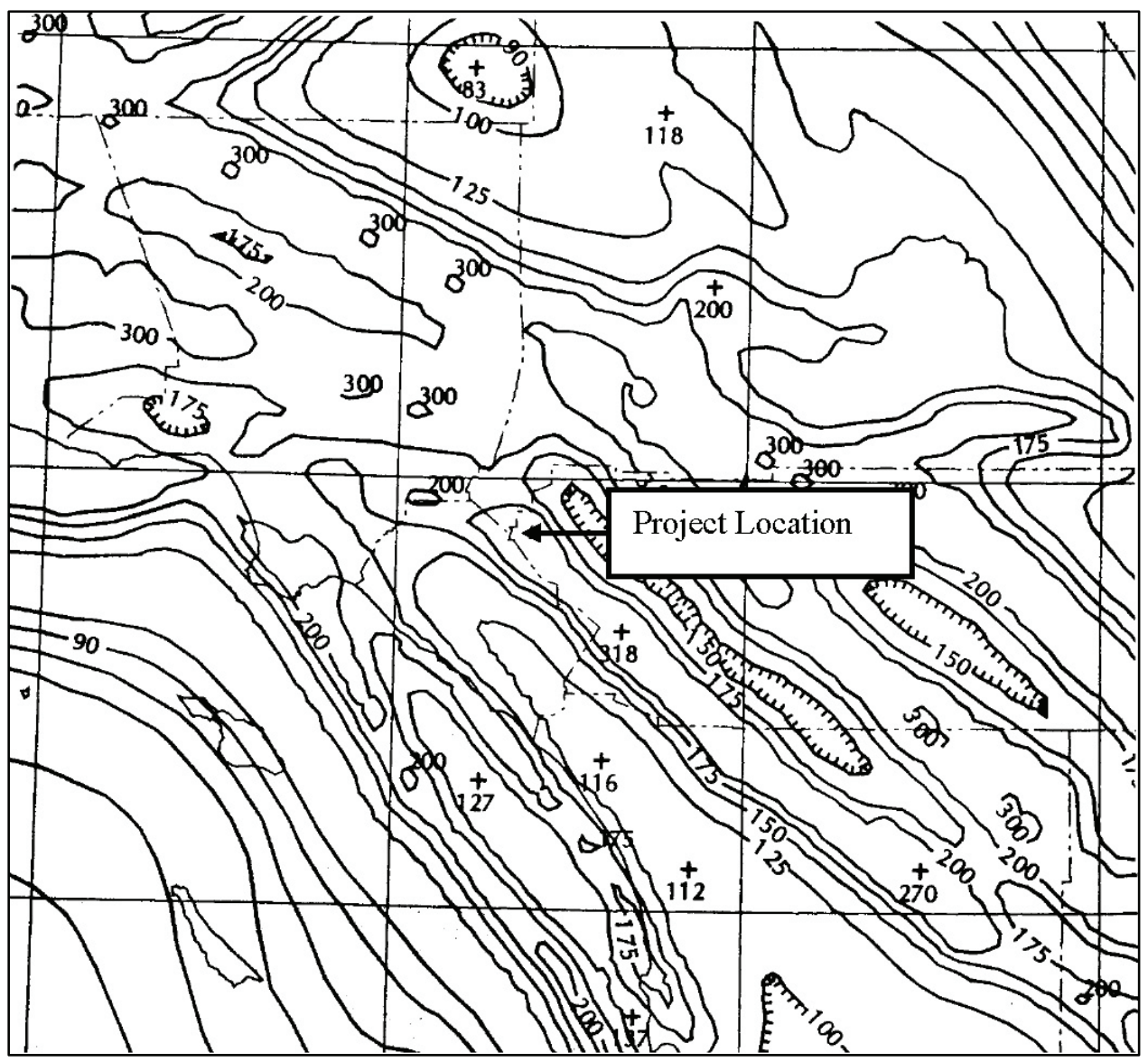

Figure C.4 USGS Map 31, probabilistic earthquake ground motion for California/Nevada, 0.20 -sec spectral response acceleration ( $5 \%$ of critical damping), $2 \%$ probability of exceedance in 50 years (return period of 1,000 years), LA Basin spillway chute retaining wall 


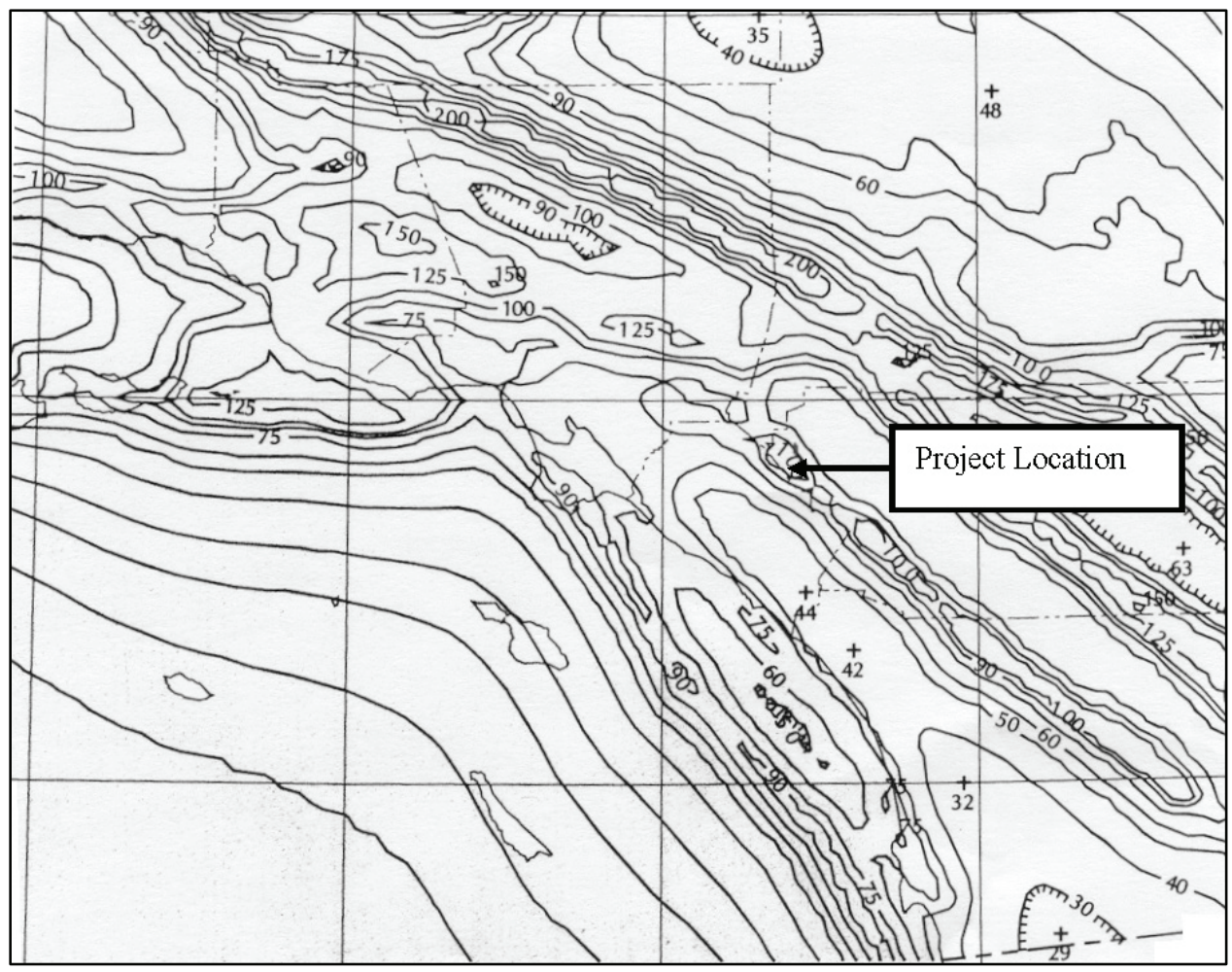

Figure C.5 USGS Map 32, probabilistic earthquake ground motion for California/Nevada, 1.00 -sec spectral response acceleration ( $5 \%$ of critical damping), $20 \%$ probability of exceedance in 50 years (return period of 475 years), LA Basin spillway chute retaining wall

C.9.2.2. Determine spectral acceleration values $S_{A(0.2)}$ and $S_{A(1.0)}$ for an MDE with a return period of 1,000 years. FEMA (2000) Equation 1-3 is recommended when the $S_{A(0.2)}$ for the 2,475-year event is greater than $1.5 \mathrm{~g}$. Therefore use $S_{A(0.2)}$ equal to $1.91 \mathrm{~g}$ for the MDE (Figure C.6). 


\begin{tabular}{|c|c|c|}
\hline \multicolumn{3}{|c|}{ Return period of interest $=1000$ years } \\
\hline $\mathrm{SA}_{0.2 \times 475}:=1.54$ & \multicolumn{2}{|c|}{$\begin{array}{l}0.2 \text {-sec. spectral acceleration } \\
\text { For return period of } 475 \text { years } \\
\text { USGS Map } 29\end{array}$} \\
\hline $\mathrm{SA}_{0.2 \times 2475}:=2.70$ & $\begin{array}{l}0.2 \text {-sec. spectral ac } \\
\text { For return period of } \\
\text { USGS Map } 31\end{array}$ & $\begin{array}{l}5 \text { years } \\
\end{array}$ \\
\hline \multicolumn{3}{|c|}{ Using FEMA 356 procedure find 0.2 -sec. spectral acceleration for 1000 years } \\
\hline $\mathrm{P}_{\mathrm{R}}:=1000$ & eriod $=1000$ years & \\
\hline By FEMA 356 Equation 1 & Note: $P_{\mathrm{R}}=\mathrm{Ret}$ & Period (years) \\
\hline \multicolumn{3}{|c|}{$\mathrm{L}_{\mathrm{PR}}:=\ln \left(\mathrm{SA}_{0.2 \times 475}\right)+\left(\ln \left(\mathrm{SA}_{0.2 \times 2475}\right)-\ln \left(\mathrm{SA}_{0.2 \times 475}\right)\right) \cdot\left(0.606 \cdot \ln \left(\mathrm{P}_{\mathrm{R}}\right)-3.73\right)$} \\
\hline \multicolumn{3}{|c|}{$\begin{array}{ll}L_{P R}=0.688 & \text { Natural } \log \text { of } P_{R} \\
& \text { For } 0.2 \text {-sec. spectral acceleration }\end{array}$} \\
\hline \multicolumn{3}{|l|}{$\mathrm{SA}_{0.2}:=\mathrm{e}^{\mathrm{L}} \mathrm{PR}$} \\
\hline \multicolumn{3}{|c|}{$\begin{array}{l}0.2 \text {-sec spectral acceleration } \\
\text { For } P_{R} \text { of } 1000 \text { years } \\
\text { is equal to } 1.989 \mathrm{~g}\end{array}$} \\
\hline By FEMA 356 Equation 1-3 & $\mathrm{n}:=0.29$ & 356 Table $1-1$ \\
\hline $\mathrm{SA}_{0.2}:=\mathrm{SA}_{0.2 \times 475}\left(\frac{\mathrm{P}_{\mathrm{R}}}{475}\right)^{\mathrm{n}}$ & $\mathrm{SA}_{0.2}=1.911$ & $\begin{array}{l}0.2-\text { sec spectral acceleration } \\
\text { For } P_{R} \text { of } 1000 \text { years } \\
\text { is equal to } 1.911 \mathrm{~g}\end{array}$ \\
\hline
\end{tabular}

Figure C.6 Mathcad calculations for 1,000-year 0.2-sec response 


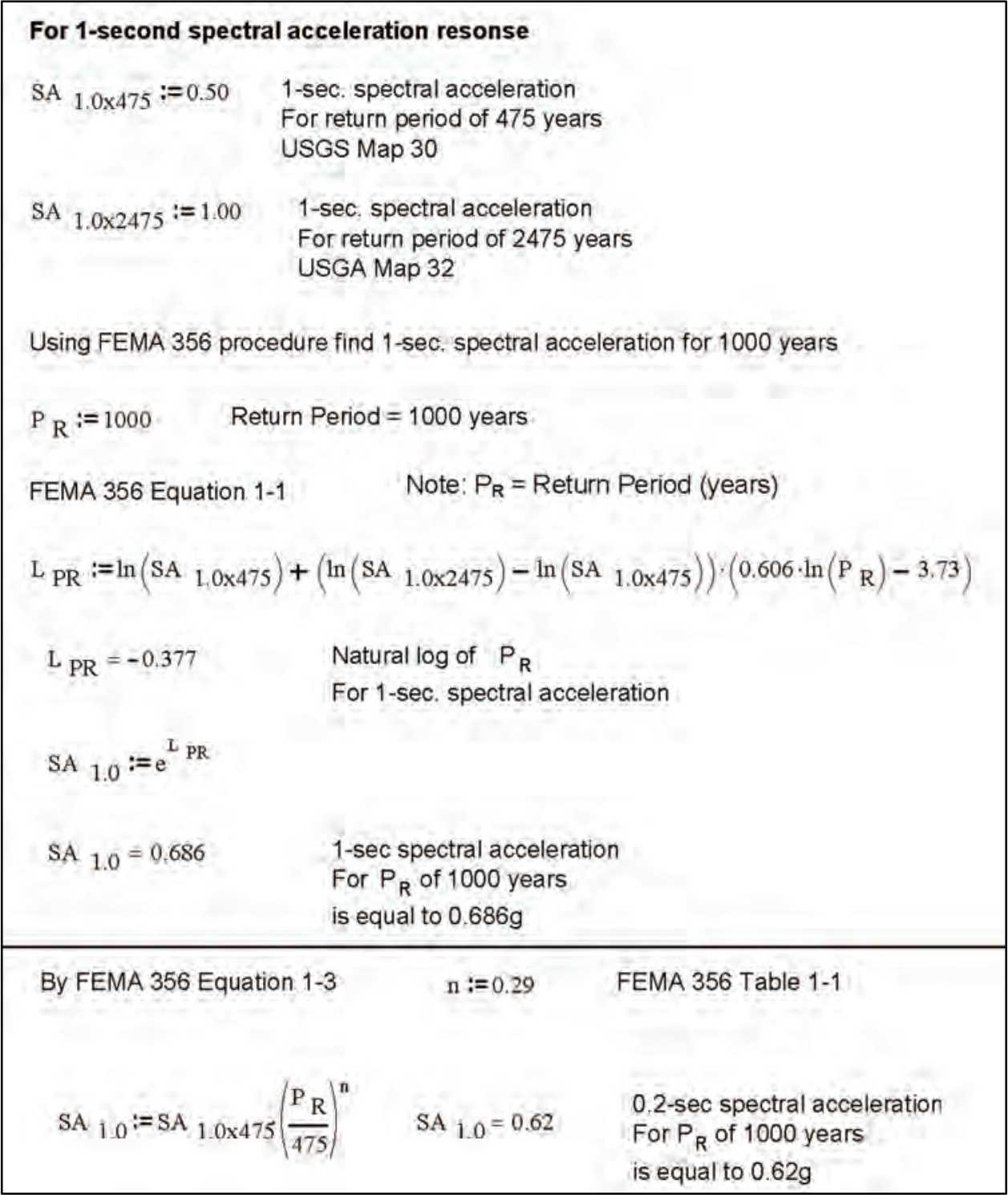

Figure C.7 Mathcad calculations for 1,000-year 1.0-sec response

FEMA (2000) Equation 1-3 is recommended when the $S_{A(1.0)}$ for the 2,475 -year event is greater than $1.5 g$. Therefore use $S_{A(1.0)}$ equal to $0.62 g$ for the MDE (Figure C.7).

C.9.2.3 Construct design response spectrum for 1,000-year MDE. Referring to Figure C. 1 and using the periods and equations in Table C. 4 construct a preliminary design response spectrum for an MDE with a 1,000-year return period.

Period $\boldsymbol{T}_{\boldsymbol{B}}: T_{B}=\frac{0.2\left(S_{A(1.0)}\right)\left(F_{(1.0)}\right)}{S_{A(0.2)}\left(F_{(0.2)}\right.}=\frac{0.2(0.62)(1)}{(1.91)(1)}=0.065 \mathrm{sec}$ 
Period $\boldsymbol{T}_{C}: T_{C}=\frac{\left(S_{A(1.0)}\right)\left(F_{(1.0)}\right)}{S_{A(0.2)}\left(F_{(0.2)}\right.}=\frac{(0.62)(1)}{(1.91)(1)}=0.32 \mathrm{sec}$

For curve A - B: $S_{A}=0.6 \frac{S_{A(0.2)}\left(F_{(0.2)}\right)(T)}{T_{B}}+0.4\left(S_{A(0.2)}\right)\left(F_{(0.2)}\right)$

$$
\begin{aligned}
& S_{A}=0.6 \frac{1.91 g(1.00)(T)}{0.065}+0.4(1.91 g)(1.00) \\
& S_{A}=17.63 g(T)+0.764 g
\end{aligned}
$$

For points B - C: $S_{A}=S_{A(0.2)}\left(F_{(0.2)}\right)=1.91 g(1.00)=1.91 g$

For the curve C $-\mathbf{D}: S_{A}=\frac{S_{A(1.0)}\left(F_{(1.0)}\right)}{T}=\frac{0.62 g}{T}$

With this information and using Figure C. 1 and Table C.4, the design response spectrum for the MDE can be constructed. The resulting standard horizontal spectrum is shown in Figure C.8. 


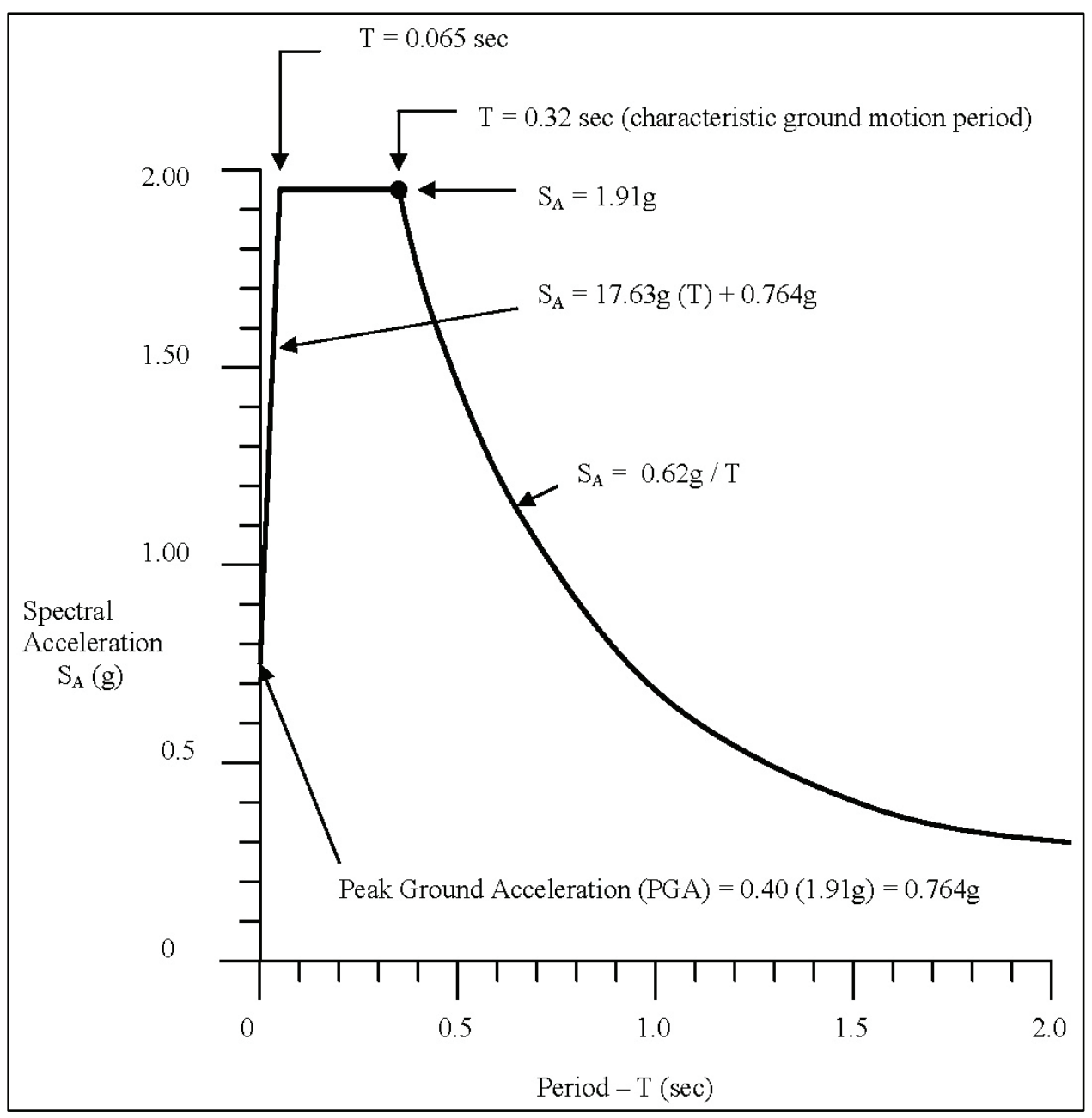

Figure C.8 Standard acceleration response spectrum for the MDE 


\section{Appendix D}

Corps Working Stress Design (WSD) Example by Working Stress Design Methods Using EM 1110-2-2502 and EM 1110-1-2101

A retaining wall similar to that described in Appendix A of Green and Ebeling (2002) ${ }^{1}$ is used to illustrate retaining wall designs that are

- Representative of the old Corps working stress design (WSD) method.

- Representative of the latest Corps ultimate strength design (USD) method.

The WSD is used to provide the flexural reinforcement for a design typical of older Corps retaining wall structures, which will later be compared to a retaining wall designed to meet current Corps USD design standards. The WSD is expected to provide the least margin of safety against demands from a major earthquake event, and will likely contain lap splice and development length deficiencies that make it more vulnerable than USD walls to major earthquake ground motion demands. Although the flexural steel in the WSD example is selected using WSD procedures, the shear will be checked using current American Concrete Institute (ACI)-USD procedures to verify that a WSD wall will not be deficient in this area with respect to current requirements.

Static earth pressure conditions are assumed to govern the design. The resulting static earth pressure design is then investigated for the maximum sustainable constant horizontal acceleration from earthquake ground motions. This is accomplished using the simplified procedure described in Ebeling and Morrison (1992). The maximum sustainable constant horizontal acceleration is determined for the conditions where the demands due to static and dynamic earth pressures

\footnotetext{
${ }^{1}$ References cited in this appendix are included in the References section at the end of the main text.
} 
initiate flexural yielding at the base of the stem wall (i.e., moment demand equals nominal moment capacity). This is the condition that will cause plastic hinging and initiate a stem wall yielding response. Displacement-based methods must be used for the stem wall yielding response to assure displacement capacity is greater than displacement demand. This process is illustrated in Appendix F.

\section{D.1 Working Stress Design}

The following material properties are used in the WSD: ${ }^{1}$

- Concrete. Ultimate strength $f_{c}^{\prime}=3,000 \mathrm{psi}$

- Reinforcement - Intermediate grade billet steel: Yield strength $f_{y}=$ $40,000 \mathrm{psi}$

- Modular ratio $n=E_{s} / E_{c}=9.2$ : ACI SP-3 (1965) "Reinforced Concrete Design Handbook -Working Stress Method"

WSD design procedures for the retaining wall are in accordance with Ferguson (1960) and based on provisions contained in the 1956 ACI Building Code, "Building Code Requirements for Reinforced Concrete," EM 1110-2-2502 (Headquarters, U.S. Army Corps of Engineers (HQUSACE) 1989) and EM 1110-1-2101. ${ }^{2}$

Applicable ACI-WSD provisions from the 1956 Code are provided in Table D.1 for allowable unit stresses in concrete, except the allowable stress in flexure is per the more stringent EM 1110-2-2101 requirement.

\begin{tabular}{||l|l||}
\hline \multicolumn{2}{||l||}{ Table D.1 } \\
Allowable Unit Stresses of Concrete (ACI-WSD) \\
\hline \hline Description & Allowable Unit Stress \\
\hline \hline Flexure - extreme fiber in compression $f_{c}$ & $0.35 f_{c}^{\prime}$ \\
\hline Shear as a measure of diagonal tension $v_{c}$ & $0.03 f_{c}^{\prime}$ \\
\hline Bond $\mu$ & $0.10 f_{c}^{\prime}$ \\
\hline Bond - top bars $\mu$ & $0.07 f_{c}^{\prime}$ \\
\hline \hline
\end{tabular}

\footnotetext{
${ }^{1}$ Each of the appendixes in this report has its own system of notation. Many of the symbols used in this appendix are defined in the text of this appendix. Others are commonplace to reinforced concrete design and retaining wall design. Readers not understanding a particular symbol notation should consult the references cited in this appendix for the definition.

${ }^{2}$ Working stress design as described in this appendix is taken from the 1963 version of EM 1110-2-2101, "Working Stresses for Structural Design," which is no longer in publication.
} 
Intermediate grade billet steel with a yield strength $f_{y}$ of $40,000 \mathrm{psi}$ and an allowable tensile unit stress $f_{s}$ of 20,000 psi per ACI-WSD will be used for the design.

The base thickness is generally assumed to be 7 to 10 percent of the overall wall height, or between 16.8 and $24.00 \mathrm{in}$. A base thickness of $18 \mathrm{in}$. is selected.

\section{D.2 Service Load Analysis}

A description of the retaining wall for the ACI-WSD design is provided in Figure D.1.

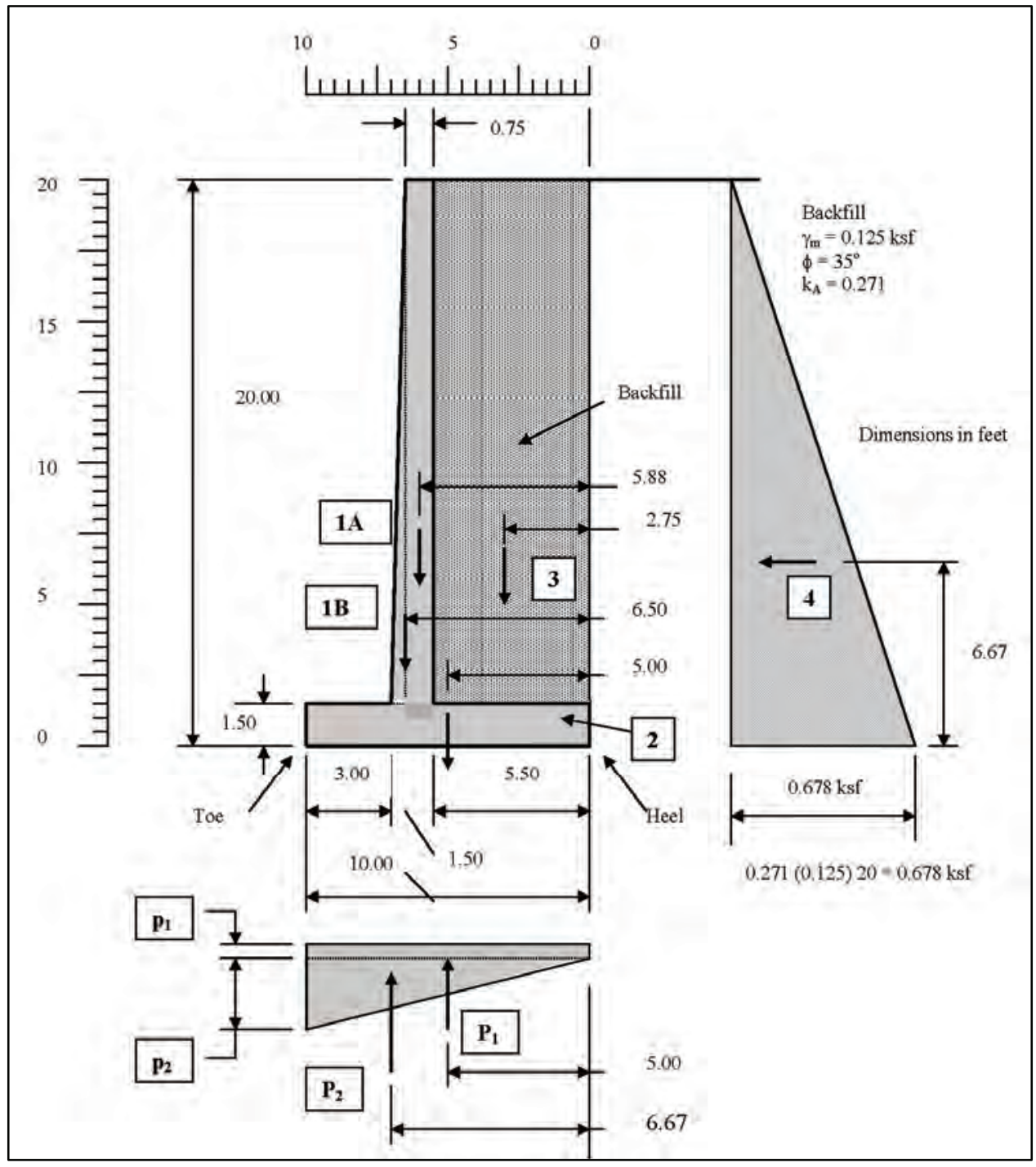

Figure D.1 Retaining wall geometry and loads

Proportions selected for the cantilever retaining wall are as illustrated in Figure D.1. Overturning and sliding stability computations are provided in Table D.2. 


\section{Table D.2 \\ Stability Computations}

\begin{tabular}{||l|l|l|l|l|l||}
\hline \hline Force & Description & $\boldsymbol{F}_{\boldsymbol{V}}, \mathbf{k i p s}$ & $\boldsymbol{F}_{\boldsymbol{H}}, \mathbf{k i p s}$ & Lever Arm, ${ }^{\mathbf{1}} \mathbf{f t}$ & Moment at Heel, kip-ft \\
\hline \hline 1A & Stem & 2.08 & & 5.88 & 12.23 \\
\hline 1B & Stem & 1.04 & & 6.50 & 6.76 \\
\hline 2 & Base & 2.25 & & 5.00 & 11.25 \\
\hline 3 & Backfill & 12.72 & & 2.75 & 34.98 \\
\hline 4 & Backfill Pressure & & 6.78 & 6.67 & 45.22 \\
\hline & Totals & $\mathbf{1 8 . 0 9}$ & $\mathbf{6 . 7 8}$ & & $\mathbf{1 1 0 . 4 4}$ \\
\hline \hline
\end{tabular}

a. Location of resultant from heel

$X=110.44 \div 18.09=6.11 \mathrm{ft} \leftarrow$ Inside middle one-third of base

b. Determine Bearing Pressures

$10.00 p_{1}+5.00 p_{2}=18.09 \leftarrow$ Equation 1 - Sum of vertical forces $=0$

$50.00 p_{1}+33.33 p_{2}=18.09(6.11) \leftarrow$ Equation $2-$ Sum of moments at heel $=0$

$50.00 p_{1}+25.00 p_{2}=18.09(5) \leftarrow$ Equation $3=$ Equation 1 multiplied by 5.0

Subtracting Equation 3 from Equation 2

$8.33 p_{2}=20.07 \quad p_{2}=2.41 \mathrm{ksf}$

Backsubstituting into Equation 1:

$10.00 p_{1}=18.09-5.00(2.41)=6.04 \quad p_{1}=0.61 \mathrm{ksf} \quad p_{1}+p_{2}=3.02 \mathrm{ksf}$

c. $\quad$ Check Bearing Pressure $=F / A \pm 6 F(e) / B^{2}$

Bearing Pressure $=[18.09 \div 10] \pm\left[6(18.09)(1.11) \div 10^{2}\right]$

$$
=1.81 \pm 1.20=3.01 \mathrm{ksf} \& 0.61 \mathrm{ksf} \text { Checks }
$$

The factor of safety against sliding is checked using EM 1110-2-2502 ${ }^{1}$ guidance. The foundation shear strength for cohesionless soil supporting the wall will be based on an angle of internal friction $\phi$ of 40 degrees per the Green and Ebeling (2002) example.

Sliding resistance $R=\sum V \tan \phi=18.09 \tan \left(40^{\circ}\right)=15.2 \mathrm{kips} / \mathrm{ft}$

$\sum H=6.78$ kips

$F S=R \div \sum H=15.2 \div 6.78=2.2$ Factor of safety against sliding greater than 1.5 Okay

Note that current Corps guidance is based on limiting equilibrium principles, which may require a larger base to meet sliding stability safety requirements.

\footnotetext{
${ }^{1}$ The retaining wall guidance described in this appendix is taken from the 1961 version of EM 1110-2-2502 (superseded).
} 


\section{D.3 Stem Moment Demands and Selection of Flexural Reinforcement}

Information from Table 1 of ACI SP-3 (1965) is presented in Table D.3. This information is used to simplify the WSD method calculations. The information from Table D.3 is illustrated in Figure D.2.

\begin{tabular}{|c|c|c|c|c|c|c|}
\hline $\begin{array}{l}\text { Tabl } \\
\text { Coe } \\
a=1\end{array}$ & $\begin{array}{l}\text { D.3 } \\
\text { cient } \\
4\end{array}$ & $k$ & p) $f$ & Rec & gular & ctions, $F_{s}=20,000 \mathrm{psi}$, \\
\hline$f_{c}^{\prime} n$ & $\boldsymbol{f}_{\mathrm{c}}$ & $K$ & $k$ & $j$ & $p$ & \\
\hline & 875 & 120 & .306 & .898 & .0067 & $k=\frac{1}{1+f \ln f}$ \\
\hline 2500 & 1000 & 149 & .336 & .888 & .0084 & \\
\hline 10.1 & 1125 & 179 & .362 & .879 & .0102 & \\
\hline & 1250 & 211 & .387 & .871 & .0121 & \\
\hline & 1500 & 277 & .431 & .856 & .0162 & $j=1-\frac{1}{3} k$ \\
\hline & 1050 & 152 & .326 & .891 & .0085 & \\
\hline 3000 & 1200 & 188 & .356 & .881 & .0107 & \\
\hline 9.2 & 1350 & 226 & .383 & .872 & .0129 & $K=\frac{t_{c}}{2} k j$ \\
\hline & 1500 & 265 & .408 & .864 & .0153 & \\
\hline & 1800 & 346 & .453 & .849 & .0204 & \\
\hline & 1400 & 221 & .359 & .880 & .0126 & $a=\frac{I_{s}}{12000}(j)$ \\
\hline 4000 & 1600 & 272 & .390 & .870 & .0156 & \\
\hline 8.0 & 1800 & 324 & .419 & .860 & .0188 & \\
\hline & 2000 & 379 & .444 & .852 & .0222 & $A_{s}=\frac{M}{2 d}$ \\
\hline & 2400 & 492 & .490 & .837 & .0294 & \\
\hline & 1750 & 292 & .383 & .872 & .0168 & \\
\hline 5000 & 2000 & 358 & .415 & .862 & .0208 & \\
\hline 7.1 & 2250 & 426 & .444 & .852 & .0250 & $M=$ Moment in foot-kips \\
\hline & 2500 & 496 & .470 & .843 & .0294 & \\
\hline & 3000 & 641 & .516 & .828 & .0387 & \\
\hline
\end{tabular}

\section{D.3.1 Flexural reinforcement needed at base of stem wall}

$M_{B A S E}=0.271(0.125) 18.5(0.5)(18.5)(0.333)(18.5)=35.71 \mathrm{ft}-\mathrm{kips}$

$K($ Table 1, ACI-WSD SP-3 $($ ACI 1965) $)=152$

$M=K b d^{2}$

$d^{2}=M_{B A S E} \div K b=35.71(12,000) \div 152(12)=234.9 \quad d=15.32$ in.

Assuming \#8 main reinforcement and a cover of 2 in. per ACI-WSD

Depth provided $=18.00-2.00-0.50=15.50$ in. $\quad$ Okay

Determine stem wall reinforcement at base using Table 1, ACI-WSD SP-3: 
$A_{s}=M_{B A S E} \div a d=35.71 \div 1.44(15.50)=1.60 \mathrm{in}^{2} /$ foot of wall

Use \#8@ 6 in. $\quad A_{s}=1.58$ in. $^{2} /$ foot of wall

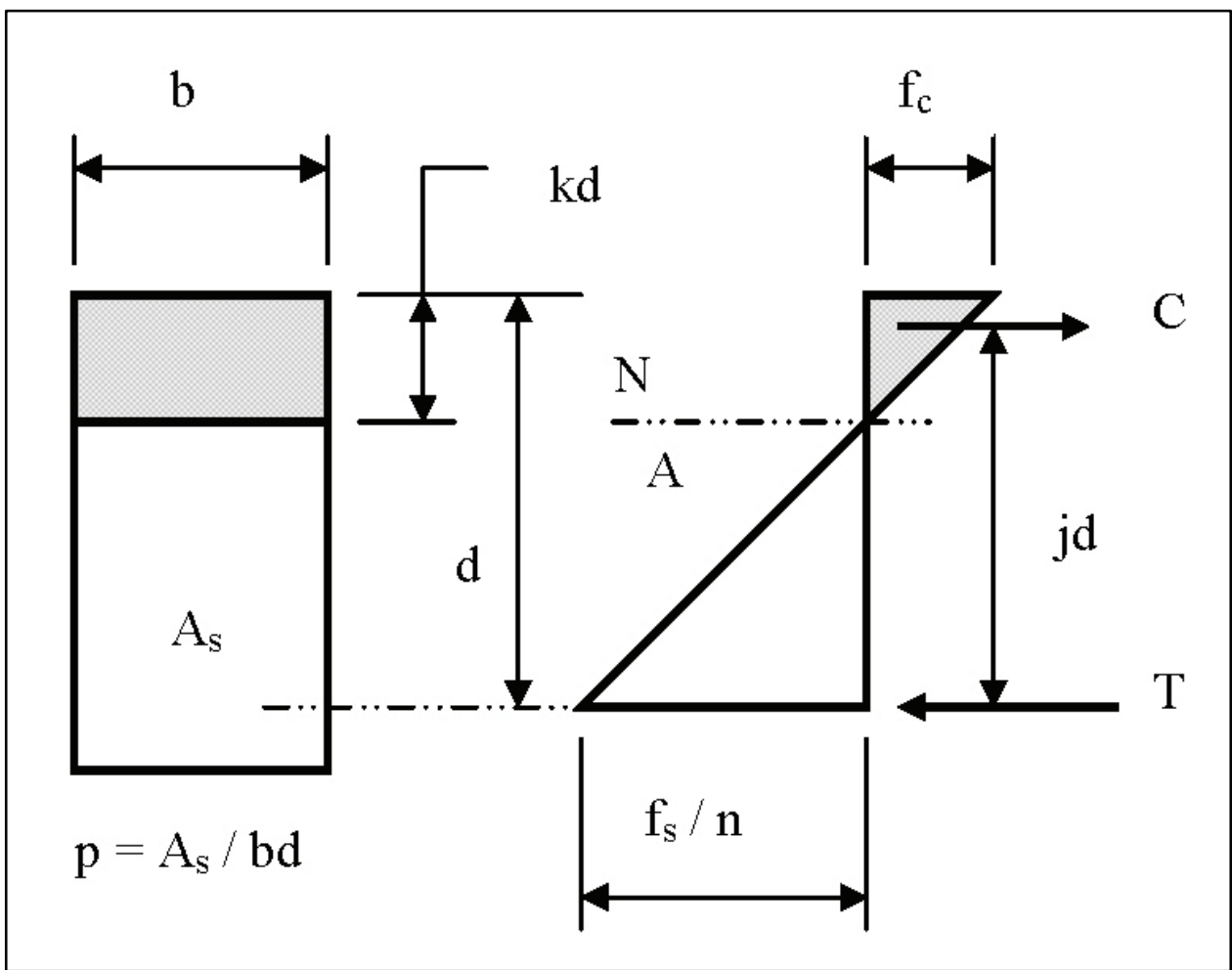

Figure D.2 Coefficients $(K, k, j, p)$ for rectangular sections

\section{D.3.2 Flexural reinforcement needed at midheight of stem wall}

Common practice in the design of cantilever retaining walls is to stop half the main flexural reinforcement at midheight of the stem wall. This practice will be used in the Appendix D examples. ACI-WSD requires that bars be carried 12 bar diameters $D$ beyond where they are no longer needed. Since \#8 bars were selected, the moment at midheight +12 in. $M_{M H^{+}}$(measured from the top of wall) will be used to calculate steel requirements for the top half of the wall.

$$
M_{M H^{+}}=0.271(0.125) 10.25(0.5)(10.25)(0.333)(10.25)=6.07 \mathrm{ft}-\mathrm{kips}
$$

The section depth at midheight is equal to $0.5(9+18)-2.5=11.0 \mathrm{in}$.

$$
A_{s}=M_{M H^{+}} \div a d=6.07 \div 1.44(11.00)=0.38 \text { in. }^{2} / \text { foot } \text { of wall } \leftarrow \text { Required }
$$

\#8@ 12 in. $\quad A_{s}=0.79$ in. $^{2} /$ foot of wall $\leftarrow$ Provided Okay

The strength envelope (nominal capacity) for the WSD stem wall is determined by current ACI-USD procedures. This will allow an assessment of the ability of the walls to withstand earthquake ground motion demands. The stem wall flexural strength envelope is shown in Figure D.3. It is compared against the 
service load demand from static earth pressure to illustrate the reserve capacity available to resist the ground motion demands of a major earthquake.

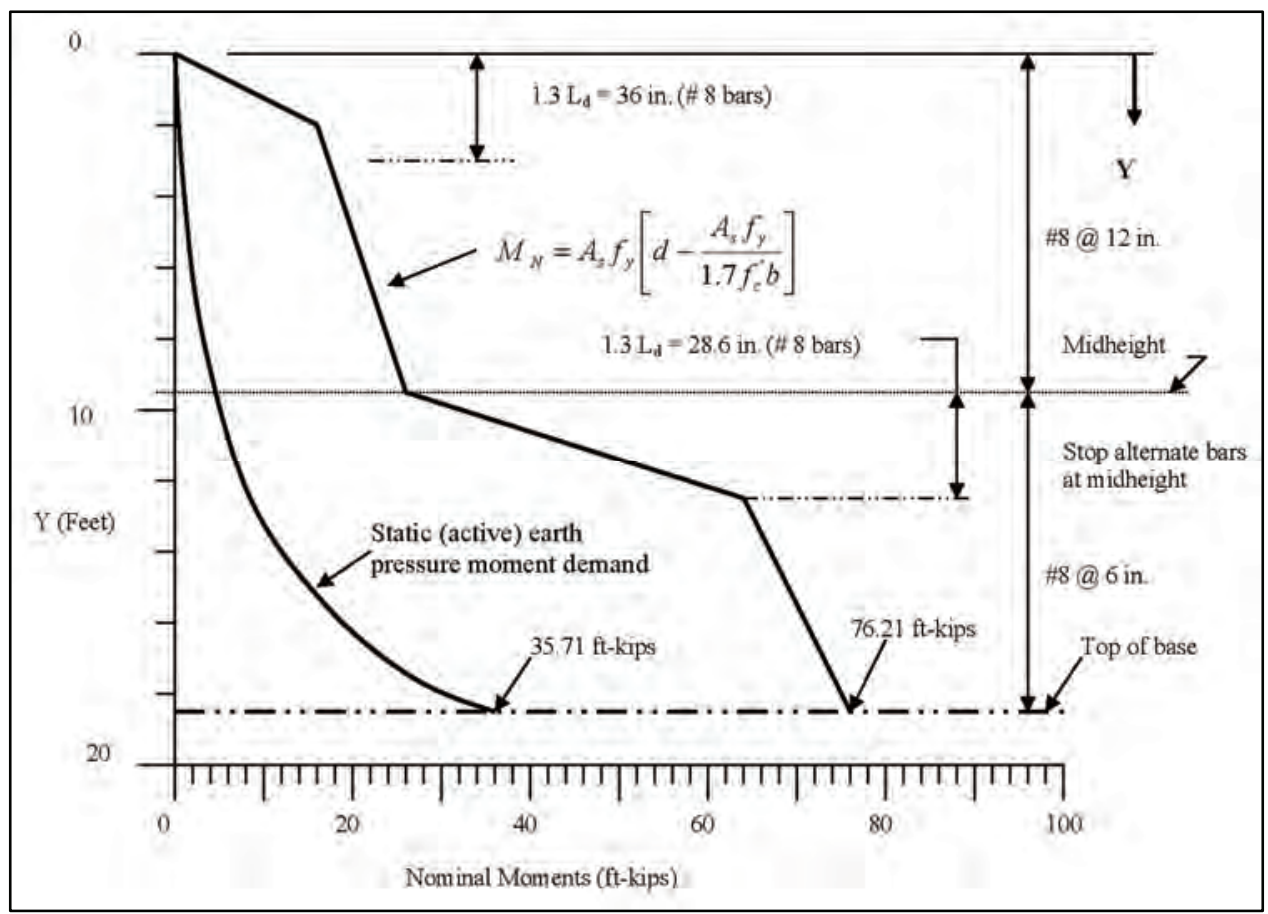

Figure D.3 Stem flexural steel — demand versus capacity

The layout of the main flexural reinforcment for the stem and base is illustrated in Figure D.4.

\section{D.3.3 Check of shear capacity stem per USD}

The critical section for shear in the stem is taken at 15.5 in. above the interface of the base and the stem, where $15.5 \mathrm{in}$. is $d$ at the base of the stem.

$V_{B A S E}=0.271(0.125) 17.2(0.5)(17.2)=5.00 \mathrm{kips}$

Ultimate shear demand at distance $d$ above base $V_{U}=1.7(5.00)=8.50$ kips

Ultimate shear capacity $\phi V_{N}=\phi(b)(d)(2)\left(f_{c}^{\prime}\right)^{1 / 2}$

$$
=0.75(12)(15.5)(2)(55)=15,345 \mathrm{lb}=15.3 \mathrm{kips}
$$

Shear capacity greater than shear demand. Okay.

\section{D.4 Base Toe Design}

\section{D.4.1 Shear}

$$
V_{T O E}=5.00 \text { kips (Figure D.5) }
$$




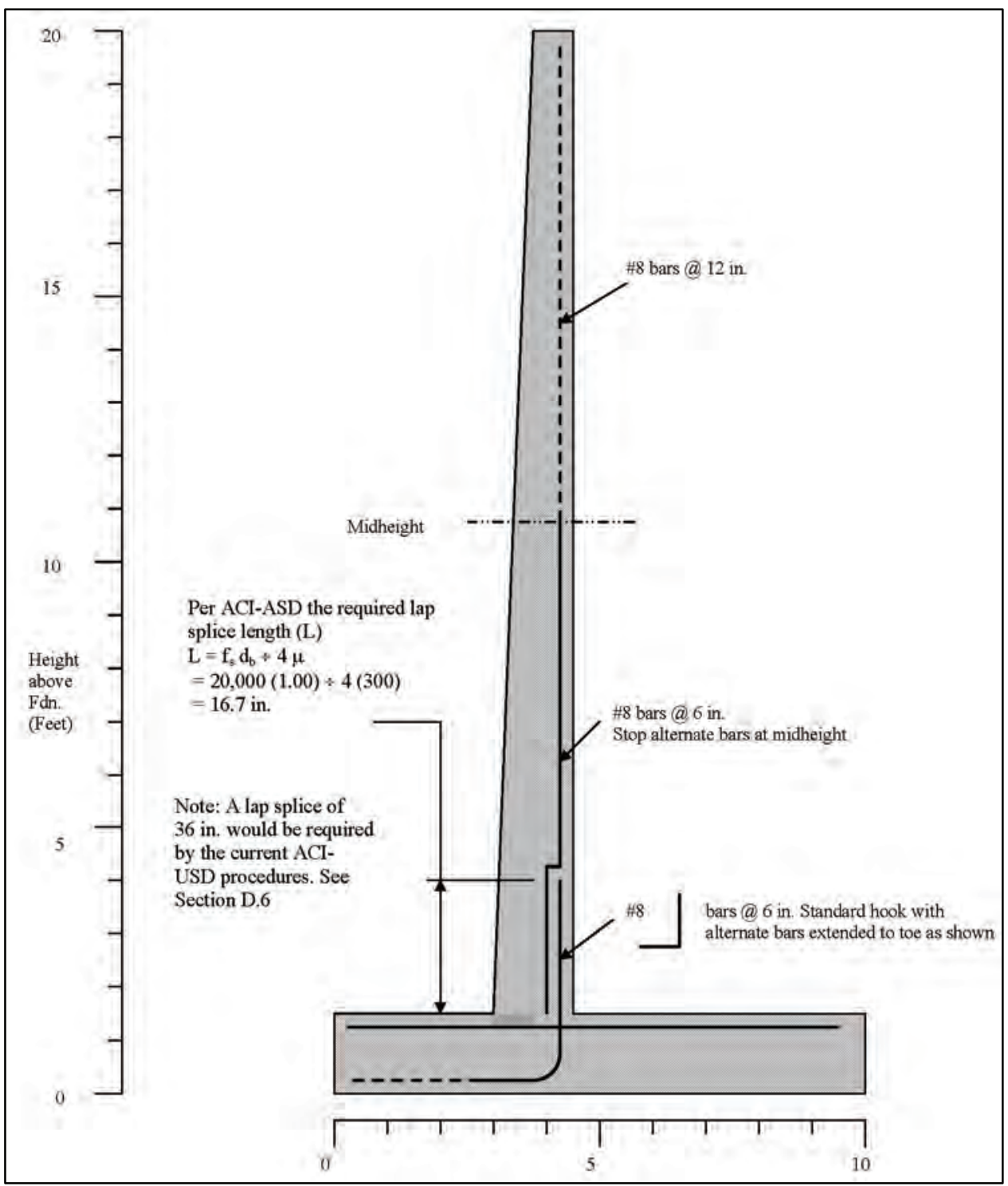

Figure D.4 Main reinforcement

Ultimate shear demand $V_{U}=1.7(5.00)=8.50 \mathrm{kips} \leftarrow$ Using a load factor equal to 1.7

$d=18.00-3.00-0.5=14.5$ in.

Ultimate shear capacity $\phi V_{N}=\phi(b)(d)(2)\left(f_{c}^{\prime}\right)^{1 / 2}$

$$
\begin{aligned}
& =0.75(12)(14.5)(2)(55) \\
& =14,355 \mathrm{lb}=14.4 \mathrm{kips}
\end{aligned}
$$

Shear capacity greater than shear demand. Okay. 


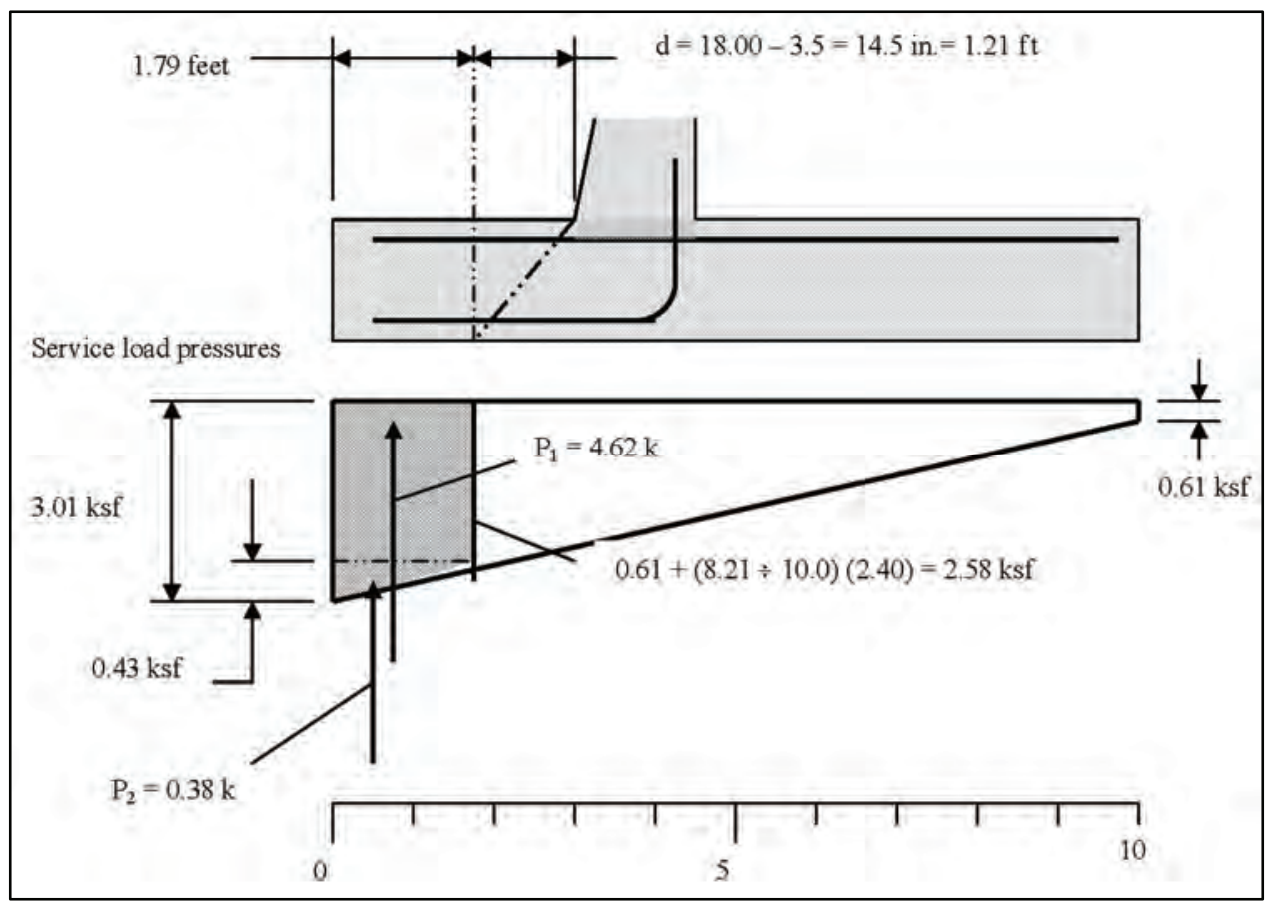

Figure D.5 Shear on toe of base

\section{D.4.2 Flexure}

$M_{T O E}=3(2.29)(1.50)+0.72(1.5)(2)=12.47 \mathrm{ft}$-kips (Figure D.6)

$A_{s}=M_{T O E} \div a d=12.47 \div 1.44(14.50)=0.60$ in. $^{2} /$ foot of wall $\leftarrow$ Require

Use \#8 bars $@ 12$ in. $\quad A_{s}=0.79$ in. $^{2} /$ foot of wall $\leftarrow$ Provided

\section{D.5 Base Heel Design}

\section{D.5.1 Shear}

Check of shear capacity stem per USD

$$
\begin{aligned}
V_{\text {HEEL }} & =2.31(5.50)+0.15(1.50)(5.5)-0.61(5.5)-1.32(5.5) \div 2 \\
& =12.71+1.24-3.36-3.63=6.96 k(\text { Figure D.7 })
\end{aligned}
$$

Ultimate shear demand $V_{U}=1.7(6.96)=11.83$ kips $\leftarrow$ Using a load factor equal to 1.7

Ultimate shear capacity $\phi V_{N}=\phi(b)(d)(2)\left(f_{c}^{\prime}\right)^{1 / 2}$

$$
\begin{aligned}
& =0.75(12)(15.5)(2)(55) \\
& =15,345 \mathrm{lb}=15.3 \mathrm{kips}
\end{aligned}
$$

Shear capacity greater than shear demand. Okay. 


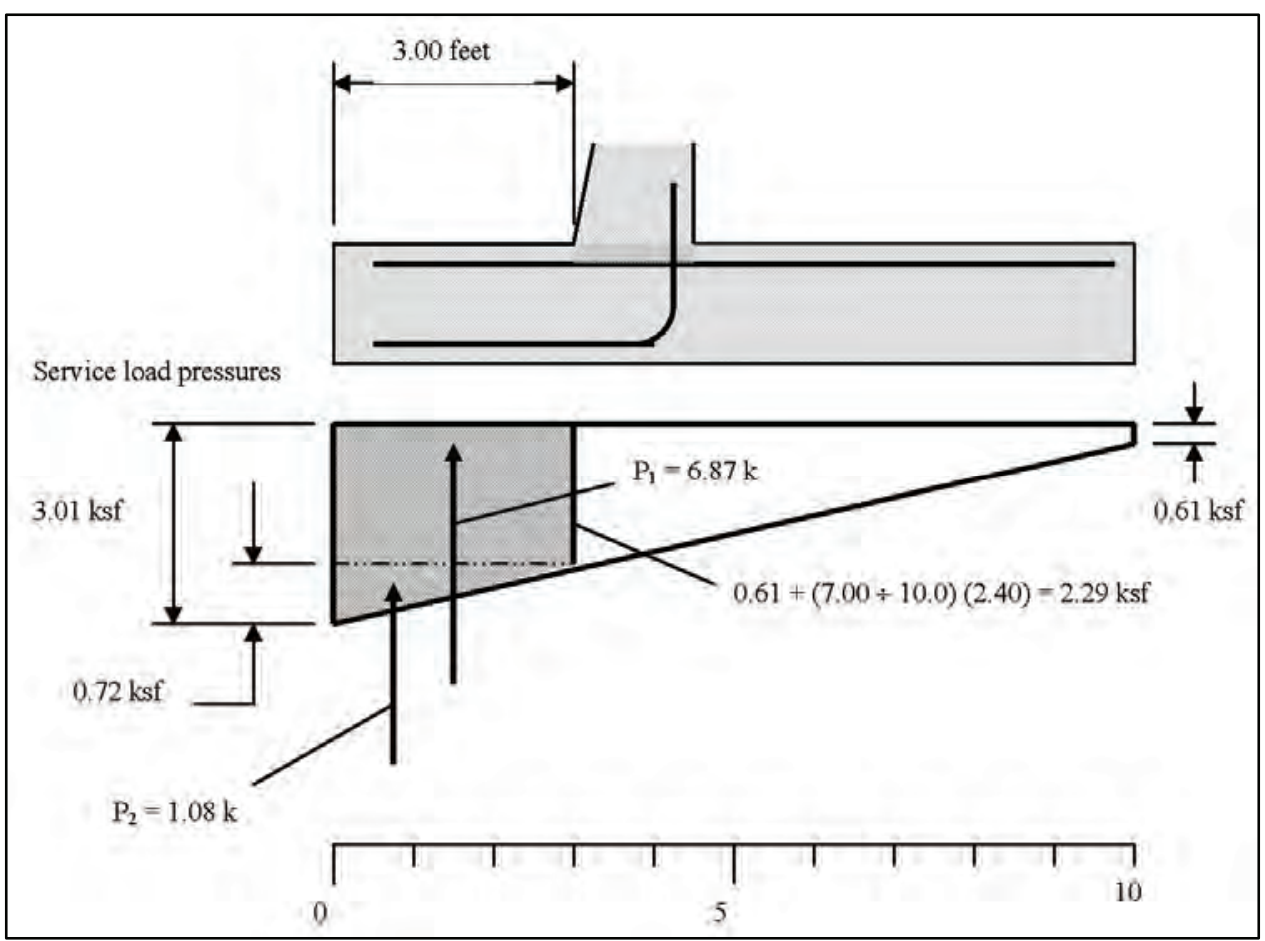

Figure D.6 Moment on toe of base

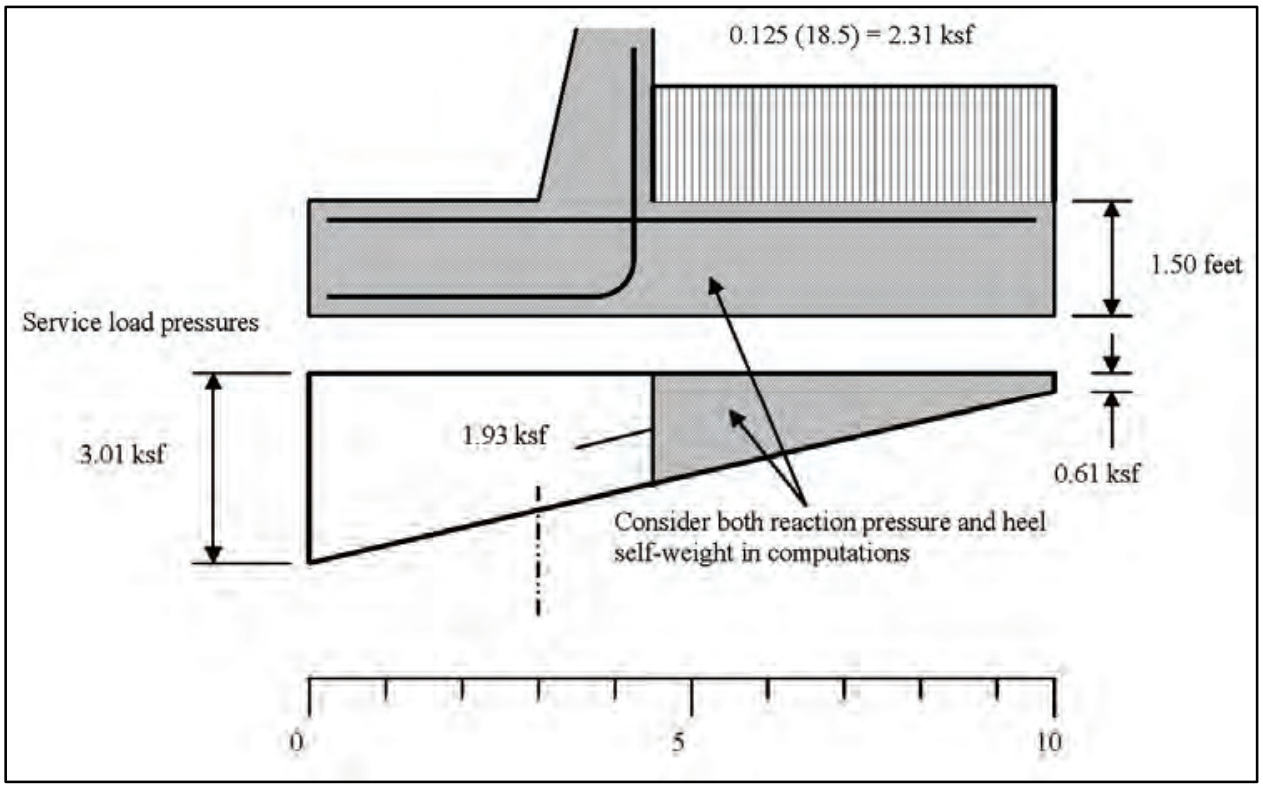

Figure D.7 Shear on heel of base

\section{D.5.2 Flexure}

$$
M_{H E E L}=12.71(2.75)+1.24(2.75)-3.36(2.75)-3.63(1.83)=23.66 \mathrm{ft}-\mathrm{kips}
$$

(Figure D.8)

$$
A_{s}=M_{H E E L} \div a d=23.66 \div 1.44(15.50)=1.06 \text { in. }^{2} / \text { foot of wall } \leftarrow \text { Required }
$$




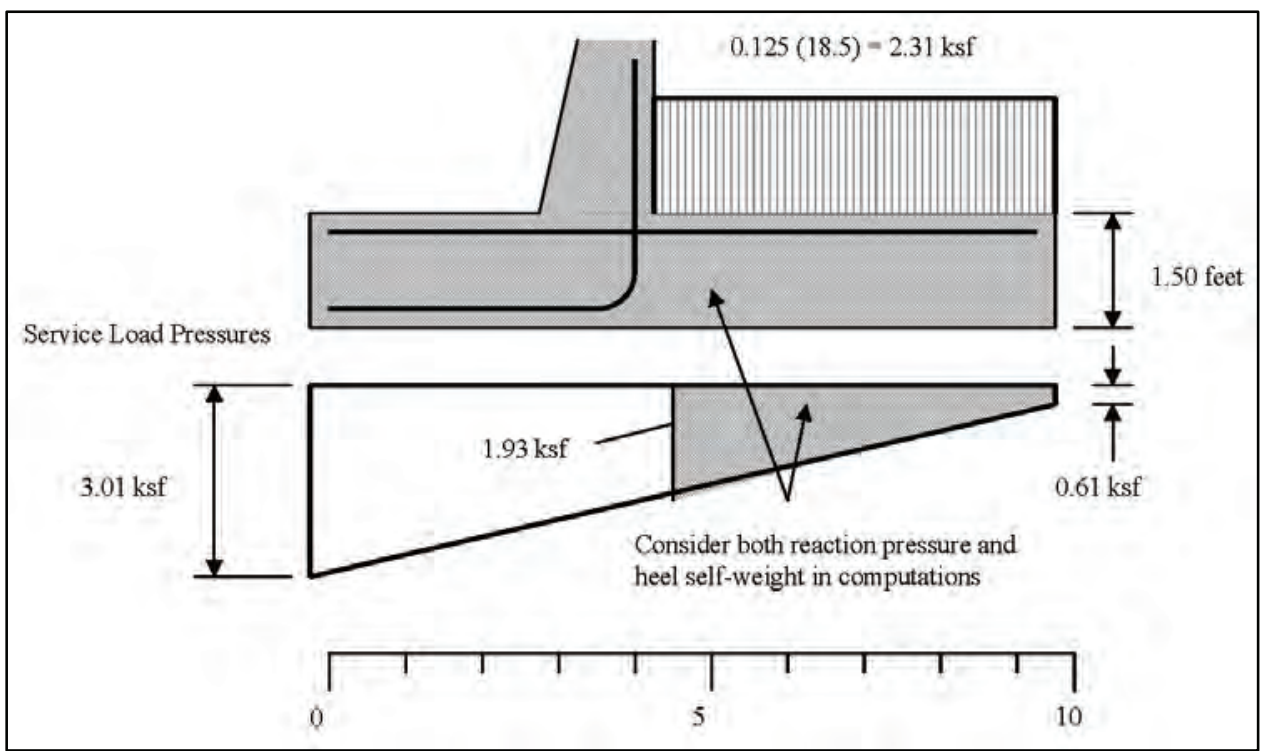

Figure D.8 Moment on heel of base

Use \#7 bars @ 6 in. $\quad A_{s}=1.20$ in. ${ }^{2} /$ foot of wall $\leftarrow$ Provided

\section{D.6 Development Requirements for \#8 Reinforcement}

\section{D.6.1 Straight bars}

Required lap splice length $=1.3 l_{d}=1.3(27.4)=36$ in. (Figure D.9). Assume for this example that the splice length required by ACI 318-02 as indicated has been provided. Refer to Appendix F for evaluating conditions where there is inadequate splice length.

\section{D.6.2 Hooks}

Minimum base slab thickness using \#8 stem reinforcement is equal to $10.2+$ $0.5+3.00=13.7$ in. (Figure D.10).

$13.7<18.00$ okay

\section{D.7 Evaluate Static Earth Pressure Design for Earthquake}

\section{D.7.1 Earthquake evaluation per Seed and Whitman (1970) and Ebeling and Morrison (1992)}

Static and incremental dynamic earth pressures are illustrated in Figure D.11. 


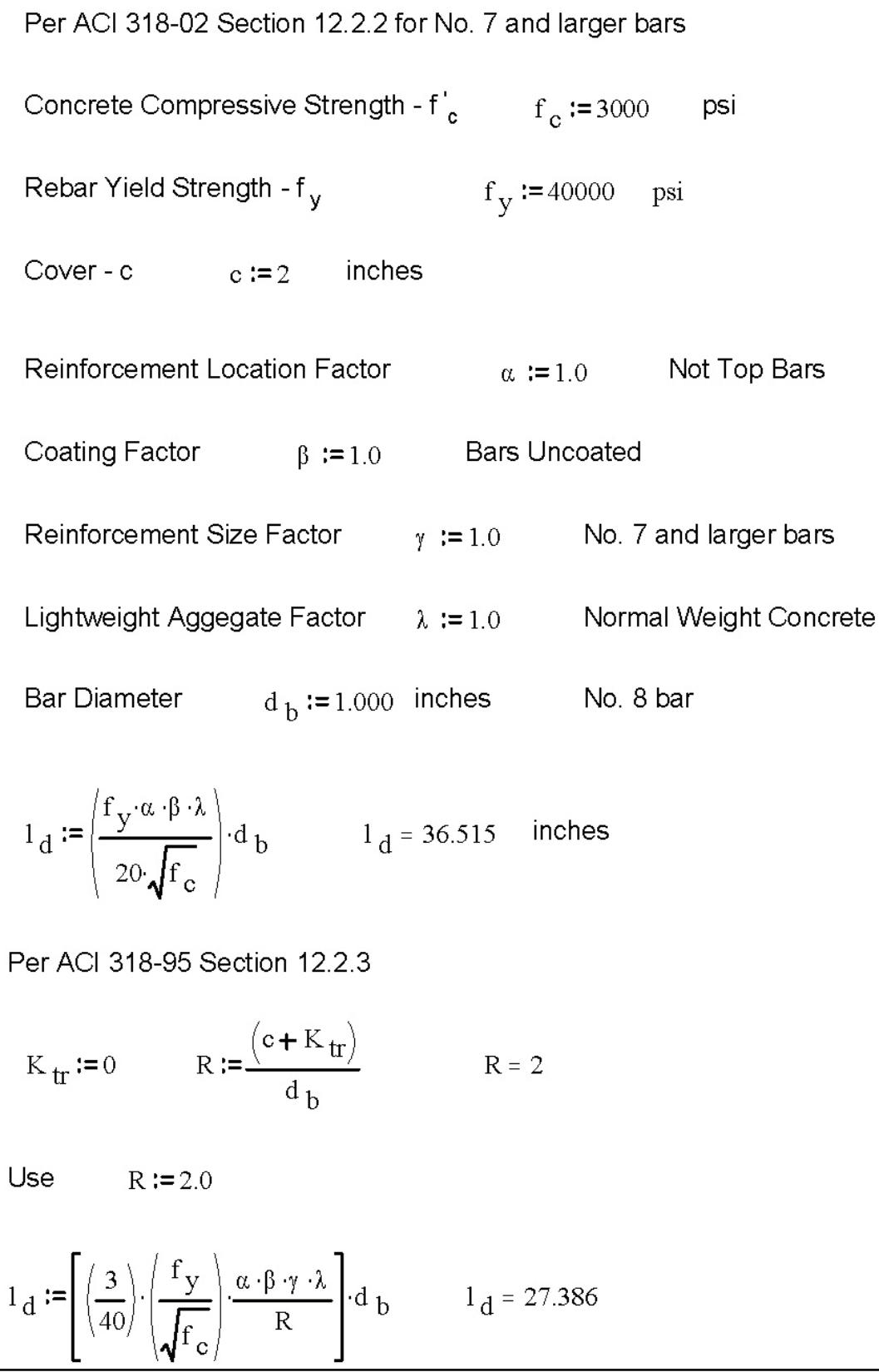

Figure D.9 Mathcad calculations for development length — straight bars

Determine peak ground acceleration (PGA) where static and dynamic earth pressure demands initiate flexural yielding at the base of the stem wall (i.e., moment demand equals nominal moment capacity).

The dynamic active earth pressure force $\Delta P_{A E}$ is determined per paragraph 4.2.2 of Ebeling and Morrison (1992):

$\triangle P_{A E}$ is located at $0.6 H$ above top of base slab $=11.1 \mathrm{ft}$ where $H$ is the height of soil retained by the wall 
Development length for hooks

Per ACl 318-02 Section 12.5.2 for hook devlopment length

Concrete Compressive Strength $-f_{c} \quad f_{c}:=3000 \quad p s i$

Rebar Yield Strength $-\mathrm{f}_{\mathrm{y}} \quad \mathrm{f}_{\mathrm{y}}:=40000 \quad \mathrm{psi}$

Reinforcement Location Factor $\quad \alpha:=1.0 \quad$ Not Top Bars

Coating Factor $\quad \beta:=1.0 \quad$ Bars Uncoated

Lightweight Aggegate Factor $\quad \lambda:=1.0 \quad$ Normal Weight Concrete

Bar Diameter $\quad \mathrm{d}_{\mathrm{b}}:=1.00$ inches No. 8 bar

Per $\mathrm{ACl}$ 318-02 Section 12.5.1

$$
\begin{aligned}
& 1_{\mathrm{dh}}:=\left(\frac{0.02 \mathrm{f}_{\mathrm{y}} \cdot \beta \cdot \lambda}{\sqrt{\mathrm{f}_{\mathrm{c}}}}\right) \cdot \mathrm{d}_{\mathrm{b}} \quad 1_{\mathrm{dh}}=14.606 \text { inches } \\
& \eta:=0.7 \quad \text { Modification factor per ACl } 318-02 \text { Section 12.5.3 } \\
& 1_{\mathrm{dhm}}:=\eta \cdot 1_{\mathrm{dh}} \quad 1_{\mathrm{dhm}}=10.224 \quad \text { inches }
\end{aligned}
$$

Figure D.10 Mathcad calculations for development length — hooks

$M_{N}=$ Nominal moment capacity at base of stem wall $=76.21 \mathrm{ft}-\mathrm{kips}$

$P_{A}=$ Lateral load due to active earth pressure=5.80 kips @ $6.17 \mathrm{ft}$ above top of base

$\Sigma$ Moment about top of base to determine reserve capacity for earthquake loading.

$11.1\left(\Delta P_{A E}\right)=76.21-5.80(6.17)=76.21-35.79=40.42$

$\Delta P_{A E}=3.64$ kips

Determine the dynamic earth pressure increment coefficient $\Delta K_{A E}$ per Equation (41), Ebeling and Morrison (1992).

$\Delta P_{A E}=\Delta K_{A E} \div 0.5 \gamma_{m} H^{2}$ 


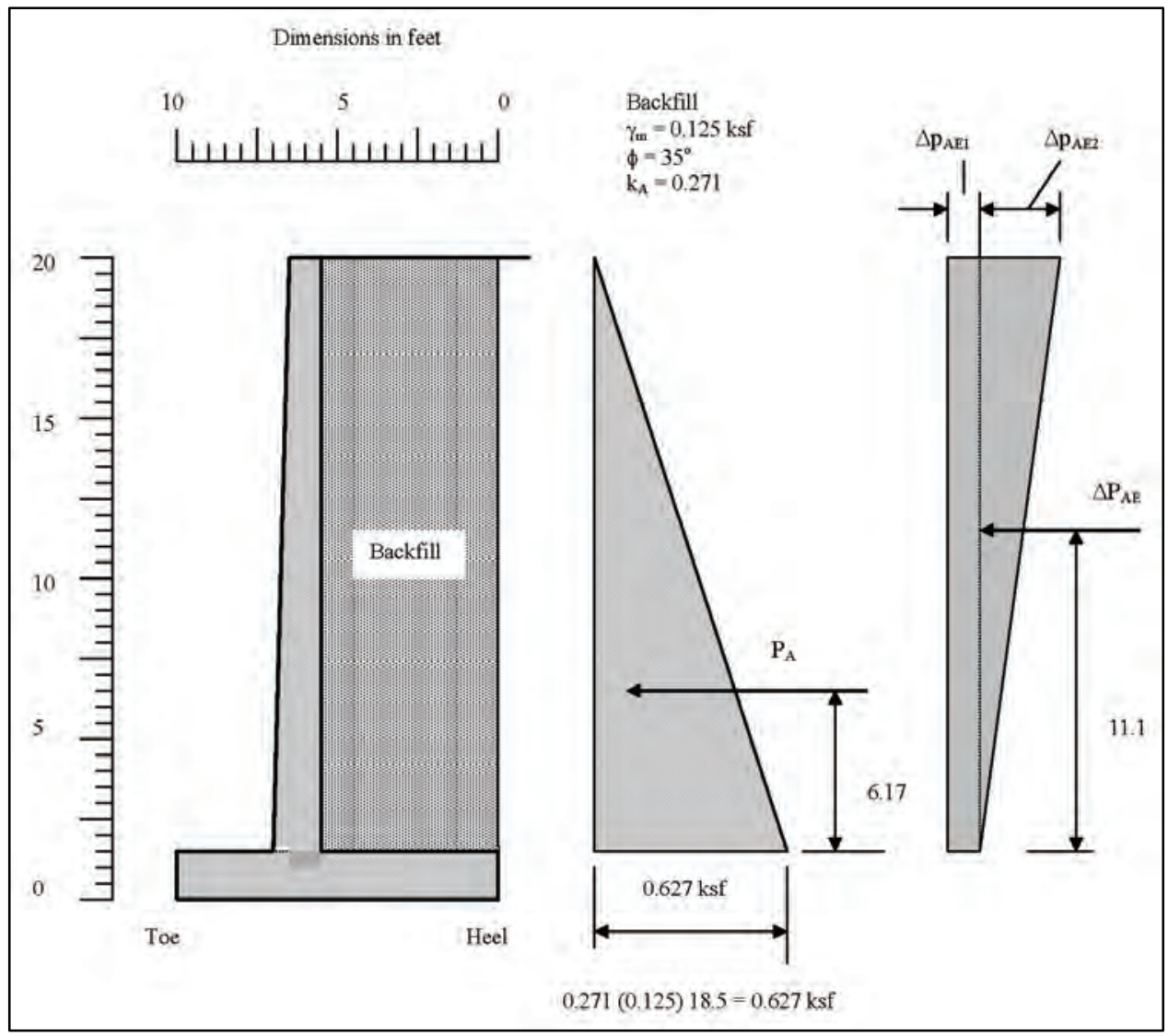

Figure D.11 Static and incremental dynamic earth pressures

$$
\Delta K_{A E}=\Delta P_{A E} \div\left(0.5 \gamma_{m} H^{2}\right)=3.64 \div 0.5(0.125)(18.5)^{2}=0.170
$$

Determine constant horizontal coefficient $k_{h}$ per Equation (43), Ebeling and Morrison (1992).

$$
\begin{aligned}
& \Delta K_{A E}=(3 / 4) k_{h} \\
& k_{h}=4\left(\Delta K_{A E}\right) \div 3=4(0.170) \div 3=0.227
\end{aligned}
$$

Observation: A constant horizontal acceleration $k_{h} g$ equal to $0.227 g$ will initiate flexural yielding in the stem wall region just above the base.

Determine dynamic earth pressures $\Delta p_{A E 1}$ and $\Delta p_{A E 2}$

$\Sigma$ Dynamic earth pressure forces in horizontal direction

$18.5\left(\Delta p_{A E 1}\right)+9.25\left(\Delta p_{A E 2}\right)=3.64 \quad$ Equation (1)

$\Sigma$ Dynamic earth pressure moments at stem wall base

$$
9.25(18.5)\left(\Delta p_{A E 1}\right)+12.33(9.25)\left(\Delta p_{A E 2}\right)=40.42 \quad \text { Equation (2) }
$$


Equation (1) $\times 9.25$ and subtract from Equation (2)

$28.49\left(\Delta p_{A E 2}\right)=6.75$

$\triangle p_{A E 2}=0.237 \mathrm{ksf}$

Backsubstituting $\Delta p_{A E 2}$ into Equation (1) and solving for $\Delta p_{A E 1}$

$\Delta p_{A E 1}=0.078 \mathrm{ksf}$

Total static and dynamic earth pressure moments in stem wall:

$$
\begin{aligned}
& M_{T}=0.167\left(k_{a}\right)\left(\gamma_{m}\right)\left(y^{3}\right) \\
& +0.500\left(\Delta p_{A E 1}\right)\left(y^{2}\right) \\
& +0.0541 \Delta p_{A E 2}(18.5-y)(18.5-0.50 y) \\
& +\left[\Delta p_{A E 2}-0.0541 \Delta p_{A E 2}(18.5-y)\right] 0.50 y(18.5-0.333 y)
\end{aligned}
$$

The total moment demand (static + dynamic) for the earthquake condition that produces initial flexural yielding at the base of the stem wall is illustrated in Figure D.12. This does not mean higher earthquake demands are unacceptable. Further investigation of the displacement capacity of the stem wall is needed to establish the level of earthquake demand that will create unacceptable performance.

It should be noted that Figure D.12 assumes that adequate splice and development lengths have been provided. The ACI-WSD example does not have an adequate splice length where the main steel exits the footing. The inadequate lap splice issue is discussed in Appendix B and demonstrated in Appendix F.

\section{D.7.2 Earthquake evaluation per Veletsos and Younan (1997)}

Assuming:

$$
\begin{aligned}
E_{W}= & 475,000 \mathrm{ksf}(3,000 \mathrm{psi} \text { normal weight concrete) (Young's modulus } \\
& \text { of elasticity for the wall) } \\
t_{W}= & 1.5 \mathrm{ft} \text { (wall thickness) } \\
v_{W}= & 0.20 \text { (Poisson's ratio for normal weight concrete) } \\
V_{S}= & 500 \mathrm{fps} \text { (shear wave velocity of retained soil) } \\
\gamma= & 0.125 \mathrm{kcf} \text { (density of retained soil) } \\
g= & \text { acceleration of gravity }=32.2 \mathrm{ft} / \mathrm{sec}^{2} \\
G= & \gamma(V S)^{2} \div g=0.125(500)^{2} \div 32.2=971 \mathrm{ksf} \text { (shear modulus of } \\
& \text { elasticity for the retained soil) }
\end{aligned}
$$

The primary parameter governing the response of the Veletsos and Younan (1997) analytic model is the relative flexibility of the wall $d_{W}$ characterized as:

$$
d_{W}=\frac{G H^{3}}{D_{W}} \quad \text { (dimensionless) }
$$




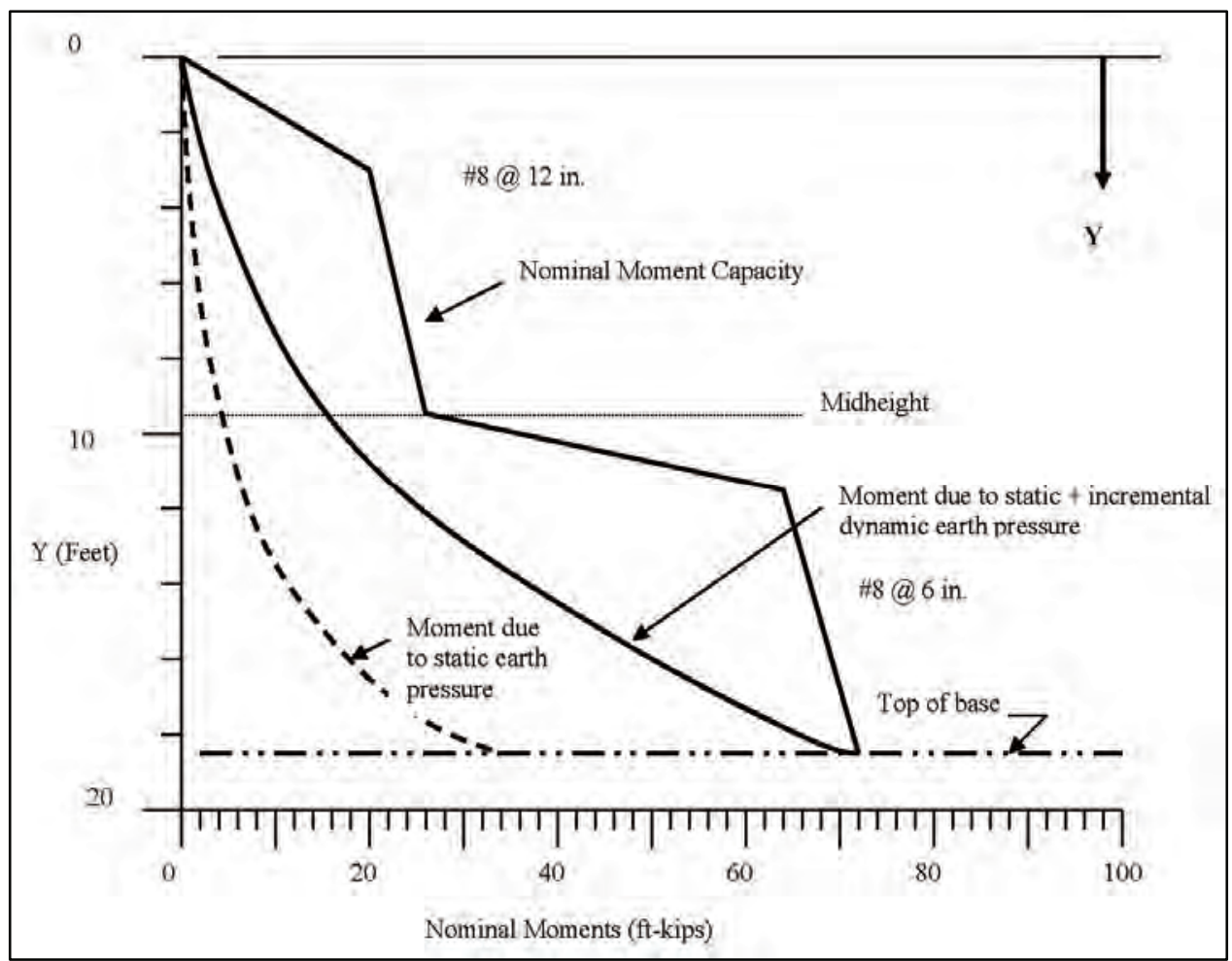

Figure D.12 Flexural capacity versus static and dynamic earth pressure demands

where

$H=$ height of soil retained by wall

$D_{W}=$ flexural rigidity of the wall per unit length of wall:

$$
D_{W}=\frac{E_{W} t_{W}^{3}}{12\left(1-v_{W}^{2}\right)}
$$

where

$$
\begin{aligned}
D_{W} & =475000(1.5)^{3} \div 12\left[1-(0.20)^{2}\right]=139,220 \mathrm{kip}-\mathrm{ft} \\
d_{W} & =971(18.5)^{3} \div 139,220=44.2
\end{aligned}
$$

From Figure 4(a) of Veletsos and Younan (1997) for $d_{W}=44.2$ :

$$
\frac{M_{S T}(\eta)}{\rho \ddot{X}_{g} H^{3}}=0.10
$$

where

$$
\begin{aligned}
M S T & =\text { dynamic earth pressure moment }- \text { rigid body motion } \\
\eta & =y / H \text { ratio }=\text { zero for stem wall-base intersection }
\end{aligned}
$$




$$
\begin{aligned}
\rho & =\text { mass density } \\
\ddot{X}_{g} & =\text { maximum ground accleration } \\
H & =\text { wall height }
\end{aligned}
$$

Assumimg the dynamic earth pressure moment equal to the reserve capacity, or $40.42 \mathrm{ft}$-kips and solving for $\ddot{X}_{g}$

$$
\ddot{X}_{g}=40.42 g \div 0.10(0.125)(18.5)^{3}=0.51 g
$$

The peak ground acceleration required to initiate yielding at the base of the stem wall is $0.51 \mathrm{~g}$, or about twice that of the Seed and Whitman (1970) methodology as detemined in the preceeding paragraph. However with the flexible wall procedure of Veletsos and Younan (1997) it is necessary to consider potential amplification effects. Assuming an amplification factor (AF) equal to 1.93 the upper bound value described in Veletsos and Younan (1997), the peak ground acceleration required to initiate yielding at the base of the stem wall is $0.265 \mathrm{~g}$, or approximately equal to that of the Seed and Whitman (1970) methodology.

\section{D.8 Summary}

A 20-ft-high retaining wall was designed using old Corps WSD practices and the resulting design evaluated for its capacity to resist earthquake ground motions.

\section{D.8.1 Reserve capacity}

The capacity available to resist earthquake loads results from the factor of safety inherent in the WSD approach. For WSD the factor of safety for flexure is generally between 2.0 and 2.5, meaning the nominal moment capacity (yield capacity) of the wall is 2.0 to 2.5 times the moment demand due to static earth pressure. Using Equation 1.3 to evaluate the capacity of the stem wall to resist earthquake loads, it was determined that flexural demands from an earthquake could be equal to the nominal moment capacity of the stem wall minus the static earth pressure moment demand, or $76.21 \mathrm{ft}$-kips $-35.79 \mathrm{ft}$-kips $=40.42 \mathrm{ft}-\mathrm{kips}$. The factor of safety for the 20 -ft-high WSD wall is equal to $76.21 \div 40.42=$ 2.13 .

\section{D.8.2 Earthquake demand}

Assuming $40.42 \mathrm{ft}-\mathrm{kips}$ of reserve flexural capacity, the peak horizontal acceleration $\left(k_{h}^{*} g\right)$ of the ground that would initiate flexural yielding (plastic hinging) at the base of the stem wall can be determined. The value of the coefficient $k_{h}{ }^{*} g$ was determined to be equal to $0.227 g$ for the pseudostatic type analysis 
performed in accordance with the Mononobe-Okabe (MO) procedure as described in Seed and Whitman (1970) and Ebeling and Morrison (1992). The value of the coefficient $k_{h}{ }^{*} g$ was determined to be equal to $0.51 g$ for the flexible cantilever wall procedure of Veletsos and Younan (1997) assuming no amplification of the transient ground motion response, and equal to $0.265 \mathrm{~g}$ when amplification is considered. This does not mean that ground motions in excess of these are not permissible. However any ground motions that cause demands in excess of yield should be evaluated using performance-based or displacement-based techniques.

Table D.4 provides formulations for the dynamic earth pressure shear and moment demands for the following:

- Seed and Whitman (1970) pseudostatic analysis (without transient amplification).

- Wood (1973) pseudostatic analysis (without transient amplification).

- Veletsos and Younan (1997) flexible wall procedure (without transient amplification).

- Veletsos and Younan (1997) flexible wall procedure (with transient amplification).

The Wood (1973) procedure, described in Section 3.5.2 of the main text, represents the dynamic response of a wall under nonyielding backfill conditions and is considered to represent an upper-bound dynamic earth pressure demand condition. The amplification factor $A F$ used in the Veletsos and Younan (1997) flexible wall procedure is assumed equal to 1.93 , the upper bound value described in their report. The values for the coefficient $k_{h}{ }^{*} g$ for the 20 - $\mathrm{ft}$-high WSD retaining wall representing the horizontal acceleration that initiates yielding at the base of the stem wall for each of these analysis procedures are also provided in Table D.4.

\begin{tabular}{|c|c|c|c|c|}
\hline \multicolumn{5}{|c|}{$\begin{array}{l}\text { Table D.4 } \\
\text { Summary of Analytical Procedure Results }\end{array}$} \\
\hline \multicolumn{5}{|c|}{$\begin{array}{ll}\text { Analytical Procedure } \\
\end{array} \quad$ Pal } \\
\hline & $\begin{array}{l}\text { Seed and } \\
\text { Whitman }\end{array}$ & Wood & $\begin{array}{l}\text { Veletsos and Younan } \\
\text { (without AF) }\end{array}$ & \begin{tabular}{|l|} 
Veletsos and Younan \\
(with AF = 1.93) \\
\end{tabular} \\
\hline Shear & $0.375 \rho k_{h}{ }^{*} g H^{2}$ & $1.00 \rho k_{h}{ }^{*} g H^{2}$ & $0.400 \rho k_{h}{ }^{*} g H^{2}$ & $0.772 \rho k_{h}{ }^{*} g H^{2}$ \\
\hline Moment & $0.225 \rho k_{h}{ }^{*} g H^{3}$ & $0.63 \rho k_{h}{ }^{*} g H^{3}$ & $0.100 \rho k_{h}{ }^{*} g H^{3}$ & $0.193 \rho k_{h}{ }^{*} g H^{3}$ \\
\hline$k_{h}^{*} g$ & $0.227 \mathrm{~g}$ & $0.081 \mathrm{~g}$ & $0.510 \mathrm{~g}$ & $0.265 \mathrm{~g}$ \\
\hline \multicolumn{5}{|c|}{$\begin{array}{l}\text { Note: } \\
\rho=\text { density of the retained soil } \\
H=\text { stem wall height }\end{array}$} \\
\hline
\end{tabular}

The seismic evaluation of earth retaining wall structures is complex due to soil-structure interaction effects. The Mononobe-Okabe equation is considered the standard for the design and evaluation of retaining structures subject to 
earthquake ground motions and active limit-state conditions. This simple pseudostatic procedure described in Ebeling and Morrison (1992) and Seed and Whitman (1970) is considered at present to be the method of choice when evaluating force demands (i.e., moments and shears) on retaining wall systems. The flexible cantilever wall procedure described in Veletsos and Younan (1997) is of special interest because it provides a methodology for assessing displacement demands on retaining wall systems dominated by a stem wall yielding response. 


\section{Appendix E Corps Ultimate Strength Design (USD) Example by Ultimate Strength Design Methods Using EM 1110-2-2104, EM 1110-2-2502, and EC 1110-2-6058}

A retaining wall similar to that described in Appendix A of Green and Ebeling (2002) $)^{1}$ is used to illustrate a retaining wall design that complies with current Corps ultimate strength design (USD) requirements. The retaining wall is considered to be a standard (noncritical) hydraulic structure. Designs performed in accordance with Corps provisions in EM 1110-2-2104 and EM 1110-2-2502 (Headquarters, U.S. Army Corps of Engineers (HQUSACE) 2003b and 1989) will provide high margins of safety since

- A single load factor of 1.7 is used for the design.

- The load factor is multiplied by an hydraulic factor (HF) equal to 1.3.

- A safety factor of 1.5 is applied to the shear strength of the soil (i.e., strength mobilization factor (SMF) equal to $2 / 3$ ) for static earth pressure conditions (under normal load conditions).

As with the working stress design (WSD) method, static earth pressure conditions are assumed to govern the design, and the resulting static earth pressure design is investigated for the maximum sustainable constant horizontal acceleration that will cause plastic hinging (i.e., initiate a stem wall yielding response).

\footnotetext{
${ }^{1}$ References cited in this appendix are included in the References section at the end of the main text.
} 


\section{E.1 Ultimate Strength Design (USD)}

The following material properties are used in the USD: ${ }^{1}$

- Concrete: Ultimate strength $\left(f_{c}^{\prime}\right)=3,000 \mathrm{psi}$

- Reinforcement: Yield strength $\left(f_{y}\right)=60,000 \mathrm{psi}$

USD design procedures for the retaining wall are in accordance with the provisions contained in the 2002 American Concrete Institute (ACI) Building Code, "Building Code Requirements for Reinforced Concrete" (ACI 318-02), EM 1110-2-2502, EM 1110-2-2104, and EC 1110-2-6058 (HQUSACE 1989, 2003b, and 2003a).

\section{E.2 Service Load Analysis}

A description of the retaining wall for the ACI-USD design is provided in Figure E.1. Overturning and sliding stability computations are summarized in Table E.1.

a. Location of resultant from heel $X=207.74 \div 26.63=7.80 \mathrm{ft} \leftarrow$ Inside middle one-third of base

b. Determine bearing pressures

$13.00 p_{1}+6.50 p_{2}=26.63 \leftarrow$ Equation $1-$ Sum of vertical forces $=0$ $84.50 p_{1}+56.36 p_{2}=26.63(7.80) \leftarrow$ Equation 2 - Sum of moments at heel $=0$

$84.50 p_{1}+42.25 p_{2}=26.63(6.50) \leftarrow$ Equation $3=$ Equation 1 multiplied by 6.50

Subtracting Equation 3 from Equation 2

$14.11 p_{2}=34.62 \quad p_{2}=2.45 \mathrm{ksf}$

Backsubstituting into Equation 1:

$13.00 p_{1}=26.63-6.50(2.45)=10.71$

$p_{1}=0.82 \mathrm{ksf} \quad p_{1}+p_{2}=3.27 \mathrm{ksf}$

c. $\quad$ Check. Bearing Pressure $=F / A \pm 6 F(e) / B 2$

Bearing Pressure $=[26.63 \div 13] \pm\left[6(26.63)(1.3) \div 13^{2}\right]$

$=2.05 \pm 1.23=3.28 \mathrm{ksf} \& 0.82 \mathrm{ksf}$

Checks

The factor of safety against sliding meets Corps requirements. Refer to Green and Ebeling (2002).

\footnotetext{
${ }^{1}$ Each of the appendixes in this report has its own system of notation. Many of the symbols used in this appendix are defined in the text of this appendix. Others are commonplace to reinforced concrete design and retaining wall design. Readers not understanding a particular symbol notation should consult the references cited in this appendix for the definition.
} 


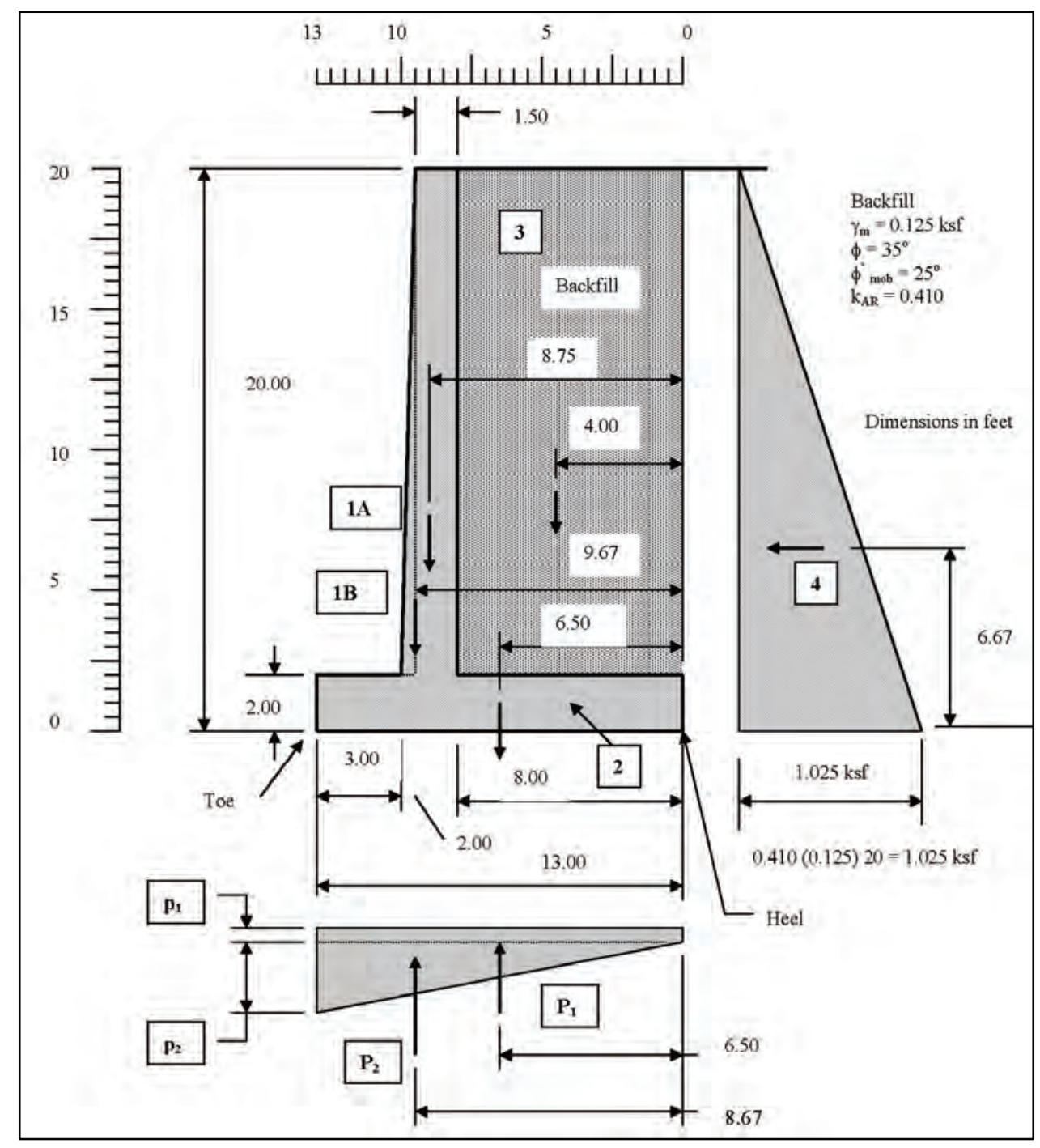

Figure E.1 Retaining wall geometry and loads

Table E.1

\section{Stability Computations}

\begin{tabular}{|l|l|c|l|l|l||}
\hline \hline Force & Description & $\boldsymbol{F}_{\boldsymbol{V}}, \mathbf{k i p s}$ & $\boldsymbol{F}_{\boldsymbol{H}}, \mathbf{k i p s}$ & Lever Arm, ${ }^{\mathbf{1}} \mathbf{f t}$ & Moment at Heel, kip-ft \\
\hline \hline 1A & Stem & 4.05 & & 8.75 & 35.44 \\
\hline 1B & Stem & 0.68 & & 9.67 & 6.58 \\
\hline 2 & Base & 3.90 & & 6.50 & 25.35 \\
\hline 3 & Backfill & 18.00 & & 4.00 & 72.00 \\
\hline 4 & Backfill Pressure & & 10.25 & 6.67 & 68.37 \\
\hline & Totals & $\mathbf{2 6 . 6 3}$ & $\mathbf{1 0 . 2 5}$ & & $\mathbf{2 0 7 . 7 4}$ \\
\hline \hline
\end{tabular}




\section{E.3 Stem Moment Demands and Selection of Flexural Reinforcement}

Mathcad computations (Mathsoft Engineering and Education, Inc., 1998) used to determine flexural steel requirements are provided in Figures E.2a through E.2d. Figure E.2a provides the service load moment demands, Figure E.2b the nominal moment demands, Figure E.2c the flexural steel required at the base of the stem wall, and Figure E.2d the flexural steel required at midheight of the stem wall.

Figure E. 3 plots demand versus capacity. Notice that compared to Figure D.2 (working stress design) there is for the USD much more additional reserve capacity between active earth pressure moment demand and nominal moment capacity.

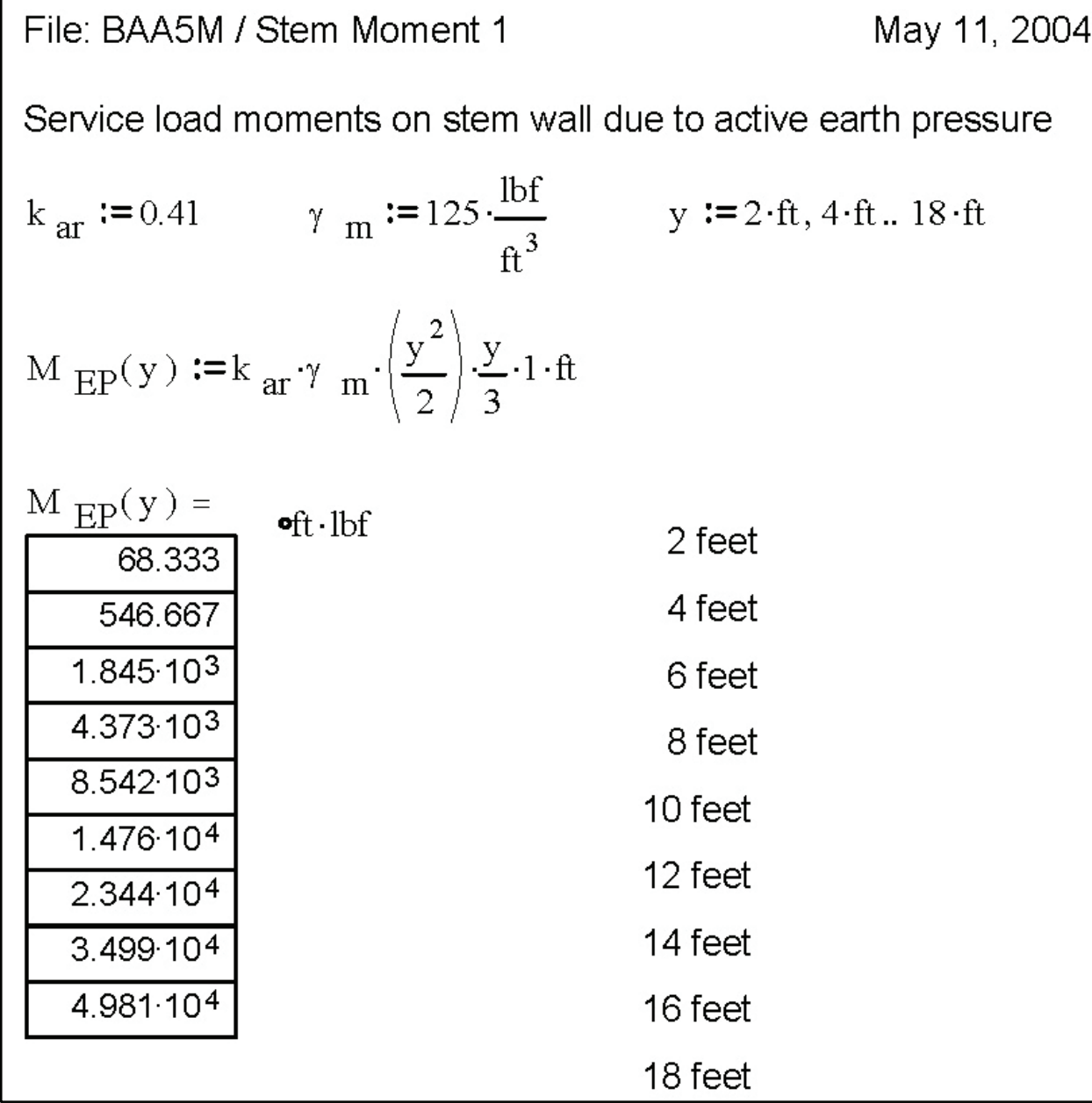

a. Mathcad calculations for static earth pressure service moments

Figure E.2 Mathcad calculations for stem wall moments and reinforcement (Sheet 1 of 3) 


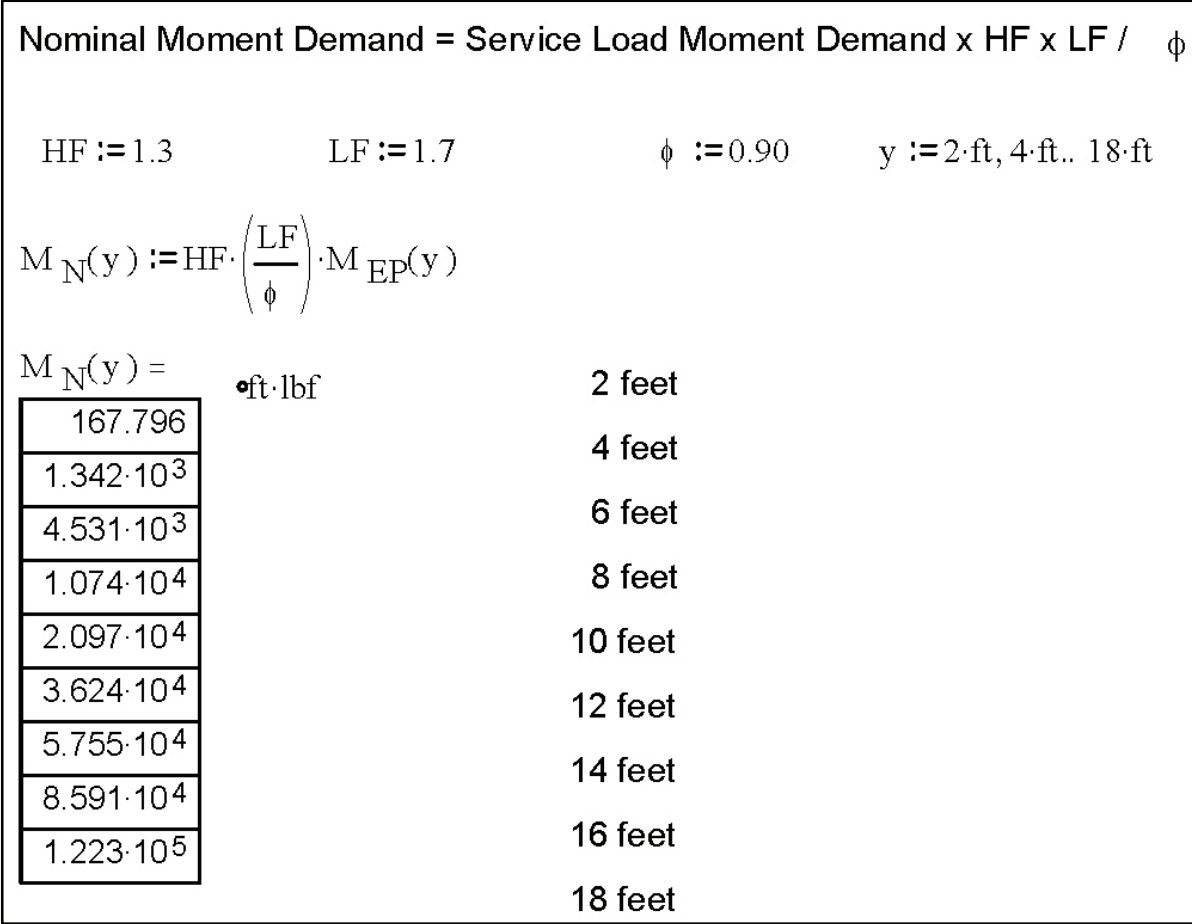

b. Mathcad calculations for static earth pressure nominal moments

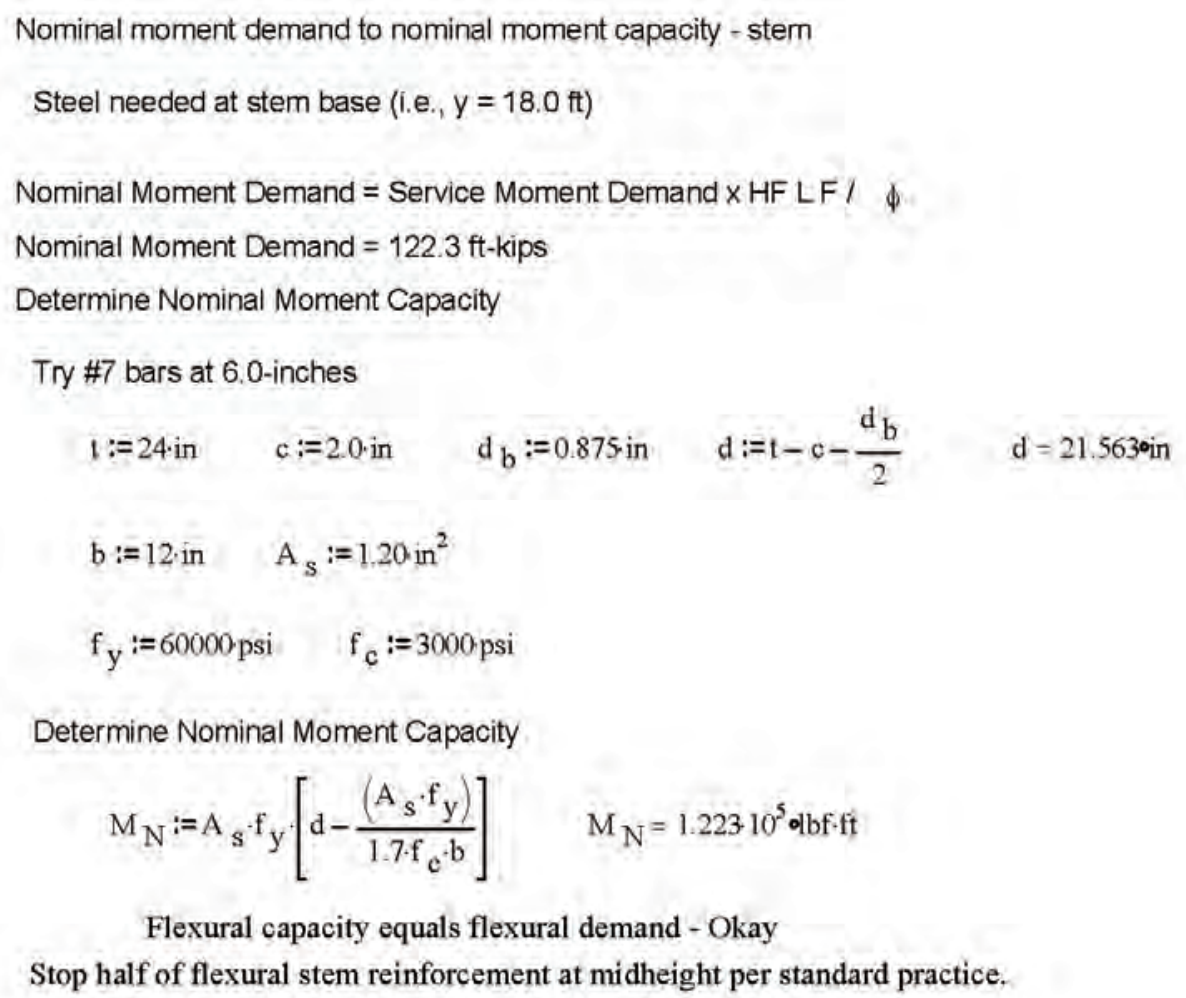

c. Mathcad calculations for flexural reinforcement at base of stem wall Figure E.2. (Sheet 2 of 3 ) 


$$
\begin{aligned}
& \text { For \#7 bars at } 12 \text {-inches } \\
& \mathrm{t}:=21 \cdot \text { in } \quad \mathrm{c}:=2.0 \cdot \text { in } \quad \mathrm{d}_{\mathrm{b}}:=0.875 \cdot \text { in } \quad \mathrm{d}:=\mathrm{t}-\mathrm{c}-\frac{\mathrm{d}_{\mathrm{b}}}{2} \quad \mathrm{~d}=18.563 \text { oin } \\
& \mathrm{b}:=12 \cdot \mathrm{in} \quad \mathrm{A}_{\mathrm{S}}:=0.60 \cdot \mathrm{in}^{2} \\
& \mathrm{f}_{\mathrm{y}}:=60000 \cdot \mathrm{psi} \quad \mathrm{f}_{\mathrm{c}}:=3000 \cdot \mathrm{psi} \\
& M_{N}:=A_{s} \cdot f_{y} \cdot\left[d-\frac{\left(A_{s} \cdot f_{y}\right)}{1.7 \cdot f_{c} \cdot b}\right] \quad M_{N}=5.392 \cdot 10^{4} \cdot \mathrm{lbf} \cdot f t
\end{aligned}
$$

d. Mathcad calculations for flexural reinforcement at stem wall midheight

Figure E.2. (Sheet 3 of 3 )

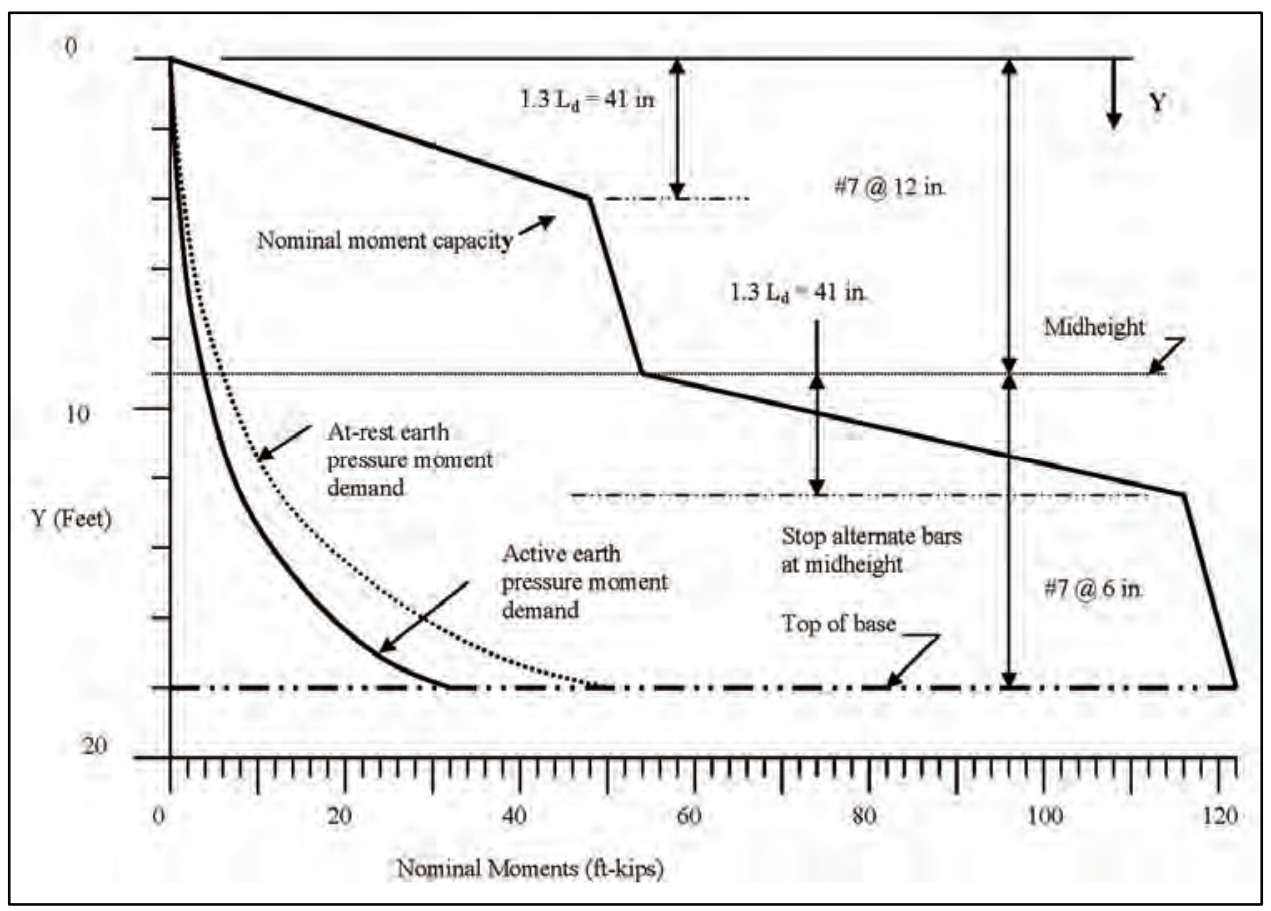

Figure E.3 Stem flexural steel — demand versus capacity

The layout of the main flexural reinforcment for the stem and base is illustrated in Figure E.4.

\section{E.4 Check of Shear Capacity Stem per USD}

The critical section for shear in the stem is taken at $21 \mathrm{in}$. above the interface of the base and the stem, where $16.75 \mathrm{in}$. is $d$ at the base of the stem.

$$
V_{B A S E}=0.41(0.125) 16.25(0.5)(16.25)=6.77 \mathrm{kips}
$$




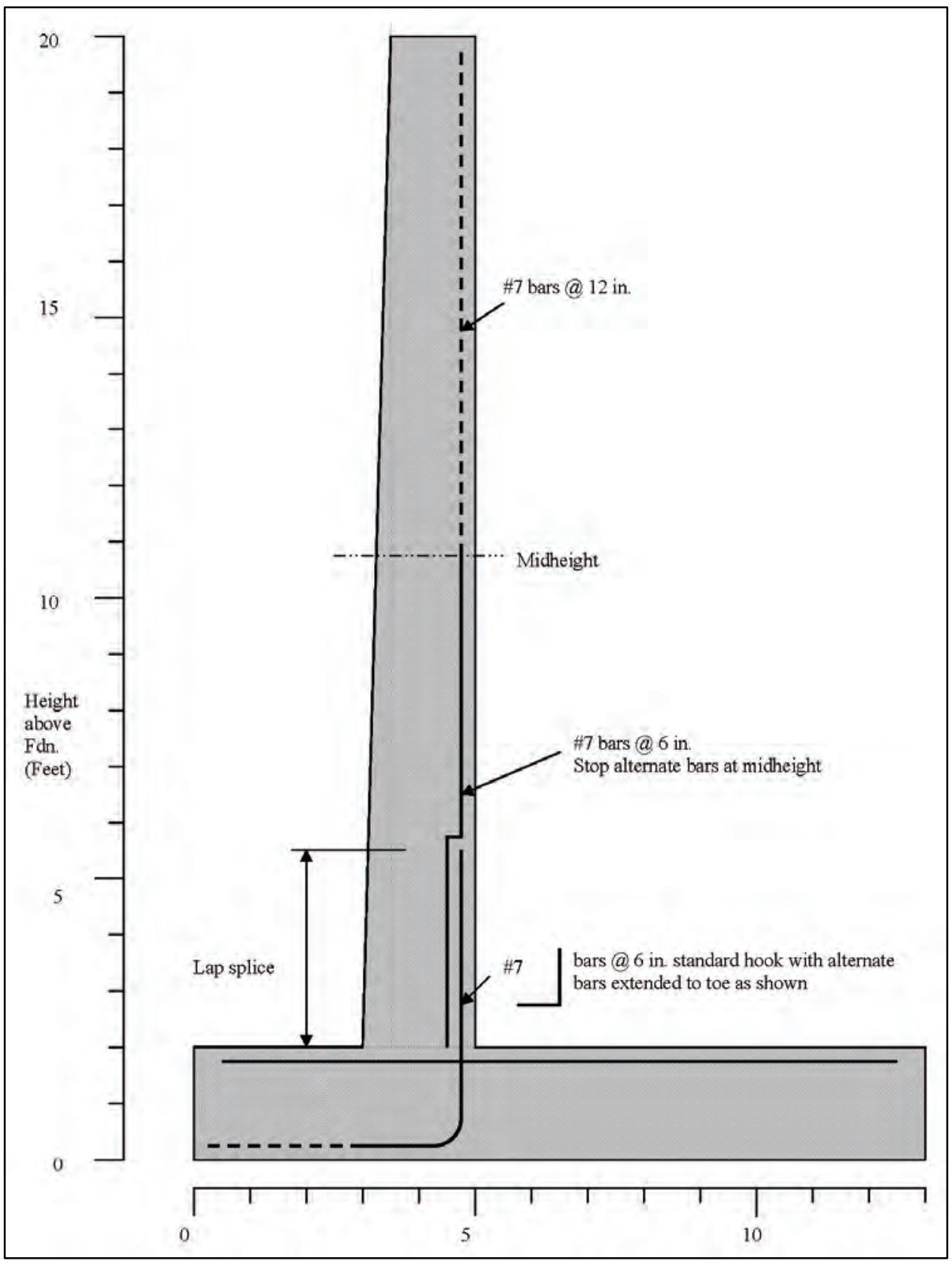

Figure E.4 Main reinforcement

Using a hydraulic factor of 1.3 and a load factor of 1.7 , the ultimate shear demand at distance $d$ above base is

$$
V_{U}=1.3(1.7)(6.77)=14.96 \mathrm{kips}
$$

Ultimate shear capacity $=\phi V_{N}=\phi(b)(d)(2)\left(f_{c}^{\prime}\right)^{1 / 2}$

$$
\begin{aligned}
& =0.75(12)(21)(2)(55)=20,790 \text { pounds } \\
& =20.79 \mathrm{kips}
\end{aligned}
$$

Shear capacity greater than shear demand. Okay. 


\section{E.5 Base Toe Design}

\section{E.5.1 Shear}

$V_{T O E}=3.67+0.14=3.81$ kips (Figure E.5)

Ultimate shear demand $V_{U}=1.3(1.7)(3.81)=8.42$ kips

$d=24.00-3.00-0.5=20.5$ in.

Ultimate shear capacity $\phi V_{N}=\phi(b)(d)(2)\left(f_{c}^{\prime}\right)^{1 / 2}$

$$
\begin{aligned}
& =0.75(12)(20.5)(2)(55)=20,295 \mathrm{lb} \\
& =20.3 \mathrm{kips}
\end{aligned}
$$

Okay.

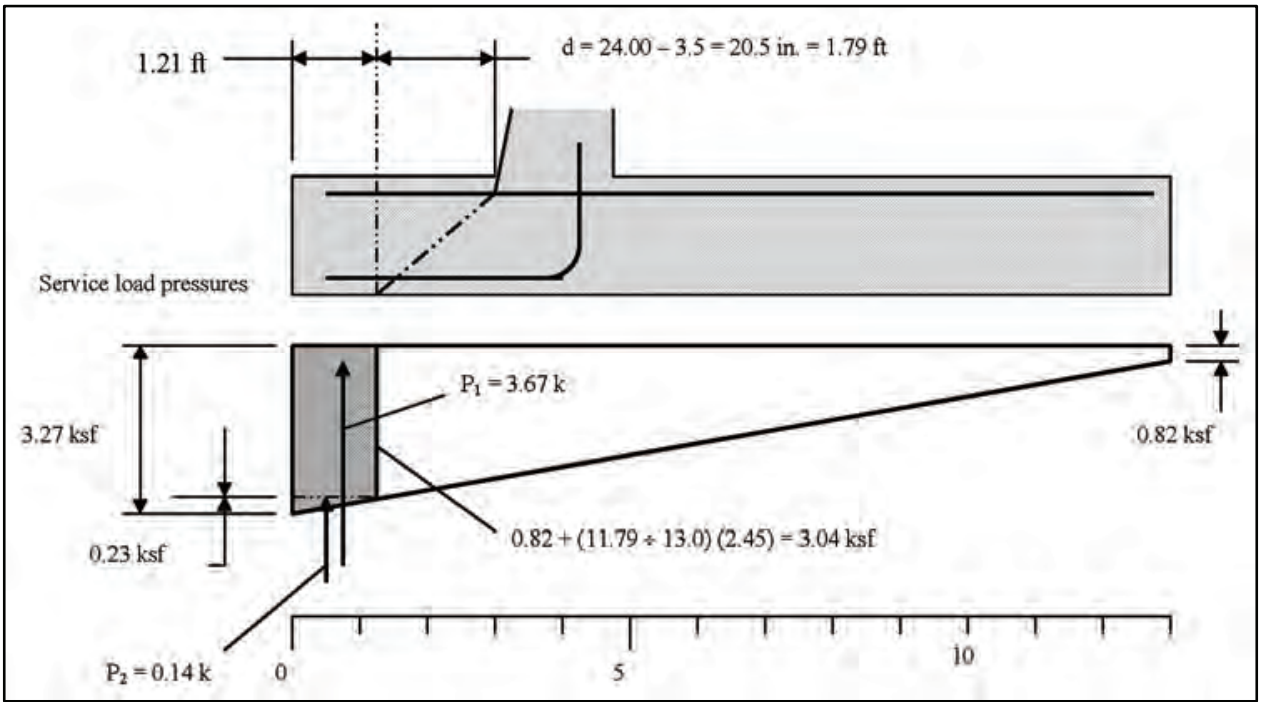

Figure E.5 Shear on toe of base

\section{E.5.2 Flexure}

Calculations for reinforcement required to satisfy nominal moment demands in the toe of the base slab are provided in Figure E.6.

$M_{T O E}=8.10(1.50)+0.86(2)=13.87 \mathrm{ft}-\mathrm{kips}($ Figure E.7)

$M_{N T O E}=13.87(1.3)(1.7) \div 0.90=34.06 \mathrm{ft}-\mathrm{kips}$ 
Try \# 7 bars at 12 -inches

$$
\begin{aligned}
& t:=24 \cdot \text { in } \quad c:=3 \cdot \text { in } \quad d_{b}:=0.875 \cdot \text { in } \quad d:=t-c-\frac{d_{b}}{2} \\
& d=20.562 \text { in } \quad b:=12 \cdot \text { in } \quad A_{S}:=0.60 \cdot \text { in }^{2} \\
& f_{y}:=60000 \text { psi } \quad f_{c}:=3000 \cdot p s i
\end{aligned}
$$

Determine Nominal Moment Capacity

$$
\mathrm{M}_{\mathrm{N}}:=\mathrm{A}_{\mathrm{s}} \cdot \mathrm{f}_{\mathrm{y}} \cdot\left[\mathrm{d}-\frac{\left(\mathrm{A}_{\mathrm{s}} \cdot \mathrm{f}_{\mathrm{y}}\right)}{1.7 \cdot \mathrm{f}_{\mathrm{c}} \cdot \mathrm{b}}\right] \quad \mathrm{M}_{\mathrm{N}}=5.992 \cdot 10^{4} \mathrm{olbf} \cdot \mathrm{ft}
$$

$59.92 \mathrm{ft}$-kips $>31.14 \mathrm{ft}$-kips Okay Extend every other stem bar into toe.

Figure E.6 Mathcad calculations for flexural reinforcement at toe of base

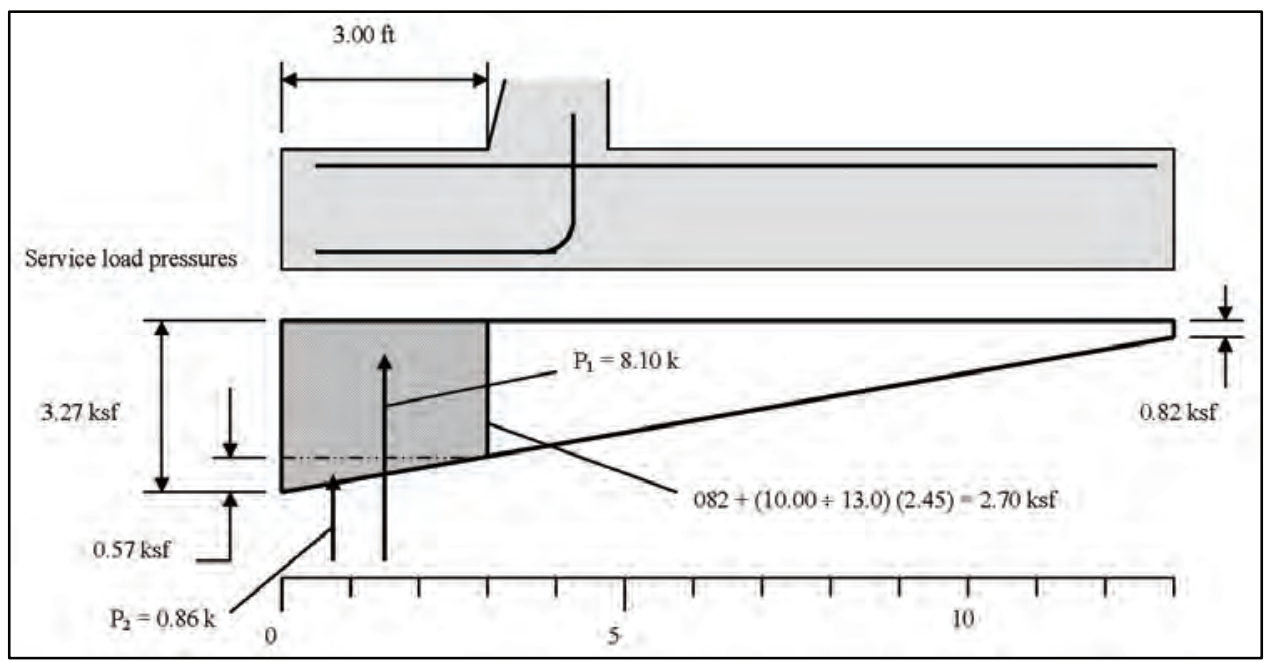

Figure E.7 Moment on toe of base

\section{E.6 Base Heel Design}

\section{E.6.1 Shear}

Check of shear capacity stem per USD

$$
\begin{aligned}
V_{\text {HEEL }} & =2.25(8.0)+0.15(2.00)(8.0)-0.82(8.0)-1.48(8.0) \div 2 \\
& =18.00+2.40-6.56-5.92=7.92 \text { kips (Figure E.8) }
\end{aligned}
$$

Ultimate shear demand $V_{U}=1.3(1.7)(7.92)=17.50$ kips 
Ultimate shear capacity $\phi V_{N}=\phi(b)(d)(2)\left(f_{c}^{\prime}\right)^{1 / 2}$

$$
\begin{aligned}
& =0.75(12)(20.5)(2)(55)=20,295 \mathrm{lb} \\
& =20.3 \mathrm{kips}
\end{aligned}
$$

20.3 kips greater than 17.50 kips. Okay

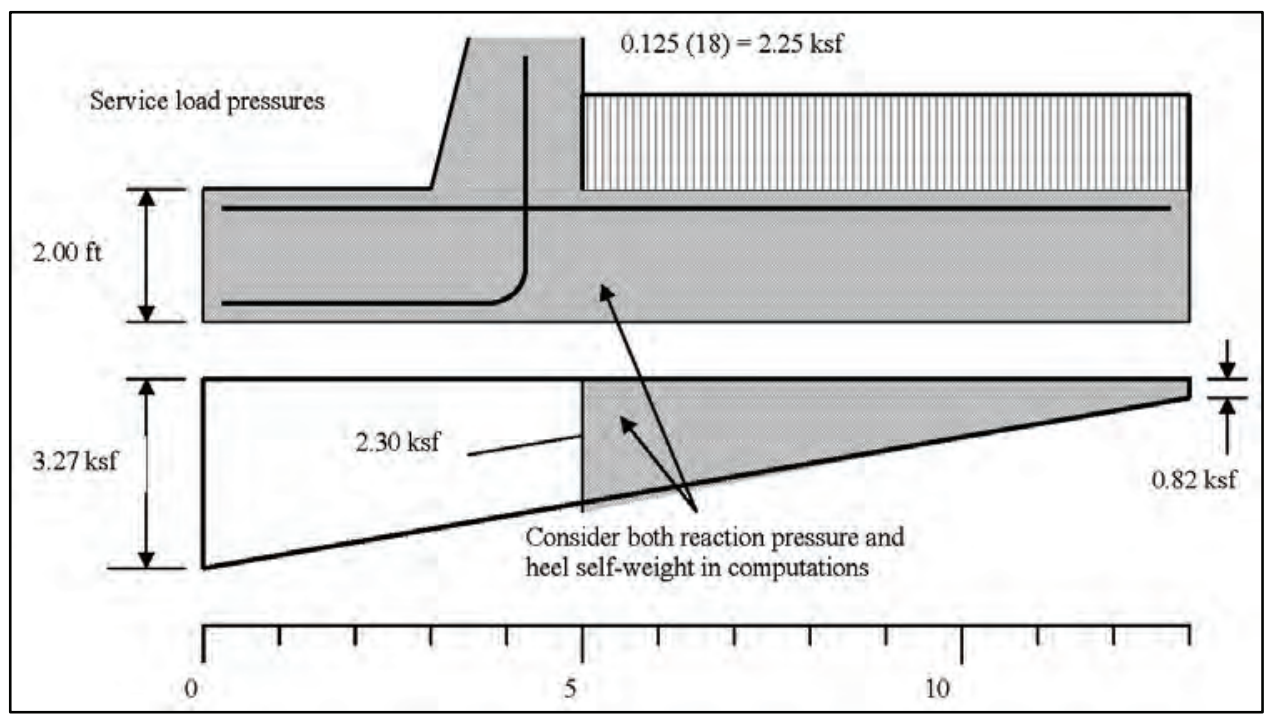

Figure E.8 Shear on heel of base

\section{E.6.2 Flexure}

Calculations for reinforcement required to satisfy nominal moment demands in the heel of the base slab are provided in Figure E.9.

$$
\begin{aligned}
M_{\text {HEEL }} & =18.00(4.0)+2.40(4.0)-6.56(4.0)-5.92(2.67) \\
& =72.00+9.60-26.24-15.80=39.56 \mathrm{ft}-\mathrm{kips} \text { (Figure E.10) } \\
M_{\text {NHEEL }} & =1.3(1.7) 39.56 \div 0.90=97.14 \mathrm{ft}-\mathrm{kips}
\end{aligned}
$$

\section{E.7 Development Requirements for \#7 Reinforcement}

\section{E.7.1 Straight bars}

Calculations of straight bar development length for \#7 bars are provided in Figure E.11.

Required lap splice length $=1.3 l_{d}=1.3(31.45)=41$ in. 


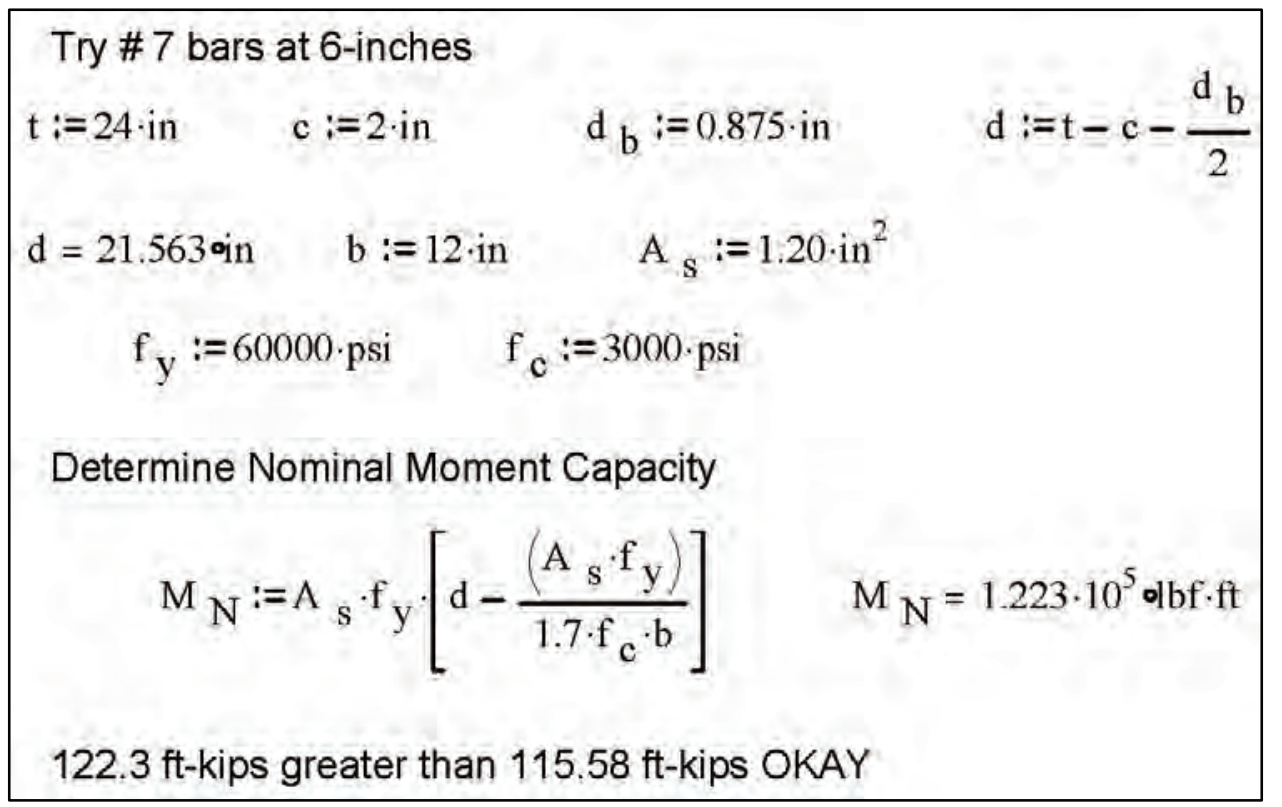

Figure E.9 Mathcad calculations for flexural reinforcement at heel of base

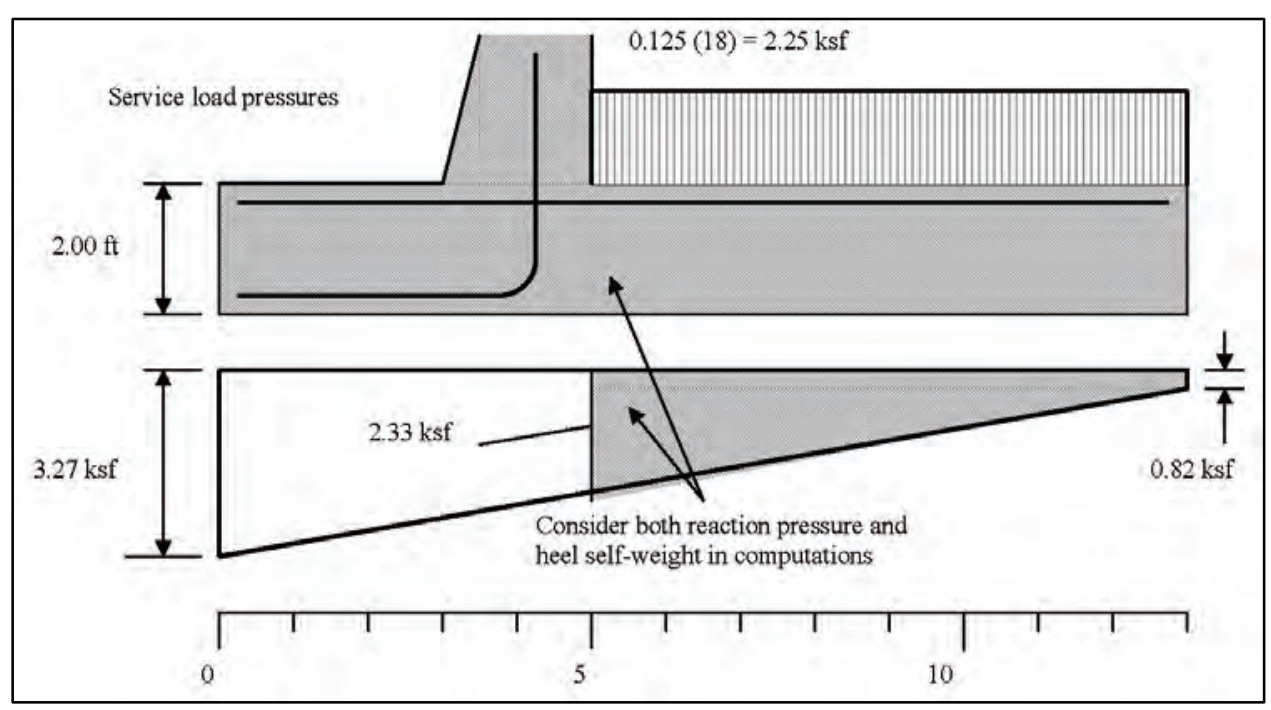

Figure E.10 Moment on heel of base

\section{E.7.2 Hooks}

Calculations of hooked bar development length for \#7 bars are provided in Figure E.12.

Minimum base slab thickness using \#7 stem reinforcement is equal to 13.42 $+0.44+3.00=16.86$ in.

$16.86<18.00$ okay 


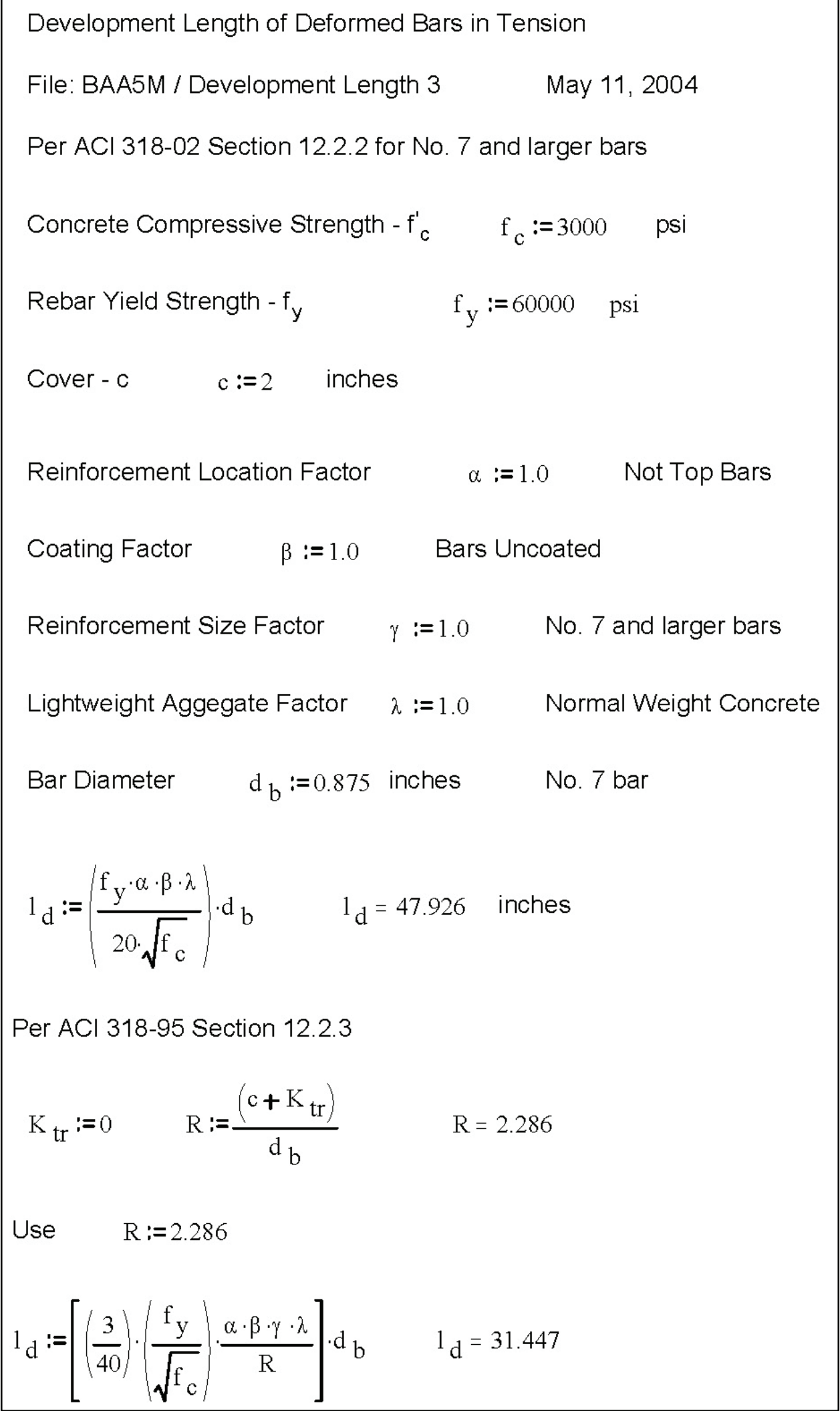

Figure E.11 Mathcad calculations for straight bar development length 
Development length for hooks

Per ACI 318-02 Section 12.5.2 for hook devlopment length

Concrete Compressive Strength $-\mathrm{f}_{\mathrm{c}}{ }_{\mathrm{C}} \quad \mathrm{f}_{\mathrm{c}}:=3000 \quad$ psi

Rebar Yield Strength $-\mathrm{f}_{\mathrm{y}} \quad \mathrm{f}_{\mathrm{y}}:=60000 \quad$ psi

Reinforcement Location Factor $\quad \alpha:=1.0 \quad$ Not Top Bars

Coating Factor $\quad \beta:=1.0 \quad$ Bars Uncoated

Lightweight Aggegate Factor $\quad \lambda:=1.0 \quad$ Normal Weight Concrete

Bar Diameter $\quad \mathrm{d}_{\mathrm{b}}:=0.875$ inches $\quad$ No. 7 bar

Per $\mathrm{ACl}$ 318-02 Section 12.5.1

$$
\begin{aligned}
& 1_{\mathrm{dh}}:=\left(\frac{0.02 \mathrm{f}_{\mathrm{y}} \cdot \beta \cdot \lambda}{\sqrt{\mathrm{f}_{\mathrm{c}}}}\right) \cdot \mathrm{d}_{\mathrm{b}} \quad 1_{\mathrm{dh}}=19.17 \quad \text { inches } \\
& \eta:=0.7 \quad \text { Modification factor per ACl 318-02 Section 12.5.3 } \\
& 1_{\mathrm{dhm}}:=\eta \cdot 1_{\mathrm{dh}} \quad 1_{\mathrm{dhm}}=13.419 \quad \text { inches }
\end{aligned}
$$

Figure E.12 Mathcad calculations for hooked bar development length

\section{E.8 Evaluate Static Earth Pressure Design for Earthquake}

\section{E.8.1 Earthquake evaluation per Seed and Whitman (1970) and Ebeling and Morrison (1992)}

Static and incremantal dynamic earth pressures are illustrated in Figure E.13.

Determine peak ground acceleration (PGA) where static and dynamic earth pressure demands initiate flexural yielding at the base of the stem wall (i.e., moment demand equals nominal moment capacity):

The dynamic active earth pressure force $\Delta P_{A E}$ is determined per paragraph 4.2.2 of Ebeling and Morrison (1992): 


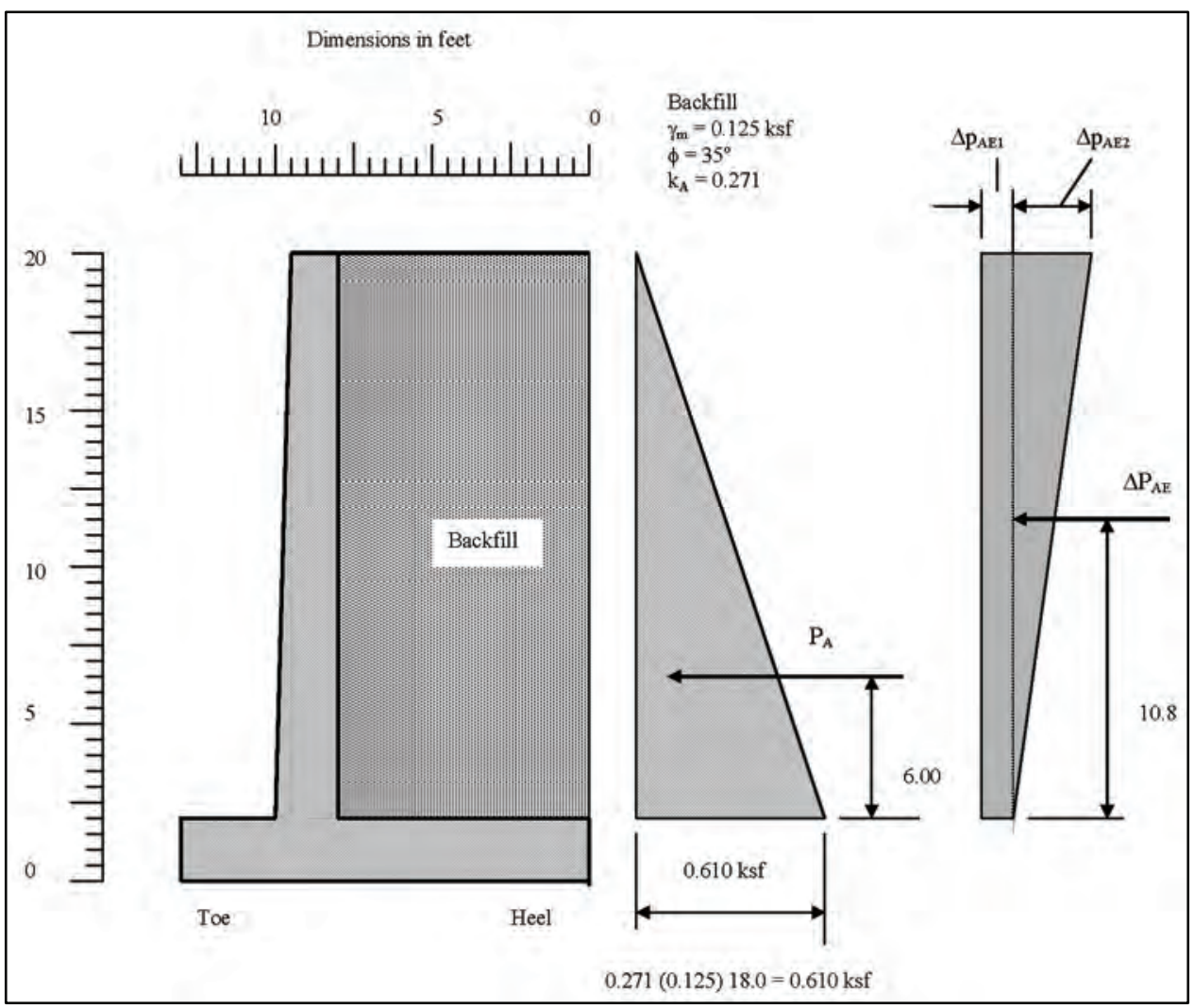

Figure E.13 Static and incremental dynamic earth pressures

$\Delta P_{A E}$ is located at $0.6 H$ where $H$ is wall height above top of base $=10.8 \mathrm{ft}$

$M_{N}=$ Nominal moment capacity at base of stem wall $=122.3 \mathrm{ft}$-kips

$P_{A}=$ Lateral loads due to active earth pressure=5.49 kips @ $6.00 \mathrm{ft}$ above top of base.

$\Sigma$ Moment about top of base to determine reserve capacity for earthquake loading

$10.8\left(\Delta P_{A E}\right)=122.3-5.49(6.00)=122.3-32.94=89.36$

$\Delta P_{A E}=8.27 \mathrm{kips}$

Determine the dynamic earth pressure increment coefficient $\Delta K_{A E}$ per Equation (41), Ebeling and Morrison (1992).

$$
\begin{aligned}
& \Delta P_{A E}=\Delta K_{A E} \div 0.5 \gamma_{m} H^{2} \\
& \Delta K_{A E}=\Delta P_{A E} \div\left(0.5 \gamma_{m} H^{2}\right)=8.27 \div 0.5(0.125)(18.0)^{2}=0.408
\end{aligned}
$$

Determine constant horizontal coefficient $k_{h}$ per Equation (43), Ebeling and Morrison (1992).

$$
\begin{aligned}
& \Delta K_{A E}=(3 / 4) k_{h} \\
& k_{h}=4\left(\Delta K_{A E}\right) \div 3=4(0.408) \div 3=0.544
\end{aligned}
$$

Observation: A constant horizontal acceleration $k_{h} g$ equal to $0.544 g$ will initiate flexural yielding in the stem wall region just above the base. 
Determine dynamic earth pressures $\Delta p_{A E 1}$ and $\Delta p_{A E 2}$

$\Sigma$ Dynamic earth pressure forces in horizontal direction

$18.0\left(\Delta p_{A E 1}\right)+9.00\left(\Delta p_{A E 2}\right)=8.27 \quad$ Equation (1)

$\Sigma$ Dynamic earth pressure moments at stem wall base

$9.00(18.0)\left(\Delta p_{A E 1}\right)+12.00(9.00)\left(\Delta p_{A E 2}\right)=89.32 \quad$ Equation (2)

Equation (1) x 9.00 and subtract from Equation (2)

$27\left(\Delta p_{A E 2}\right)=14.89$

$\triangle p_{A E 2}=0.551 \mathrm{ksf}$

Backsubstituting $\Delta p_{A E 2}$ into Equation (1) and solving for $\Delta p_{A E 1}$

$\Delta p_{A E 1}=0.184 \mathrm{ksf}$

Equation for total static and dynamic earth pressure moments in stem wall:

$M_{T}=0.167\left(k_{a}\right)\left(\gamma_{m}\right)\left(y^{3}\right)$

$+0.500\left(\Delta p_{A E 1}\right)\left(y^{2}\right)$

$+0.184 \Delta p_{A E 2}(18.0-y)(18.0-0.50 y)$

$+\left[\Delta p_{A E 2}-0.184 \Delta p_{A E 2}(18.0-y)\right] 0.50 y(18.0-0.333 y)$

The total moment demand (static + dynamic) for the earthquake condition that produces initial flexural yielding at the base of the stem wall is illustrated in Figure E.14. This does not mean higher earthquake demands are unacceptable. Further investigation of the displacement capacity of the stem wall is needed to establish the level of earthquake demand that will create unacceptable performance.

\section{D.8.2 Earthquake evaluation per Veletsos and Younan (1997)}

Assuming:

$E_{W}=475,000 \mathrm{ksf}$ (3,000 psi normal weight concrete) (Young's modulus of elasticity for the wall)

$t_{W}=2.0 \mathrm{ft}$ (wall thickness)

$v_{W}=0.20$ (Poisson's ratio for normal weight concrete)

$V_{S}=500 \mathrm{fps}$ (shear wave velocity of retained soil)

$\gamma=0.125 \mathrm{kcf}($ density of retained soil)

$g=$ acceleration of gravity $=32.2 \mathrm{ft} / \mathrm{sec}^{2}$

$G=\gamma\left(V_{S}\right)^{2} \div g=0.125(500)^{2} \div 32.2=971$ ksf (shear modulus of elasticity for the retained soil) 


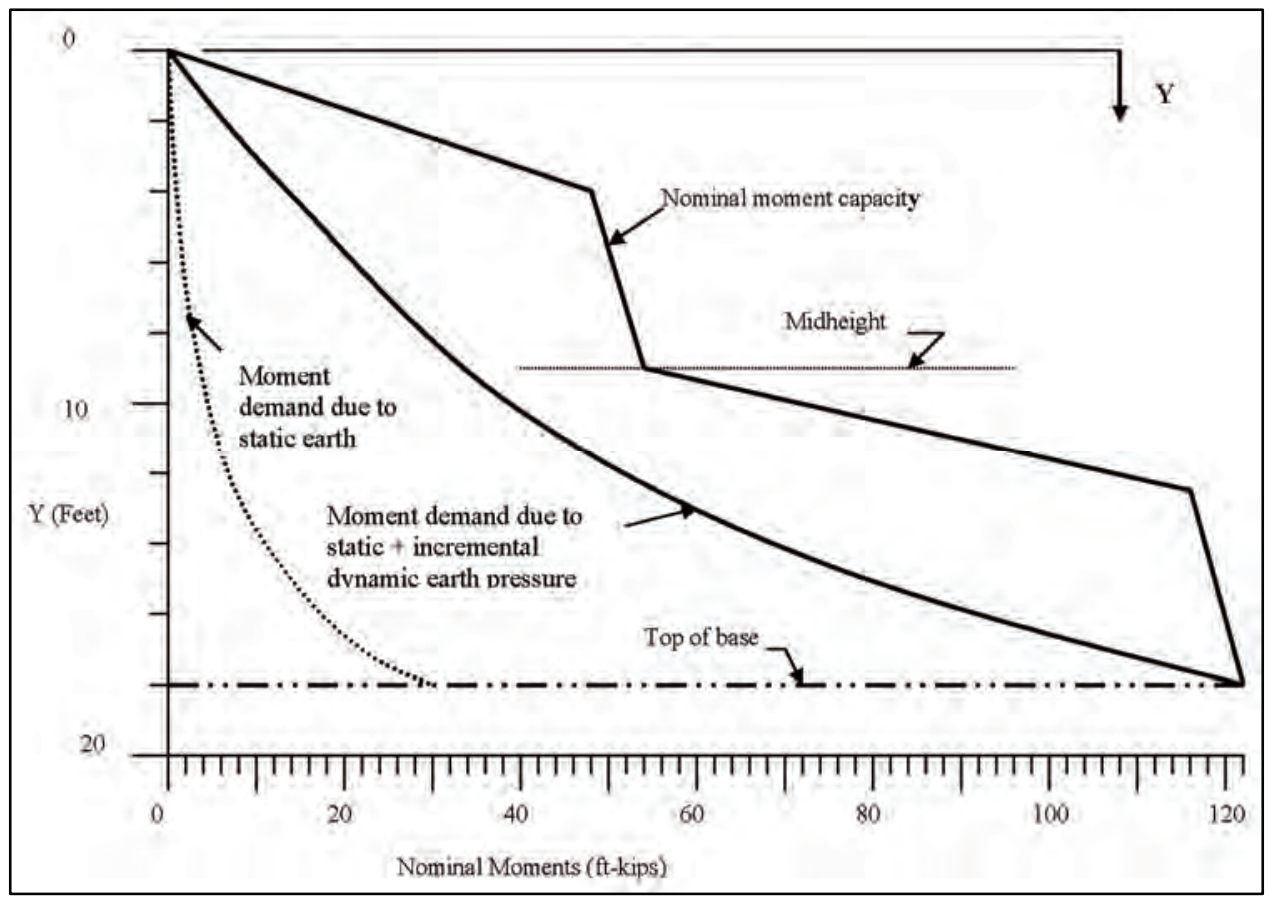

Figure E.14 Flexural capacity versus static and dynamic earth pressure demands

The primary parameter governing the response of the Veletsos and Younan (1997) analytic model is the relative flexibility of the wall $d_{W}$ characterized as:

$$
d_{W}=\frac{G H^{3}}{D_{W}} \text { (dimensionless) }
$$

where

$$
\begin{aligned}
H & =\text { height of soil retained by wall } \\
D_{W} & =\text { flexural rigidity of the wall per unit length of wall }
\end{aligned}
$$

$$
D_{W}=\frac{E_{W} t_{W}^{3}}{12\left(1-v_{W}^{2}\right)}
$$

where

$$
\begin{aligned}
D_{W} & =475000(2)^{3} \div 12\left[1-(0.20)^{2}\right]=330,000 \mathrm{kip}-\mathrm{ft} \\
d_{W} & =971(18)^{3} \div 330,000=17.2
\end{aligned}
$$

From Figure 4(a) of Veletsos and Younan (1997) for $d_{W}=17.2$ :

$$
\frac{M_{S T}(\eta)}{\rho \ddot{X}_{g} H^{3}}=0.13
$$


where

$$
\begin{aligned}
M_{S T} & =\text { dynamic earth pressure moment }- \text { rigid body motion } \\
\eta & =y / H \text { ratio }=\text { zero for stem wall-base intersection } \\
\rho & =\text { mass density } \\
\ddot{X}_{g} & =\text { maximum ground accleration } \\
H & =\text { wall height }
\end{aligned}
$$

Assuming the dynamic earth pressure moment equal to the reserve capacity, or $89.36 \mathrm{ft}-$ kips and solving for $\ddot{X}_{g}$

$$
\ddot{X}_{g}=89.36 g \div 0.13(0.125)(18)^{3}=0.94 g
$$

The peak ground acceleration required to initiate yielding at the base of the stem wall is $0.94 \mathrm{~g}$, or about twice that of the Seed and Whitman (1970) methodology as detemined in the preceeding paragraph. However, with the flexible wall procedure of Veletsos and Younan (1997) it is necessary to consider potential amplification effects. Assuming an amplification factor (AF) equal to 1.93 the upper bound value described in Veletsos and Younan (1997), the peak ground acceleration required to initiate yielding at the base of the stem wall is $0.487 g$, or approximately equal to that of the Seed and Whitman (1970) methodology.

\section{E.9 Summary}

A 20-ft-high retaining wall was designed using current Corps ultimate strength design (USD) practices and the resulting design evaluated for its capacity to resist earthquake ground motions.

\section{E.9.1 Reserve capacity}

The capacity available to resist earthquake loads results from the factor of safety provided in the USD approach. For USD the minimum factor of safety (SF) for flexure is equal to the load factor (LF) times the hydraulic factor (HF) times the limiting equilibrium safety factor on the shear strength of the soil $\left(\tan \phi^{\prime} / \tan \phi_{\mathrm{mob}}^{\prime}\right)$, all divided by the strength reduction factor $\phi$. For this particular wall the minimum safety factor is equal to $(1.7 \times 1.3 \times 1.5) \div 0.90=3.68$, meaning the nominal moment capacity (yield capacity) of the wall must be at least 3.68 times the moment demand due to static active earth pressure. Using Equation 1.3 to evaluate the capacity of the stem wall to resist earthquake loads, it was determined that flexural demands from an earthquake could be equal to the nominal moment capacity of the stem wall minus the static earth pressure moment demand, or $122.3 \mathrm{ft}$-kips $-32.49 \mathrm{ft}-\mathrm{kips}=89.36 \mathrm{ft}-\mathrm{kips}$. The actual factor of safety for flexure for the 20 -ft-high USD wall is equal to $122.3 \div 32.49=$ 3.76 . 


\section{E.9.2 Earthquake demand}

Assuming $89.36 \mathrm{ft}$-kips of reserve flexural capacity, the peak horizontal acceleration $k_{h}{ }^{*} g$ of the ground that would initiate flexural yielding (plastic hinging) at the base of the stem wall can be determined. The value of the coefficient $k_{h}{ }^{*} g$ was determined to be equal to $0.544 \mathrm{~g}$ for the pseudostatic type analysis performed in accordance with the Mononobe-Okabe (MO) procedure as described in Seed and Whitman (1970) and Ebeling and Morrison (1992). The value of the coefficient $k_{h}{ }^{*} g$ was determined to be equal to $0.94 g$ for the flexible cantilever wall procedure of Veletsos and Younan (1997) assuming no amplification of the transient ground motion response, and equal to $0.487 \mathrm{~g}$ when amplification is considered. This does not mean that ground motions in excess of those described are not permissible. However, any ground motions that cause demands in excess of yield should be evaluated using performance-based or displacementbased techniques. Table E.2 provides formulations for the dynamic earth pressure shear and moment demands for the following:

- Seed and Whitman (1970) pseudostatic analysis (without transient amplification).

- Wood (1973) pseudostatic analysis (without transient amplification).

- Veletsos and Younan (1997) flexible wall procedure (without transient amplification).

- Veletsos and Younan (1997) flexible wall procedure (with transient amplification).

Table E.2

Summary of Analytical Procedure Results

\begin{tabular}{|c|c|c|c|c|}
\hline \multicolumn{5}{|c|}{ Analytical Procedure } \\
\hline & $\begin{array}{l}\text { Seed and } \\
\text { Whitman }\end{array}$ & Wood & $\begin{array}{l}\text { Veletsos and Younan } \\
\text { (without AF) }\end{array}$ & $\begin{array}{l}\text { Veletsos and Younan } \\
\text { (with AF = 1.93) }\end{array}$ \\
\hline Shear & $0.375 \rho k_{h}{ }^{*} g H^{2}$ & $1.00 \rho k_{h}{ }^{*} g H^{2}$ & $0.400 \rho k_{h}{ }^{*} g H^{2}$ & $0.772 \rho k_{h}{ }^{*} g H^{2}$ \\
\hline Moment & $0.225 \rho k_{h}{ }^{*} g H^{3}$ & $0.63 \rho k_{h}{ }^{*} g H^{3}$ & $0.130 \rho k_{h}{ }^{*} g H^{3}$ & $0.251 \rho k_{h}{ }^{*} g H^{3}$ \\
\hline$k_{h}{ }^{*} g$ & $0.544 \mathrm{~g}$ & $0.194 \mathrm{~g}$ & $0.940 \mathrm{~g}$ & $0.487 \mathrm{~g}$ \\
\hline \multicolumn{5}{|c|}{$\begin{array}{l}\text { Note: } \\
\rho=\text { density of the retained soil } \\
H=\text { stem wall height }\end{array}$} \\
\hline
\end{tabular}

The Wood (1973) procedure, described in Section 3.5.2 of the main text, represents the dynamic response of a wall under nonyielding backfill conditions and is considered to represent an upper-bound dynamic earth pressure demand condition. The amplification factor (AF) used in the second flexible wall procedure is assumed equal to 1.93 the upper bound value described in Veletsos and Younan (1997). 
The values for the coefficient $k_{h}{ }^{*} g$ for the 20 -ft-high USD retaining wall representing the horizontal acceleration that initiates yielding at the base of the stem wall for each of these analysis procedures are also provided in Table E.2.

The seismic evaluation of earth retaining wall structures is complex due to soil-structure interaction effects. The Mononobe-Okabe equation is considered the standard for the design and evaluation of retaining structures subject to earthquake ground motions and active limit-state conditions. This simple pseudostatic procedure described in Ebeling and Morrison (1992) and Seed and Whitman (1970) is considered at present to be the method of choice when evaluating force demands (i.e., moments and shears) on retaining wall systems. The flexible cantilever wall procedure described in Veletsos and Younan (1997) is of special interest because it provides a methodology for assessing displacement demands on retaining wall systems dominated by a stem wall yielding response. 


\section{Appendix $F$ Evaluating an Older Wall}

\section{F.1 Problem Description}

Older retaining walls will likely not have development and splice lengths that comply with current American Concrete Institute (ACI) Code (ACI 318-02) requirements (ACI 2002). ${ }^{1}$ In addition, retaining walls constructed before 1947 are unlikely to have the high-bond deformation patterns typical of modern-day reinforced concrete structures. Information on the yield and tensile strength properties of older reinforcing steel is provided in Appendix A. This appendix provides by example one method to evaluate the seismic performance of an older retaining wall that does not have adequate splice and development lengths. The splice length deficiency can be the result of either past ACI Code design practice or because the older reinforcement has a low-bond deformation pattern. This example demonstrates the process described in Appendix B. It will be assumed that the reinforced concrete retaining wall designed by working stress design (WSD) in Section D.1 has twisted square reinforcing bars with yield strength of 33.000 psi. It also will be assumed that the allowable working stress for the steel is $(0.5 \times 33,000)=16,500$ psi. Using the same depth of section and increasing the steel area by $(20 \div 16.5) 1.58$ in. $^{2}=1.915$ in. $^{2}$, the nominal moment capacity $M_{N}$ for the ACI-WSD designed wall is determined per Figure F.1. ${ }^{2}$

\section{F.2 Moment Capacity}

Quantities used in the following computations are described in Figure F.1.

Summing forces to get the compressive force $C$ and the depth of the stress block $a$ :

$$
C=T=A_{S} f_{Y}=1.915(33 \mathrm{ksi})=63.2 \mathrm{kips}
$$

\footnotetext{
${ }^{1}$ References cited in this appendix are included in the References section at the end of the main text.

${ }^{2}$ Each of the appendixes in this report has its own system of notation. Many of the symbols used in this appendix are defined in the text of this appendix. Others are commonplace to reinforced concrete design and retaining wall design. Readers not understanding a particular symbol notation should consult the references cited in this appendix for the definition.
} 


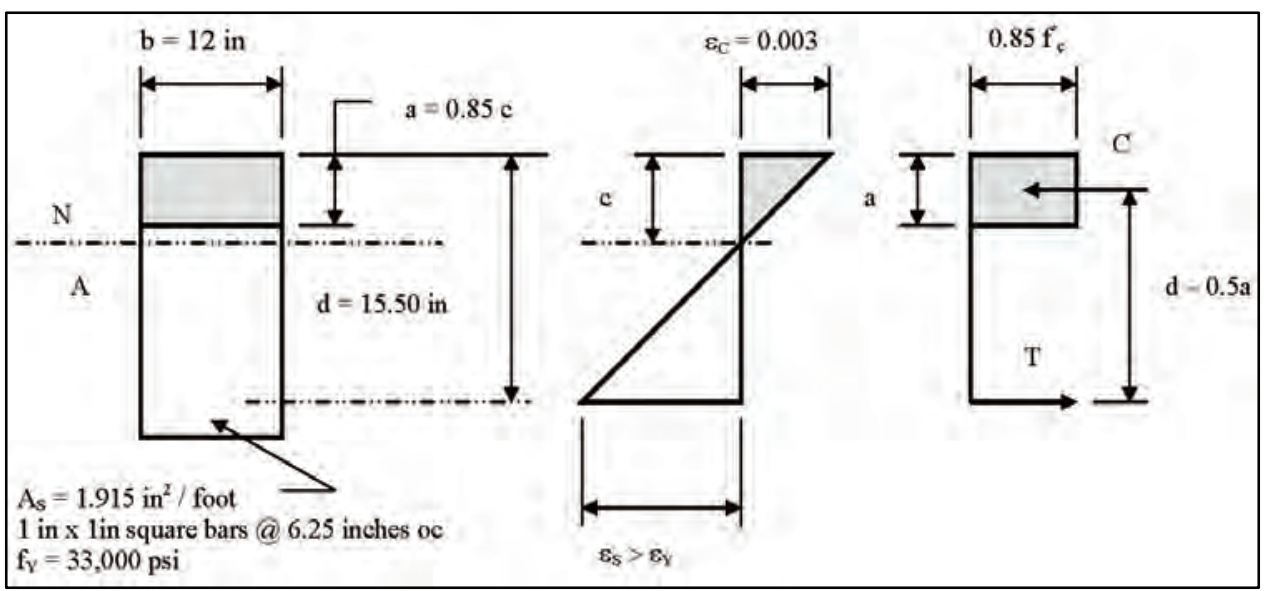

Figure F.1 Stem wall section properties, strain distribution and stresses

$$
a=C \div 0.85 b\left(f_{c}^{\prime}\right)=63.2 \div 0.85(12)(3)=2.07 \text { in. }
$$

Summing moments about the compressive force $C$ to get the nominal moment capacity $M_{N}$ :

$$
M_{N}=T(d-0.5 a)=63.2(15.5-1.035)=914.2 \text { in.-kips }=76.18 \mathrm{ft}-\mathrm{kips}
$$

where $d$ is the depth from compression face to centroid of longitudinal tension reinforcement.

Assuming for calculation purposes that a lap splice of 20 in. (approximately 20 bar diameters) was provided for the main reinforcement (at the location where it laps with the footing steel), the nominal moment capacity at the base of the stem wall is determined using procedures described in Appendix B. See Figure F.2 and following calculations.

A 1-in.-square bar would be equivalent in area to a \#9 round bar with a bar diameter $d_{b}$ equal to $1.125 \mathrm{in}$. Assuming the displacement ductility demand is low (less than two) and neglecting the splice classification per Federal Emergency Management Agency (FEMA) 356 (2000), paragraph 6.4.5, the required lap splice length for a 33,000-psi yield strength \#9 bar per ACI 318-02 Chapter 11 requirements is $28.6 \mathrm{in}$. and the hook development length is $9.5 \mathrm{in}$. (see calculations in Figures F.3 and F.4).

By the FEMA 356 (2000) guidance the splice development length required for the twisted square bar reinforcement would be 28.6 in. Since a lap splice length of $20 \mathrm{in}$. is provided, the maximum ultimate stress $f_{S}$ that can be developed in the bar per FEMA 356 (2000) requirements is 33,000 psi:

$$
f_{S}=\left(l_{b} \div l_{d}\right) f_{Y}=(20.0 \div 28.6) 33,000=23,100 \mathrm{psi}
$$




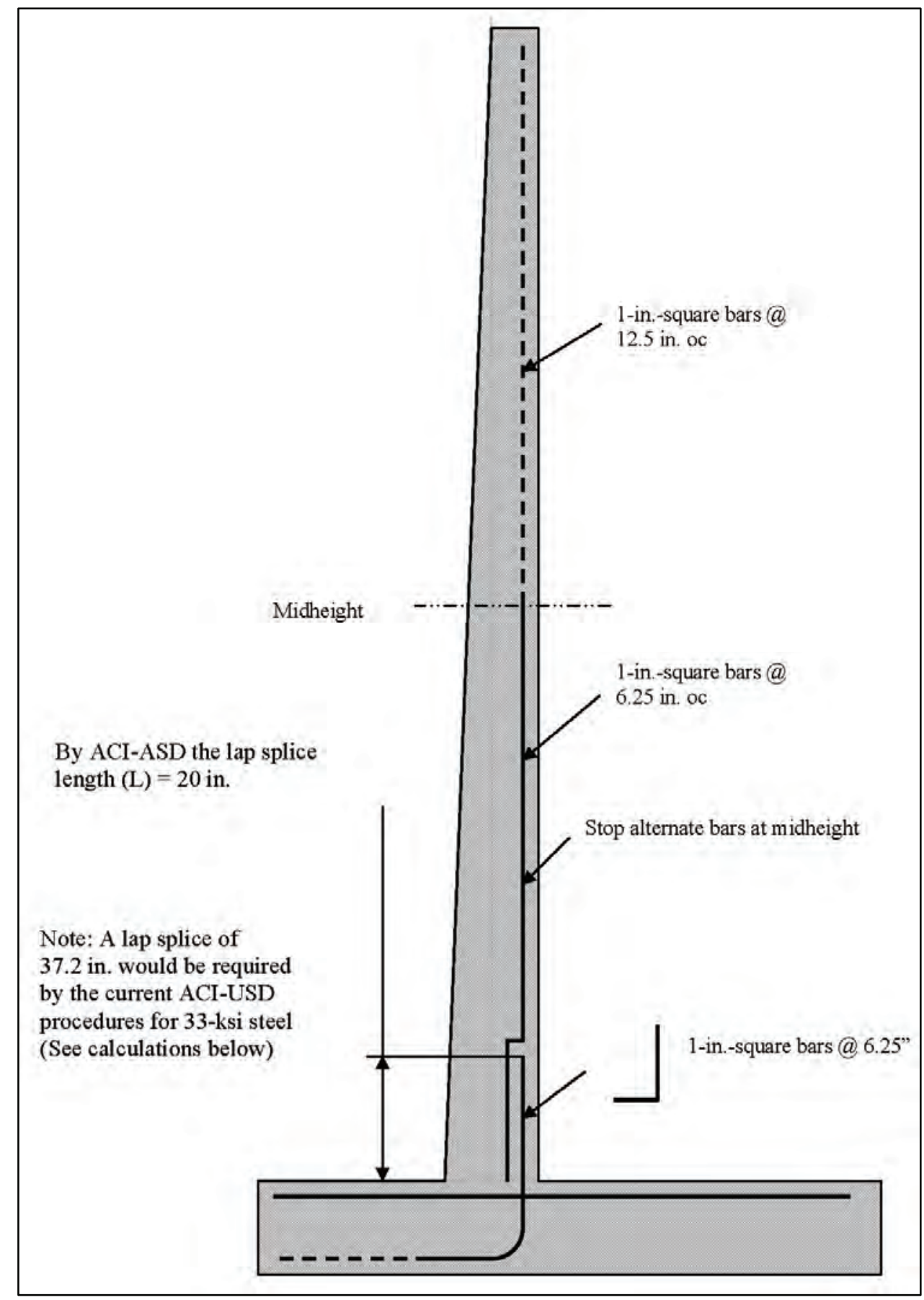

Figure F.2 Main reinforcement

where

$l_{b}=$ lap or splice length provided

$l_{d}=$ lap or splice length required by ACI 318-02 (ACI 2002)

Referring to Figure F.1 and summing forces to get the compressive force $C$ and the depth of the stress block $a$ : 
Development Length of Deformed Bars in Tension

File: BAA5M / Development Length $4 \quad$ May 18, 2004

Per $\mathrm{ACl}$ 318-02 Section 12.2.2 for No. 7 and larger bars

Concrete Compressive Strength $-\mathrm{f}^{\prime}{ }_{\mathrm{c}} \quad \mathrm{f}_{\mathrm{c}}:=3000 \quad$ psi

Rebar Yield Strength $-\mathrm{f}_{\mathrm{y}} \quad \mathrm{f}_{\mathrm{y}}:=33000 \quad$ psi

Cover $-\mathrm{c} \quad \mathrm{c}:=2 \quad$ inches

Reinforcement Location Factor $\quad \alpha:=1.0 \quad$ Not Top Bars

Coating Factor $\quad \beta:=1.0 \quad$ Bars Uncoated

Reinforcement Size Factor $\quad \gamma:=1.0 \quad$ No. 7 and larger bars

Lightweight Aggegate Factor $\quad \lambda:=1.0 \quad$ Normal Weight Concrete

Bar Diameter $\quad \mathrm{d}_{\mathrm{b}}:=1.125$ inches No. 9 bar

$1_{\mathrm{d}}:=\left(\frac{\mathrm{f}_{\mathrm{y}} \cdot \alpha \cdot \beta \cdot \lambda}{20 \cdot \sqrt{\mathrm{f}_{\mathrm{c}}}}\right) \cdot \mathrm{d}_{\mathrm{b}} \quad 1_{\mathrm{d}}=33.89 \quad$ inches

Per $\mathrm{ACl}$ 318-95 Section 12.2 .3

$\mathrm{K}_{\mathrm{tr}}:=0 \quad \mathrm{R}:=\frac{\left(\mathrm{c}+\mathrm{K}_{\mathrm{tr}}\right)}{\mathrm{d}_{\mathrm{b}}} \quad \mathrm{R}=1.778$

Use $\quad \mathrm{R}:=1.778$

$1_{\mathrm{d}}:=\left[\left(\frac{3}{40}\right) \cdot\left(\frac{\mathrm{f}_{\mathrm{y}}}{\sqrt{\mathrm{f}_{\mathrm{c}}}}\right) \cdot \frac{\alpha \cdot \beta \cdot \gamma \cdot \lambda}{\mathrm{R}}\right] \cdot \mathrm{d}_{\mathrm{b}} \quad 1_{\mathrm{d}}=28.591$

Figure F.3 Mathcad calculations for straight bar development length 


$$
\begin{aligned}
& \text { Per ACI 318-02 Section 12.5.2 for hook devlopment length } \\
& \text { Concrete Compressive Strength }-f_{c}^{\prime} \quad f_{c}:=3000 \quad \text { psi } \\
& \text { Rebar Yield Strength }-f_{y} \quad f_{y}:=33000 \quad \text { psi } \\
& \text { Reinforcement Location Factor } \quad \alpha:=1.0 \quad \text { Not Top Bars } \\
& \text { Coating Factor } \quad \beta:=1.0 \quad \quad \text { Bars Uncoated } \\
& \text { Lightweight Aggegate Factor } \quad \lambda:=1.0 \quad \text { Normal Weight Concrete }
\end{aligned}
$$$$
\text { Bar Diameter } \quad \mathrm{d}_{\mathrm{b}}:=1.125 \text { inches No. } 9 \text { bar }
$$

Per $\mathrm{ACl}$ 318-02 Section 12.5.1

$$
\begin{aligned}
& 1_{\mathrm{dh}}:=\left(\frac{0.02 \mathrm{f}_{\mathrm{y}} \cdot \beta \cdot \lambda}{\sqrt{\mathrm{f}_{\mathrm{c}}}}\right) \cdot \mathrm{d}_{\mathrm{b}} \quad 1_{\mathrm{dh}}=13.556 \text { inches } \\
& \eta:=0.7 \quad \text { Modification factor per ACl 318-02 Section 12.5.3 } \\
& 1_{\mathrm{dhm}}:=\eta \cdot 1_{\mathrm{dh}} \quad 1_{\mathrm{dhm}}=9.489 \quad \text { inches }
\end{aligned}
$$

Figure F.4 Mathcad calculations for hooked bar development length

$$
\begin{aligned}
& C=T=A_{S} f_{S U}=1.915(23.1 \mathrm{ksi})=44.24 \mathrm{kips} \\
& a=C \div 0.85 b\left(f_{c}^{\prime}\right)=44.24 \div 0.85(12)(3)=1.44 \mathrm{in} .
\end{aligned}
$$

Summing moments about the compressive force $C$ to get the nominal moment capacity $M_{N}$ :

$$
M_{N}=T(d-0.5 a)=44.24(15.5-0.72)=653.9 \text { in.-kips }=54.50 \mathrm{ft}-\mathrm{kips}
$$

With a static earth pressure moment demand of $35.71 \mathrm{ft}$-kips the reserve moment capacity to resist dynamic earth pressures generated by earthquake ground motions is $54.50-35.71=18.79 \mathrm{ft}-\mathrm{kips}$. This compared to a reserve moment capacity of 40.47 with full lap splice development capability. 


\section{F.3 Moment Demand for Design Earthquake}

\section{F.3.1 By Veletsos and Younan (1997)}

Assume that the design earthquake is that determined in Appendix $\mathrm{C}$ for the 1,000 -year event (peak ground acceleration $(\mathrm{PGA})=0.764 \mathrm{~g}$ ), and the relative flexibility of the wall $d_{w}$ is equal to 44.2 as determined in Appendix D.

By Figure 4a, Veletsos and Younan (1997), the moment at the base of the stem wall assuming rigid body motion $M_{s t}$ is as follows:

$$
M_{s t}=0.10(0.125)(0.764)(18.5)^{3}=60.47 \mathrm{ft}-\mathrm{kips}
$$

Assuming an amplification factor (AF) of 1.93 per Figure 13a, Veletsos and Younan (1997), the active earth pressure earthquake induced moment $M_{A E}$ is:

$$
M_{A E}=1.93(60.47)=116.71 \mathrm{ft}-\mathrm{kips}
$$

The total moment demand on the wall $M_{T}$ is

$$
M_{T}=35.71+116.71=152.42 \mathrm{ft}-\mathrm{kips}
$$

The total moment demand (static + incremental dynamic) of 152.42 exceeds the nominal moment capacity of $54.50 \mathrm{ft}$-kips; therefore, a displacement-based analysis is required.

\section{F.3.2 By Seed and Whitman (1970) and Ebeling and Morrison (1992)}

Referring to Section 4.2.2 of Ebeling and Morrison (1992)

$k_{h}=$ constant horizontal coefficient $=0.764$

$\Delta K_{A E}=$ dynamic earth pressure increment coefficient $=0.75\left(k_{h}\right)=0.573$

$\Delta P_{A E}=\Delta K_{A E}(0.50) \gamma_{t}(H)^{2}=0.573(0.50)(0.125)(18.5)^{2}=12.257 \mathrm{kips}$

$M_{A E}=12.257(0.60)(18.5)=136.05 \mathrm{ft}-\mathrm{kips}$

$P_{A}=0.50 k_{A} \gamma_{t}(H)^{2}=0.50(0.271)(0.125)(18.5)^{2}=5.797 \mathrm{kips}$

$M_{A}=5.797(0.333)(18.5)=35.71 \mathrm{ft}-\mathrm{kips}$

The total moment demand on the wall $M_{T}$ is:

$M_{T}=35.71+136.05=171.76 \mathrm{ft}-\mathrm{kips}$

The total moment demand (static + incremental dynamic) of 171.76 is slightly larger than the total moment demand of Veletsos and Younan (1997) (including amplification effects). 


\section{F.4 Displacement Capacity}

\section{F.4.1 For a weak bond condition}

It can be assumed that the displacement capacity will be limited since severe bond-slip and strength deterioration can occur when stresses in the steel exceed yield. Therefore the displacement capacity will be based on strain penetration associated with a pseudo-yield stress of $23.1 \mathrm{ksi}$ assuming a single crack forms at the base of the stem wall. The yield curvature capacity $\phi_{y}$ will be based on a strain in the steel due to a stress of $23.1 \mathrm{ksi}$. The ultimate curvature capacity $\phi_{u}$ will be based on a strain in the steel of 0.3 percent for a weak bond condition based on information suggested in Figure 5 of Monti and Spacone (2000).

Calculations for yield curvature $\phi_{y}$ and ultimate curvature $\phi_{u}$ are illustrated in Figure F.5.

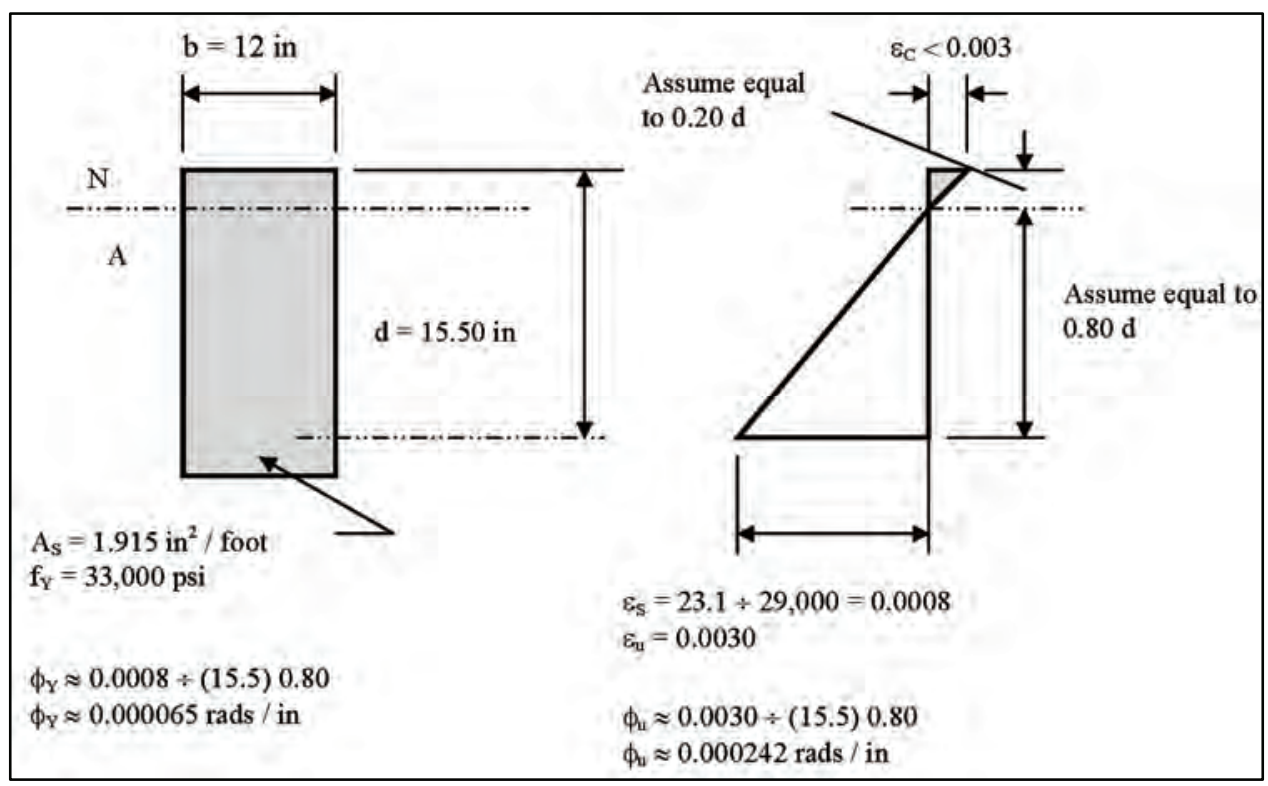

Figure F.5 Strains at yield and ultimate

The ultimate displacement capacity $\delta_{\mu}$ is only equal to the elastic contribution prior to first yield of the reinforcing steel at $23.1 \mathrm{ksi}$ plus an inelastic contribution. Conservatively assuming a triangular distribution of total earth pressure (static + incremental dynamic) as shown in Figure F.6, the elastic component of the displacement capacity $\left(\delta_{\mathrm{y}}\right)$ can be determined.

$\delta_{y}=0.20\left(\phi_{y}\right) h^{2}=0.20(0.000065)(18.5 \times 12)^{2}=0.64$ in.

The total ultimate displacement capacity is

$$
\delta_{\mu}=\delta_{y}+\left(\phi_{\mu}-\phi_{y}\right) l_{p}\left(l-\frac{l_{p}}{2}\right)
$$

For the single crack condition it will be assumed the plastic hinge length $l_{p}$ is: 


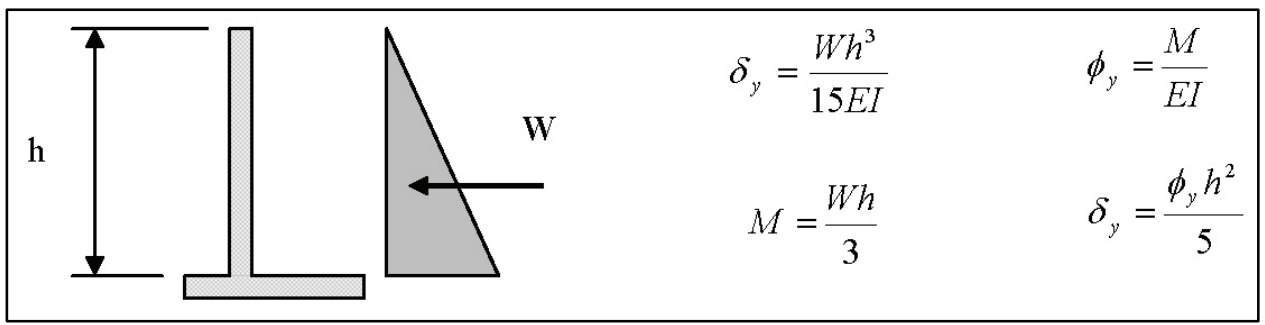

Figure F.6 Yield displacement formulation

$$
l_{p}=0.30 f_{y} d_{b}=0.30(23.1) 1.00=7.0 \text { in. (see Equation 4.7). }
$$

where

$f_{y}=$ yield strength of the reinforcing steel $(\mathrm{ksi}) \leftarrow$ Use $23.1 \mathrm{ksi}$

$d_{b}=$ diameter of reinforcing steel $\leftarrow$ Use 1.0 in. for the square bars

$\delta_{\mu}=0.64+(0.000242-0.000065)(7.0)(222-3.5)=0.64+0.27=$ $0.91 \mathrm{in}$.

\section{F.4.2 For a strong bond condition}

With strong bond (full splice development) the ultimate displacement capacity will increase due to a larger yield displacement capacity and a longer plastic hinge length.

The cracking moment capacity $M_{C R}$ per Equation 3.2 is

$$
M_{C R}=12(18)^{2}(410) \div 6=265,680 \text { in. }-\mathrm{lb}=22.14 \mathrm{ft}-\mathrm{kips}
$$

The nominal moment capacity $M_{N}$ is $76.18 \mathrm{ft}$-kips.

Since $M_{N}$ is greater than $2 M_{C R}$, then the plastic hinge length $l_{p}$ per Equation 4.8 is

$$
l_{p}=0.08 L+0.15\left(f_{y}\right) d_{b}=0.08(18.5 \times 12)+0.15(33)(1)=22.71 \text { in. }
$$

Referring to Figure F.7, the ultimate displacement capacity is

$$
\begin{aligned}
\delta_{\mu} & =\frac{\phi_{y} h^{2}}{5}+\left(\phi_{\mu}-\phi_{y}\right) l_{p}\left(l-\frac{l_{p}}{2}\right) \\
\delta_{\mu} & =0.91+(0.004032-0.000092)(22.71)(222-11.35) \\
& =0.91+18.85=19.76 \mathrm{in} .
\end{aligned}
$$

This would indicate that with adequate splice length the displacement capacity would be much greater than the displacement demand, and displacementbased performance objectives would be met. 


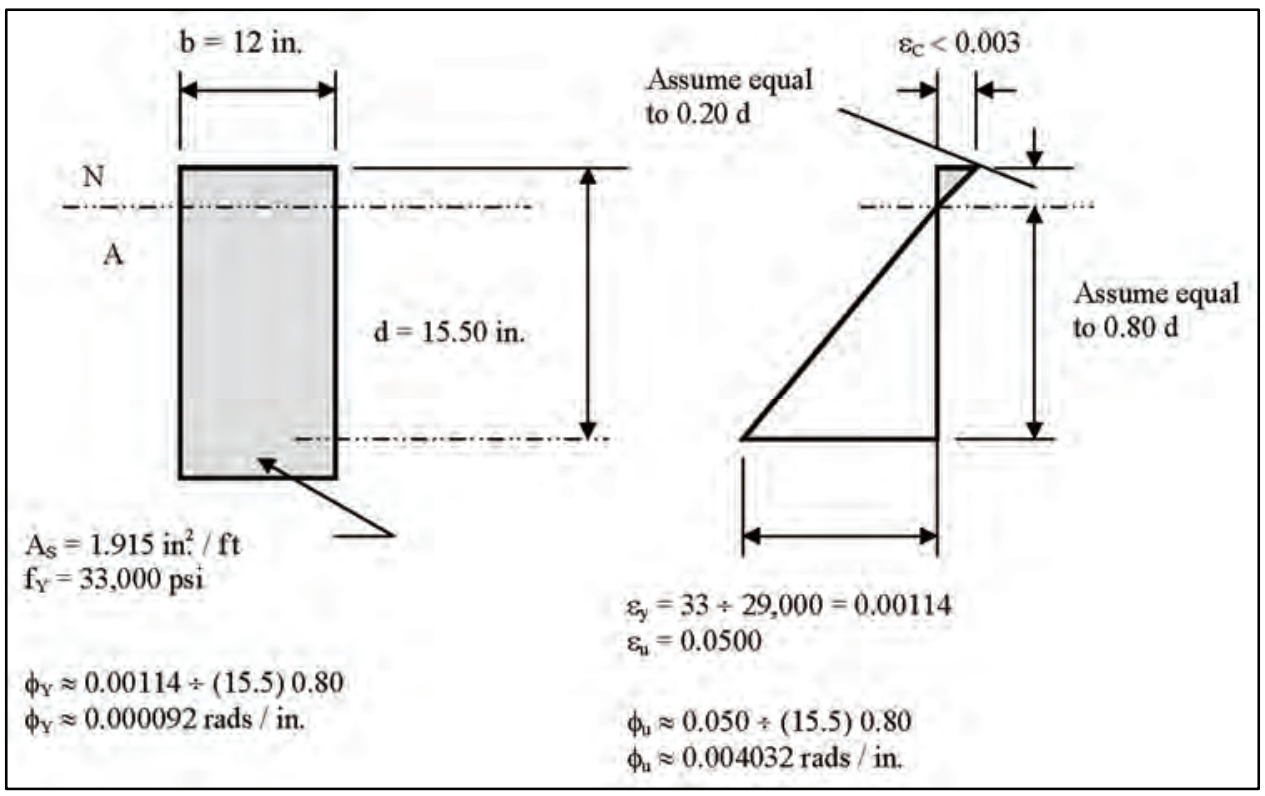

Figure F.7 Strain conditions at ultimate

\section{F.5 Total Displacement Demand $\delta_{\mathrm{T}}$}

\section{F.5.1 By Veletsos and Younan (1997)}

By Veletsos and Younan (1997), assuming the spectral acceleration $S_{a}$ is equal to the AF times the PGA, the maximum dynamic earth pressure displacement at the top of the stem wall $\delta_{E}$ via a shear-beam simplified model is

$$
\delta_{E}=0.50 S_{a} h^{2} \div V_{S}^{2}
$$

Assuming an AF of 2.38 per Veletsos and Younan (1997), a shear wave velocity of $500 \mathrm{fps}$, and a PGA of $0.764 g$, the maximum dynamic earth pressure displacement at the top of the stem wall $\delta_{E}$ is

$$
\delta_{E}=0.50(2.38)(0.764)(32.2)(18.5)^{2} \div(500)^{2}=0.040 \mathrm{ft}=0.48 \mathrm{in} .
$$

The contribution from static active earth pressure $\delta_{A}$ is

$$
\begin{aligned}
\delta_{A} & =W h^{3} \div 15 E I=5.8(18.5)^{3} \div 15(475,000)(1.953) \\
& =0.00264 \mathrm{ft}=0.032 \mathrm{in} .
\end{aligned}
$$

Note: The gross moment of inertia at a distance of $6.5 \mathrm{ft}$ above the base was used.

The total displacement demand on the wall $\delta_{T}$ is

$$
\delta_{T}=0.48+0.032=0.512 \text { in }
$$




\section{F.5.2 By FEMA $356(2000)$}

By FEMA 356 (2000) assume the system period is equal to $4 h \div V_{S}$ per Veletsos and Younan (1997) and $C_{1}$ is per Whittaker et al. (1998).

Assume the strength ratio $e$ is equal to the nominal moment capacity $\div$ the earthquake moment demand $=76 \mathrm{ft}$-kips $\div 172 \mathrm{ft}$-kips $\approx 0.50$.

Assume the effective moment of inertia $I_{E}$ to gross moment of inertia $I_{G}$ ratio is per Equation 3.1 and is equal to $0.8-0.9[(77 \div 22)-1]=0.8-2.5 \leftarrow$ negative so minimum ratio of 0.25 governs.

Per Equation 4.25: $T_{1}=4 h \div V_{S}=4(18.5) \div 500=0.15 \mathrm{sec}$.

From Figure 8(b), Whittaker et al. (1998), the value for $C_{1} \approx 2.0$.

Using the FEMA 356 (2000) target displacement equation, substituting this formulation for period and assuming all coefficients except for $C_{1}$ are equal to 1.0 , and the spectral acceleration $S_{A}$ is $1.91 \mathrm{~g}$ per the Appendix C 1,000-year response spectrum:

$$
\begin{aligned}
& \delta_{E}=C_{1} \bullet S_{A} \bullet\left[4 h^{2} \div\left(\pi^{2} \bullet V_{S}^{2}\right)\right]=2.0(0.405) S_{a} h^{2} \div V_{S}^{2}=0.81 S_{A} h^{2} \div V_{S}^{2} \\
& \delta_{E}=0.81(1.91)(32.2)(18.5)^{2} \div(500)^{2}=0.0682 \mathrm{ft}=0.818 \mathrm{in} . \\
& \delta_{T}=0.818+0.032=0.848 \mathrm{in} .
\end{aligned}
$$

\section{F.5.3 By Seed and Whitman (1970)}

Using the total pressure from Seed and Whitman (1970) to determine wall displacement and assuming the total pressure is uniform at approximately $1.0 \mathrm{ksf}$.

$$
\delta_{T}=w h^{4} \div 8 E I=1.0(18.5)^{4} \div 8(475,000)(1.953)=0.01578 \mathrm{ft}=0.19 \mathrm{in} .
$$

Note: The gross moment of inertia at a distance of $6.5 \mathrm{ft}$ above the base was used for this approximate calculation. A SAP90 analysis, accounting for the variation in moment of inertia along the stem height and accounting for the actual Seed and Whitman (1970) total pressure distribution, was used to verify the displacement demand at the top of the wall. By SAP90 analysis the displacement demands at the top of the wall were equal to $0.0131 \mathrm{ft}=0.16 \mathrm{in}$.

Assuming as before the effective moment of inertia is equal to 25 percent of the gross section moment of inertia, the displacement at the top of the wall is equal to $4(0.16)$ in. $=0.64$ in. 


\section{F.6 Shear Demand to Capacity Check}

\section{F.6.1 Shear demand for design earthquake per Veletsos and Younan (1997)}

Assuming the design earthquake is that determined in Appendix $\mathrm{C}$ for the 1,000 -year event $(\mathrm{PGA}=0.764 \mathrm{~g})$, and the relative flexibility of the wall $d_{w}$ is equal to 44.2 as determined in Appendix D.

By Figure 3a, Veletsos and Younan (1997), the shear at the base of the stem wall assuming rigid body motion $V_{s t}$ is as follows:

$$
V_{s t}=0.40(0.125)(0.764)(18.5)^{2}=13.07 \mathrm{kips}
$$

Assuming an AF of 1.93 per Figure 13a, Veletsos and Younan (1997), the active earth pressure earthquake induced shear $V_{A E}$ is

$V_{A E}=1.93(13.07)=25.23 \mathrm{kips}$

The total shear demand on the wall $V_{T}$ is

$$
V_{T}=5.80+25.23=31.03 \mathrm{kips}
$$

\section{F.6.2 Shear demand for design earthquake per Seed and Whitman (1970)}

Per Seed and Whitman (1970) the active earth pressure earthquake induced shear $V_{A E}$ is

$$
V_{A E}=0.375 \rho k_{h}{ }^{*} g H^{2}=0.375(0.125)(0.764)(18.5)^{2}=12.26 \mathrm{kips}
$$

The total shear demand on the wall $V_{T}$ is

$$
V_{T}=5.80+12.26=18.06 \mathrm{kips}
$$

\section{F.6.3 Shear demand as limited by flexural capacity}

By limiting the total shear demand to 1.5 times the shear associated with the nominal flexural strength per Section 4.2.1 then:

$$
V_{T}=1.5(76.18 \div 35.71)(5.8)=18.56 \text { kips } \leftarrow \text { Assumes governs }
$$

\section{F.6.4 Shear demand to shear capacity evaluation}

The total shear demand of 18.56 kips is compared to the concrete shear capacity $V_{C}$ per Equation 4.1. Assuming a displacement ductility demand equal to two (low ductility demand), using $k$, a factor dependent on member flexural displacement ductility demand, equal to 2.0, per Section 6.4.4 of FEMA 356 (2000) 
and using the actual concrete compressive strength as equal to $1.5(3000)=$ 4,500 psi.

$$
V_{N}=2(4500)^{1 / 2}(0.80 \times 18 \times 12)=23184 \mathrm{lb}=23.18 \mathrm{kips}
$$

$V_{U}=$ total ultimate shear strength $=\phi V_{N}=0.85(23.18)=19.70 \mathrm{kips}$

Shear capacity greater than shear demand - Okay

\section{F.7 Sliding Shear Demand to Capacity Check}

Sliding shear capacity at the stem-to-base contact interface due to shear friction $V_{S F}$ is

$$
V_{S F}=\mu_{S F}\left(P+0.25 A_{s} f_{y}\right)
$$

where

$$
\begin{aligned}
\mu_{S F}= & \text { sliding shear coefficient of friction, per ACI } 318-02=1.0 \\
P= & \text { axial load on section }=3.12 \mathrm{kips}(\text { See Table D. }) \\
A_{s}= & \text { area of the longitudinal reinforcing steel across the potential failure } \\
& \text { plane } \\
A_{s}= & 1.915 \text { in. }^{2} \\
f_{y}= & \text { yield strength of the reinforcing steel } \leftarrow \text { Use } 23.1 \mathrm{ksi} \\
V_{S F}= & 1.0[3.12+0.25(1.915)(23.1)]=14.18 \mathrm{kips}<18.71 \mathrm{kips}
\end{aligned}
$$

Demand greater than capacity - NG

However, it may be considered okay since sliding shear failures do not generally lead to collapse. ${ }^{1}$ Would be okay if development length were adequate to develop the full yield capacity of $33 \mathrm{ksi}$.

\section{F.8 Fracture of Reinforcing Steel}

Fracture of the reinforcing steel will not occur since the nominal moment capacity $M_{N}$ is more than 1.2 times the cracking moment $M_{C R}$.

\section{F.9 SAP90 Check of Seed and Whitman (1970) Results}

Input to the SAP90 analysis (Wilson and Habibullah 1990) is illustrated in Figure F.8.

\footnotetext{
${ }^{1}$ M.J.N. Priestley, 1997, "Criteria Review for Corps - Seismic Design and Evaluation of Powerhouse Superstructures," presented in Appendix G of this report.
} 


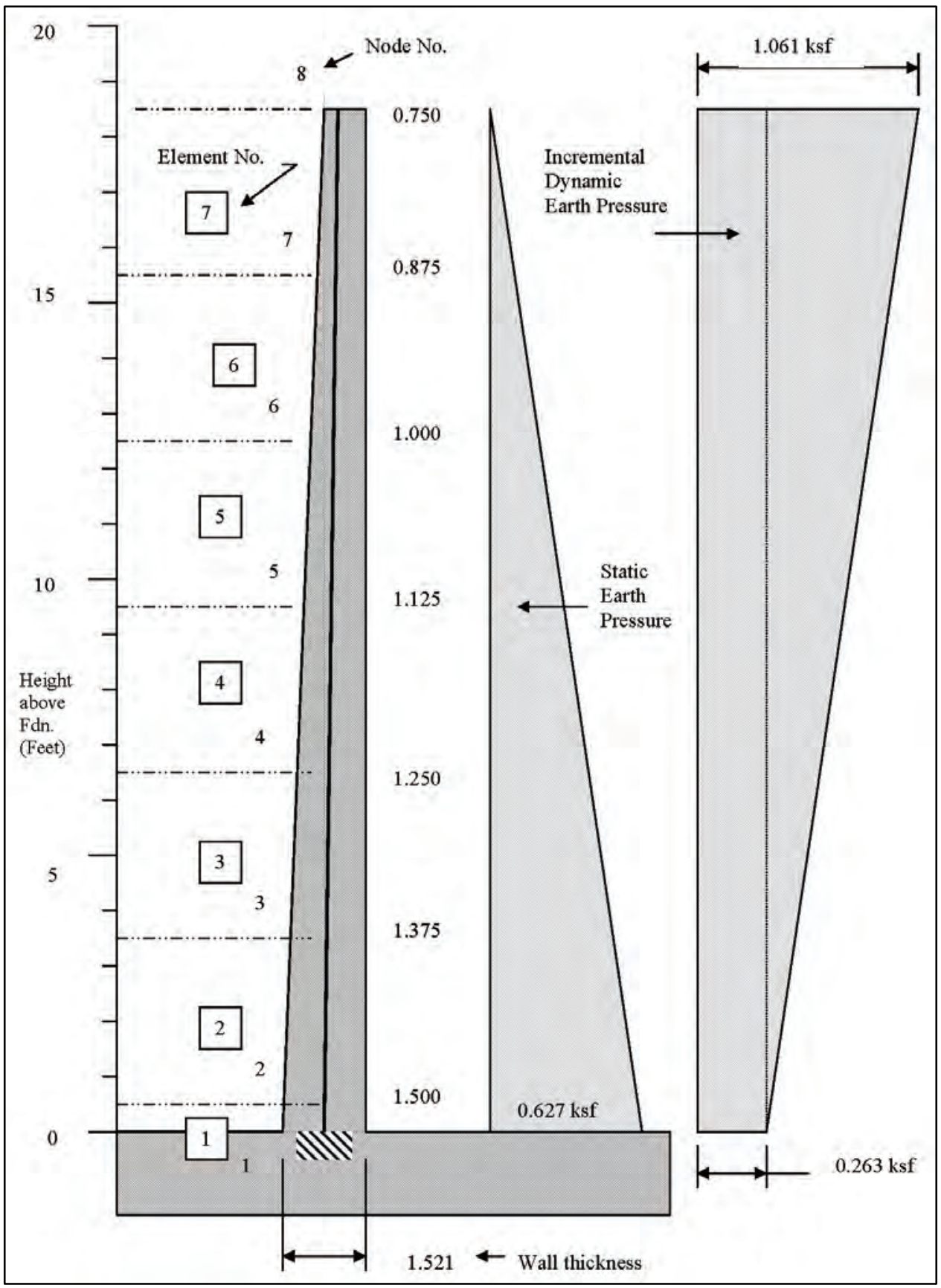

Figure F.8 SAP90 analytical model

Moment and shear demands by the following SAP90 analysis check with those computed in Sections F.3.2 and F.6.2, respectively. Displacement demands agree reasonably with the approximate displacement demands computed in Section F.5.3.

\section{SAP90 INPUT}




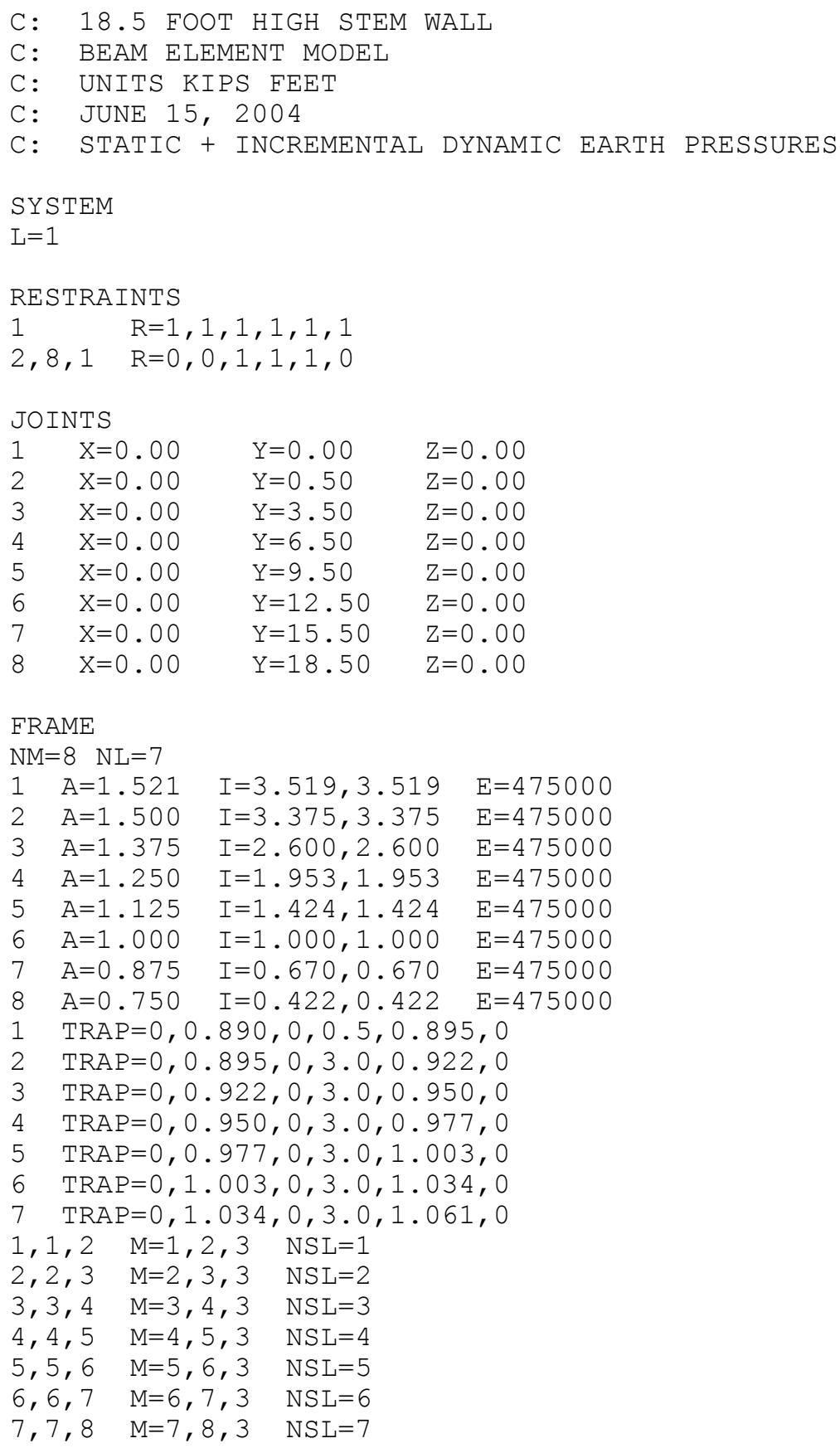

\section{SAP90 DISPLACEMENTS}

\begin{tabular}{rcll} 
LOAD CONDITION & \multicolumn{1}{l}{ DISPLACEMENTS } & U" AND R \\
JOINT & \multicolumn{1}{c}{$\mathrm{U}(\mathrm{X})$} & \multicolumn{1}{c}{$\mathrm{U}(\mathrm{Y})$} & $\mathrm{R}(\mathrm{Z})$ \\
1 & 0.000000 & 0.000000 & 0.000000 \\
2 & $-0.1279 \mathrm{E}-04$ & $0.0000 \mathrm{E}+00$ & $0.5108 \mathrm{E}-04$ \\
3 & $-0.6105 \mathrm{E}-03$ & $0.0000 \mathrm{E}+00$ & $0.3429 \mathrm{E}-03$ \\
4 & -0.002037 & 0.000000 & 0.000602 \\
5 & -0.004175 & 0.000000 & 0.000815 \\
6 & -0.006866 & 0.000000 & 0.000968
\end{tabular}




$\begin{array}{rrrr}7 & -0.009910 & 0.000000 & 0.001049 \\ 8 & -0.013095 & 0.000000 & 0.001066\end{array} \quad \begin{array}{r}\text { Max } \delta=0.013095 \text { feet } \\ =0.16 \text { inches }\end{array}$

\section{SAP90 MOMENTS AND SHEARS}

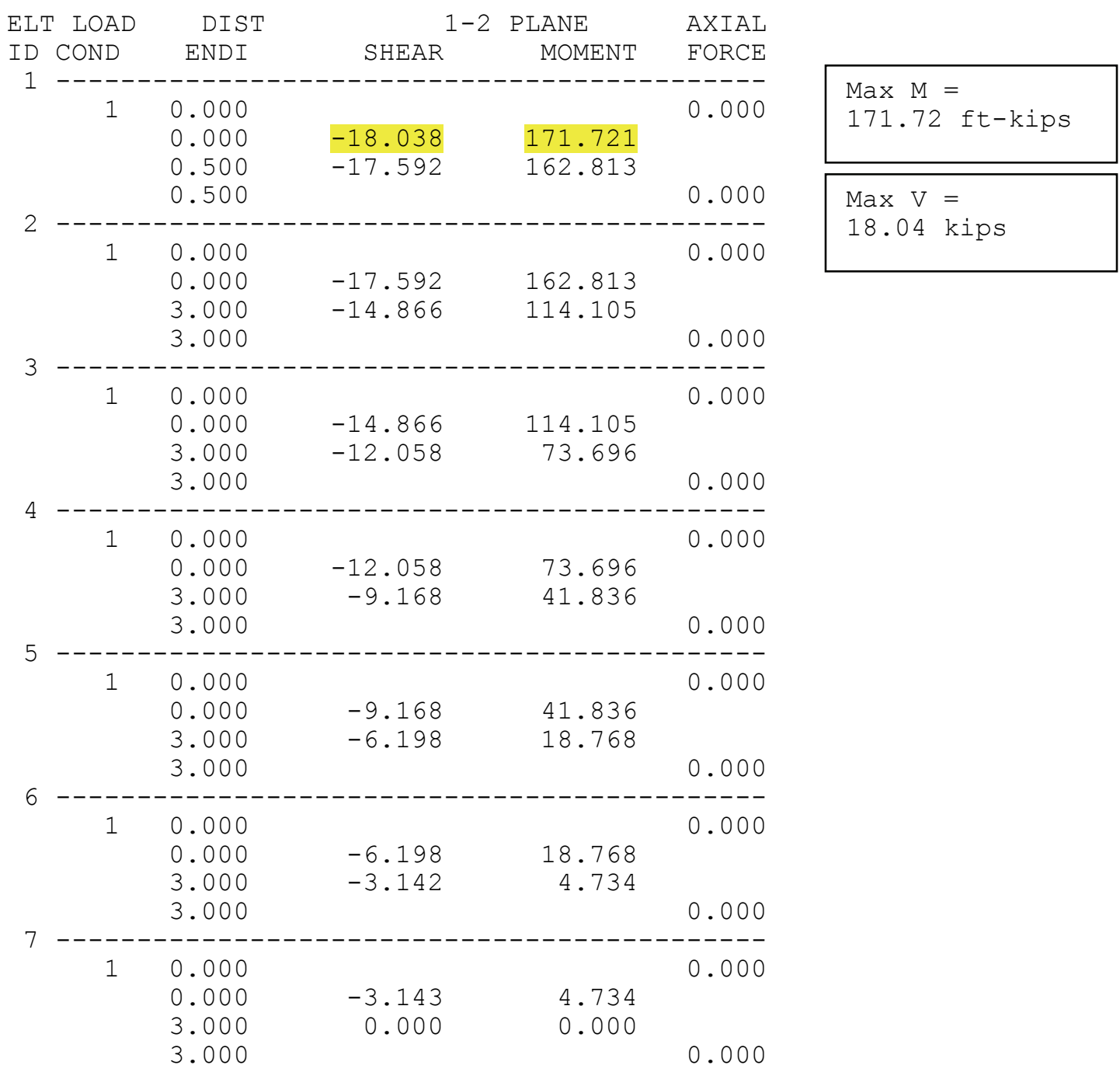

\section{F.10 Summary}

These computations suggest the displacement capacity of the retaining wall because of inadequate splice lengths may be marginal with respect to earthquake displacement demands.

It appears as if the Seed and Whitman (1970) approach will provide reasonable estimates of moment and shear demands for the stem of a cantilever retaining wall. Displacement demands under conditions where a residual displacement does not accumulate (i.e., few postyield excursions) are also reasonable provided 
the effective moment of inertia is used in combination with the total earth pressure demands per Seed and Whitman (1970). However, it is believed that the Veletsos and Younan (1997) approach will give more reliable estimates of displacement demands because it accounts for the dynamic characteristics of the soil-wall system. Displacement demands will be small if wall performance is near yield with few postyield excursions. Except for walls where the lap splices are deficient, the displacement demands should be within the displacement capacity of the wall. For cases where there are expected to be several postyield excursions, a method to account for residual displacement build-up is needed. The next section describes a method with some aspects that are speculative. However, the authors of this report believe that the approach described contains the essential fundamental features to characterize the response.

\section{F.11 A Proposed Methodology for Estimating Residual Displacements}

A step-by-step methodology for determining residual displacement is described in this section. In this methodology it is assumed the CWRotate computer program has been enhanced to perform the incremental pulse-excursion response history analysis needed to assess residual displacement demands. The methodology is illustrated using the example of Appendix D, assuming that there is a lap splice deficiency as described in preceding sections of this appendix. Residual displacement demand is the total permanent displacement demand at the top of the wall with respect to the stem wall base (Figure 4.6, main text).

\section{F.11.1 Step-by-step methodology for determining residual displace- ment demand for retaining wall with moist backfill (no water table)}

F.11.1.1 Step 1. Determine yield acceleration. Using the loading combination described by Equation 1.3 it can be seen that a flexural "yield" condition would be created at the base of the stem wall when earthquake demands due to dynamic earth pressures equal or exceed the reserve nominal moment capacity $M_{R}$ of the stem wall

$$
M_{R}=M_{N}-M_{A}
$$

where $M_{A}$ is the moment demand due to static "active" earth pressure.

For the wall described previously:

$$
M_{R}=54.50 \mathrm{ft}-\mathrm{kips}-35.71 \mathrm{ft}-\mathrm{kips}=18.79 \mathrm{ft}-\mathrm{kips}
$$

This formulation assumes that flexural yielding in the stem wall will create a displacement demand at the top of the wall consistent with an active state condition in the backfill (otherwise static earth pressures consistent with wall movements are used to compute $M_{A}$ ). Using the simplified formulations for determining dynamic active earth pressure as described in Ebeling and Morrison (1992) 
the moment demand due to incremental dynamic earth pressures $M_{A E}$ can be determined as described in the following text.

The incremental dynamic earth pressure force $\Delta P_{A E}$ is:

$$
\Delta P_{A E}=\Delta K_{A E}(0.5) \gamma H^{2}
$$

where

$$
\begin{aligned}
\Delta K_{A E} & =0.75 k_{h} \\
k_{h} & =\text { fraction of horizontal acceleration } \\
\gamma & =\text { moist unit weight of backfill } \\
H & =\text { height of backfill above stem wall base }
\end{aligned}
$$

With $\Delta P_{A E}$ assumed to act at $0.6 H$ above the stem wall base, the incremental dynamic earth pressure moment at the stem wall base $\Delta M_{A E}$ is

$$
\Delta M_{A E}=\Delta P_{A E}(0.6) H=0.225 k_{h} \gamma H^{3}
$$

In terms of mass density $\rho$

$$
\Delta M_{A E}=0.225 k_{h} g \rho H^{3}
$$

By setting the incremental dynamic earth pressure moment $\Delta M_{A E}$ equal to the reserve nominal moment capacity $M_{R}$, the yield acceleration $a_{y}$, or the acceleration that causes yielding to occur at the base of the stem wall, can be determined.

$0.225 k_{h} g \rho H^{3}=M_{R}$

With $a_{y}=k_{h} g$, and $\rho=\gamma \div g$

$$
a_{y}=\frac{M_{R} g}{0.225 \gamma H^{3}}
$$

For the wall described previously

$$
a_{y}=\frac{18.79 g}{0.225(0.125)(18.5)^{3}}=0.106 g
$$

The reserve nominal moment capacity $M_{R}$ will depend on the flexural reinforcement used in the stem wall, the depth of the stem wall, and factors that may reduce the reserve nominal moment capacity such as inadequate splice length and low bond deformation reinforcement. The yield acceleration $a_{y}$ will be unique to each particular wall. Therefore it will be a user-specified input quantity to be used when performing a CWRotate residual displacement evaluation of a retaining wall dominated by a stem wall yielding response. 
F.11.1.2 Step 2. Determine incremental pulse-excursion displacement

demands at top of stem wall. Laboratory-based structural seismic research conducted to date on model Corps cantilever retaining walls has been limited. There is no laboratory-based Corps relationship between the permanent seismic displacement at the top of the stem wall and ground motion parameters. However, at this time and pending the results of future Corps research, procedures described in Veletsos and Younan (1997) may be used to approximate incremental displacement demands at the top of the stem wall. As indicated in Figure 7a of Veletsos and Younan (1997), at the top of the stem wall the upper bound displacement of the shear beam $\delta_{g}$ when subject to a ground acceleration $a_{g}$ is approximately equal to

$$
\delta_{g}=\frac{0.50\left(a_{g}\right) H^{2}}{v_{s}^{2}}
$$

This formulation, when used with an $a_{g}$ value representing the peak ground acceleration, provides an estimate of the peak displacement response (at the top of the stem wall relative to its base) for an elastic system.

For systems dominated by a flexural yielding response (i.e., with all brittle modes of failure suppressed) it is necessary to sum all the nonrecoverable displacements associated with postyield behavior. These nonrecoverable displacements are assumed to occur during each pulse excursion $i$ where the ground acceleration $a_{g(i)}$ exceeds the yield acceleration $a_{y}$.

For a given pulse excursion $i$ the total displacement (elastic and inelastic) for that pulse excursion increment $\delta_{g(i)}$ is

$$
\delta_{g(i)}=\frac{0.50\left(a_{g(i)}\right) H^{2}}{v_{s}^{2}}
$$

For this example:

$$
\delta_{g(i)}=\frac{0.50\left(a_{g(i)}\right)(18.5)^{2}}{500^{2}}=0.000685 a_{g(i)}
$$

By subtracting the yield displacement $\delta_{y}$ from the total displacement for a given pulse excursion $i$ the nonrecoverable inelastic residual displacement for that pulse excursion $\delta_{r(i)}$ can be determined as illustrated in Figure F.9. The nonrecoverable displacements that occur during each pulse excursion $i$ where the ground acceleration $a_{g(i)}$ exceeds the yield acceleration $a_{y}$ are summed to obtain the total residual displacement $\Sigma \delta_{r(i)}$ for a given time-history record. This process is illustrated in Figure F.10. Illustrated in Figure F.10a are four pulse excursions where the yield acceleration has been exceeded. The residual displacements are shown and summed in the bottom of Figure F.10. 


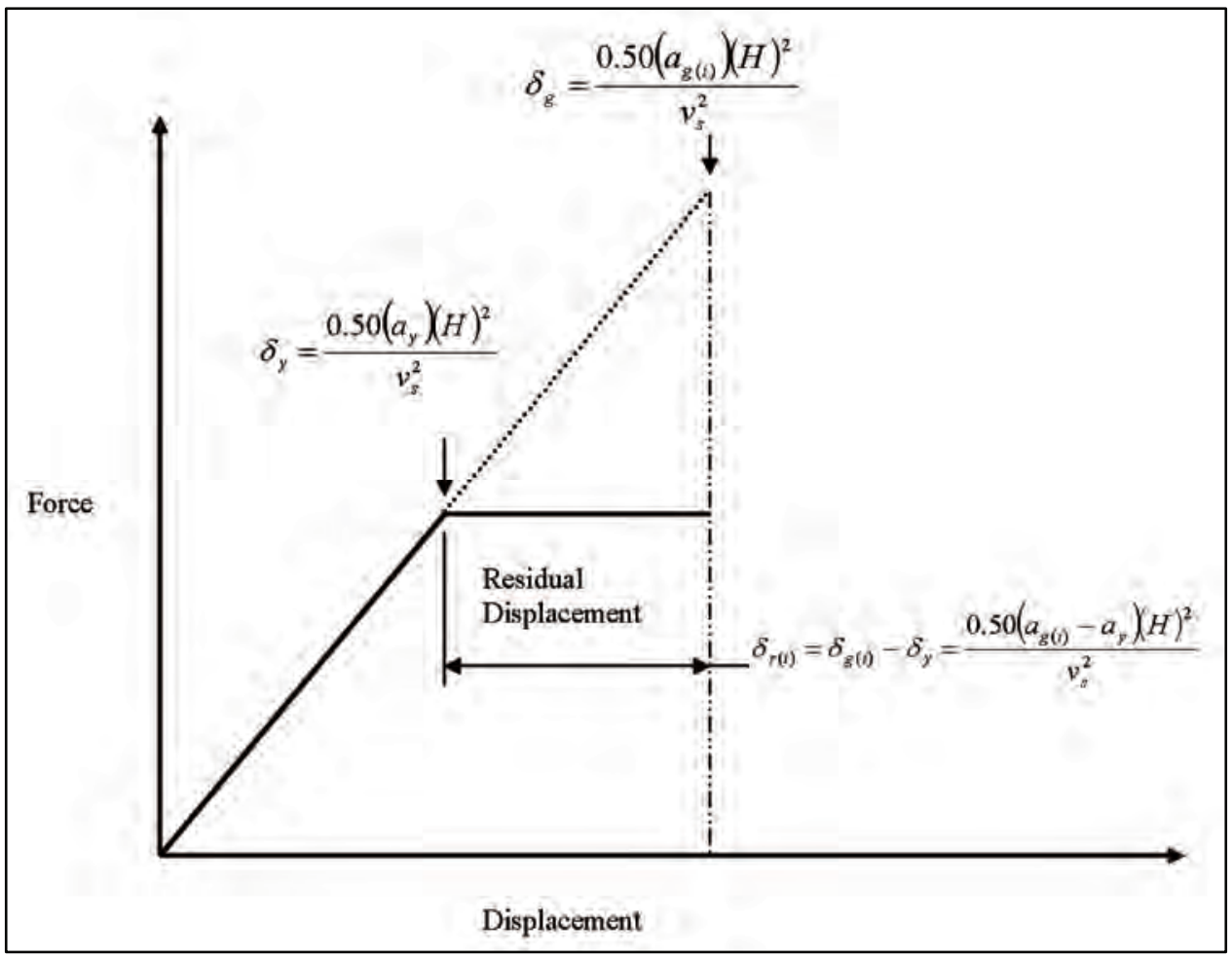

Figure F.9 Stem wall elasto-plastic behavior, residual displacement $\left(\delta_{\mathrm{r}(\mathrm{i})}\right)$, for a single pulse excursion where $a_{g(i)}>a_{y}$

It should be observed that the yield displacement $\delta_{y}$ can be determined by setting ground acceleration $a_{g(i)}$ equal to the yield acceleration $a_{y}$. For this example:

$$
\delta_{y}=0.000685(0.106)(32.2)=0.00234 \mathrm{ft}=0.028 \text { in. }
$$

It should also be noted that in the pulse excursion determination of residual displacement the potential amplification of the transient response should be captured by appropriate modifications to the time-history record. The influence on the backfill deposit will be greatest near the predominant period of the deposit $T_{1}$, which for the shear-beam model is

$$
T_{1}=\frac{4 H}{v_{s}}
$$

Modifications to top of rock time-history records are needed to reflect average conditions in the backfill. These modifications can be approximated by ground motion experts using equivalent linear dynamic soil response methods such as SHAKE (Schnabel et al. 1972) or Idriss and Sun (1992), as well as provide an earthquake-induced strain-compatible value of average shear wave velocity within the retained soil. The equivalent linear dynamic soil response approach is necessary to reasonably assess the number of excursions beyond yield as well as the magnitude of these excursions. 


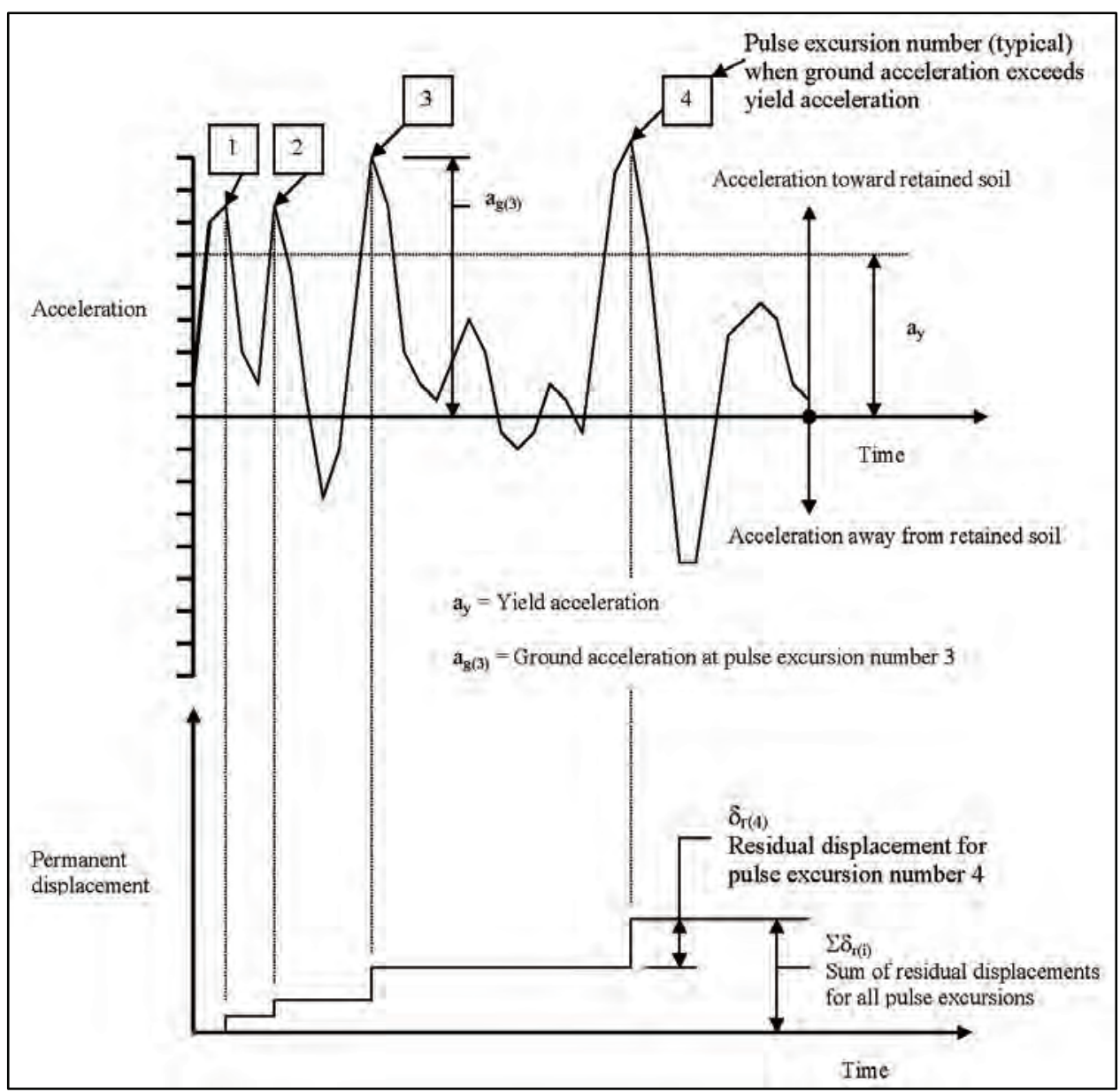

Figure F.10 Permanent displacement at top of wall relative to base $\left(\Sigma \delta_{\mathrm{r}(\mathrm{i})}\right)$

F.11.1.3 Step 3. Perform incremental pulse-excursion response history analysis and sum (permanent) incremental displacements. As indicated in the preceding paragraphs, the incremental pulse-excursion response history analysis to be incorporated into CWRotate for the purpose of determining residual (permanent) displacement demand is illustrated in Figures F.9 and F.10. Figure F.9 illustrates the determination of the residual displacement occurring at each pulseexcursion increment. The top portion of Figure F.10 illustrates pulse-excursion increments where the peak time-history acceleration $a_{g(i)}$ exceeds the yield acceleration $a_{y}$. The bottom portion of Figure F.10 illustrates the accumulation of residual displacement with each pulse excursion where the peak time-history acceleration exceeds the yield acceleration.

\section{F.11.2 Assumptions used for proposed determination of residual displacement (permanent displacement at the top of the stem wall relative to the base)}

At any pulse excursion increment where the incremental ground acceleration $a_{g(i)}$ is less than the yield acceleration $a_{y}$ it will be assumed all displacements are 
elastic and will not result in a residual displacement accumulation (i.e., displacements are recoverable).

At any pulse-excursion increment where the incremental ground acceleration $a_{g(i)}$ is greater than the yield acceleration $a_{y}$ it will be assumed the portion of the displacement up to yield is recoverable but the postyield component of the displacement is nonrecoverable and will add to any previous residual displacement accumulation.

With each pulse excursion increment of postyield displacement it is assumed that plastic flow will take place in the soil such that subsequent postyield displacement will be additive. 


\section{Appendix G Criteria Review for Corps by Dr. Priestley and Dr. Moehle}

This appendix includes general observations and comments made by Dr. M. J. N. Priestley, Department of Applied Mechanics and Engineering Sciences, University of California, San Diego, CA, and Dr. J. P. Moehle, Earthquake Engineering Research Center, University of California, Richmond, CA, on guidance proposed for use in evaluating the seismic performance of Corps intake towers and powerhouses. Some recommendations in this report are based on these observations and comments. It should be noted that Dr. Priestley's and Dr. Moehle's comments were edited to remove editorial comments, and rewritten in a form consistent with current terminology.

\section{G.1 Seismic Evaluation of Intake Towers - Dr. M. J. N. Priestley - June 1995}

\section{a. General Comments}

(1) The design and evaluation procedures are based on the following precepts:

(a) Limited flexural ductility is permitted. This is expressed by allowing a force reduction factor $\left(\mathrm{R}_{\mathrm{M}}\right)$ equal to two. Because of the expected low periods of intake structures $(0.1<\mathrm{T}<0.5$ seconds $)$ the "equal energy" relationship between elastic and inelastic displacement response is assumed to be appropriate, implying displacement ductility factors of about $\mu_{\Delta}=3$.

(b) Comment: For a lightly reinforced structure with low axial load, a value of $\mu_{\Delta}=3$ will generally be less than that corresponding to onset of spalling of concrete in the compression zone. Since the intake structures are essentially unconfined, this design criterion is appropriately conservative. An exception could occur with rectangular structures subjected to diagonal response. The reduced width of the compression zone under this case forces a deeper compression zone, particularly for hollow sections, and may result in premature crushing. Although this is permitted under the MDE, the extent of damage will be uncertain. Since the design approach is to check only the principal axes for 
strength, it is recommended that some detailed analysis of the diagonal response should be carried out to determine that response will be satisfactory under diagonal attack at $\mu_{\Delta}=3$ (note: flexural and shear strength under diagonal attack are likely to be similar to that in the principal directions, so similar ductility demand can be expected).

(c) Strength of all potentially brittle failure modes must exceed the force levels corresponding to fully elastic response. This effectively relates only to shear strength. Because of the brittle nature of shear failure it must be avoided.

(d) Comment: Strictly speaking, the maximum shear force that can be developed is not directly related to the elastic response shear force, but to the maximum feasible flexural strength, and the potential for dynamic amplification of shear in inelastic response. However, it can be shown that the elastic shear response resulting from a multi-mode spectral analysis is an upper limit to the shear force that can be derived. The approach is thus conservative. In many cases, given the low flexural ductility expected, a lower required shear strength, say 1.5 times that corresponding to nominal flexural strength, could be considered acceptable. Although this refinement may not be justified for new design, it could be adopted for assessment of existing structures to avoid unnecessary conservatism and unwarranted retrofit (but note comments below on the method of determining actual flexural strength).

(e) Strength reduction factors are not included in estimation of design or dependable strength.

(f) Comment: Although this is contrary to general practice in the United States, it is not unreasonable, since the main purpose of a strengthreduction factor is to ensure that an adequate margin of strength over loads exists to account for unexpectedly low material strengths, or errors in analytical methods for predicting strengths. Since actual flexural strength is expected to be developed in a ductile or limited ductile design, the use of a strength reduction factor is, at best, of limited relevance. However, the same argument cannot be applied to shear strength. Theoretically, a strength reduction factor should still be applied. In the capacity design approach as adopted in New Zealand, the lack of usage of a strength reduction factor for shear is justified on the basis of the conservative excess of required shear strength over flexural strength, and the conservative nature of design shear strength equations. Although a more consistent approach would be preferably with a lower required enhancement factor for design shear force, and a strength reduction factor incorporated in the estimation of design shear strength, the proposed approach seems suitably conservative.

\section{b. Specific Comments:}

(1) Anchorage Failure Checks. The design approach is conservative and simple to satisfy for new designs. The equation should be:

$$
l_{a}=1200 d_{b} \frac{f_{y}}{60,000 \sqrt{f_{c}^{\prime}}}
$$


(2) Splice Failure Check in Existing Towers: If it is assumed that the actual stress in longitudinal reinforcement may be as high as $1.4 f_{y}$ as a result of strain hardening, and the actual yield strength exceeding nominal strength, then the equation as presented is theoretically correct for a coefficient of friction of 1.4 across naturally occurring splitting cracks. However, this equation may be excessively conservative in existing structures. Bond deterioration under cyclic loading only occurs if the maximum compressive strain at the location of the splice reaches levels where longitudinal micro-cracking develops, reducing the concrete tensile strength, and hence the bond competence. If section analysis indicates that peak compressive strains at the lap do not exceed about 0.002 , then the concrete tensile strength can be relied upon, and provided the lap length is adequate, splice failure is not expected. The necessary splice length may conservatively be estimated from codified development lengths, or by first-principal approaches.

(3) Splice Design-New Towers: Wherever possible, lap splices should be excluded from plastic hinge regions. If permitted, the provisions are reasonably conservative as noted above, but no more than every alternate longitudinal bar should be spliced at a given section. Consideration might be given to mechanical splices, but only if test results indicate that the splice enables the ultimate strength (not yield strength) of the bar to be developed. Although the requirement that transverse reinforcement for clamping the splices be additional to requirements for shear reinforcement is conservative, it is not clear that it is necessary. Given a series of diagonal cracks in the webs of a tower, diagonal compression struts parallel to these cracks will be developed as part of the truss mechanism. These compression struts will tend to clamp the splices. Secondly, it should be noted that the critical splice condition occurs for the extreme tension longitudinal reinforcement, whereas critical conditions for shear occur at midsection depth. Thus the two actions are not simultaneously critical at the same location. Thus the requirement for additive transverse steel amounts need not be made. This may be of particular benefit in assessing existing structures.

(4) Shear Failure Check - Existing Towers and New Towers: A conservative approach for determining concrete shear strength is to use:

$$
V_{C}=2\left[k+\frac{P}{2000 A_{g}}\right] \sqrt{f_{c a}^{\prime}}\left(A_{e}\right)(\mathrm{psi})
$$

Where $k=1$ for $\mu_{\Delta}=1$, and $k=0.5$ for $\mu_{\Delta}=2$ with linear interpolation between these values, where $\mu_{\Delta}$ is the flexural displacement ductility demand and

$$
\begin{aligned}
P & =\text { Axial load on section (lb) } \\
f_{c a}^{\prime} & \left.=\text { Actual concrete compressive strength (typically } f_{c a}^{\prime} \geq 1.5 f_{c}^{\prime}\right) \\
A_{e} & =0.8 A_{\text {gross }}\left(A_{\text {gross }}=\text { actual cross-section area) }\left(\text { in. }{ }^{2}\right)\right.
\end{aligned}
$$

For circular towers and rectangular towers under diagonal attack the tensile force in transverse reinforcement crossing cracks will not, in general, be parallel with 
the applied shear force, and expressions different from those presented in the ACI building code for shear reinforcement apply.

For circular towers the appropriate equation is:

$$
V_{S}=\frac{\pi}{2}\left[\frac{A_{h} f_{y} D^{\prime}}{s}\right]
$$

where

$$
\begin{aligned}
A_{h} & =\text { Hoop cross section area (in. }{ }^{2} \text { ) } \\
D & =\text { Diameter of the hoop (in.) }
\end{aligned}
$$

For rectangular towers, the appropriate equations depends on the section shape, but for a square tower in the diagonal direction:

$$
V_{S}=\frac{1}{\sqrt{2}}\left[\frac{A_{V} f_{y} d}{s}\right]
$$

In this case $d$ is longer than for the principal directions, but does not compensate for the 30 percent reduction in transverse reinforcement efficiency.

Note: $d$ is the depth to the centroid of the longitudinal steel in the diagonal direction of attack.

(5) Spalling Criterion: Spalling criterion of $\varepsilon_{\mathrm{c}}=0.003$ is conservative, since experiments indicate larger strains at the onset of crushing or spalling. However, the very large tower section sizes and lack of relevant test data indicate a need for conservatism. The use of $\varepsilon_{\mathrm{c}}=0.003$ will not normally limit displacement ductility capacity.

(6) Sliding Shear Failure: The following equation is appropriate for determining sliding shear resistance at low levels of displacement ductility demand:

$$
V_{s l}=\left[P+0.25 f_{y} A_{V F}\right]
$$

It should be noted that sliding shear does not necessarily constitute a failure condition, and that a sliding shear force corresponding to a shear displacement ductility demand $\mu_{\Delta}=1$ is incompatible with a flexural displacement ductility demand $\mu_{\Delta}=2$, since sliding shear is limited by flexural strength.

(7) Minimum Tensile Reinforcement Requirements: It is desirable to have nominal moment capacity 20 percent greater than the cracking moment capacity. Existing codes normally require at least a 20 percent margin, which is a 
lower limit. However, given the low ductility demand levels permitted, a 20 percent margin would be sufficient.

c. Priestley Procedure for Estimating the Plastic Displacement Capacity of Intake Towers.

The plastic displacement capacity $\left(\delta_{\mathrm{p}}\right)$ shall be calculated from:

$$
\delta_{p}=\phi_{u} L_{p} H
$$

where

$$
\begin{aligned}
& \phi_{\mathrm{u}}=\text { Plastic curvature } \\
& L_{P}=\text { Plastic hinge length } \\
& H=\text { The height from the critical section to the top of the tower. }
\end{aligned}
$$

The plastic curvature is:

$$
\phi_{p}=\phi_{u}-\phi_{y}
$$

Where $\phi_{\mathrm{U}}=$ the ultimate curvature capacity.

Corresponds to a maximum concrete strain:

$\left(\varepsilon_{\mathrm{c}}=0.002\right.$ when needed to prevent bond deterioration), or

$\left(\varepsilon_{\mathrm{c}}=0.004\right.$ when needed to prevent concrete spalling), or

Corresponding to a maximum reinforcement strain:

$\left(\varepsilon_{\mathrm{s}}=0.05\right.$ when needed to prevent fracturing of the reinforcing steel $)$

Whichever occurs first, and $\phi_{\mathrm{Y}}=$ the yield curvature of the bilinear approximation to the moment-curvature response.

When $M_{N} \leq 1.2 M_{C R}$, the plastic hinge length shall be:

$$
L_{p}=0.30 f_{y} d_{b l}
$$

Where $f_{y}$ is the yield strength of the longitudinal reinforcement of diameter $d_{b l}$.

When $M_{N} \geq 2 M_{C R}$, the plastic hinge length shall be:

$$
L_{p}=0.08 H+0.15 f_{y} d_{b l}
$$

For 1.2 $M C R<M_{N}<2 M_{C R}$, the plastic hinge length shall be from linear interpolation between the two above values of $L_{p}$. 


\section{d. References.}

(1) Paulay and Priestley, "Seismic Design of Concrete and masonry Buildings." John Wiley and Sons, 192, 749 pp.

(2) "Design of Concrete Structures." NZ53101:1982, Standards Association of New Zealand

(3) Priestley, M.J.N., Seible, F., “Assessment of Existing Concrete Bridges." Proc. $2^{\text {nd }}$ International Workshop on Seismic Design of Bridges. Queenstown, NZ, 1994.

(4) "Draft Seismic Design Provisions for Concrete Bridges" ATC-32 Applied Technology Council.

(5) Priestley, M.J.N., Verma, R., and Xiao, Y., "Seismic Shear Strength of Concrete Columns" ASCE Journal of Structures Division, 1994

(6) Benzoni, G., Priestley, M.J.N., and Seible, F., "Seismic performance of Bridge Columns with Low Longitudinal Reinforcement Ratios.", Structural Systems Research Report No. SSRP-93, University of California, San Diego

\section{G.2 Seismic Design and Evaluation of Powerhouse Superstructures - Dr. M. J. N. Priestley — December 1997}

a. Response to Major Issues

(1) Effective Stiffness. An effective stiffness equal to one-third the gross section stiffness may not be appropriate for lightly reinforced walls, such as powerhouse walls. Figure G.1 shows the variation of cracked section stiffness, expressed as a fraction of the gross section stiffness, related to the ratio of ultimate to cracking moment $\left(M_{N} / M_{c r}\right)$. Values are given for both grade 40 and grade 60 rebar, using the nominal strength values, since yield curvatures are essentially inversely proportional to reinforcement yield strength. Put another way, a wall with grade 60 rebar will have a lower reinforcement ratio than one with grade 40 rebar, for the same $M_{N} / M_{c r}$, and hence will have a lower cracked section stiffness.

It will be seen that these values of $I_{c r} / I_{g}$, particularly those for $f_{y}=60 \mathrm{ksi}$, are considerably lower than 0.33 , especially for low ratios of $M_{N} / M_{c r}$. However, when the wall is lightly reinforced, the extent of cracking will be limited and it is inappropriate to use the $I_{c r}$ value for the full height for period of deflection calculations.

The ACI 318 approach recognizes the stiffening effect of lightly reinforced members through the Branson Equation: 


$$
I_{\text {eff }}=\left[\frac{M_{c r}}{M_{a}}\right]^{3} I_{g}+\left[1-\left[\frac{M_{c r}}{M_{a}}\right]^{3}\right] I_{c r}
$$

Where $M_{a}=$ maximum moment on member. The results of the Branson Equation are also included in Figure G.1 for both grades of reinforcement, with $M_{a}=M_{N}$. It will be seen that the stiffening effect for low $M_{N} / M_{c r}$ ratios more than compensates for the reduced cracked-section stiffness, and the proposed value of 0.33 $I_{g}$ will seriously underestimate the effective stiffness for values of $M_{N} / M_{c r}<1.5$ which are common in powerhouse designs.

It is suggested that the following improved and simple expression be adopted:

$$
\begin{aligned}
0.8 \leq \frac{I_{e}}{I_{g}}=0.8-0.9\left[\frac{M_{N}}{M_{c r}}-1\right] & \geq 0.35 \quad\left(f_{y}=40 \mathrm{ksi}\right) \\
& \geq 0.25 \quad\left(f_{y}=60 \mathrm{ksi}\right)
\end{aligned}
$$

Note that an upper value of 0.8 is used even if $M_{N} / M_{c r}<1$, since a single crack will then form at the wall base which will reduce stiffness due to strain penetration over a small but significant end region.

\section{b. Load Factor Equations}

It is customary in seismic design to include dead load and live load effects when comparing capacity and demand. However, there is considerable inconsistency in adopted approaches. Some relevant points follow.

- It is usual to adopt a reduced value of live load, reflecting the low probability of full live load coinciding with full seismic load.

- In ductile systems it can be argued that it is unnecessarily conservative to use the expression:

$$
M_{N} \geq M_{D L}+M_{L L}+M_{D I}
$$

Where $M_{D I}=$ Inelastic earthquake demand moment = elastic earthquake demand moment $/ R$.

The reason is illustrated in Figure G.2 where, for example, $M_{D L}+M_{L L}=0.5 M_{N}$. If the ductility of the wall is assumed to be $\mu=3$, then the structure can deform 3 times the yield displacement. Assuming the "equal displacement" approximation, the equivalent elastic strength is $3 M_{N}$. Note that if $M_{D I}$ is limited to $M_{N}-\left(M_{D L}+\right.$ $M_{L L}$ ), then the equivalent elastic response will be $M_{D L}+M_{L L}+3 M_{D I}$, corresponding to point A, with $\delta_{A}=0.5 \delta_{y}+3 \times 0.5 \delta_{y}=2 \delta_{y}$, which is only $2 / 3$ of the displacement capacity. It is more consistent to use the requirement: 


$$
M_{N} \geq\left(M_{D L}+M_{L L}+M_{D I}\right) / R
$$

Where in this case $R=3=\mu$, since this equates behavior at maximum response. This approach reduces the influence of gravity load moments still further, and probably makes them insignificant for design.

c. Moment Reduction Factor (R).

The moment reduction factor $R=1+0.67(\mu-1) T / T_{0} \leq \mu$ is a good representation of the observation that structures on the rising portion of the acceleration spectrum $\left(T<T_{0}\right)$ have ductility demands greater than force reduction factors. This is particularly the case when hysteretic response is pinched, as might happen with base shear sliding, which is possible in powerhouse walls. I agree with its usage in the powerhouse design criteria document. Note that the approach is more conservative than in most existing codes (e.g., UBC 1997) which typically put $R=\mu$ regardless of period. It is in line with suggestions in recent documents that recognize the non-conservative nature of existing codes for short-period structures (e.g., 2,3).

\section{d. Center of Mass height for Ductility Calculations.}

The correct height to use for ductility calculations is the height of the center of seismic force, rather than the center of mass. The effective height $L_{\text {eff }}$ representing the center of seismic force is:

$$
L_{e f f}=\frac{\sum\left(m_{n} \phi_{n} L_{n}\right)}{\sum m_{n} \phi_{n}}
$$

\section{e. Minimum Flexural Displacement Ductility}

In the document $\mu=3$ is assumed to be a lower bound for walls with $M_{N} / M_{c r} \geq$ 2 . This is very conservative. The values defining the ultimate curvature, namely $\varepsilon_{\mathrm{s}}=0.05, \varepsilon_{\mathrm{c}}=0.04$ (to prevent spalling), or $\varepsilon_{\mathrm{c}}=0.02$ (to prevent bond deterioration at splices) are suitable design values for both 40 and 60 grade rebar. The yield curvature is insensitive to the longitudinal steel ratio, and may be approximated by:

$$
\phi_{y}=\frac{1.25 \varepsilon_{y}}{h}
$$

When the steel strain is more critical than the concrete strain (when $\varepsilon_{\mathrm{s}}=0.05$ is reached first), the ultimate curvature can be approximated by:

$$
\phi_{u}=\frac{0.05}{0.8 h}
$$


Where: $h=$ Wall thickness

Thus for walls of with low reinforcement ratios (normal for powerhouse walls) and taking the more critical case of 60 grade rebar:

$$
\frac{\phi_{u}}{\phi_{y}}=\frac{0.05}{0.8(0.00207)}=30
$$

Now the plastic hinge length can be conservatively approximated by:

$$
L_{p}=0.08 L_{e f f}
$$

Thus a conservative estimate of the displacement ductility capacity is:

$$
\mu=1+3(30-1)(1-0.04)=7.7
$$

It would thus be quite reasonable to adopt a higher minimum ductility (say $\mu=5$ or 6) for routine checking, when:

$$
M_{N} / M_{c r} \geq 2
$$

There is also a case to be made for allowing higher default displacement ductilities for:

$$
M_{N} / M_{c r}<2
$$

A possible expression, reaching a maximum of 5.5 at $M_{N} / M_{c r}=2$, and conforming with $\mu=1.5$ at $M_{N} / M_{c r}=1.0$, is:

$$
\mu=1.5+4\left[\frac{M_{N}}{M_{c r}}-1\right], \quad 1.5 \geq \mu \leq 5.5
$$

The use of the above equation would reduce the number of times the displacement ductility capacity would be unnecessarily checked.

\section{f. Additional Comments}

(1) Shear Design. The shear demand need not be taken equal to the elastic demand. This is unnecessarily conservative when the flexural force reduction factor may be 3 or more. It would be sufficient to check for a shear force 50 percent higher than the shear corresponding to flexural capacity. This can be expressed as: 


$$
V_{N} \geq V_{D E}(1.5) \frac{M_{N}}{M_{D E}}
$$

Shear friction, although it rarely governs, should be checked at the wall base, with a reduced effectiveness from the vertical reinforcement, because of its expected inelastic response. A suitable expression would be:

$$
V_{s f}=\mu_{s f}\left[P+0.25 A_{s} f_{y}\right] \geq V_{D E} \frac{1.5 M_{N}}{M_{D E}}
$$

where

$$
\begin{aligned}
V_{D E} & =\text { Elastic shear demand from response spectrum analysis } \\
M_{D E} & =\text { Elastic moment demand from response spectrum analysis } \\
M_{N} & =\text { Nominal moment capacity }
\end{aligned}
$$

The value for the shear friction coefficient $\left(\mu_{\mathrm{sf}}\right)$ is 1.4 for a naturally occurring crack, 1.0 for a crack forming on a roughed construction joint, and 0.7 for a crack forming on a smooth construction joint.

However, even if the above shear friction strength requirements are not satisfied, this does not necessarily mean uncontrolled shear response. This is because sliding shear has been shown to dissipate significant energy from Coulumb friction. This can be relied on at low displacement ductility levels, but is less reliable at higher ductilities where inelastic elongation of reinforcement may result in a wide open bare crack, particularly for the $\mu_{\mathrm{sf}}=0.7$ case. It may be best to deal with shear friction by commentary, rather than mandatory code clauses.

(2) Anchorage. The following equation is recommended for the initial check of anchorage of wall reinforcement to the base slab:

$$
l_{a}=\frac{f_{y}}{2000} d_{b}
$$

This results in the familiar old expressions of $20 d_{b}$ and $30 d_{b}$ for $f_{y}=40 \mathrm{ksi}$ and $f_{y}$ $=60 \mathrm{ksi}$ respectively. Note that this equation is slightly (but not much) more conservative than the FHWA equations using $f_{c}{ }^{\prime}=3000 \mathrm{psi}$, and $c / d_{b}=2$, which are typical for powerhouses.

(3) Reinforcing Steel Splices. Realistic criteria for splice development length, such as that in Reference 1, which for widely spaced longitudinal bars outside of plastic hinge regions, results in:

$$
l_{a}=\frac{A_{b} f_{y}}{4 \sqrt{f_{c}^{\prime}}\left(2 \sqrt{2}\left(c+d_{b}\right)\right)}
$$


Where:

$\mathrm{c}=$ Cover to main bars

For $f_{c}^{\prime}=4000$ psi, $f_{y}=40,000$ psi, $c=2$ inches, and $d_{b}=1$ in. (\#8 bar) results in a required lap splice length of 14.6 in. Note that it is likely that lap splices will be at least $20 d_{b}$, in walls, which will satisfy the lap splice requirement of the above equation.

\section{g. References.}

(1) Priestley, M.J.N., Seible, F., and Calvi, M, "Seismic Design and Retrofit of Bridges," John Wiley, New York, 1996

(2) ATC 32, "Improved Seismic Design Criteria for California Bridges: Provisional Recommendations, Applied Technology Council, 1996

(3) NZNSEE, "Recommendations for Seismic Design of Bridges", Bulletin, New Zealand national Society for Earthquake Engineering, Vol. 13, No. 3, Sept 1980.

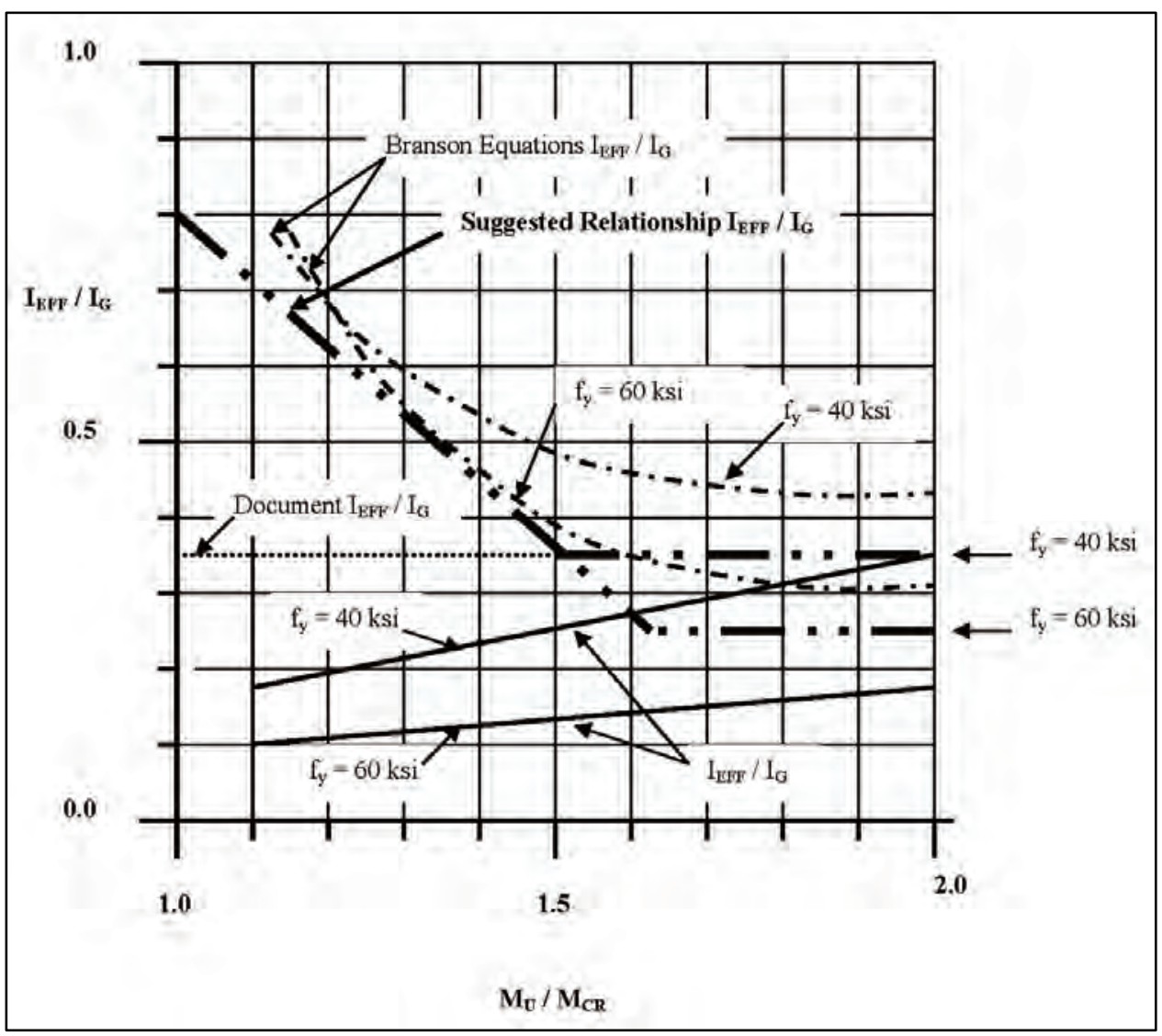

Figure G.1 Effective stiffness of lightly reinforced walls 


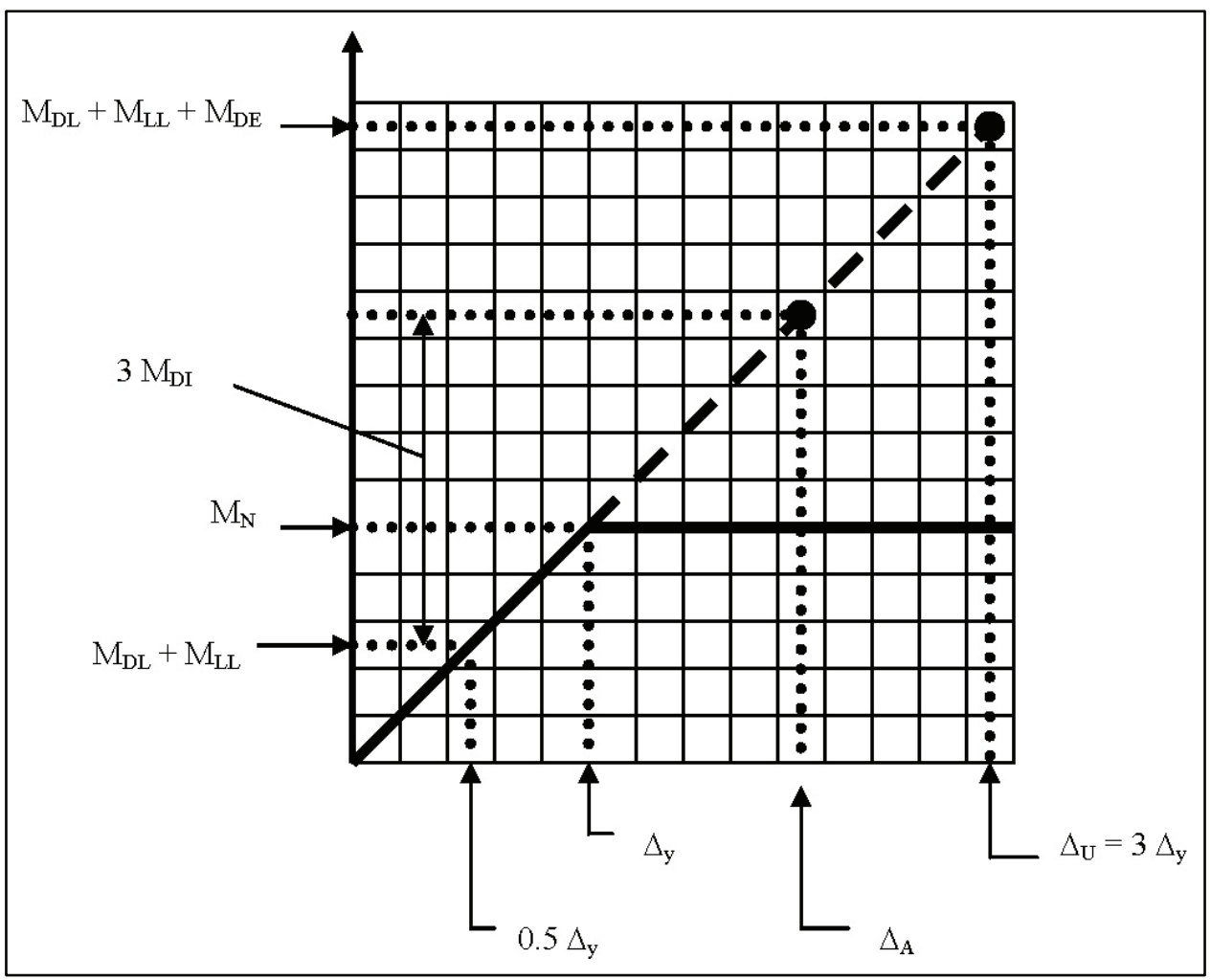

Figure G.2 Influence of gravity moments on seismic response

\section{G.3 Experimental Research and Seismic Design Guidance for Intake Towers - Dr. J. Moehle - July 22, 1997}

a. Analytical Model Some models for deformation capacity of lightly reinforced walls were discussed. The conventional approach of using yield curvature at the base is inappropriate for walls where the cracking moment exceeds the yield moment because the wall is uncracked above the base. Instead, the yield curvature at the base should be the maximum moment divided by $E I_{\text {Gross. }}$. The approach used by the Waterways Experiment Station (WES) which estimates the plastic rotation as the sum of the rotations due to yield curvature and post-yield curvature appears to correctly represent behavior observed in the intake tower model. An alternate approach directly involving the tension reinforcement strains and section dimensions was proposed and discussed. A steel ultimate tension strain capacity of 0.05 is recommended. This capacity although less than the ultimate strain capacity measured under monotonic tests will account for the loss of strain capacity that occurs under cyclic loading. On an interim basis, it is recommended to use the plastic hinge length proposed by M.J.N. Priestley for the case of formation of a single crack. The results should be compared with experimental data to verify the adequacy of this plastic hinge length.

b. Effective Stiffness The nonlinear load-deformation relation of a wall having a cracking moment exceeding the yield moment consists primarily of an 
initial linear portion to cracking, followed by a plastic plateau to fracture of the reinforcement. Therefore, it appears more logical to define the OBE and MCE earthquake response parameters relative to a nominal yield point having a moment equal to the yield moment and stiffness corresponding to the grosssection value.

c. Displacements It is unclear how well the gross-section approach will work in estimating maximum displacements. I recommend that a small analytical study be undertaken to investigate the response maxima of systems having yield moment and cracking moment nearly equal. A key issue in estimating the displacement capacity of a lightly reinforced wall is determining if there will be one crack or if cracks will be distributed. Dr. Fernando Yanez at the University of Chile in Santiago should be contacted. He has completed a series of tests to identify the transition. Another key issue in estimating the displacement capacity of lightly reinforced walls is the strain penetration. I believe the experimental work by WES using small-scale specimens is producing a conservative estimate of the displacement capacity. Tests on larger-scale sub-components of the walls should be considered. The work at the University of Texas at Austin on lap-splice behavior of large-diameter bars should be investigated (contact: James Jirsa).

d. Initial Stiffness. I recommend (in addition to the analytical study above) as a interim that the gross-section properties be used for walls having a yield moment less than the cracking moment. The reason for this is that the initial stiffness is controlled by the uncracked behavior. For walls having yield moment significantly exceeding the cracking moment, say a factor of two or more, I would use the gross-section shear stiffness with the cracked section flexural stiffness. A transition for intermediate values may be appropriate.

e. Demand Reduction. For the MCE, I believe flexural demand reductions of two are appropriate even for shorter period structures. For shear failures, I would not use a shear demand reduction factor. However, I would not require the design shear to exceed 1.5 times the plastic shear determined from a pushover analysis. For shear strength determination, I would use the ACI 318 Equations. I doubt that shear failure is ever going to be an issue for these walls.

f. Load Factors and Strength Reduction Factors. For the OBE, I believe that the strength reduction factor and the load factor should both be unity. In the event that a crack forms during shaking at this intensity level, it will not result in brittle failure, and after shaking it is very likely to completely close under the action of gravity loads.

g. Minimum Reinforcing and Lap Lengths. Regarding the minimum reinforcement to be required for the design of new towers, I would defer to the work of Yanez. For future testing, I believe the highest priority should be on testing larger-scale components of the lap-splice and anchorage region of the longitudinal reinforcement at the base. The tests should be conducted at nearly full scale. In addition to strain penetration, these tests will be valuable for identifying the propensity for lap-splice failure. I believe that lap-splice failure can occur without the compression strain under reversed loading reaching 0.002 if the lap length is too short. However, I do not know that it will be critical given the large cover and the lap lengths typical in these structures. The likelihood for this type of 
failure could be investigated using empirical equations that are available in the literature.

h. Additional Testing. A second priority should be on biaxial testing of a box section. With biaxial testing, there is the possibility of spalling of the concrete at the corner, which could lead to rebar buckling or to deterioration in the behavior of the lap slices upon reverse loading. 


\section{Appendix $\mathrm{H}$ Notation}

This Notation includes only symbols used in the main text. Each appendix has its own system of notation. Many of the symbols used are defined in the text of each appendix. Others are commonplace to reinforced concrete design and retaining wall design. Readers not understanding a particular symbol notation should consult the references cited in that appendix for the definition.

$a_{g}$ Ground acceleration

$a_{h}$ Maximum horizontal ground acceleration, equal to $k_{h} g$

$a_{v}$ Maximum vertical ground acceleration, equal to $k_{v} g$

$A$ Area; Seismic coefficient representing the peak ground acceleration expressed as a fraction of the acceleration of gravity

$A_{e} \quad 0.8 A_{g}$

$A_{g}$ Gross concrete area

$A_{s}$ Area of the longitudinal reinforcing steel across the potential failure plane

$A_{V}$ Area of shear reinforcement within a distance $s$

$C_{0}$ Modification factor to relate spectral displacement to inelastic displacement at the top of the structure

$C_{1}$ Modification factor to relate "top of structure" inelastic displacement to displacement btained for the elastic response obtained by pseudo-lateral load analysis, response spectrum analysis, or linear elastic time-history analysis

$C_{2}$ Modification factor to represent the effects of severe strength deterioration (i.e., pinched hysteresis curve)

$C_{3}$ Modification factor to account for any second-order displacement $(\mathrm{P} \bullet \Delta)$ effects 
$C_{U}$ Ultimate crack width

$d$ Depth from compression face to centroid of longitudinal tension reinforcement

$d_{b}$ Diameter of reinforcing steel, in.

$d_{w}$ Relative flexibility of the wall

$D_{w}$ Flexural rigidity of the wall per unit length of wall

$E_{w}$ Young's modulus of elasticity for the wall

$f_{c}^{\prime}$ Actual concrete compressive strength (per Priestley, ${ }^{1}$ the actual concrete compressive strength, which may be as high, or higher than 1.5 times the design compressive strength, should be used when calculating the shear capacity)

$f_{r}$ Modulus of rupture $=7.5 \sqrt{f_{c}^{\prime}}$ (psi units)

$f_{s}$ Maximum stress that can be developed in an embedded bar having an embedment length $l_{e}$, psi; maximum stress that can be developed in the bar for the lap or splice length provided $l_{b}$

$f_{y}$ Yield capacity of reinforcement; yield strength of the reinforcing steel

$F_{E}$ Force for elastic response

$F_{h}$ Dynamic earth pressure force in horizontal direction

$F_{v}$ Dynamic earth pressure force in vertical direction

$F_{Y}$ Force for yield response

$g$ Acceleration of gravity

$G$ Shear modulus of elasticity for the retained soil

$H$ Height of wall; height of soil retained by wall

$I_{E}$ Effective stiffness

$I_{G}$ Gross stiffness

$k$ Factor dependent on member flexural displacement ductility demand

$k_{h}, k_{v}$ Fraction of horizontal and vertical acceleration, respectively

\footnotetext{
${ }^{1}$ M. J. N. Priestley, 1995, “Criteria Review for Corps—Seismic Evaluation of Intake Towers," presented in Appendix G of this report.
} 
$k_{y}$ Yield coefficient expressed as a fraction of the acceleration of gravity, representing the yield acceleration that initiates sliding (sliding factor of safety equal to 1.0); factor dependent on member flexural displacement ductility demand. As shown in Figure 4.1, "k" can range from a maximum of 3.5 at low ductility demand levels to 1.2 at high ductility demand levels

$K$ Stiffness of the structure-foundation system

$K_{A}$ Static coefficient of earth pressure

$K_{A E}$ Active stress coefficient, which is a function of (a) the friction angle of the retained soil, (b) the interface friction angle between the backfill and the wall, (c) the horizontal and vertical acceleration coefficients $k_{h}$ and $k_{v}$, respectively, as per Equation 33 in Ebeling and Morrison (1992). $K_{A E}$ is given in Equation 34 in Ebeling and Morrison (1992).

$l$ Length of cantilever

$l_{b}$ Lap or splice length provided

$l_{d}$ Lap or splice length required by ACI 318-02 (ACI 2002)

$l_{e}$ Embedment length, in.

$l_{\text {eff }}$ Effective height

$l_{n}$ Height from base to mass at level $n$

$l_{p}$ Plastic hinge length

$l_{w}$ Depth of member

$L$ Length of member

$m_{n}$ Mass at level $n$ of a multiple lumped mass system

$M$ System mass

$M_{C R}$ Cracking moment

$M_{N}$ Nominal moment capacity

$N^{*} g$ Maximum transmissible acceleration

$P$ Axial load on section

$P_{A E}$ Total active earth pressure force (dynamic + static)

$P_{\text {resist }}$ Limit-state resisting force

$Q_{D}$ Dead load effect 
$Q_{D C}$ Combined action due to maximum design earthquake loads, dead load, and live load for use in evaluating performance

$Q_{L} \quad$ Live load effect

$Q_{M D E}$ Earthquake load effect from maximum design earthquake ground motions

$R$ Resultant force on soil wedge; force reduction factor

$s$ Spacing of shear reinforcement

$S_{a}$ Peak response acceleration; spectral acceleration; spectral acceleration of the design earthquake for period $T_{e}$

$S_{b}$ Section modulus

$t_{w}$ Wall thickness

$T$ Fundamental period of vibration

$T_{e}$ Fundamental period of vibration based on the effective stiffness of the structural system

$T_{o}$ Characteristic ground motion period

$v_{g}$ Peak ground velocity of the earthquake, in./sec

$v_{s}$ Shear wave velocity of soil

$V_{A E}$ Active earth pressure earthquake-induced shear

$V_{c}$ Concrete component of shear strength

$V_{s}$ Contribution to shear capacity provided by the shear reinforcement

$V_{T}$ Total shear demand on the wall

$V_{s t}$ Shear at the base of the stem wall assuming rigid body motion

$V_{S F}$ Shear friction shear capacity

$V_{U}$ Total ultimate shear strength

$W$ Weight of rigid body (i.e., wall or soil wedge)

$\ddot{X}_{g} \quad$ Peak ground acceleration

$y$ Distance above the base of the cantilever retaining wall

$\gamma$ Moist unit weight of the backfill; density of soil 
$\delta$ Angle of $P_{A E}$ with respect to landside wall face

$\delta_{A E}$ Amplified displacement

$\delta_{E}$ Maximum displacement demand

$\delta_{r}$ Permanent (residual) displacement

$\delta_{t}$ Target displacement

$\delta_{\mu} \quad$ Ultimate displacement capacity

$\Delta$ Permanent sliding displacement

$\Delta_{E}$ Displacement for elastic response

$\Delta_{Y}$ Displacement for yield response

$\Delta_{s}$ Sliding displacement

$\varepsilon_{U}$ Ultimate rupture strain of reinforcing steel

$\varepsilon_{c u}, \varepsilon_{s u}$ Ultimate strain capacity of the concrete in compression and of the steel in tension, respectively

$\eta$ Ratio of distance above the base to total wall height

$\theta_{r}$ Earthquake-induced rocking motion

$\theta_{u}$ Ultimate rotational capacity

$\mu$ Ultimate displacement ductility capacity

$\mu_{S F}$ Sliding shear coefficient of friction (ACI 2002)

$\mu_{\Delta}$ Displacement ductility capacity

$\mathrm{v}_{\mathrm{w}}$ Poisson's ratio for the wall

$\varphi$ Angle of $R$ with respect to the soil wedge slip plane

$\varphi_{n}$ Modal value at mass level $n$

$\varphi_{u}$ Ultimate curvature capacity

$\varphi_{y}$ Curvature at first yield of the reinforcing steel 


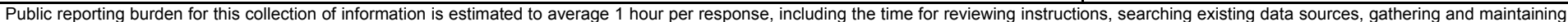

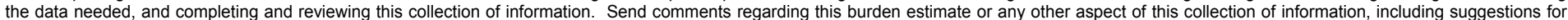

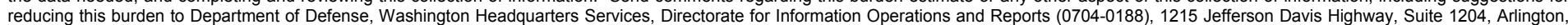

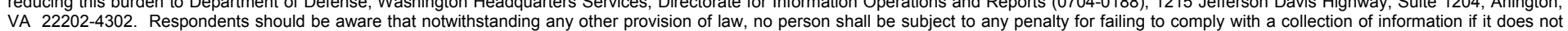
VA 22202-4302. Respondents should be aware that notwithstanding any other provision of law, no person shall be sube
display a currently valid OMB control number. PLEASE DO NOT RETURN YOUR FORM TO THE ABOVE ADDRESS.

\begin{tabular}{l|c}
$\begin{array}{l}\text { 1. REPORT DATE (DD-MM-YYYY) } \\
\text { May } 2005\end{array}$ & $\begin{array}{c}\text { 2. REPORT TYPE } \\
\text { Final report }\end{array}$ \\
\hline
\end{tabular}

\section{TITLE AND SUBTITLE}

Seismic Structural Considerations for the Stem and Base of Retaining Walls Subjected to Earthquake Ground Motions

3. DATES COVERED (From - To)

5a. CONTRACT NUMBER

5b. GRANT NUMBER

5c. PROGRAM ELEMENT NUMBER

5d. PROJECT NUMBER

6. AUTHOR(S)

Ralph W. Strom and Robert M. Ebeling

5e. TASK NUMBER

5f. WORK UNIT NUMBER

$33215 \mathrm{a}$

7. PERFORMING ORGANIZATION NAME(S) AND ADDRESS(ES)

9474 S.E. Carnaby Way, Portland, OR 97266;

U.S. Army Engineer Research and Development Center, Information Technology

Laboratory, 3909 Halls Ferry Road, Vicksburg, MS 39180-6199

8. PERFORMING ORGANIZATION REPORT NUMBER

ERDC/ITL TR-05-3

9. SPONSORING / MONITORING AGENCY NAME(S) AND ADDRESS(ES)

U.S. Army Corps of Engineers

Washington, DC 20314-1000

10. SPONSOR/MONITOR'S ACRONYM(S)

11. SPONSOR/MONITOR'S REPORT NUMBER(S)

\section{DISTRIBUTION / AVAILABILITY STATEMENT}

Approved for public release; distribution is unlimited.

\section{SUPPLEMENTARY NOTES}

\section{ABSTRACT}

Cantilever retaining walls can respond externally to earthquake ground motions by sliding or by rotating, or internally by stem wall yielding. The type of response that will have the greatest impact on post-earthquake performance will likely depend on restraint conditions at the base of the wall. Walls founded on soil without an invert slab are most likely to dissipate the inertial energy imposed by earthquake ground motions by sliding. This may also be true for walls founded on fissured or fractured rock. Walls founded on soil or on fissured or fractured rock and prevented by an invert slab from moving laterally are more likely to tip (i.e., rotate) than to slide during a major earthquake event. Walls founded on competent rock without significant joints, faults, or bedding planes and prevented by a strong bond at the rock-footing interface from either translating or rotating are likely to dissipate energy through plastic yielding in the stem wall. All three responses can leave the retaining wall in a permanently displaced condition.

The purpose of this report is to provide methodologies for conducting a performance-based earthquake evaluation related to plastic yielding in the stem wall. The methodologies include evaluation of brittle or force-controlled actions and the evaluation of ductile or deformation-controlled actions. The later evaluation provides estimates of permanent (residual) displacement for walls dominated by a stem wall yielding response.

(Continued)

\section{SUBJECT TERMS}

Earthquake resistance

Lap-splice deficiencies

16. SECURITY CLASSIFICATION OF:

\begin{tabular}{|l|l|}
\hline $\begin{array}{l}\text { a. } \text { REPORT } \\
\text { UNCLASSIFIED }\end{array}$ & $\begin{array}{l}\text { b. ABSTRACT } \\
\text { UNCLASSIFIED }\end{array}$ \\
\hline
\end{tabular}

Performance-based evaluation

Retaining walls

(6.)

\begin{tabular}{|l|c|c|c|} 
& $\begin{array}{l}\text { 17. LIMITATION } \\
\text { OF ABSTRACT }\end{array}$ & $\begin{array}{l}\text { 18. NUMBER } \\
\text { OF PAGES }\end{array}$ \\
\cline { 1 - 1 } $\begin{array}{l}\text { c. THIS PAGE } \\
\text { UNCLASSIFIED }\end{array}$ & & 202 & \\
\cline { 5 - 5 } & &
\end{tabular}

19a. NAME OF RESPONSIBLE PERSON

19b. TELEPHONE NUMBER (include area code) 


\section{ABSTRACT (cont.)}

Performance-based evaluation methodologies are demonstrated with respect to a wall designed to current Corps ultimate strength design criteria and with respect to an older retaining wall designed to working stress design criteria. Lap splice deficiencies related to older walls are discussed and performance-based evaluation techniques proposed.

At present the Corps computer program CWRotate is able to estimate permanent displacements associated with a sliding response and a rotational response. An enhancement is proposed to provide estimates of permanent (residual) displacement for walls dominated by stem wall yielding. 